\title{
PUBLIC DEBT \\ SUSTAINABILITY IN DEVELOPING ASIA
}

\section{Edited by}

Benno Ferrarini, Raghbendra Jha, and Arief Ramayandi 


\section{Public Debt Sustainability in Developing Asia}

Addressing the global financial crisis has required fiscal intervention on a substantial scale by governments around the world. The consequent buildup of public debt, in particular its sustainability, has moved to center stage in the policy debate. If the Asia and Pacific region is to continue to serve as an engine for global growth, its public debt must be sustainable. Public Debt Sustainability in Developing Asia addresses this issue for Asia and the Pacific as a whole as well as for three of the most dynamic economies in the region: the People's Republic of China, India, and Viet Nam.

The book begins with a discussion of the reasons for increased attention to debt-related issues. It also introduces fiscal indicators for the Asian Development Bank's developing member countries and economies. The sustainability of their debt is assessed through extant approaches and with the most up-to-date data sources. The book also surveys the existing literature on debt sustainability, outlining the main issues related to it, and discusses the key implications for the application of debt sustainability analysis in developing Asia. Also highlighted is the importance of conducting individual country studies in view of wide variations in definitions of public expenditure, revenues, contingent liabilities, government structures (e.g., federal), and the like, as well as the impact of debt on interest rates. The book further provides in-depth debt sustainability analyses for the People's Republic of China, India, and Viet Nam.

Public Debt Sustainability in Developing Asia offers a comprehensive analytical and empirical update on the sustainability of public debt in the region. It breaks new ground in examining characteristics that are crucial to understanding sustainability and offers richer policy analysis that should prove useful for policymakers, researchers, and graduate students.

Benno Ferrarini is a Senior Economist at the Macroeconomics and Finance Research Division, Economics and Research Department, Asian Development Bank.

Raghbendra Jha is Rajiv Gandhi Chair Professor and Executive Director, Australia South Asia Research Centre, College of Asia and the Pacific, Australian National University.

Arief Ramayandi is an Economist at the Macroeconomics and Finance Research Division, Economics and Research Department, Asian Development Bank. 


\title{
Public Debt Sustainability in Developing Asia
}

\author{
Edited by Benno Ferrarini, \\ Raghbendra Jha, \\ and Arief Ramayandi
}

Co-publication of the Asian Development Bank and Routledge 
First published 2012

By Routledge

2 Park Square, Milton Park, Abingdon, Oxon, OX14 4RN

Simultaneously published in the USA and Canada

By Routledge

711 Third Avenue, New York, NY 10017

Routledge is an imprint of the Taylor \& Francis Group, an informa business

(C) 2012 Asian Development Bank

All rights reserved. No part of this book may be reprinted or reproduced or used in any form or by any electronic, mechanical, or other means, now known or hereafter invented, including photocopying and recording, or in any information storage or retrieval system, without permission in writing from the publishers.

The views expressed in this book are those of the authors and do not necessarily reflect the views and policies of the Asian Development Bank (ADB) or its Board of Governors or the governments they represent.

ADB does not guarantee the accuracy of the data included in this publication and accepts no responsibility for any consequences of their use.

By making any designation of or reference to a particular territory or geographic area, or by using the term "country" in this document, ADB does not intend to make any judgments as to the legal or other status of any territory or area.

ADB encourages printing or copying information exclusively for personal and noncommercial use with proper acknowledgment of ADB. Users are restricted from reselling, redistributing, or creating derivative works for commercial purposes without the express, written consent of ADB.

In this book, the symbol "\$" refers to the United States dollar unless otherwise specified.

Trademark notice: Product or corporate names may be trademarks or registered trademarks, and are used only for identification and explanation without intent to infringe.

6 ADB Avenue, Mandaluyong City

1550 Metro Manila, Philippines

Tel: +6326324444

Fax: +6326362444

www.adb.org

British Library Cataloguing in Publication Data

A catalogue record for this book is available from the British Library

Library of Congress Cataloging in Publication Data

A catalog record for this title has been requested

ISBN: 978-0-415-52221-2 (hbk)

ISBN: 978-0-203-08571-4 (ebk)

Typeset in Times New Roman

by Cenveo Publisher Services 


\section{Contents}

List of illustrations viii

Foreword $\quad$ xi

Contributors xiii

Abbreviations and acronyms $\quad \mathrm{xV}$

1 Introduction 1

BENNO FERRARINI, RAGHBENDRA JHA, AND ARIEF RAMAYANDI

Setting the scene 1

Public debt in developing Asia after the global financial crisis $\quad 4$ Structure of the book 7

Appendix: selected developing Asian economies' responses

to the global financial crisis 9

Notes 11

References 11

2 Analytical approaches to assessing public debt sustainability

RAGHBENDRA JHA

Introduction 14

Why does the fiscal deficit matter and what does it measure? 15

Public debt dynamics and fiscal sustainability 18

Methodological aspects of debt sustainability analysis 23

Issues in debt sustainability analysis 30

Conclusions: the importance of country studies 40

Notes 41

References 43

3 Public debt sustainability assessments for developing Asia

BENNO FERRARINI AND ARIEF RAMAYANDI

Introduction 47

Public debt and fiscal performance in developing Asia 49 
vi Contents

Fiscal reaction functions and Asia's fiscal prudence 55

The interest rate-growth differential and the debt stabilizing primary balance 61

Debt sustainability analysis based on macroeconomic forecasts 66

Assessing the impact of shocks in the deterministic and stochastic debt sustainability analysis frameworks 73

Conclusion 83

Appendix 3.1: Data issues 86

Appendix 3.2: Data availability and sources 88

Appendix 3.3: Regression analysis samples and functions 96

Appendix 3.4: Estimating fiscal reaction functions 99

Appendix 3.5: Assumptions underlying the 2011-16 baseline

projections 102

Appendix 3.6: Data issues in stochastic debt sustainability

analysis 103

Appendix 3.7: The stochastic simulation analysis 104

Notes 105

References 108

4 Public debt sustainability and hidden liabilities in the People's Republic of China

RICHARD HEMMING

Introduction 110

What do official debt numbers say? 111

Are hidden liabilities masking a more serious debt problem? 113

Standard debt sustainability analysis 116

Hidden liabilities and the measurement of government debt 119

Debt sustainability analysis and fiscal risk 127

Fiscal management and policy issues 130

Conclusions 133

Notes 134

References 136

5 Public debt sustainability and fiscal management in India

MUKUL G. ASHER

Introduction 139

Trends in the level and composition of public debt 141

Trends in fiscal debt, and cost and ownership patterns of Indian government securities 145

Government securities market: evolution and reforms 146

Debt sustainability analysis 149

Constitutional and institutional framework for debt management 153

Measures to address fiscal deficits and public debt sustainability 159 
Concluding remarks 164

Notes 166

References 167

6 Public debt sustainability and fiscal vulnerability in Viet Nam

CHARLES ADAMS

Introduction and overview 170

Debt sustainability analyses 176

Fiscal vulnerabilities in Viet Nam 183

Conclusions and policy implications 188

Notes 189

References 191

7 Conclusions and other country perspectives

BENNO FERRARINI, RAGHBENDRA JHA, AND ARIEF RAMAYANDI

Introduction 193

Public debt and fiscal performance in developing Asia: trends and implications 194

Issues with assessing debt sustainability in developing Asia 197

Debt sustainability issues for small, isolated countries: the case of Pacific Island economies 205

Policy lessons and implications 209

Notes 211

References 211 


\section{Illustrations}

\section{Box}

7.1 Government finance statistics of the Republic of Korea

\section{Figures}

1.1 General government debt/GDP ratio projections 2

1.2 General government fiscal balance/GDP ratio projections 2

1.3 Developing Asia: average government debt ratio 6

3.1 Debt indicators 51

3.2 Primary balance and public debt 53

3.3 Debt/GDP ratios $\quad 56$

3.4 Spline and cubic fiscal reaction functions 60

3.5 Actual and debt stabilizing primary balance $\quad 62$

3.6 Interest rate-growth differential 63

3.7 Actual and debt stabilizing primary balance with 1 standard
deviation shock on the interest rate-growth differential

3.8 Actual and debt-stabilizing primary balance with a positive $1 \%$ deviation on the interest rate-growth differential $\quad 67$

3.9 Public debt scenarios by subregion 69

3.10 Contributions to change in public debt in developing Asia 70

3.11 The deterministic approach to debt sustainability analysis 76

3.12 Annual changes in the central government debt ratios, 2011-16 78

3.13 Stochastic approach to debt sustainability analysis 80

3.14 Stochastic approach to debt sustainability analysis - primary budget balanced $\quad 84$

4.1 General government debt, 1990-2010 111

4.2 Fiscal stance, 2000-10 112

4.3 General government debt, 2000-16 113

4.4 Gross debt by economy, $2010 \quad 114$

4.5 Standard \& Poor's sovereign bond rating, 1992-2010 114

4.6 Government bond index and sovereign risk score 115

4.7 Debt scenarios and sensitivity analysis, 2006-16 117 
$\begin{array}{lll}4.8 & \text { The spectrum of government obligations } & 120\end{array}$

4.9 Commercial bank nonperforming loans, 2001-10 122

$\begin{array}{lll}4.10 & \text { Local government debt, 1996-2010 } & 123\end{array}$

4.11 Revised debt scenario and sensitivity analysis, 2009-16 128

$\begin{array}{ll}4.12 & \text { Integrating fiscal risk into debt sustainability analysis } \\ 4.13 & 129\end{array}$

4.13 Debt sustainability and contingent liabilities, 2009-16 130

5.1 Combined deficits of central and state governments and increase in total liabilities, 1990-2010 146

5.2 Composition of the holders of Government of India securities 149

$\begin{array}{lll}5.3 & \text { Scenarios of India's public debt/GDP ratio } & 151\end{array}$

$\begin{array}{lll}6.1 & \text { Policy scenarios_-Viet Nam's public sector debt } & 173\end{array}$

6.2 Macroeconomic scenarios-Viet Nam's public sector debt 173

$\begin{array}{lll}6.3 & \text { Viet Nam's debt sustainability analysis } & 183\end{array}$

7.1 Aid per capita: selected Pacific island economies 207

\section{Box figure}

7.1.1 Debt dynamics residual and adjustment factors 200

\section{Tables}

A1.1 Selected developing Asian economies' fiscal policy responses to the global financial crisis

2.1 Definition of fiscal crisis across advanced and emerging market economies

3.1 Fiscal indicators $\quad 50$

3.2 Fiscal reaction functions - panel regression results for seven Asian economies 58

3.3 Fiscal characteristics of economies selected for debt sustainability analysis

A3.2.1 Data availability for Asian Development Bank developing members

A3.2.2 Data sources $\quad 89$

A3.3.1 Samples for regression analysis 96

A3.3.2 Fiscal reaction functions - panel regression results for 32 Asian economies

A3.3.3 Fiscal reaction functions - spline regressions for seven Asian economies

A3.3.4 Fiscal reaction functions - spline regressions for 32 Asian economies

A3.5.1 Assumptions underlying the 2011-16 baseline projection 102

4.1 Total government debt, $2009 \quad 116$

4.2 Augmented total government debt, 2009 and 2010

5.1 Public debt and selected fiscal and macroeconomic indicators, 1999-2010 
$\mathrm{X}$ Illustrations

5.2 Maturity and yield of central government securities 148

$\begin{array}{ll}\text { 5.3 Maturity profile of central government securities } & 148\end{array}$

$\begin{array}{ll}5.4 & \begin{array}{l}\text { Medium-term deterministic debt sustainability analysis } \\ \text { projections }\end{array}\end{array}$

5.5 Residual maturity profile of the outstanding state development $\begin{array}{ll}\text { loans and power bonds } & 160\end{array}$

5.6 Tax arrears as a percentage of gross domestic product 161

$\begin{array}{lll}5.7 & \text { Estimates of tax expenditures } & 162\end{array}$

6.1 Viet Nam — debt sustainability analysis scenarios 172

\section{Box table}

B7.1.1 Coverage of national debt and fiscal balance statistics in the Republic of Korea 


\section{Foreword}

The fiscal stimulus measures that many Asian countries took to counteract the 2008/09 global financial crisis helped the region lead the global recovery. Yet, with few exceptions, the increased spending and weakened revenues have caused government budget balances and debt ratios to deteriorate across the region. The research underpinning this book, Public Debt Sustainability in Developing Asia, clearly illustrates the extent that the crisis response has altered fiscal positions in the region and the implications for the future path of public debts.

The study also raises important questions about the techniques used to gauge debt sustainability, demonstrating how the use of stochastic forecasting techniques can enrich the analysis. The research contributes to the ongoing debate among policy makers, academicians, and other practitioners on how best to assess a country's debt dynamics.

A dedicated team of researchers helped bring this book to fruition. Benno Ferrarini, Raghbendra Jha, and Arief Ramayandi, the book's editors, coordinated the contributions of the six authors, including themselves plus Charles Adams, Mukul Asher, and Richard Hemming. Kiseok Hong and Paul Holden provided inputs for two articles presented as boxes. Rogelio Mercado Jr. and Olimpia Jenneth Taja assisted with gathering needed data. Elenita Pura helped with the country workshops, travel, and project logistics.

The two country study workshops (held in Beijing on 22 July 2011 and Singapore on 21 November 2011) produced helpful discussion and insights. Thanks are due to all the participants, and especially to Shasanta Bhide, Mark Kruger, Louis Kuijs, Rajeev Malik, Ajit Ranade, T.N. Srinivasan, and Xuejin Zuo. From the Asian Development Bank (ADB), Yang Dan, Yolanda FernandezLommen, Song Ying, and other colleagues from ADB's People's Republic of China Resident Mission helped to set up the project's workshop in Beijing. Rana Hasan and Dominic Mellor provided liaison with the India and Viet Nam resident missions, respectively, for information and assistance as needed with the country chapters. Christopher Edmonds, Emma Veve and other colleagues of the ADB Pacific regional department provided helpful comments about debt sustainability in the Pacific.

Robert Hugh Davis, Anna Juico, April-Marie Gallega, and Vicente Angeles of ADB's Department of External Relations coordinated the publication with 


\section{xii Foreword}

Routledge, Priscilla del Rosario provided valuable advice on house style. Yongling Lam was Routledge's coordinator.

Jill Gale de Villa, manuscript editor, helped shape the chapters while promoting patience, perseverance, and peace among the project contributors.

A special acknowledgement is due to Cindy Castillejos-Petalcorin for her great dedication to this project since its inception, for her tireless efforts to compile a consistent database of public debt in the region, for research assistance on several chapters, and for administrative coordination and the efficient organization of workshops and seminars.

Joseph E. Zveglich, Jr. Assistant Chief Economist Economics and Research Department Asian Development Bank 


\section{Contributors}

Charles Adams is a Visiting Professor at the Lee Kuan Yew School of Public Policy, National University of Singapore. For about 25 years, he was an official at the International Monetary Fund (IMF). His research areas include exchange rates, financial market developments and issues, monetary policy formulation, and regional economic integration and cooperation. He has published widely in various journals and recently co-edited a book on financial and corporate restructuring in the aftermath of the Asian crisis. He has a PhD in Economics from Monash University, Australia.

Mukul G. Asher is a Professor at the Lee Kuan Yew School of Public Policy, National University of Singapore. He teaches applied public sector economics and economic reasoning for public policy, and also specializes in social security issues in Asia. He has published extensively in international journals, has authored and edited several books, and is an adviser to the editorial board of International Social Security Review and an editor with seven other journals. He has been a consultant to the Asian Development Bank (ADB), IMF, Organisation for Economic Co-operation and Development (OECD), World Bank, World Health Organization (WHO), and other institutions. He is resource person for policymakers in several Asian countries. He has a $\mathrm{PhD}$ from Washington State University, United States.

Benno Ferrarini is a Senior Economist in ADB's Economics and Research Department. Prior to joining ADB, he was Senior Research Fellow at the Swiss National Research Center and previously Director of Economic Research of the World Trade Institute, Switzerland. He has been a consultant to the United Kingdom Department for International Development (DFID), the United Nations Conference on Trade and Development (UNCTAD), the World Bank, and other institutions. His publications are in the fields on development finance and international trade. He has a $\mathrm{PhD}$ in Economics from the University of London, United Kingdom.

Richard Hemming is a Visiting Professor of the Practice of Public Policy Studies at Duke Center for International Development, Duke University, United States. He worked at the IMF during 1985-2008. He is an economist and fiscal policy 
expert with wide-ranging industrial and developing country expertise. In recent years, his work has focused on the fiscal consequences of financial globalization, fiscal sustainability, fiscal vulnerability and financial crises, fiscal responsibility frameworks, accounting and reporting standards, public investment, and publicprivate partnerships. He has published widely on tax, social security, public expenditure, and other fiscal issues. He has a $\mathrm{PhD}$ in Economics from the University of Stirling, Scotland, United Kingdom.

Raghbendra Jha is Rajiv Gandhi Professor of Economics and Executive Director of Australia South Asia Research Centre, Australian National University, Canberra, Australia. He has taught in universities in Canada, India, the United Kingdom, and the United States. His research interests include macroeconomic problems of developing countries, optimal tax and price policy, fiscal federalism, and Indian economic problems. He is on the Editorial Board of Macroeconomics and Finance in Emerging Market Economies and International Tax and Public Finance. He has served as consultant to numerous international organizations and agencies and to the Reserve Bank of India and the Government of India. He has a $\mathrm{PhD}$ in Economics from Columbia University, United States.

Arief Ramayandi is an Economist in ADB's Economics and Research Department. Prior to joining ADB, he was the Director for the Center of Economics and Development Studies at Padjadjaran University in Bandung, Indonesia. He is published in the field of macroeconomics and development, and served as a consultant for the ASEAN Secretariat, Australian Agency for International Development (AusAID), the Commonwealth Scientific and Industrial Research Organization (CSIRO), United States Agency for International Development (USAID), and the World Bank. He has a PhD in Economics from the Australian National University, Australia. 


\section{Abbreviations and acronyms}

$\begin{array}{ll}\text { ADB } & \text { Asian Development Bank } \\ \text { AFC } & \text { Asian financial crisis } \\ \text { AMC } & \text { asset management company } \\ \text { CDS } & \text { credit default swap } \\ \text { CIT } & \text { corporate income tax } \\ \text { CPI } & \text { consumer price index } \\ \text { DSA } & \text { debt sustainability analysis } \\ \text { DSPB } & \text { debt stabilizing primary balance } \\ \text { EME } & \text { emerging market economy } \\ \text { FGLS } & \text { feasible generalized least squares } \\ \text { FY } & \text { fiscal year } \\ \text { GDP } & \text { gross domestic product } \\ \text { GFC } & \text { global financial crisis } \\ \text { GFS } & \text { Government Finance Statistics } \\ \text { ICOR } & \text { incremental capital output ratio } \\ \text { IMF } & \text { International Monetary Fund } \\ \text { IRGD } & \text { interest rate-growth differential } \\ \text { JSB } & \text { joint-stock bank } \\ \text { LIC } & \text { low income country } \\ \text { MOR } & \text { Ministry of Railways } \\ \text { ODA } & \text { official development assistance } \\ \text { OLS } & \text { ordinary least squares } \\ \text { NPL } & \text { nonperforming loan } \\ \text { PBOC } & \text { People's Bank of China } \\ \text { PPP } & \text { public-private partnership } \\ \text { PRC } & \text { People's Republic of China } \\ \text { SGMM } & \text { system general method of moments } \\ \text { SOCB } & \text { state-owned commercial bank } \\ \text { SOE } & \text { state-owned enterprise } \\ \text { US } & \text { United States } \\ \text { VaR } & \text { value at risk } \\ \text { VAR } & \text { vector autoregression } \\ \text { WEO } & \text { World Economic Outlook } \\ & \end{array}$




\title{
1 Introduction
}

\author{
Benno Ferrarini, Raghbendra Jha, and \\ Arief Ramayandi
}

\section{Setting the scene}

In the aftermath of the global financial crisis (GFC), many countries engaged in fiscal and monetary stimuli to revive their economies. Most central banks sharply lowered policy interest rates, several of them to zero. Bank balance sheets were supported through guarantees and transfers, and deep tax cuts and public expenditure increases (fiscal stimulus packages) were put in place. As a consequence, the advanced economies' fiscal deficits, which were $1.1 \%$ of their gross domestic product (GDP) before the crisis, went up to $8.8 \%$ in 2009 and dropped only marginally to $7.5 \%$ in $2010 .{ }^{1}$ The deficits were expected to decrease marginally to $6.7 \%$ of GDP in 2011 and $5.4 \%$ in 2012. In the case of emerging market economies, fiscal deficits and debt were low in 2007, but the fiscal deficits rose to $4.8 \%$ of GDP in 2009 , dropped to $3.7 \%$ of GDP in 2010, and were expected to drop further to $2.6 \%$ in 2011 and $2.3 \%$ in $2012 .^{2}$

The GFC of 2008/09 had a particularly strong impact on the public finances of advanced economies, from whose financial sectors it had originally propagated. Massive financial sector bailouts and fiscal stimulus measures, combined with the work of automatic stabilizers, caused fiscal deficits and government debt ratios to expand (Figures 1.1 and 1.2). Although fiscal deficits have been narrowing since 2009, as stimulus measures faded and the global economy started recovering, International Monetary Fund (IMF) projections suggest that dealing with the consequences of large structural fiscal deficits and the buildup of public debt will dominate advanced economies' fiscal policies well into the future.

This massive stockpiling of debt, particularly by developed countries, has led to impacts on financial markets because the debt is often held by banks and other financial institutions. Indeed, in January 2012, global financial markets were in turmoil after sovereign debt downgrades of Europe and the United States, and with growing worries that the debt crisis in the eurozone was spreading from the periphery to the core. Global capital markets have become excessively volatile against the backdrop of growing risks to the global fiscal environment in a frail and weakening world economy. As a group, advanced economies face the prospects of debt/GDP ratios rising well into the decade spanning 2010-19, and surging borrowing costs have forced the more troubled eurozone countries to take austerity 


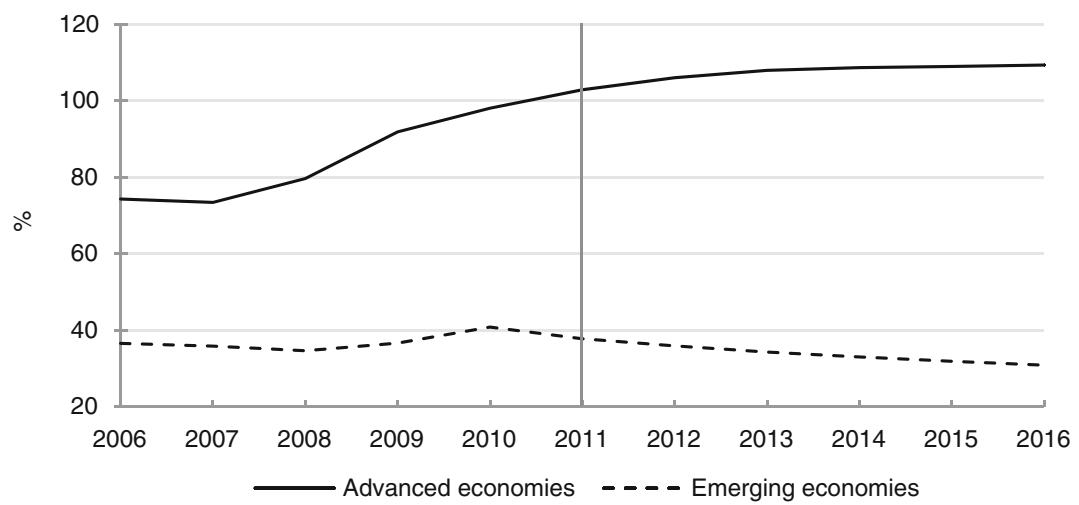

Figure 1.1 General government debt/GDP ratio projections.

$\mathrm{GDP}=$ gross domestic product.

Source: IMF (2011b).

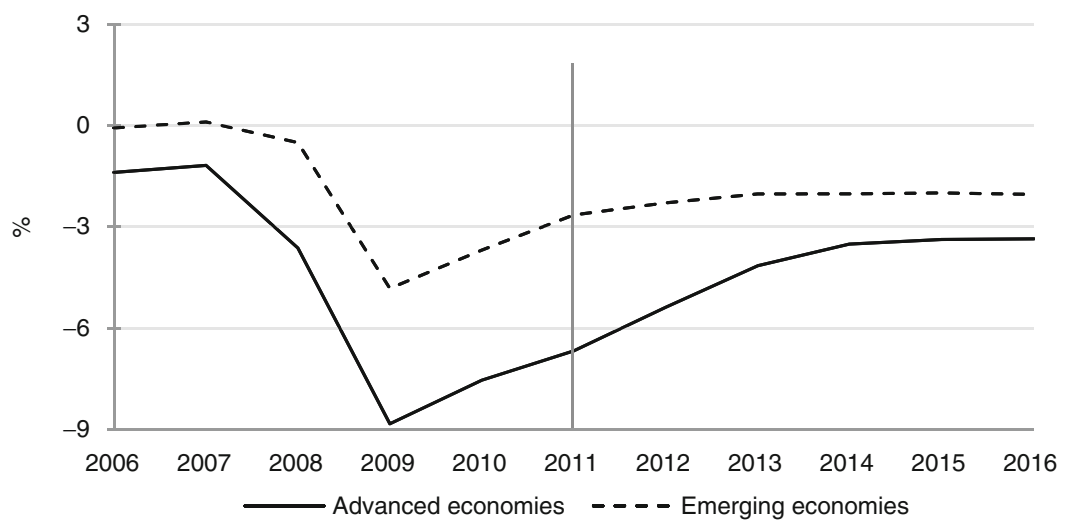

Figure 1.2 General government fiscal balance/GDP ratio projections. $\mathrm{GDP}=$ gross domestic product.

Source: IMF (2011a).

measures of a severity unprecedented since 1945. It is difficult to envisage that these countries will return to more manageable debt levels other than through the painful options of prolonged stagnation, high inflation, partial default, or some combination of the three.

The IMF Fiscal Monitor of September 2011 expects the general government gross debt/GDP ratio of the United States to have crossed the 100\% mark in 2011 and to reach $115 \%$ by 2016 , up from $61 \%$ only 5 years ago. ${ }^{3}$ The country's rating downgrade by a notch from triple-A in 2011, combined with a political stalemate over the conduct of fiscal policy, ${ }^{4}$ has sharpened markets' worries about the ability 
of the United States to define a viable and growth-supporting medium-term plan that could stem rising debt ratios and growing budgetary pressures, such as in relation to health care and age-related spending.

In the United Kingdom, the government debt ratio almost doubled in the last 5 years, from $43 \%$ in 2006 to $81 \%$ in 2011 . The country is steering toward a prolonged period of austerity, against the prospects of stalling growth and rising borrowing needs.

Similarly, Japan's gross debt/GDP ratio climbed from 191\% of GDP in 2006 to $220 \%$ in 2010 and was expected to have reached $233 \%$ in 2011 . Without serious adjustment of the primary balance, the debt/GDP ratio is bound to climb higher in coming years.

More worrying still, the eurozone is facing a deepening sovereign debt crisis that has moved from Ireland, Portugal, and Greece to affect Spain and Italy, and currently risks spilling over to France and the other countries at the eurozone's core. Market confidence has been lost, sovereign bond yields have soared in the crisis-ridden economies, and liquidity-starved European banks have cut lending to each other and to the real sector. Currently, European banks' aggregate loans exceed their deposits so that banks have to make up the deficit by borrowing in the wholesale markets. However, because these banks have eurozone bonds on their books and European governments with weak finances are either wary of supporting the bonds or financial markets perceive the banks as being unable to support the bonds for long, investors in wholesale markets are unwilling to lend to such banks. In response, banks are shedding assets in order to raise cash. This is further depressing the price of the assets, thereby perpetuating the credit crunch and adding downward pressure on economic growth in Europe and the global economy. The outlook for 2012 is gloomy and highly uncertain, but is likely to be a year of recession in Europe with negative spillovers onto the global economy. ${ }^{5}$ The survival of the eurozone and the bearing of this crisis on the world economy largely hinge on decisive and concerted action by the leading European countries and key institutions, in particular the European Central Bank and the European Stability Mechanism.

The outlook is generally more favorable among the emerging economies, which as a group had less direct exposure to the toxic assets and the financial sector meltdown associated with the GFC. ${ }^{6}$ The emerging economies were affected mainly through the collapse of global demand for their exports between the last quarter of 2008 and the first quarter of 2009. Output in many of the smaller and more export-dependent countries contracted, but growth quickly resumed as world trade rebounded after the first quarter of 2009. The larger emerging economies were more resilient to the global downturn, and their growth slowed less as a result. Crisis-related discretionary fiscal stimulus, although substantial in some emerging economies, did not have the proportions experienced in the advanced economies, and because the automatic stabilizers were relatively undeveloped in emerging economies, they played a limited role in increasing structural deficits. ${ }^{7}$ As a result, emerging economies as a group experienced less deterioration of fiscal deficits in 2008/09 than did the more developed economies (Figure 1.1), 
and only a temporary increase of the debt ratio (Figure 1.2). Against the prospects of continuing robust growth and despite the fiscal pressures associated with the GFC, the latest World Economic Outlook projections suggest that by 2017 the average public debt ratio in emerging economies will fall well below its pre-GFC level (IMF 2011b).

Nevertheless, emerging market economies continue to face significant downward risks deriving from their exposure to the vicissitudes of the battered advanced economies. For example, the IMF (2010) estimates that the higher debt burden of the advanced countries, which is projected to rise to about $110 \%$ of GDP by 2015 , could lead their long-term growth rates to drop by as much as $0.5 \%$ per annum. The study further notes that although developing countries' budgetary and current account deficits have been shrinking since the GFC, they have done so at a lower rate than expected. Moreover, countries are likely to find it difficult to build the political consensus necessary to lower debt/GDP ratios through tax reform and reducing or rationalizing expenditure. Ultimately, debt sustainability in the developing world remains highly exposed to the vulnerabilities facing the global economy, including the downward risks to economic performance from a Europe-led debt crisis and recession.

\section{Public debt in developing Asia after the global financial crisis}

As a region, developing $\mathrm{Asia}^{8}$ has weathered the GFC remarkably well. ${ }^{9}$ Its exposure to the toxic assets that originated in western financial markets was limited. Most of the financial systems of the region's economies were well prepared for the crisis. The ratio of nonperforming loans to total loans was generally low, banks were well capitalized, and most countries had minimal credit lines to western banks. Also, macroeconomic fundamentals were generally sound, having been profoundly reshaped after the Asian financial crisis 1997/98. By the time the GFC hit, external accounts in the region were mostly in surplus, many countries had piled up huge foreign currency reserves, and their debt positions were mostly low and manageable. Although sound fundamentals shielded the region from direct contagion through the GFC, Asia's strong export orientation made it highly vulnerable to the collapse of international trade. The more open economies of East and South Asia_-such as Hong Kong, China; the Republic of Korea; Singapore; Taipei,China; and Thailand - were hardest hit, and their output contracted significantly from the second half of 2008 until the first quarter of 2009 (ADB 2009b). Imports also contracted, due to the large proportion of regional trade in parts and components supporting global supply chains.

Amid the dramatic fall in exports, business and consumer confidence declined, dampening private investment and consumption. With weak domestic demand and the inability to "export their way out of the GFC," governments were left to act as the consumer of last resort. Across developing Asia, governments implemented measures to stimulate aggregate demand through fiscal and monetary expansion. The fiscal stimulus packages were geared mostly toward public spending, rather than tax cuts, and spending concentrated mainly on infrastructure projects and 
less on social protection programs and transfer spending (Appendix, Table A1.1). The size of these stimulus packages was largely unprecedented in Asia, given the region's limited history of countercyclical stabilization. ${ }^{10}$

Sound macroeconomic fundamentals along with good monetary and fiscal management just prior to the onset of the GFC, as well as the benign conditions prevailing in the global economy, led to the emergence of strong buffers in many of the countries. Consequently, they were able to put in place solid fiscal stimulus packages and yet emerge with relatively robust debt positions. Indeed, in the period leading up to the onset of the GFC, the region was characterized by excess (rather than deficient) net saving, ${ }^{11}$ which it was exporting to the rest of the world through large current account surpluses. ${ }^{12}$ Moreover, as Anderson, Silva, and VelandiaRubiano (2011) point out, many countries in the region had used the period leading up to the GFC to diversify their portfolio, reduce their share of external debt, step up their debt management capacity, and increase the maturity of their debt.

The size and impact of the policy response by the People's Republic of China (PRC) overshadowed other interventions in the region. The economy's crisis measures during 2008-10 exceeded CNY4 trillion (about $\$ 576$ billion), mostly in the form of investment to boost aggregate demand and close infrastructural gaps. Due to the PRC's central role as an assembly hub within the regional production networks, its massive economic stimulus lifted both domestic and regional demand at a time when global external demand was failing. The PRC's extraordinary resilience during the global meltdown-its economy grew by $7.3 \%$ in 2008 , slowed to $6.8 \%$ in 2009 , and rebounded to $9.6 \%$ in 2010 - benefitted its closest network trading partners in East and Southeast Asia and its global trading partners, such as Brazil and Germany (ADB 2011a).

The region's high resilience to the GFC, supported by decisive policy interventions, enabled it to weather the global meltdown well, with regional GDP slowing by merely $0.7 \%$ in 2009 , down from $6.7 \%$ in 2008 . Developing Asia was the first world region to emerge from the global turmoil in 2010, when it staged a spectacular V-shaped recovery and regional output expanded by $9 \%$ (ADB 2011b). ${ }^{13}$ Fiscal intervention to stem the global turmoil raised the average public debt ratio in the region by about $5 \%$ in 2009 , thus breaking a period of fiscal consolidation that began in the aftermath of the Asian financial crisis (Figure 1.3). However, despite the temporary upward spike in the debt ratio, the gradual fading of fiscal stimulus measures and strong output growth in 2010 and 2011 caused debt ratios in the region to resume a downward path.

Figure 1.3 also suggests that, on average, debt ratios in developing Asia will be declining through to 2016. Underlying this projection are the latest Asian Development Outlook (Asian Development Bank [ADB]) and World Economic Outlook (IMF) macroeconomic forecasts and fiscal policy assumptions (ADB 2011b, IMF 2011b), which are indeed compatible with falling debt ratios for most economies in the region. This is certainly not the case for all economies, but by and large the outlook on future debt dynamics in the region appears benign.

The broad objective of the analysis in the subsequent chapters of this book is to assess the foundations underlying the apparently benign outlook for developing 


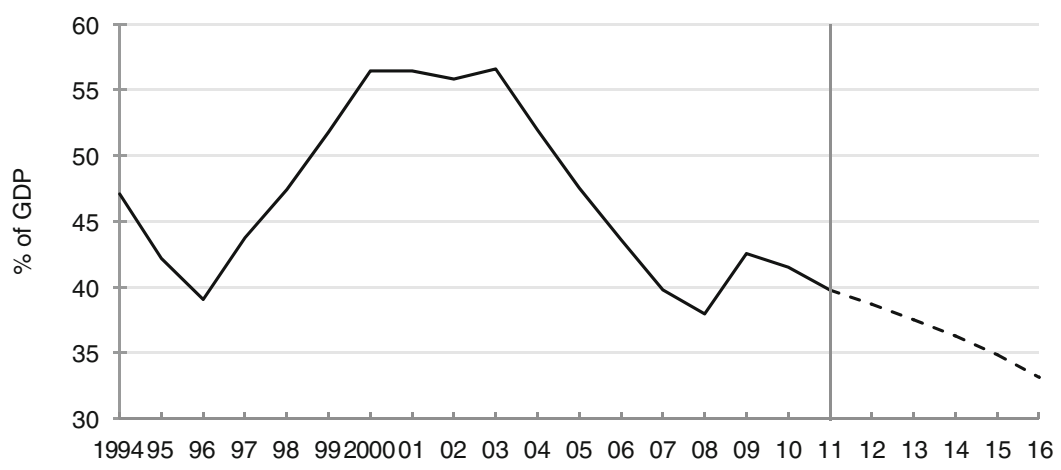

Figure 1.3 Developing Asia: average government debt ratio.

$\mathrm{GDP}=$ gross domestic product.

Source: Asian Development Bank database.

Asia, with particular focus on economy-specific vulnerabilities and global risk factors that may undermine the sustainability of public debt. The timeframe of debt projections is the medium-term, up to 2016. The analysis will thus focus mainly on the key macroeconomic assumptions underlying debt ratio projections for the region, particularly with regard to the growth and interest rate forecasts underlying public debt projections. For example, the analysis will show that most economies are vulnerable to a significant narrowing of the interest rate-growth differential, a scenario that is conceivable in the presence of a global economic environment mired in low growth and with substantial financial fragilities and spillover risks in some areas.

Owing to the medium-term focus of the analysis, structural factors that are likely to introduce a significant upward pressure on the regions' fiscal budgets and debt ratios in the longer term are not considered. For example, health care, pension spending, and social safety nets will have to expand because developing countries' abilities and needs to accomplish the expansion will increase with economic development and rising social pressures. The related fiscal outlays will add significant pressure on general government budgets across the region, shifting debt ratios upward. The analysis of such factors would be far beyond the scope of this project, and is unlikely to have a significant bearing on the debt projections over the medium term considered in the subsequent chapters.

The analysis thus mostly evolves within the framework of debt sustainability analysis (DSA) suitable for medium-term projections, as it has been applied by the IMF, World Bank, and regional development banks, including ADB. The analysis is mainly aimed at offering an interpretative key to the methods and concepts underlying DSA, as well as to the results from its application. Toward that end, the following chapters frequently highlight stylized aspects of DSA, instead of adhering to the stricter terms and guidelines of its application as typically applied to official DSA exercises, such as those found in IMF Article IV documents. 
Thus, the analysis in this book must be clearly distinguished from, and has no bearing on, any input ADB would officially provide for country DSA. The authors of Chapters 4, 5, and 6 were specifically asked for analyses that go beyond the mechanics of standard DSA, particularly as necessary to highlight specific areas of vulnerability and risk factors that DSA is ill-suited to represent. The analyses performed for the three economy-specific studies-for the PRC, India, and Viet Nam - highlight their specificities and a level of nuance that is not typically part of DSA. Through a mixed approach that includes conceptual, empirical, and country studies, this book aims at addressing some of the issues in depth, including crucial aspects concerning hidden liabilities, institutional factors, and macroeconomic volatility. The book does not claim to be comprehensive, but rather aims to shed some light on the sustainability of the public debt in major subregions of developing Asia and on their economies' readiness to meet the challenging prospects of a difficult global economic environment.

\section{Structure of the book}

Public debt sustainability. Chapter 2 reviews the concept of public debt sustainability assessment from both a theoretical and practical perspective. It emphasizes the need to have a unified analytical approach to assessing debt sustainability and to recognize the sharp differences across economies in the region with respect to a wide variety of relevant factors, including data, financial institutions, projections of future tax and expenditure, liquidity experience, and exposure to global financial markets (as well as several other factors). In view of this, the importance of assessing the sustainability of individual countries is underscored.

Fiscal indicators. Chapter 3 reviews fiscal indicators for developing Asia since the mid-1990s and projects debt ratios over the medium term, up to 2016. Econometric and simulation analysis is applied to assess the role played by fiscal policy and the macroeconomic environment in determining the debt dynamics in the region. The robustness of debt forecasts in the region is assessed against scenarios of less favorable macroeconomic conditions, whether deriving from a gradual narrowing of interest rate-growth differentials or temporary shocks to the debt dynamics that have hitherto benefitted the conduct of fiscal policy in the region.

People's Republic of China. Chapter 4 analyzes the sustainability of public debt in the PRC, with particular focus on the measurement of hidden liabilities. The chapter asks whether there is more to PRC government's debt position and outlook than the official numbers suggest, and in particular if they mask a debt problem that poses a serious threat to growth. The chapter then assesses the potential benefits from greater fiscal transparency about the nature and extent of hidden liabilities, both for informed policy decisions in view of the fiscal risks that the debts pose and to avoid the possibility of ill-guided speculation about government debt. 


\section{B. Ferrarini, R. Jha, and A. Ramayandi}

India. Chapter 5 assesses the sustainability of India's public debt. The focus is mainly on the challenges the country faces in terms of fiscal responsibility and debt management at the central government and state levels. Issues discussed relate to the optimal location of the debt management office, the implications that the evolution of the corporate debt and municipal bond markets have for debt sustainability, the tackling of differences of debt sustainability capacities among the states, and the preparation for deregulating savings banks' interest rates. In addition, the importance of increased policy emphasis on macroeconomic management, particularly ensuring fiscal sustainability and financial stability, is discussed.

Viet Nam. Chapter 6 focuses on the sustainability of public debt in Viet Nam since it began the process of economic (Doi Moi) reforms in the late 1980s. The analysis suggests that economic reforms went well, due to fiscal consolidation and responsibility so that public debt in Viet Nam was manageable until about 2000. Then the public debt deteriorated, but the authorities have concentrated on correcting the issue. Their efforts appear to have succeeded and Viet Nam's public debt is, once again, at manageable levels. However, Viet Nam has measurement issues, as does the PRC. In particular, attention is needed to a possible understatement of contingent liabilities in the banking sector, the impact of interest rates on the budget, and exchange rate and rollover risks.

Conclusion. Chapter 7 summarizes the outlook for debt sustainability in developing Asia and highlights the issues with assessing debt sustainability in the region. It also discusses aspects of public debt sustainability specific to developing economies in the Pacific subregion, which differ somewhat from the main focus on market-access countries in the previous chapters. 


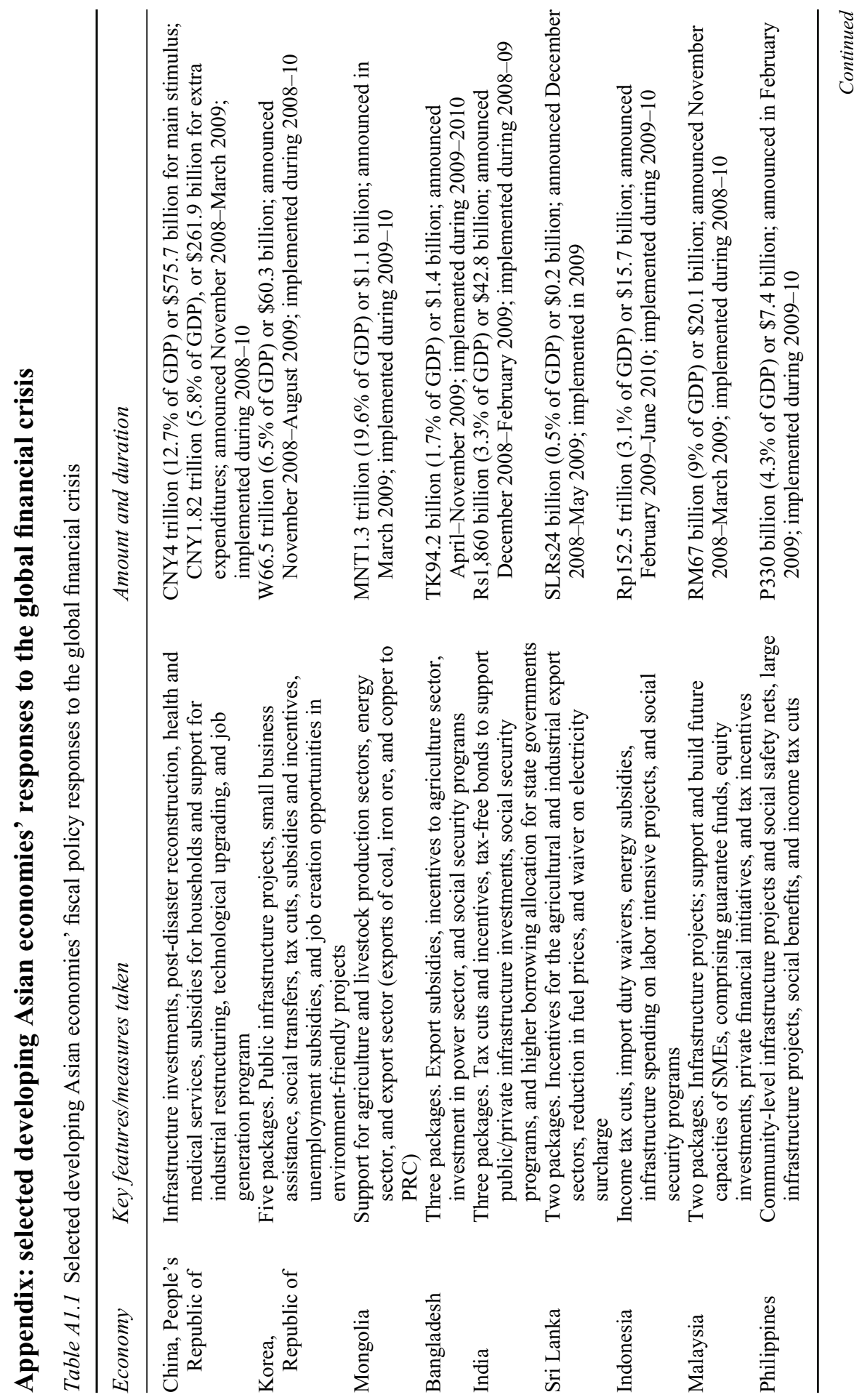




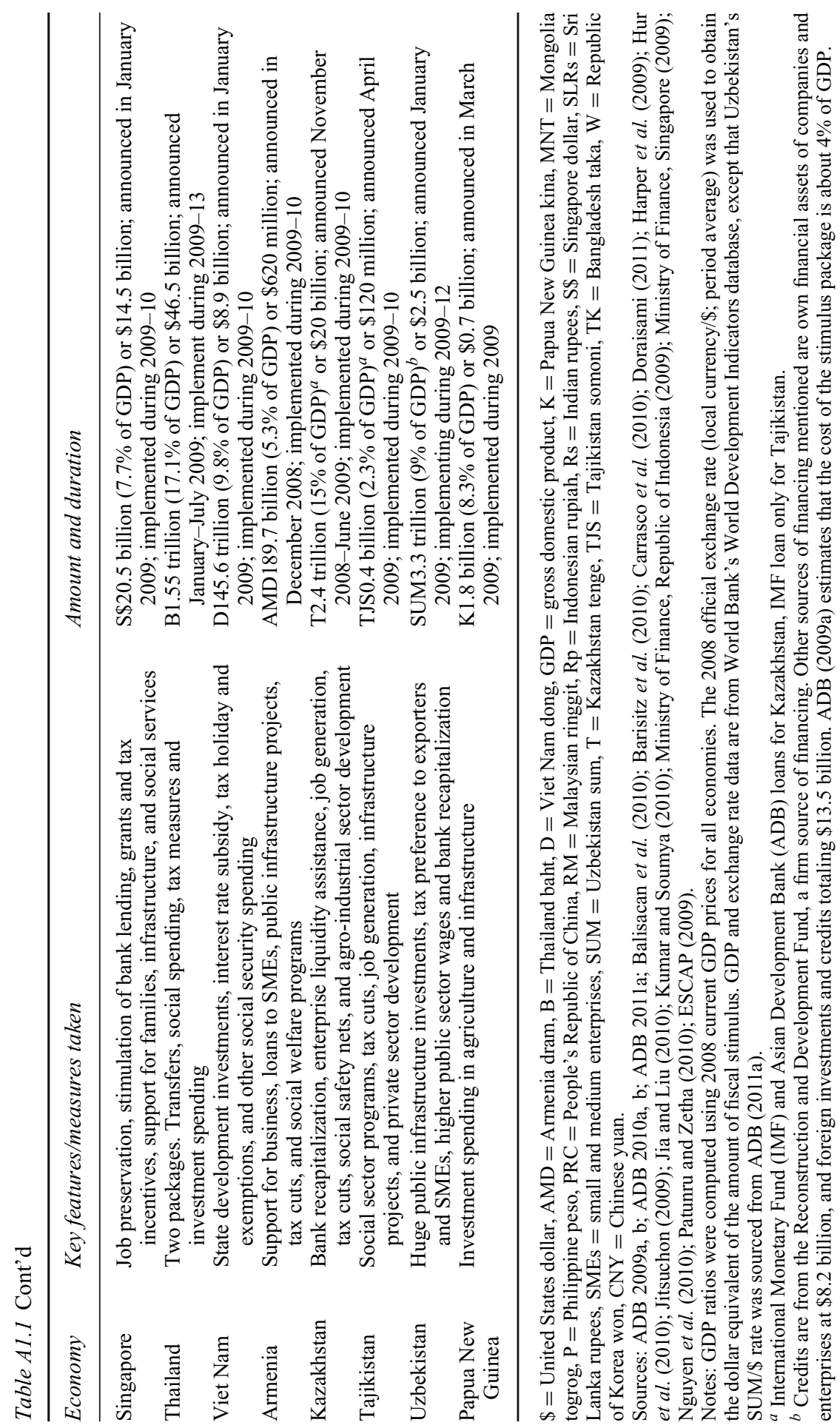




\section{Notes}

1 As noted in several sources, for example, IMF (2010, 2011a).

2 See also Baraga and Vincelette (2011).

3 Unless indicated otherwise, all data in this section are from the IMF Fiscal Monitor (IMF 2011a).

4 As an indication of the political stalemate, in late 2011 a United States (US) Congressional "supercommittee" could not agree on measures to reduce the US deficit by $\$ 1.2$ trillion over the next 10 years. This amount, while sounding large in nominal terms, is only $0.6 \%$ of US GDP-less than $25 \%$ of the $\$ 5$ trillion in cuts and less than $3 \%$ of federal government spending, respectively, over this period.

5 The Asia Economic Monitor (ADB 2011c) forecasts growth of only $0.5 \%$ for Europe in 2012. Other agencies have forecast outright recession. World Bank (2012) forecasts that 2012 will be a year of turbulence and lower growth, particularly for the advanced economies, but also for the emerging market economies.

6 With the notable exception of developing Europe, where several countries were hit hard by the GFC through financial contagion.

7 For further reading on the role of automatic stabilizers, see ADB (2009b).

8 Throughout the book, "developing Asia" refers to the ADB developing members: Afghanistan; Armenia; Azerbaijan; Bangladesh; Bhutan; Brunei Darussalam; Cambodia; China, People's Republic of; Cook Islands; Fiji; Georgia; Hong Kong, China; India; Indonesia; Kazakhstan; Kiribati; Korea, Republic of; Kyrgyz Republic; Lao People's Democratic Republic; Maldives; Malaysia; Marshall Islands; Micronesia, Federated States of; Mongolia; Myanmar; Nauru; Nepal; Pakistan; Palau; Papua New Guinea; Philippines; Samoa; Singapore; Solomon Islands; Sri Lanka; Tajikistan; Taipei,China; Thailand; Timor-Leste; Tonga; Turkmenistan; Tuvalu; Uzbekistan; Vanuatu; and Viet Nam. In this chapter and book, the terms "developing Asia" and ADB's developing members often pertain to a specific subsample of countries, depending on the context and availability of data.

9 The impact of the GFC on developing Asia and the region's subsequent recovery has been traced closely in the Asian Development Outlook (ADO) reports, on which this section draws (ADB 2009a, 2010a, 2011a).

10 Hur et al. (2010) explain the relative inexperience in the region by pointing out policymakers' penchant to maximize output growth rather than minimize output volatility. Monetary and fiscal policy in the region typically has been pursuing noninflationary macroeconomic stability, to facilitate a high-growth environment and the ultimate goal of poverty reduction. Furthermore, the strong growth performance over a prolonged period of time by many countries in developing Asia rendered countercyclical output stabilization less important than in the advanced countries.

11 Net saving is defined as the difference between saving and investment.

12 For an extensive discussion on the patterns of saving in Asia, see ADB (2009a).

13 According to the convention adopted for ADB's Asian Development Outlook, the regional growth rate is computed as an average weighted by countries' gross national product adjusted for purchasing power parity. Consequently, the PRC and other large economies are major contributors to the regional growth performance.

\section{References}

Asian Development Bank (ADB) (2009a) Asian Development Outlook, Mandaluyong City: ADB. (2009b) Asian Development Outlook Update, Mandaluyong City: ADB. (2010a) Asian Development Outlook, Mandaluyong City: ADB. (2010b) Asian Development Outlook Update, Mandaluyong City: ADB. 
(2011a) Asian Development Outlook, Mandaluyong City: ADB.

(2011b) Asian Development Outlook Update, Mandaluyong City: ADB.

(2011c) Asia Economic Monitor, December, Mandaluyong City: ADB.

Anderson, P., Silva, A., and Velandia-Rubiano, V. (2011) "Public Debt Management in Emerging Market Economies: Has this time been different?" in C. Baraga and S. Vincelette (eds), Sovereign Debt and the Financial Crisis, Washington, DC: World Bank.

Balisacan A., Piza, S., Mapa, D., Abad Santos, C., and Odra, D. (2010) "The Philippine Economy and Poverty During the Global Economic Crisis," Philippine Review of Economics, 47(1): 1-37.

Barisitz, S. Holzhacker, H., Lytvyn, O., and Sabyrova, L. (2010) "Crisis Response Policies in Russia, Ukraine, Kazakhstan and Belarus-Stock-Taking and Comparative Assessment," Focus on European Economic Integration, Oesterreichische National Bank (Austrian Central Bank), 4: 48-77.

Baraga, C., and Vincelette, S. (eds) (2011) Sovereign Debt and the Financial Crisis, Washington, DC: World Bank.

Carrasco, B., Hayashi, T., and Mukhopadhyay, H. (2010) "The Impact of the Global Crisis on South Asia," South Asia Working Paper No. 1, Manila: Asian Development Bank.

Doraisami, A. (2011) “The Global Financial Crisis: Countercyclical Fiscal Policy Issues and Challenges in Malaysia, Indonesia, the Philippines, and Singapore," ADBI Working Papers No. 288, Tokyo: Asian Development Bank Institute.

Harper, C., Gavrilovic, M., Jones, N., Marcus, R., Pereznieto, P., Binazarova, K., and Mukhametov, I. (2009) "Impact of the Economic Crisis and Food and Fuel Price Volatility on Children and Women in Kazakhstan," Research reports and studies, Overseas Development Institute. Available HTTP: http://www.odi.org.uk/resources/ docs/5827.pdf (accessed 29 November 2011).

Hur, S-K., Jha, S., Park, D., and Quising, P. (2010) "Did Fiscal Stimulus Lift Developing Asia Out of the Global Crisis? A Preliminary Empirical Investigation," Economics Working Paper No. 215, Mandaluyong City: ADB.

International Monetary Fund (IMF) (2010) World Economic and Financial Surveys. Fiscal Monitor: Navigating the Fiscal Challenges Ahead, Washington, DC: IMF.

(2011a) World Economic and Financial Surveys. Fiscal Monitor: Addressing Fiscal Challenges to Reduce Economic Risks, September 2011, Washington, DC: IMF, Available HTTP: http://www.imf.org/external/pubs/ft/fm/2011/02/fmindex.htm

(2011b) World Economic Outlook Database, September 2011, Washington, DC: IMF.

Jia, K. and Liu, W. (2010) "China's fiscal policies during the post-crisis era." Beijing: Research Institute for Fiscal Science, Ministry of Finance.

Jitsuchon, S. (2009) "Fiscal Policy Issues in Thailand after the Current Economic Crisis," Public Policy Review, 6(10), Tokyo: Ministry of Finance of Japan.

Kang, J. and Lui, W. (2010) "China's Fiscal Policies during the Post-Crisis Era," China Development Research Foundation. Available HTTP: http://www.cdrf.org.cn (accessed 29 November 2011).

Kumar, R. and Soumya, A. (2010) "Fiscal Policy Issues for India after the Global Financial Crisis (2008-2010)," ADBI Working Papers 249, Tokyo: Asian Development Bank Institute.

Ministry of Finance, Singapore (2009) "Budget Speech 2009," Available HTTP: http:// www.mof.gov.sg/budget_2009/speech_toc/downloads/FY2009_Budget_Statement.pdf 
Ministry of Finance, Republic of Indonesia (2009) “The 2009 Revised Budget Fiscal Stimulus Programme: Mitigating the Impact From the Global Crisis and State Budget 2008 and 2009," Available HTTP: http://www.bi.go.id/NR/rdonlyres/AE350D5EBCB8-4AA4-BE29-9FB44C66B04B/15743/APBNPenyesuaian_2009_ENGLISH1.pdf (accessed 29 November 2011).

Nguyen, N., Nguyen, D., and Nguyen, T. (2010) "Current Global Crisis, Fiscal Stimulus Package and Implication for Vietnam," Working Papers 10, Ha Noi: Development and Policies Research Center.

Patunru, A., and Zetha, E. (2010) "Indonesia's Savior: Fiscal, Monetary, Trade, or Luck?," Public Policy Review 6(4), Tokyo: Ministry of Finance of Japan.

United Nations Economic and Social Commission for Asia and the Pacific (ESCAP) (2009) "Fiscal Stimulus Packages in Selected Asia-Pacific Countries," Available HTTP: http://www.unescap.org/pdd/publications/survey2009/stimulus/fiscalstimulus.pdf (accessed 28 November 2011).

World Bank (2012) "Turbulent Year Ahead for Global Economy," Available HTTP: http://econ.worldbank.org/WBSITE/EXTERNAL/EXTDEC/0,,contentMDK: 23088429 pagePK:64165401 piPK:64165026 theSitePK:469372,00.html (accessed 23 January 2012).

(2012). World Development Indicators database, Available HTTP: http://data. worldbank.org/data-catalog/world-development-indicators (accessed 30 January 2012). 


\title{
2 Analytical approaches to assessing public debt sustainability
}

\author{
Raghbendra Jha*
}

\section{Introduction}

Chapter 1 notes that the debt implications of the global financial crisis (GFC) of 2008/09 have been less severe in the Asian and Pacific economies than in developed market economies. Anderson, Silva, and Velandia-Rubiano (2011) review the reasons that 24 emerging market economies (EMEs) fared better than developed countries during the GFC. ${ }^{1}$ They argue that sound macroeconomic fundamentals along with good monetary and fiscal management just prior to the onset of the GFC, as well as the benign conditions prevailing in the global economy, led to the emergence of strong buffers in many of the EMEs, so that they were able to put in place strong fiscal stimulus packages and yet emerge with relatively robust debt positions. Many of the EMEs had used the period leading up to the GFC to diversify their debt portfolio, reduce their share of external debt, and increase the maturities of their debt. The EMEs' overall debt management capacities had improved considerably in the decade prior to the GFC. The continued availability of multilateral aid also helped. Economies with better developed bond markets outperformed those with thin bond markets.

This relatively sanguine backdrop, however, does not necessarily translate into an optimistic outlook for the future. Anderson et al. (2011) mention two reasons for this. First, the world debt situation worsened considerably in 2011, with many countries in Europe as well as the United States (US) facing huge debt burdens that they are finding hard to service. Moreover, many large commercial banks have substantial exposure to debt, which weakens their balance sheets and leads to a deterioration of the external borrowing environment for the Asia and Pacific region. Thus, particularly in the current global situation, proper management of public debt remains crucial for its own sake and for financial stability (Das et al. 2011).

\footnotetext{
* I am grateful to Arief Ramayandi, Charles Adams, Mukul Asher, and Richard Hemming for their advice on the contents of this chapter. Particular thanks are due to Benno Ferrarini for his extensive comments on an earlier draft. However, the author is solely responsible for the views expressed here.
} 
Second, the low interest rate regime and accommodative monetary policy pursued in many Asian and Pacific economies during the GFC have ceased to be sustainable in the face of the recovery in this region and incipient inflation. Moving from a low interest rate regime to one with a higher rate, and from an accommodative to a restraining monetary stance, would be difficult, particularly if debt stocks were large.

Hence, there are important reasons to inquire deeply into the sustainability of public debt in the Asia and Pacific region and to explore the implications of new challenges to debt sustainability that have emerged in the aftermath of the GFC. This chapter provides an analytical background to testing for the sustainability of public debt and reviews some pertinent issues.

The next section discusses why the fiscal deficit matters and how it is measured. Then section three articulates the basic notions of public debt dynamics and fiscal sustainability. Section four discusses some methodological aspects of debt sustainability analysis (DSA), in particular two key approaches to DSA as discussed in recent analyses (such as IMF 2008, Adams et al. 2010, and Adams and Ferrarini 2010), and points out some shortcomings of these tests. ${ }^{2}$ Section five presents an overview of some recent issues in analyses devoted to debt sustainability, including the relevance of separating external from internal debt, an evaluation of the risk of meeting debt service obligations, including using valueat-risk (VaR) models, problems with debt dilution, an analysis of fiscal stress and quantification of fiscal stress thresholds, the impact of the composition of debt, broader interpretations of sovereign debt crises, and the quality of revenue and expenditure data. Finally, section six underscores the need for country-level studies of debt sustainability and concludes.

\section{Why does the fiscal deficit matter and what does it measure?}

The fiscal deficit of a government is defined as the excess of government expenditure over government revenue. ${ }^{3}$ At any point in time, the accumulated value of this deficit is the public debt. Thus, the deficit is a flow whereas the debt is a stock. High fiscal deficits impinge on the economy in several ways. A high fiscal deficit alters the allocation of resources between the private and the public sectors. In the public sector, a fiscal deficit might favor some forms of spending over others, again distorting market forces. In several developing and emerging market economies, public expenditures on wasteful, often poorly targeted, subsidies on food, fertilizers, petroleum, and the like gain higher proportions of state expenditure as the fiscal deficit rises. This process also builds up expectations of future government expenditure patterns and thus alters the allocation of resources between the present and the future. A high fiscal deficit can, by raising interest rates, lead to enhanced debt service payments and thus accentuate distortions in the distribution of income. ${ }^{4}$ Higher debt service charges reduce the amount of investment the public sector can make, and hence lower potential economic growth. This detracts from efforts to raise living standards, lower poverty, and service the debt. 


\section{R. Jha}

That economic growth is central to poverty alleviation is widely accepted. Hence, a particularly important question is: "What is the impact of the fiscal deficit on the rate of growth, particularly in developing countries?" In the neoclassical model of economic growth in the tradition of Solow, over the long run, the level of income can be altered by fiscal changes (relative to some initial fiscal policy stance). However, in the long run, economic growth will return to its initial rate. Further, since the mid-1980s, the new endogenous growth models have added new insights on the effects of fiscal policy on economic growth. Indeed the endogenous growth theory has proposed a number of channels through which fiscal policy could have "permanent" growth effects. Thus, fiscal policy could have enduring effects on growth rates and on levels of income. Gemmell (2004) reviews the literature on this issue and the applicability of this analysis to developing countries. He finds some tentative evidence that fiscal deficits may affect growth in such countries. Although he qualifies this evidence, the overall conclusion is that fiscal adjustments are likely to yield significant gains, such as consistently ensuring that an intertemporal budget constraint is satisfied. It is even more important to ensure that the fiscal deficit is adjusted in a cogent program of tax and expenditure reform.

Using a threshold regression model of the impact of debt on economic growth, Caner, Grennes, and Koehler-Geib (2011) show that, for their full sample of 101 countries (75 developing and 26 developed) for the period 1980-2008, there are well-defined levels of public debt, beyond which debt starts having deleterious effects on economic growth. This critical level is $77 \%$ of gross domestic product (GDP) for the full sample and $64 \%$ of GDP for the developing country sample. Hence, the critical value of public debt is lower in developing and emerging market economies. $^{5}$

Although the fiscal deficit is a clear accounting concept to articulate, its conceptual foundation as an economic entity can be controversial. Tanzi (1993) argues that this conventional measure of the deficit fails to recognize that different tax and expenditure categories have different types of effects on aggregate demand. For example, an excess of expenditure on infrastructure creates productive capacity and promotes economic growth and will hence have a different impact than an excess of expenditure due to consumption subsidies. Tanzi also notes that the level of public expenditure determines national income, a major component of which is expenditure, which then determines tax revenue, at least in part. Hence, there are important problems of mutual endogeneity. In view of this, the notion of a "full employment budget surplus" was defined and used during the KennedyJohnson presidencies in the US - a period of full employment. The deficit was pinned with reference to the employment of an important scarce factor-labor, in the case of the US. In the context of developing and emerging market economies in the Asia and Pacific region, the availability of credit in "hard" currencies may be a more binding constraint than labor supply.

Tanzi (1993) also discusses difficulties arising from the variations in sources of financing the deficit. In developing countries, sources of financing have included central bank financing, commercial bank financing, domestic sale of 
government bonds to cover deficit, and foreign financing. Each has different macroeconomic consequences. Central bank financing raises the monetary base and the money supply. This blurs the distinction between monetary and fiscal policies, compromising the mutual independence of the two policies and thus reducing overall policy effectiveness (Jha 2003). Foreign financing will raise the cost of servicing external debt, whereas domestic bond issues will raise interest rates. Further difficulty arises because some sources of finance are available only under particular circumstances. For example, a country with a thin bond market can hardly afford to issue government bonds to cover the fiscal deficit and may have to rely on central bank financing or some such measure. If a country with a large external debt attempts to finance its deficit by external borrowing, it will be able to do so only in the short term and at high interest rates. This would make it difficult to finance the external debt and may put pressure on the currency (Jha 2004). In developed countries, bond markets are much better developed and deficits are largely financed by floating bonds that domestic residents and foreigners can buy.

Another issue with the fiscal deficit is its sensitivity to the business cycle. Thus, during a cyclical downturn, revenues are likely to fall because incomes drop and public expenditures are likely to rise because of automatic stabilizers (such as welfare and unemployment benefits). The reverse is likely to happen during a cyclical upturn. Hence, there is merit to designing a measure of the fiscal health of an economy that would adjust for these cyclical swings. The resulting deficit has been referred to as a cyclically adjusted fiscal deficit. Similarly, because inflation affects the real values of government assets and liabilities asymmetrically, some authors call for an inflation-adjusted measure of the deficit. However, even cyclically adjusted and inflation-adjusted measures of the deficit are only imprecise indicators of the true deficit because capital gains and losses on government assets and liabilities are not included in the conventional flow of funds accounts. Examples of the gains and losses include changes in relative prices (such as changes in mineral prices) and in the real value of nominal debt during an episode of inflation (Buiter 1985, 1993). ${ }^{6}$

In many developing countries, particularly those in which public investment has played a significant role (e.g., the South Asian countries), a distinction is made between revenue or current account deficit and capital account deficit. The former is the deficit on expenses of a recurrent nature after netting out investment expenditure. The latter is the deficit on account of public activities in building up national assets. All else being equal, a large revenue or current account deficit is a greater cause for concern than a capital account deficit of equal magnitude. However, some authors have argued that the distinction between capital and current account expenditures is often artificial, and would be meaningful only if all capital account expenditures were productive in nature. In practice, even some capital account expenditures associated with capacity building might be wasteful-for example, if the project in question had not been evaluated carefully, involves equipment that is highly capital intensive or has an unduly import-intensive bias, or is, in some other way, inappropriate for 
the economy. Bhatt (2010) argues that the composition of public expenditure can have a significant impact on prospects for economic growth and, ultimately, on public debt. In particular, all else being equal,investment-oriented public expenditure has a lower impact on the public debt than does public investment geared toward consumption.

Accounting for arrears is another issue that has been discussed in the literature, particularly in the case of foreign debt. When debt is rescheduled, for example, it is hard to decide whether the debt has gone down. And, if the government delays paying some domestic debts (e.g., the public wage bill) but takes in all its revenues, does fiscal deficit go down? This question becomes particularly relevant during a period of high inflation when delaying payments denominated in nominal terms can have a significant impact on the real value of the payments and the accounting deficit.

Another challenge to computing the fiscal deficit arises when governments are multilayered or the debt is the responsibility of more than one agency. Typically in federal structures, deficits of the central, state, and lower levels of government are included in the computed measure of the national deficit. Nevertheless, other government agencies may be running a deficit that is not included in the measured fiscal deficit. Examples include deficits of central banks, deficits of local (particularly municipal) governments, and the so-called "oil pool" deficit where payments for petroleum imports exceed what is collected from consumers. The oil pool deficit can become very large when international oil prices rise sharply and/or the domestic currency depreciates against the US dollar. Often the government issues temporary "oil bonds" to shift part of the burden of adjustment to the future, but such transactions are not reflected in the fiscal deficit. There are the so-called "contingent liabilities" such as bailouts of failing financial institutions. Thus, the computed fiscal deficit may not be an entirely accurate measure of the true deficit.

An additional complication arises when, in trying to forecast the future value of the fiscal deficit, the forecast values of revenue and expenditure are assumed to be riskless. If, for example, a government's revenues are perceived to be risky, even if its fiscal deficit is low, the government may have difficulty borrowing and the perceived problem of insolvency can lead to a liquidity crisis. This issue is pursued further in the section "Issues in debt sustainability analysis," which discusses fiscal stress.

\section{Public debt dynamics and fiscal sustainability}

\section{Analyzing the sustainability of public debt}

In the very long run, the government should not be a net debtor. "The fiscal policy stance can be regarded as unsustainable if, in the absence of adjustment, sooner or later the government would not be able to service its debt" (IMF 2011). Unsustainable debt levels can lead, and have led, to major disruptions in economic activity and to reorientations of priorities in an economy. ${ }^{7}$ Therefore, clear 
indicators of debt sustainability are essential and policies that ensure continued debt sustainability must be pursued. Consequently, the analytics of ascertaining debt sustainability and their application to recent data from the major Asian and Pacific economies are the primary focus of this book. The current section develops the simple analytics of sustainability for domestic and external deficits and applies them to a spectrum of developing economies. For a review of alternative approaches to the sustainability of the fiscal deficit, see Cuddington (1997), Chalk and Hemming (2000), de Haan and Zelhorst (1990), Easterly and Schmidt-Hebbel (1993), Hakkio and Rush (1991), Issler and Lima (2000), Sargent (1999), and Trehan and Walsh (1991); and, for more recent discussions, see Adams et al. (2010) and Adams and Ferrarini (2010).

DSAs are almost exclusively concerned with market-access countries rather than overseas development assistance countries (see Chapter 3). The track record of DSAs in predicting actual debt crises has been rather poor (IMF 2003a). Wyplosz (2007), in an insightful review of the mechanics and performance of DSA, argues that one of the principal reasons for DSA's poor performance is the so-called "impossibility principle"-DSA is based on past data but needs to make judgments about the future value of debt. Wyplosz (2007: 25) notes that DSA is valid only "within the bounds of the underlying guesses" and argues that standard DSA is biased in the direction of discovering sustainability. In summarizing the logic behind some of these tests, this section closely follows Adams et al. (2010) and Adams and Ferrarini (2010).

Consider a government financing the excess of its expenditure over its revenue. Assume that the central bank does not finance any part of the public debt. In that case, the excess of government expenditure over government taxation must be financed by government borrowing, that is, by issuing bonds. In other words we have the identity

$$
R_{t}-G_{t}=-\left[B_{t+1}-B_{t}\right], \quad t=1, \ldots, N,
$$

where $R_{t}$ is revenue, $G_{t}$ is expenditure, and $B_{t}$ is one period of public debt, all at time $t$.

Because bonds carry an element of interest payment (a flow) whereas the public debt is a stock, it is useful to separate all central government interest payments from $G_{t}$ and concentrate on the primary surplus, $P S_{t}$. Primary government spending may be denoted by $G_{t}^{*}$, so that $P S_{t}=R_{t}-G_{t}^{*}$, and thus bond issue in period $t+1$, can be written as

$$
\Delta B_{t+1}=r B_{t}-P S_{t}, \quad t=1,2,3, \ldots, N
$$

where $r$ is the nominal one period interest rate and $r B_{t}$ is the interest payment on the last period's bonds. The interest payment on the last period's bonds less the government's current primary surplus must be covered by issuing new bonds. Equation (2.2) also states that if the primary surplus is zero, public debt will grow at the nominal rate of interest. Difference equation (2.2) can be solved forward 
through time to yield

$$
B_{t}=\sum_{j=0}^{\infty} r_{(t, t+j)^{-1}} P S_{t+j}+\lim _{T \rightarrow \infty}(t, t+T)^{-1} B_{t, T+1},
$$

where $r$ is the discount factor between periods $t, t+j$ and is defined as $\prod_{k=0}^{j} r_{t+k}$, and $B_{t, T+1}$ is terminal or very long-term debt. An initial notion of sustainability is that $B_{t, T+1}$, discounted at a positive rate, should approach zero as $T$ becomes arbitrarily large.

Alternatively, the revenue, expenditure, and bond issue terms can be expressed as ratios of GDP. In that case the sustainability condition of equation (2.3) would be reinterpreted to say that the terminal nominal rate of interest should be no larger than the rate of growth of nominal GDP. Both these conditions would rule out a situation, known as "the Ponzi game condition," where government debt is rolled over by issuing new debt. So long as Ponzi games are not being played, any public debt that does not exceed the discounted stream of future surpluses will find willing buyers and no default will occur. Conversely, a default is said to occur when this condition is not satisfied.

A succinct and convenient way to articulate the no-Ponzi game condition is in terms of the interest rate-growth differential (IRGD). ${ }^{8}$ Consider a situation of public debt where the government is running a fiscal deficit that is financed by issuing bonds, thus accumulating further debt. If the interest paid on this debt is lower than the growth rate of the economy (IRGD $<0$ ) then, all else being equal, the debt will stabilize below the current level. Then, assuming unchanging elasticity of government revenue with respect to GDP, government revenue will grow at a faster rate than the rate at which debt is being accumulated. Hence, public debt would be lower in steady state. The opposite conclusion holds for the situation in which IRGD $>0$.

Associated with the need for the IRGD to be less than zero is the notion of debt stabilizing primary balance. Let the change in the debt/GDP ratio be defined as

$$
\Delta b_{t}=b_{t}-b_{t-1}
$$

where $b_{t}$ is the debt/GDP ratio. This difference will go up to the extent that IRGD $>0$ and will fall if the primary surplus (i.e., if the surplus without interest payments) is positive. In other words

$$
\Delta b_{t}=b_{t}-b_{t-1}=\frac{r_{t}}{1+g_{t}} b_{t-1}-\frac{g_{t}}{1+g_{t}} b_{t-1}-p s_{t}=\frac{\theta_{t}}{1+g_{t}} b_{t-1}-p s_{t},
$$

where $\theta_{t}$ is the IRGD, $p s_{t}$ is the primary surplus/GDP at time $t, r$ is the interest rate, and $g$ is the GDP growth rate. Fiscal sustainability over a horizon can be judged according to whether the path of debt is stabilizing or explosive. Then, define $b^{*}$ 
as the level to which this stable debt/GDP ratio gravitates. For debt to stabilize at this level, the primary surplus/GDP today must exactly pay for the IRGD in the last period, that is,

$$
p s_{t}^{*}=\frac{\theta_{t}}{1+g_{t}} b_{t-1}^{*} \text {. }
$$

Thus, debt stabilization requires the primary surplus to be obtained today. However, as Chapter 3 makes clear, eventually for efficiency, the IRGD should turn out to be positive for any economy close to steady state. So long as the IRGD is negative and the debt/GDP is falling, rational agents will have the incentive to borrow at low interest rates and finance higher consumption and rollover debt. This is the "modified golden rule" efficiency condition discussed in Blanchard and Fischer (1989).

What is the evidence on the sign of the IRGD in EMEs and low-income countries in comparison to developed market economies? Escolano, Shabunina, and Woo (2011) show that the IRGD is persistently negative in the case of EMEs and low-income countries, but it is usually positive in the case of mature market economies. Data reported by Escolano et al. (2011) indicate that, during the period 1966-2010, the mean real interest rate was 3.16\% for advanced economies 9 whereas their average growth of real GDP was $2.58 \%$, giving the real interest rate minus the growth rate of real GDP at $0.58 \%$ and an average IRGD of $0.63 \%$. In the case of all EMEs and for the same time period, the average real interest rate was $0.97 \%$ whereas the average growth rate of real GDP was $4.47 \%$, giving the real interest rate minus the growth rate of real GDP at $-3.50 \%$ and an average IRGD of $-3.07 \%$. Further, they show that the IRGD is positively correlated with income per capita. If this position were accepted uncritically, two conclusions would follow. First, as incomes in EMEs catch up with those in developed market economies, debt sustainability would become harder to attain in the EMEs. Second, so long as the IRGD is negative there would be little reason to be concerned about debt sustainability because increments to debt would be more than made up by increases in revenue, that is, there would be little reason to be concerned about debt sustainability in EMEs.

However, Escolano et al. (2011) argue that the real interest rate in many EMEs is artificially low as a result of financial repression and other factors that deliberately undervalue the cost of capital. ${ }^{10}$ The true cost of capital is typically much higher than that reported in many of the EMEs. As capital markets are liberalized in the EMEs and become integrated with global capital markets, EMEs' interest rates are likely to more accurately reflect the cost of capital and, hence, climb sharply. Two conclusions follow from this. First, in the case of EMEs, the IRGD may turn from negative to positive both because of the catch-up effect of per capita income growth as the EMEs grow faster than the advanced economies and as a consequence of relaxing the financial controls in the EMEs. Second, there is no room for complacency about the public debt situation in EMEs, because the fact that the IRGD is negative may largely be a function of repressed 
capital markets. It follows, then, that the IRGD criterion is not an adequate method for assessing debt sustainability and other approaches are needed.

The representation of debt sustainability given by equation (2.3) has some limitations, including:

- the difficulty of applying it,

- insufficient government control over future revenues,

- the insufficiency of past data for predicting future outcomes, and

- $\quad$ issues determining the appropriate levels of debt vis-à-vis debt sustainability.

The sustainability condition implied by equation (2.3) is hard to apply in practice, for two reasons. First, because the condition holds for an infinite time, one can always argue that any current deficit, no matter how large, can be met by sufficiently large primary surpluses in the future. Conversely, no matter how large the current primary surplus, it can always be overwhelmed by large deficits in the future. Second, the sustainability condition is silent on what the relationship between revenues and expenditures should be in the future and, in particular, places no constraints on this relationship. Nevertheless, satisfying equation (2.3) remains the basic sustainability condition. Practical assessment of sustainability is often said to be an art rather than a science. ${ }^{11}$

A further limitation of the standard analysis is that in some cases the government has only partial control over its future surpluses and may hence face an illiquidity issue, even before an unsustainable level of debt is reached (Besancenot, Huyn, and Vranceanu 2004). However, equation (2.3) should be interpreted as a risk-free measure where future primary surpluses are viewed as being certain.

In practice, because revenue could be lower or higher than expected, or both, the government may face a solvency issue, even before the level of debt implied by the long-run value of equation (2.3) is reached. Particularly in the case of market access countries, potential buyers of the public debt would foresee the emergence of insolvency and refuse to buy the debt, even at levels much below those predicted as sustainable by equation (2.3), as noted in Bordo (2008). This implies that, after accounting for risk, the sustainable level of debt is lower than the level given in equation (2.3). At this lower level of debt, the country may find it difficult to acquire credit even though its debt, as such, may be sustainable. As a result, the country could face a liquidity crisis. A frequently cited example is the Mexican default of 1995, although Mexico's debt in 1993 was quite low at $30 \%$ of GDP. In fact most so-called debt crises of the recent past-for example, the Asian financial crisis of 1997/98 - have actually been solvency and liquidity crises. Bordo (2008) argues that many financial crises in the US (e.g., those of $1857,1893,1907,1929-33$, and the GFC of 2008/09) had similar origins.

Two other limitations of the standard DSA should be mentioned. First, it is important to restate that DSA assesses whether the effects of past policies encapsulated in a path of primary balance imply a sustainable debt path in future. In fact, because data from the past are being used, nothing substantial can be said about actual debt sustainability in the future (IMF 2008). Further, the DSA tests 
for the sustainability of the debt path but does not determine the level at which this debt settles. For example, the debt path may be sustainable, but the level at which the debt settles may be unacceptably high. Servicing such high levels of debt may take an unacceptably large share of the government's current expenditure and divert resources from other important efforts such as measures to enhance economic growth or reduce poverty.

\section{Methodological aspects of debt sustainability analysis}

Because the foregoing DSA tests often yielded ambiguous results, therefore alternative tests have been developed. The two broad classes of such tests are static and dynamic tests. Failed public debt auctions are a static test for debt sustainability and one indicator of debt servicing difficulties and the potential that public debt may be unsustainable (ADB 2009). ${ }^{12}$ If a government finds it difficult to auction its debt at expected terms or has to sell it at deep discounts, then it is assumed that the market perceives that the government is having trouble financing its expenditure.

This book deals explicitly with dynamic tests. Adams et al. (2010) provide a lucid account of these tests. This section discusses the time series and fiscal reaction function (also called "primary balance") tests, while paying the greatest attention to the latter. The two tests can be complementary and several authors have used both to assess debt sustainability. Stress tests are also used in conjunction with the primary balance and fiscal reaction function tests.

\section{Time series properties of the public debt}

The time series approach tries to assess whether the stock of public debt and/or the public debt/GDP ratio are stationary in a time series. If the debt stock shows explosive behavior, that is, the debt/GDP ratio has a unit root, then it would indicate that debt is not sustainable. ${ }^{13}$

A straightforward way to model public debt as a proportion of GDP and assess the sustainability of a public debt situation is to start from the governmental intertemporal budget constraint. This is written in nominal terms as

$$
G_{t}-T_{t}+r_{t} B_{t-1}=B_{t}-B_{t-1},
$$

where $G_{t}$ is the value of government expenditures (purchases of goods and services plus transfer payments), $B_{t}$ is the government debt at the end of period $t, T_{t}$ is the government's tax revenue, and $r_{t}$ is the one-period rate of interest payable on the government debt. Equation (2.4) states that, in the absence of money finance, the government budget deficit must be financed by new debt. ${ }^{14}$ Hence

$$
b_{t}=\left(1+r_{t}\right)\left(1+\pi_{t}+y_{t}\right)^{-1} b_{t-1}\left(\omega_{t}-\psi_{t}\right),
$$

where the lowercase letters denote the ratio of the corresponding uppercase variables to nominal GDP: $b_{t}=B_{t} / P_{t} Y_{t} ; \omega_{t}=G_{t} / P_{t} Y_{t} ;$ and $\psi_{t}=T_{t} / P_{t} Y_{t}$; with $P$ 


\section{R. Jha}

being the price level and $Y$ being real GDP. The equation $\pi_{t}=\frac{P_{t}-P_{t-1}}{P_{t-1}}$ is the rate of inflation and $y_{t}=\frac{Y_{t}-Y_{t-1}}{Y_{t-1}}$ is the rate of growth of real GDP. In the derivation of equation (2.5), the relation used is

$$
P_{t} Y_{t}=\left(1+\pi_{t}\right)\left(1+y_{t}\right) P_{t-1} Y_{t-1} \approx\left(1+\pi_{t}+y_{t}\right) P_{t-1} Y_{t-1} .
$$

The primary deficit - the deficit without interest payments-expressed as a percentage of GDP is $\left[\left(\omega_{t}-\psi_{t}\right)\right]=\left(-p s_{t}\right)$. The sustainability of the fiscal deficit is intimately related to this primary deficit. Sustainability is essentially an intertemporal question over an infinite horizon. Every temporary deficit can be sustainable so long as it is matched by an adequate future surplus. So, if the primary deficit keeps growing, the fiscal deficit will not be sustainable. In other words, for the deficit to be sustainable, in the long run, revenue and deficit have a one-to-one relation so that the primary deficit does not grow out of bounds. This is the intuition behind the tests for sustainability developed in a number of studies. Recent advances include permitting structural breaks in the revenue and expenditure series as well as in the relationship between them, as in Jha and Sharma (2004). ${ }^{15}$ This is because the existence of a cointegrating relationship between revenue and expenditure depends on whether the series have structural breaks.

A difficulty with time series approaches is that they are "backward looking" and do not work with estimates or forecasts of future revenue and expenditure (Adams et al. 2010). Therefore, the approaches implicitly assume that the future will unfold much like the past. Finally, the time series approach gives little guidance about the kind of fiscal reaction needed to assure that debt will be sustainable.

\section{Fiscal reaction function tests}

These tests use past behavior to model and estimate a fiscal reaction function of the government. The approach attempts to test whether policy responds to the accumulation of debt. Work in this area was initiated by Bohn (1998), who sought to assess the sustainability of the public debt by examining it in a time series context (for the US). He shows that although the US debt/GDP ratio has a unit root, and is thus potentially unsustainable, corrective action exists because the primary surplus rises whenever the debt/GDP ratio rises. Hence, so long as there is such a corrective policy response, the debt could (ultimately) become sustainable. This was an initial articulation of the fiscal reaction function.

Bohn (1998) used the following simple fiscal reaction function:

$$
p s_{t}=\rho b_{t}+\beta_{0}+\varepsilon_{t} .
$$

In this equation, $b_{t}$ stands for the debt/GDP ratio, $p s_{t}$ stands for the primary surplus/GDP ratio, and $\varepsilon_{t}$ is an error term. This function is used to study the US 
fiscal policy in the period 1916-95, with the primary surplus as the dependent variable and debt as the independent variable. However, Bohn argued that this simple theoretical regression might omit some problems, and the empirical research should be based on a more practical model. Therefore, Bohn expanded his analysis to include the Barro (1974) tax-smoothing model to support the simple fiscal reaction function above. Bohn therefore included temporary government spending $(\tilde{g})$ and a business indicator $(\tilde{y})$ in the model. The Bohn (1998) extended model is, therefore

$$
p s_{t}=\rho b_{t}+\beta_{0}+\beta_{G} \tilde{g}_{t}+\beta_{Y} \tilde{y}_{t}+\varepsilon_{t} .
$$

Bohn indicates that this model fits the US data well and that the fiscal policy of the United States up to 1995 was sustainable.

Following from this, Khalid, Malik, and Sattar (2007) estimate the fiscal reaction function for Pakistan using the vector autoregression technique with three main variables: fiscal deficit, output gap, and inflation. Turrini (2008) estimates the fiscal reaction function for the eurozone in good and bad times with the businesscycle adjusted fiscal balance as the dependent variable and lag of dependent variable, debt, output gap, and some political and dummy variables as independent variables. Afonso and Hauptmeier (2009) adopt this method to estimate the fiscal reaction for the European Union with two main variables: the primary balance/GDP ratio $\left(p s_{t}\right)$, and the debt/GDP ratio $\left(b_{t}\right)$. Afonso and Hauptmeier also use output gap, fiscal rule indicator, institutional, political, and other control variables. More recently, Egert (2010) includes some business cycle variables as independent variables.

In a study of the Brazilian debt data, de Mello (2007) extends this model to include the monetary factor. With the monetary factor, the fiscal reaction function in de Mello has the following form:

$$
p s_{t}+\left(r_{t}+g_{t}\right) b_{t-1}=\Delta b_{t}+\Delta m_{t}+\left(\pi_{t}+g_{t}\right) m_{t-1},
$$

where $p s_{t}$ is the primary balance/GDP ratio, $g_{t}$ is the real GDP growth rate, $r_{t}$ is the real interest rate, $m_{t}$ is a monetary base/GDP ratio, and $\pi_{t}$ is the inflation rate. Then, de Mello assumes $\Delta m=0$ and imposes the "no Ponzi game condition" to estimate the empirical model:

$$
p s_{t}=\alpha_{0}+\alpha_{1} p s_{t-1}+\alpha_{2} b_{t-1}+\alpha_{3} C_{t}+\varepsilon_{t},
$$

where $C_{t}$ represents various control variables, $\alpha$ represents coefficients, and $\varepsilon_{t}$ is an error term.

In general, this fiscal reaction function has the same functional form as that in Bohn (1998). Results show the strong statistical significance of the lags of primary balance and debt in the fiscal reaction function. However, other variables, including lag of output gap and inflation, do not show the same statistical significance in the test. Later, de Mello (2007) extends the paper to establish firm cointegrating relationships between the key variables. 
Budina and Wijnbergen (2008) consider a simple fiscal model for the closed economy. The novelty in their analysis is the explicit consideration they give to the role of issuing money. In their opinion, the seigniorage revenue (the difference between the value of issued money and the cost of issuing money) is a source of income for governments and should, therefore, be added to the government budget constraint. Thus, the empirical model they estimate has the form

$$
b_{t}=b_{t-1}(1+r)-\left(p s_{t}+\sigma_{t}\right),
$$

or, equivalently,

$$
b_{t-1}=\frac{p s_{t}+\sigma_{t}}{1+r}+\frac{b_{t}}{1+r},
$$

where $p s_{t}$ is the primary surplus/GDP ratio, $r$ is the interest rate, and $\sigma_{t}$ is seigniorage. From this budget constraint, Budina and Wijnbergen (2008) derive the initial sustainable debt level as

$$
b_{0}=\sum_{1}^{\infty} \frac{p s_{t}+\sigma_{t}}{(1+r)^{t}} .
$$

Thus, for sustainability, the initial debt should equal all the discounted primary surplus and seigniorage in the future. The de Mello (2007) and Budina and Wijnbergen (2008) papers, which include the monetary factors, provide good estimation results.

Burger et al. (2011) emphasize the role of policy reaction to the evolution of public debt and estimate a novel fiscal reaction function for South Africa. They aim to assess how the current primary balance/GDP ratio responds to the one period lagged public debt/GDP ratio. This notion is motivated by Bohn (2007). The simple debt dynamics may be written as

$$
B_{t}=B_{t-1}+r B_{t-1}-P S_{t},
$$

where $B_{t}$ is the debt in period $t, P S_{t}$ is the primary balance in period $t$, and $r$ is the interest rate. From equation (2.12), an expression for the change in the level of indebtedness measured against GDP can be derived and written as

$$
\Delta \frac{B_{t}}{Y_{t}}=\frac{r-g}{1+g} \frac{B_{t-1}}{Y_{t-1}}-\frac{P S_{t-1}}{Y_{t-1}},
$$

where $Y$ is GDP, $r$ is the interest rate and $g$ is the growth rate of GDP. Time subscripts have been omitted from $r$ and $g$.

For a constant debt/GDP ratio, one can set the left hand side of equation (2.13) equal to zero and solve for the primary surplus that will lead to a constant debt/GDP ratio. This is

$$
\frac{P S_{t}}{Y_{t}}=\frac{r-g}{1+g} \frac{B_{t-1}}{Y_{t-1}} .
$$


If the initial debt/GDP ratio is acceptable, equation (2.14) gives the primary surplus response to debt needed in the last period that is required to maintain this acceptable debt/GDP ratio. This is similar to the analysis of debt stabilizing primary surplus already discussed, but the innovation in this approach lies in working with the fact that the required primary surplus is not observed. Accordingly, in terms of actual values of variables, equation (2.14) is rewritten as

$$
\frac{P S_{t}^{\text {actual }}}{Y_{t}^{\text {actual }}}=\beta^{*} \frac{B_{t-1}^{\text {actual }}}{Y_{t-1}^{\text {actual }}}+\varepsilon_{t},
$$

where actual refers to actual values, $\beta^{*}$ is a parameter to be estimated, and $\varepsilon_{t}$ is a random error term. On average,

$$
\beta^{*}=\frac{(r-g)}{(1+g)}
$$

The estimated form of equation (2.16) carries terms indicating inertia in adjustment and is written as

$$
\frac{P S_{t}^{\text {actual }}}{Y_{t}^{\text {actual }}}=\beta_{1}+\beta_{2} \frac{P S_{t-1}^{\text {actual }}}{Y_{t-1}^{\text {actual }}}+\beta_{3} \frac{B_{t-1}^{\text {actual }}}{Y_{t-1}^{\text {actual }}}+\beta_{4}(\hat{y})_{t}+\varepsilon_{t},
$$

where $\hat{y}_{t}$ is the current growth rate of output and $\beta_{4}$ indicates the response of the fiscal authority to current stabilization pressures. This equation is a simplified version of the fiscal reaction function that Burger et al. (2011) estimated. ${ }^{16}$

This book uses standard DSA as elaborated in Adams et al. (2010) and discussed at length in Chapter 3, Appendix 3.4. Their fiscal reaction function is written as

$$
p s_{t}=\rho b_{t-1}+\beta \tau_{t}+\varepsilon_{t},
$$

where $p s_{t}$ is the primary surplus/GDP ratio, $\tau$ denotes temporary (stationary) influences on the primary balance/GDP ratio, ${ }^{17} \varepsilon$ is a random error term, and $\beta$ and $\rho$ are parameters to be estimated. If $0<\rho<1$, the current primary surplus responds positively to the debt in the last period, and the larger the $\rho$ is, the stronger is this response. If, however $\rho=0$ (i.e., the estimated value is insignificant) or is negative (and significant), then the primary surplus either does not respond or actually tends to exacerbate the debt. Hence, $\beta$ measures the response of the primary surplus to these temporary factors. The variance of possible debt outcomes will rise as the weight given to stabilization rises vis-à-vis debt. Such a reaction function could be used to forecast actual primary surpluses and primary surpluses desired to maintain debt sustainability. ${ }^{18}$ Further refinements of this could result in the development of leading indicators of debt vulnerability.

One shortcoming of this approach is that it focuses exclusively on current response to past debt, which may or may not be a good guide to the sustainability of the debt at least in the short run. If the growth rate of the economy is higher 
than the interest rate, the debt may be sustainable, even if $\rho$ is near zero (see the earlier discussion on the IRGD). However, in the long run, equation (2.18) needs to be satisfied with $0<\rho<1$ for sustainability to hold. In that case, the long-run expected value $(E)$ of the debt ratio can be written as

$$
E\left(b_{t}\right)=\left[\frac{-\bar{\tau}+(1-\rho) \operatorname{cov}\left(1+\theta, b_{t-1}\right)}{\rho(1+\theta)-\theta}\right],
$$

where $\theta$ is the IRGD (assumed to be positive in the long run), cov stands for covariance, and $\bar{\tau}$ stands for the long-run value of $\tau$.

\section{The International Monetary Fund's approach to debt sustainability analysis}

The International Monetary Fund (IMF) provides a comprehensive discussion of the definitions, dynamics, and sustainability analyses of public sector debt and of external debt used in Adams et al. (2010) and in this book (IMF 2008). The following provides a brief overview of the IMF discussion.

Total public debt evolves according to the following equation:

$$
B_{t+1}=\left[(1+\epsilon)\left(1+r^{f}\right) B F_{t}\right]+\left(1+r^{d}\right) B D_{t}-P S_{t+1},
$$

where $B_{t+1}$ is total debt in period $t+1, \epsilon=\frac{e_{t+1}-e_{t}}{e_{t}}$ is the change in the exchange rate with $e$ being the nominal exchange rate (i.e., units of domestic currency per dollar), $r^{f}$ the interest rate on foreign debt, $B F_{t}$ the debt denominated in foreign currency, $r^{d}$ the interest rate paid on domestic debt, $B D_{t}$ debt denominated in domestic currency; and $P S$ the primary surplus - that is, revenue minus expenditure excluding interest paid on the debt. Thus, debt goes up when foreign currency debt increases, foreign interest rates rise, and the domestic currency depreciates. Total debt also rises when domestic debt and interest paid on domestic debt rise. Debt falls when the primary surplus rises.

Typically, DSA is conducted for the debt/GDP ratio. So the last displayed expression is divided to get

$$
b_{t-1}=\frac{(1+\epsilon)\left(1+r^{f}\right)}{(1+g)(1+\pi)} b f_{t}+\frac{\left(1+r^{d}\right)}{(1+g)(1+\pi)} b d_{t}-p s_{t+1},
$$

where lowercase letters represent corresponding uppercase letters divided by GDP, that is, $g$ is the rate of growth of real GDP and $\pi$ is the rate of price inflation, typically of the GDP deflator. Rearrangement leads to the expression

$$
\begin{aligned}
b_{t+1}(1+g+\pi+g \pi)= & (1+\epsilon)\left(1+r^{f}\right) b f_{t}+\left(1+r^{d}\right) b d_{t} \\
& -(1+g+\pi+g \pi) p s_{t+1} .
\end{aligned}
$$


Using $b_{t}=b f_{t}+b d_{t}$ and expanding the right hand side of the foregoing expression yields

$$
\begin{aligned}
b_{t+1}(1+g+\pi+g \pi)= & b_{t}+\epsilon\left(1+r^{f}\right) b f_{t}+\left(r^{f} b f_{t}+r^{d} b d_{t}\right) \\
& -(1+g+\pi+g \pi) p s_{t+1} .
\end{aligned}
$$

Sometimes data on debt denominated in domestic and foreign currencies are not consistently available but, on average, $\phi$ may be the share of total public debt held in foreign currency, that is, $\left(b f_{t}=\phi b_{t}\right) ; 1 \geq \phi \geq 0$. Further, let the weighted average of the interest rate on debt be $\hat{r}=\phi r^{f}+(1-\phi) r^{d}$. Rearranging and letting $\hat{r}=r^{f}$ gives the final form of the IMF type of fiscal reaction function:

$$
b_{t+1}-b_{t}=\frac{1}{(1+g+\pi+g \pi)}[\hat{r}-\pi(1+g)-g+\epsilon \phi(1+\hat{r})] b_{t}-p s_{t+1} .
$$

Because the denominator of the first term in the right hand side of this expression is unambiguously positive, debt goes up, all else being equal, whenever the weighted interest rate goes up, the home currency depreciates, and the share of debt denominated in foreign currency goes up. Debt falls with rises in inflation, the growth rate, and the primary surplus.

The IMF DSA considers the evolution of debt using the foregoing equation under a business-as-usual scenario, given forecasts of means of $\pi, g, \hat{r}, \epsilon, \phi$, and $p s_{t}$.

In actual practice, the fiscal reaction function is used to trace the time path of the debt/GDP ratio. The country chapters of this book use the same procedure. Using baseline forecasts for the variables on the right hand side of the fiscal reaction function, the debt/GDP ratio for the near future (usually up to 5 years) is also forecast. This permits conjectures about whether future debt will stabilize or grow excessively.

\section{Stress tests}

The projections are also supplemented with forecasts of the debt/GDP ratio in case the variables on the right hand side of the fiscal reaction function are subject to shocks (usually half of the standard deviation of the forecast values) from the values implied in the baseline projections. This gives rise to the fan-chart analysis, as explained in Chapter 3 and shown in Chapters 4-6 of this book.

International organizations such as the Asian Development Bank, IMF, and World Bank have conducted further tests to see how the current fiscal policy would impact debt sustainability or to ascertain the gap between the surplus today and that required to attain sustainability. To make this operational, the proportionate change in the debt/GDP ratio $\left(\Delta b_{t}\right)$ is written as

$$
\Delta b_{t}=\theta_{t}-\frac{p s_{t}}{b_{t}}
$$


where $\theta$ denotes the IRGD and $p s_{t}$ is the primary balance/GDP ratio. Then, given assumptions about the future behavior of $p s_{t}$ and $\theta_{t}$, the time paths of $\Delta b_{t}$ and $b_{t}$ are charted. If the paths are "explosive," then the debt is said to be unsustainable as it might violate the terminal condition in equation (2.3). Alternatively, a "sustainable" path of $b_{t}$ is assumed and the associated path of $p s_{t}$ is calculated. ${ }^{19}$

In the stochastic analysis and the projections for the future, one should try to build in a response of the interest rate to levels of debt and/or deficit. Higher levels of government borrowing will, all else being equal, put upward pressure on interest rates, because this would involve additional government borrowing from limited "loanable" funds, and would thus make government borrowing and future debt sustainability more difficult to attain. Better forecasts of revenue and expenditures are needed. For example, projected population demographics could be used to determine future liabilities for pensions and health care.

While this book considers sustainability of public debt, denominated in both domestic and foreign currency, it does not consider external aspects of sustainability because to do so would involve the current account of the economy as well. Thus, the analysis in Chapter 3 discusses the impact of a negative IRGD on fiscal dynamics in the Asia and Pacific region and introduces the notion of debt stabilizing primary balance. Chapter 3 then conducts DSA for 24 of ADB's developing members and performs stress tests of the debt. Results of the stress tests are then compared with results from stochastic simulations.

IMF (2008) lists some limitations of the stress tests. For example, they do not permit any interaction among the variables. Thus, projections of one variable (such as the interest rate) are changed but the projections of all other variables are kept unchanged. Further, even though many of the variables involved in the DSA are endogenous, very few variables are permitted to be endogenously determined in the stress tests. Only interest payment on the debt, public sector revenues (determined by GDP), and debt stocks are endogenous. Hence, both the DSA and the stress tests are subject to some limitations.

\section{Issues in debt sustainability analysis}

This section surveys the literature on several key issues that are relevant to DSA but are not within the scope of this book.

\section{Sustainability of external debt}

An important question is whether external debt should be treated separately from domestic debt in DSA. Kraay and Nehru (2006) make a case for separate treatment and argue that many heavily indebted poor countries are in debt to foreign governments rather than private creditors. The extant literature (Reinhart et al. 2003) shows that a country's history of not repaying debt and of macroeconomic 
instability drives market perceptions and thus influences the possibility of default. Kraay and Nehru further show that even contemporaneous factors influence the possibility of debt default and argue that a common single debt sustainability measure for internal and external debt may not be appropriate, because domestic institutions play a key role in determining the possibility of debt distress. Hence, they favor multiple indicators of debt sustainability. They argue that a debt distress episode involves one or more of the following conditions:

- The sum of interest and principal arrears is "large" compared to the stock of debt outstanding.

- The country is receiving debt relief from multilateral or bilateral creditors.

- The country is receiving balance-of-payments support from the IMF.

Kraay and Nehru (2006) use a probit specification to model the determinants of debt stress:

$$
P\left[Y_{c t}=1\right]=\Phi\left(\beta^{\prime} X_{c t}\right)
$$

where $Y_{c t}$ is an indicator taking the value 1 with a debt distress episode and 0 otherwise for each beginning in country $c$ at time $t, X_{c t}$ is a set of explanatory variables, $\beta$ is a vector of parameters to be estimated, and $\Phi($.$) connotes a normal$ distribution function. Three explanatory variables are tried:

- future value of debt service obligations,

- a World Bank measure (country policy and institutional assessment scores) of the policy environment, and

- real GDP growth as a proxy for shocks.

The principal result is that countries with high debt service obligations, poor policy environments, and negative GDP growth shocks are likely to experience episodes of debt distress. However, this approach is able to explain only $23.4 \%$ of the probability of debt distress, which is not a stellar performance.

\section{Blurring of the distinction between domestic and external debt}

However, Panizza (2006) argues that in practice the distinction between internal and external debt can be blurred. The three aspects to the distinction between domestic and external public debt are:

- typically, domestic debt is denominated in local currency, whereas external debt is denominated in foreign currency;

- domestic debt is usually owed to domestic residents, whereas external debt is owed to foreigners; and

- the place of issuance and legislation of the debt contract is a domestic court in the case of domestic debt, but it is a foreign court for external debt. 
However, Panizza shows that there can be considerable blurring of the distinction between domestic and external debt in the first two criteria-for example, with open capital accounts, foreigners may buy domestic debt and domestic residents may buy debt of foreign countries.

In the not-too-distant past, many developing countries borrowed domestically only when all avenues for external debt were exhausted, essentially because domestic debt markets were not well developed. However, most developing countries currently opt for a mix of domestic and foreign debt. Hence, it becomes important to ascertain the optimal mix of such debt as well as to model the dynamics of total debt. All else being equal, most developing countries would prefer to use long-term domestic debt rather than short-term external debt; however, they may not have deep enough bond markets to absorb sufficient domestic debt. This often leads to domestic commercial banks becoming captive holders of large shares of domestic debt. Similarly, if foreign interests are allowed to purchase domestic debt, it may thus be converted to external debt. Another consideration is that the development of a market for domestic debt may crowd out the market for corporate bonds.

The upshot of the argument is that the traditional dichotomy between domestic and external debt does not have much validity in a world with open capital accounts. Further, the tradeoffs between domestic and external debt accentuate the artificiality of this distinction. This distinction will be further blurred as EMEs' domestic debt is traded in international bond markets. Hence, as suggested by the IMF (2003a, 2007), total debt sustainability needs to be analyzed. This, however, is beset with data difficulties, as meaningful aggregates of domestic and external debt may be hard to construct for many developing countries. In any case, and as indicated earlier, considerations of sovereign debt involve the current account of the economy as well and are, hence, outside the scope of this investigation.

\section{Evaluating the risk of meeting debt sustainability obligations}

Celasun, Debrun, and Ostry (2006) argue that DSA must account for the risk associated with meeting debt sustainability conditions. The notion of government solvency must be consistent with the necessity to honor current and future financial obligations, including providing public goods into the indefinite future and contractual payments such as pensions and medical benefits. Thus, two notions of solvency can be defined:

- The intertemporal budget constraint condition. The present value of all government disbursements, including payments of principal and interest on inherited sovereign debt as well as noninterest expenditure, should not exceed the present value of all revenues.

- The primary balance condition. The primary balance (the present value of future revenues net of noninterest expenditures) should at least cover the existing public debt. 
What is an appropriate strategy for meeting the solvency constraint? Clearly, solvency cannot be met by defaulting or through high inflation tax that reduces the real value of the debt, ${ }^{20}$ or forced restructuring of the debt. At the same time, forecasting future revenues, expenditures, and interest rates over the long horizon for which debt sustainability is typically assessed is usually difficult. Hence, when there is uncertainty, assessing solvency requires making judgments. But, the validity of these judgments is also uncertain. ${ }^{21}$

Thus, the DSA exercise must account for the risk accompanying it, and a DSA that accounts for risk becomes a probabilistic exercise. Celasun et al. (2006) provide a useful methodology for conducting such a risk analysis. They argue that extant DSAs are incomplete because they do not take solvency risk into account. In particular, extant DSAs ignore the correlation between shocks and the joint dynamic response of the variables relevant to debt dynamics (e.g., GDP growth, interest rate, and exchange rate). Further, extant DSAs ignore the response of fiscal policy to the simulated economic developments. Finally, risk is difficult to qualify given that individual stress tests used in DSA have near zero probability of occurrence.

Celasun et al. (2006) improve on the extant methodology by including three elements. First, they develop an unrestricted vector autoregression model that models the comovements between determinants of debt dynamics (e.g., GDP growth, interest rate, and exchange rate). On the basis of this, they derive the joint distribution of shocks to the unrestricted vector autoregression model. They then project the debt dynamics.

Second, they model an explicit fiscal reaction function so that the endogeneity of fiscal policy is explicitly accounted for. This is estimated using panel data for 34 EMEs for the period 1990-2004. The estimation can be adjusted to accommodate country-specific information on future policies. Of course, country-level fiscal reaction functions can be estimated as in Burger et al. (2011).

Finally, the simulated economic scenario from the first step is interacted with the fiscal reaction function from the second step to generate paths of public debt and associated magnitudes of key macroeconomic variables such as interest rates, exchange rates, GDP growth, and fiscal policy. Repeated simulations of the interaction of the three blocks generate frequency distributions of the forecasts, and $95 \%$ confidence intervals around median forecasts for each of the variables can be generated. This gives a "fan-chart" of forecasts. Celasun et al. (2006) apply this technique to analyses for Argentina, Brazil, Mexico, South Africa, and Turkey. However, as Wyplosz (2007) argues, the fan-chart analysis has at least two significant drawbacks. ${ }^{22}$ First, it is too complex to be administered in many, particularly developing, countries, so that the employment of exogenous shocks (as in the previous section) remains useful. Second, the results from the fan-chart analysis are only as good as the quality of the data used in the analysis, the econometric technique used, and the relevance of past data for the evolution of debt in the future. 


\section{R. Jha}

\section{Value-at-Risk models}

Closely related to the approach evaluating the risk of meeting debt service obligations is the value-at-risk (VaR) approach, which models the value of a risky asset and the confidence with which this value is held for different time horizons. ${ }^{23}$ The VaR approach tries to measure the risk associated with holdings of different portfolios, including public debt. For a given portfolio, VaR is the loss expected to be exceeded during $x \%$ of $t$-day holding periods. Values of $x$ and $t$ are exogenously fixed and are typically $1 \%, 2 \%$, and $5 \%$ for $x$ and a month or less for $t$. For any given $t$, the loss suffered will rise as $x$ falls.

Three methods are typically used to determine the VaR of a portfolio:

- In the historical simulation approach, historical data on market rates and prices are used to construct future portfolio profits and losses over the period $t$. Given this, one reads off the loss that is exceeded only $x \%$ (exogenously determined) of the time.

- The delta-normal approach assumes that underlying market factors have a multivariate normal distribution. Using this assumption, the approach determines the distribution of portfolio profits and losses and assumes that this is normal as well. The expected change in portfolio value is then computed over the predetermined $t$ and, if $x=5 \%$, computes $\mathrm{VaR}$ as

$$
\begin{aligned}
\text { VaR }= & -\{[\text { Expected change in portfolio value }] \\
& -1.65[\text { standard deviation of change in portfolio value }]\}
\end{aligned}
$$

This computation uses the fact that, for the normal distribution, outcomes less than or equal to 1.65 standard deviations below the mean occur only $5 \%$ of the time.

- Finally, the Monte Carlo simulation approach is similar to the historical simulation approach. The principal difference is that instead of using historical data for the simulation, one chooses a statistical distribution that is assumed to approximate the possible changes in market forces. Unfortunately, however, prior reasoning does not favor any one of these methods over the remaining two.

The VaR approach can be used to assess the riskiness of a portfolio that consists of public debt and indicates the market's view of holding such debt.

\section{Problems with debt dilution}

The term "debt dilution" refers to a situation in which the government, by issuing new debt, demonstrates a lack of commitment to decreasing the value of debt issued in the past. Hatchondo, Martinez, and Padilla (2011) study the welfare implications of this situation. They argue that the possibility of being able to dilute debt may lead to excessive issuance of short-term debt. This, in turn, could increase 
the possibility and/or severity of sovereign debt crises. Expanding on the work of Eaton and Gersovitz (1981) and Eaton and Fernandez (1995), the empirical and simulation model of Hatchondo et al. suggests that, even without commitment to future repayment policies and without the contingency of sovereign debt, eliminating debt dilution would lower the default risk by $86 \%$, the mean spread by $92 \%$, and the spread volatility by $71 \%$. Hence, debt dilution should not be used to avoid an emerging sovereign debt crisis, or at least should be used only in exceptional circumstances.

\section{Assessing fiscal stress}

Fiscal stress is defined as a situation of extreme government funding difficulties. Such difficulties can arise from a variety of sources, including contingent liabilities that become a fiscal burden, drastic falls in public revenue, and unaddressed expenditure commitments such as high and rising retirement commitments. Further difficulties may arise from market perceptions that the composition of the debt makes the government susceptible to default.

Fiscal stress testing is designed to measure and give early warning signs of the inability to pay off sovereign debt and, hence, of risk to fiscal sustainability. Baldacci et al. (2011) describe three factors that impact this risk of nonsustainability:

- whether fiscal policies currently being followed, or anticipated to be followed, satisfy standard tests for sustainability,

- whether these tests are subject to error because macroeconomic assumptions behind the sustainability tests have been belied, and/or because there have been unanticipated shocks to contingent liabilities and

- whether extraneous fiscal factors exist, such as current account imbalances and global financial market risk increasing the chances of a financial crisis.

A good measure of fiscal stress would provide early warning signs about the potential realization of one or more of the foregoing risks.

Fiscal stress is formally defined as an episode of one or more of the following: public debt default and/or restructuring; the need for large-scale financial support from international lending organizations; hyperinflation; and drastically enhanced financing problems, such as spikes in sovereign bond spreads. Baldacci et al. (2011) claim that the fiscal stress index (see the following section) can be used to assess fiscal stress both over time and across economies.

Prior literature on this topic varies in the definitions of what constituted a crisis, the methodology used for quantifying a crisis, and the set of indicators employed. Further, two approaches to modeling stress are used in the literature. The "signaling" approach identifies a critical threshold beyond which a set of composite indicators signals a crisis. In the multivariate approach, a panel or cross-section analysis is conducted using probit or logit models with the dependent variable taking a value of 1 if there is a crisis and 0 otherwise. The determinants 
Table 2.1 Definition of fiscal crisis across advanced and emerging market economies

\begin{tabular}{|c|c|c|c|}
\hline Event & Criteria & Advanced Economies & Emerging Economies \\
\hline $\begin{array}{l}\text { Public debt } \\
\text { default or } \\
\text { restructuring }\end{array}$ & $\begin{array}{l}\text { Failure to service } \\
\text { debt as payments } \\
\text { come due, as well } \\
\text { as distressed debt } \\
\text { exchanges }\end{array}$ & $\begin{array}{l}\text { Standard \& Poor's } \\
\text { definition }\end{array}$ & $\begin{array}{l}\text { Standard \& Poor's } \\
\text { definition }\end{array}$ \\
\hline Large financing & $\begin{array}{l}\text { Large IMF-supported } \\
\text { program }\end{array}$ & $\begin{array}{l}\text { Access to } 100 \% \\
\text { quota or more }\end{array}$ & $\begin{array}{r}\text { Access to } 100 \% \\
\text { quota or more }\end{array}$ \\
\hline $\begin{array}{l}\text { Implicit/internal } \\
\text { public debt } \\
\text { default }\end{array}$ & High inflation rate & $\begin{array}{l}\text { Inflation greater than } \\
35 \% \text { per annum }\end{array}$ & $\begin{array}{l}\text { Inflation greater than } \\
500 \% \text { per annum }\end{array}$ \\
\hline $\begin{array}{l}\text { Extreme } \\
\text { financing } \\
\text { constraint of } \\
\text { the sovereign }\end{array}$ & $\begin{array}{l}\text { Sovereign yield } \\
\text { pressure }\end{array}$ & $\begin{array}{l}\text { Sovereign spreads } \\
\text { greater than } 1,000 \\
\text { basis points or } \\
2 \text { standard } \\
\text { deviations from } \\
\text { the country } \\
\text { average }\end{array}$ & $\begin{array}{l}\text { Sovereign spreads } \\
\text { greater than } 1,000 \\
\text { basis points or } \\
2 \text { standard } \\
\text { deviations from } \\
\text { the country } \\
\text { average }\end{array}$ \\
\hline
\end{tabular}

$\mathrm{IMF}=$ International Monetary Fund.

Source: Baldacci et al. (2011).

of such a crisis are then modeled. Berg and Patilo (1999) and Berg et al. (2005) provide evidence that the multivariate models outperform the signaling model for in-sample and cross-country forecasts whereas the signaling model performs better for out-of-sample forecasts. Hence, neither approach is unambiguously superior.

Baldacci et al. (2011) combine the following five criteria to denote a situation of fiscal stress: debt default or restructuring, implicit default, recourse to exceptional financing, sharp deterioration in market access, and sharp spikes in borrowing costs as reflected in government bond yield pressures. The last is designed to capture short-term financing constraints. Table 2.1 outlines the characteristics of fiscal stress that Baldacci et al. use for empirical purposes.

\section{Fiscal stress thresholds}

To define when an episode of fiscal stress has occurred, a threshold must be chosen. As the threshold lowers, the chances that a noncrisis episode will be labeled a crisis episode increase, and the opposite happens as the threshold is increased. In interpreting episodes of fiscal stress, both Type I and Type II errors can occur. The lower the threshold, the greater the chance that an actual stress episode would be captured, that is, a Type II error will occur. However, as the chance that a noncrisis episode will be labeled a crisis episode increases, so does the chance of Type I errors. The opposite happens if a high threshold level is chosen. 
Baldacci et al. (2011) define an indicator variable at time $t, d_{t}$, as follows:

$$
d_{t}=\left\{\begin{array}{c}
1 \text { for } \forall j, \text { if } x_{t-1}>C \\
0, \text { otherwise }
\end{array},\right.
$$

where $x_{t}$ is a fiscal indicator that rises with crisis probabilities and $C$ is a fixed cut-off point for $x_{t}$. Baldacci et al. define the signal/noise ratio, $S N R(C)$, as

$$
S N R(C)=\frac{\frac{T P(C)}{N_{C}}}{\frac{F P(C)}{N_{N C}}},
$$

where $T P(C)$ is the number of correctly classified crisis observations and $N C$ is the number of actual crisis observations, so that the numerator of this expression is the percentage of correctly classified observations ( 1 minus the probability of Type II error), $F P(C)$ is the number of noncrisis events classified as "crisis" (i.e., false positives), and $N_{N C}$ is the number of noncrisis events so that the denominator is the percentage of incorrectly classified noncrisis events (Type I error). The optimal threshold is chosen so as to minimize $\operatorname{SNR}(C)$. Baldacci et al. (2011) compute a fiscal stress index in two steps. First, if an indicator crosses its chosen threshold it is given a value of 1 and weighted proportionately to its predictive power. Second, the overall fiscal stress index is computed as

$$
\text { Overall index }=\sum_{g} \theta_{g} \sum_{i} \theta_{i, g} d_{i},
$$

where $\theta_{i, g}$ is the weight of each individual indicator, $i$, in group $g, \theta_{g}$ is the weight of the group, and $d_{i}$ is a dummy that takes the value 1 in case of a crisis event and 0 otherwise.

Baldacci et al. (2011) find that fiscal stress has grown quite rapidly during the GFC. Further, fiscal stress has increased more rapidly in advanced economies than in EMEs. They compute weighted fiscal stress indexes for advanced economies and EMEs, with purchasing power parity-GDP as weights. They find that this index is higher in 2011 in the developed economies than in EMEs - whereas the emerging market index has risen it is still below the level reached during the Asian financial crisis of the late 1990s.

\section{Composition of public debt}

As indicated earlier, Bhatt (2010) argues that, all else being equal, the composition of public expenditure can have an important impact on the evolution of public debt. The paper develops a theoretical model of the impact of productive (capitalrelated) and unproductive expenditure on public debt and estimates the model using time series data for India. Bhatt finds that the share of capital expenditure in public expenditure has an inverse long-run relationship with the public debt. The paper suggests that this share can be used to forecast public debt in the future. 


\section{Broader interpretation of sovereign debt crises}

Failure to satisfy the sustainability tests discussed does not mean that a fiscal crisis will occur, and a country may have a sustainability crisis even if it satisfies all the conditions for sustainability — a good example is the Mexican debt crisis of 1993. Hence, the question is: What is the set of economic and political conditions that are associated with the occurrence of a crisis?

Manasse and Roubini (2009) indicate that at least three types of crises can influence each other: a liquidity crisis, an insolvency or a nonsustainability crisis, and a macroeconomic crisis involving the exchange rate. A major implication is that unconditional thresholds (e.g., for debt/output ratios) have little value for assessing the probability of default. Depending on the values of countries' liquidity and macroeconomic and exchange rate risks, a high debt/output ratio may not lead to insolvency in one country, but another country may face debt default although it has a low debt/output ratio.

Furthermore, Manasse and Roubini (2009) emphasize the joint (and sometimes mutually reinforcing) nature of the three types of crises. For example, a country with a low debt/output ratio may have a severe liquidity crisis, causing it to borrow on unfavorable terms to service the debt, thus triggering a liquidity crisis that may then become a solvency crisis. Manasse and Roubini (2009) use the Classification and Regression Tree analysis, a computer-based algorithm, to identify explanatory variables, their critical values, and their interaction in order to isolate crisis from noncrisis events. In a sample of 47 EMEs during the period 1970-2002, they find 10 variables to be of particular significance to solvency crises: (1) total external debt/GDP ratio, (2) short-term debt/reserves ratio, (3) real GDP growth, (4) public external debt/fiscal revenue ratio, (5) inflation rate, (6) number of years to the next election, (7) US Treasury bill rates, (8) current account balance plus short-term debt as a ratio of foreign exchange reserves, (9) exchange rate overvaluation, and (10) exchange rate volatility. Most debt crises in the 47 EMEs could be classified in three categories: insolvency (high debt and high inflation); illiquidity (large stock of shortterm debt relative to foreign exchange reserves); and macro and exchange rate weaknesses manifested as a large overvaluation of the currency and negative GDP growth shocks.

This analysis leads naturally to the conclusion that economic activity and debt default are mutually endogenous, for example, the interest rate on public debt can depend on the business cycle phase that the economy is going through. The next logical step is, therefore, to pursue general equilibrium modeling of sovereign default and business cycles. Research in this area has very recent origins (see, e.g., Mendoza and Yue 2011). ${ }^{24}$ The core of this model is a financial amplification mechanism that links sovereign debt default risk with production plans. Increases in default risk increase the cost of financing working capital by raising the cost of imported inputs, which then induces a business cycle downturn. Thus, there are feedback effects between default risk, business cycles, and the output costs of default. 
Akyuz (2008) argues that EMEs are more prone to the effects of such endogeneity. These economies are considerably prone to supply shocks, both domestic (e.g., weather shocks) and foreign (e.g., oil price shocks). With inflexible subsidies (e.g., on food and petroleum), the fiscal deficit and, subsequently, the debt are likely to rise in response to such shocks. Hence, a "safe" level of the $\mathrm{debt/GDP}$ ratio is likely to be lower in economies that are shock-prone than in those that are not.

Indeed some of the effects of foreign shocks may spill over into higher levels of foreign debt. With sharply rising and volatile international commodity prices, such risks are growing over time. In response, particularly after the Asian financial crisis of 1997/08 and subsequent financial crises, many transition economies have sharply increased their foreign exchange reserves. The cost of operating and maintaining large reserves and, since these reserves provide low yields, the income foregone, are intrinsic debt-related costs these economies bear. Akyuz (2008) argues that, unless global conditions are favorable (and they have only deteriorated since) these debt-related costs could impinge on the transitional economies' prospects of meeting their Millennium Development Goals. (This study does not consider sovereign debt issues further, which would involve analyzing the current account.)

\section{Quality of revenue and expenditure data}

The extant DSAs have taken the revenue and expenditure data at face value and thus can be extended in two major directions: other types of crises (e.g., a liquidity crunch) can trigger a debt sustainability crisis; and the revenue and expenditure data can give an incomplete and perhaps even misleading picture of the debt sustainability situation. For example, the government can have many unfunded liabilities, such as pension payments, as well as contingent liabilities, which it may ultimately have to meet. Appendix 3.1 in Chapter 3 summarizes the data issues faced when doing DSA.

In this context, Chapter 4, on debt of the People's Republic of China, argues that, whereas its official public debt was $17.7 \%$ of GDP in 2009 , hidden liabilities, amounted to a further $67 \%$ of GDP. This means that total government debt was as high as $84 \%$ of GDP. Hence, for purposes of DSA, it matters a great deal where the line is drawn with respect to the government liabilities.

Heller (2004) provides a useful ranking of the "hardness" of different public sector liabilities. Official debt is clearly the hardest government obligation. Government obligations become softer moving progressively to arrears; contingent liabilities, such as deposit insurance; contractual obligations, such as public pensions; "stand-behind obligations," such as implicit guarantees; bailouts and disaster relief; and constructive obligations, such as the provision of health, education, and law and order. Chapter 4 discusses the importance of incorporating public liabilities of different levels of hardness in the case of the People's Republic of China. 
It is important to be clear about what constitutes appropriate revenue and expenditure data for a credible sustainability analysis. The boundaries of the government sector have to be clear. Assets and liabilities at all levels of government have to be included in the analysis. In this context, Liu and Waibel (2011) indicate that the period leading up to the GFC was also one of greater decentralization in the Asia and Pacific region. As subnational governments are increasingly responsible for public expenditure, they are therefore running up larger deficits. In December 2009 , the debt of Indian states amounted to as much as $29 \%$ of GDP. Hence, subnational debt crisis could occur. In the face of this, many countries have instituted rules for subnational debt accumulation (subnational debt issues are discussed in Chapter 5).

Liu and Waibel (2011) argue that subnational governments may be able to circumvent rules on debt accumulation by, for example, showing some elements of debt as off-budget items. Hence, any DSA must be cognizant of these possibilities.

Further, the government may be responsible for liabilities such as unfunded pensions, deficits of state-owned enterprises, central bank liabilities, ${ }^{25}$ and contingent liabilities, ${ }^{26}$ which need to be brought into the fold of public expenditure. In the case of external debt, the exchange rate to be used for valuation must be clear. What can justifiably be termed tax and nontax revenue must also be clear, especially if tax evasion and avoidance are widespread.

\section{Conclusions: the importance of country studies}

Developments in the international economy in the aftermath of the GFC and the resulting policy responses have led to substantial increases in debt holdings across economies, whether developed, emerging market, or developing. The sustainability of public debt has suddenly been called into question in several countries. Unsustainable public debt can have broad consequences for financial stability and for the real economy. Hence, it is imperative to assess the prospects for debt sustainability in the Asia and Pacific region.

The present chapter briefly discusses the role of the fiscal deficit in the economy and reviews the current literature on debt sustainability, including literature on time series, fiscal reaction function, and stress tests. The chapter outlines in some detail the IMF approach to its DSA. It then outlines some old and some emerging issues in DSA not addressed by the standard analysis and emphasizes the need to have both a unified analytical approach to assessing debt sustainability and to recognize the wide differences among countries in a variety of relevant factors, including data, financial institutions, projections of future tax and expenditure, liquidity experience, and exposure to global financial markets. Such differences highlight the importance of individual country assessments of debt sustainability. Thus, this chapter provides the context for the following empirical and individual country chapters.

Some of the most significant differences across countries in several areas relevant to DSA are as follows. First, the definition of the "government sector" 
differs across countries as does their treatment of the deficit/debt magnitudes of different levels of government. When forecasting future public revenue and expenditure, a differentiated approach should be adopted across countries in view of their varying circumstances. Some countries, for example, have pending privatization programs to complete (the proceeds of which could add to revenue); similarly, countries' treatments of contingent liabilities and practices for unfunded liabilities vary.

Further, in DSA, attention needs to be given to the composition of public debtwhether it is concessional or not; whether public capital expenditure has played a significant role in its evolution; and whether a significant proportion of the debt is owed to foreigners, in which case the exchange rate at which the debt is valued and the expected time path of the exchange rate becomes relevant. All these vary quite significantly across countries. Often, reporting of data and, hence, the extent of imputation required differ across countries.

In addition, fiscal policy rules and practices may differ across countries. For example, a country with a hard fiscal policy rule that the fiscal deficit may not exceed a specific percentage of GDP may more realistically be expected to attain debt sustainability, all else being equal, than a country without such a rule. And among countries that follow fiscal rules, the efficacy with which these fiscal rules are implemented may vary. Different countries may follow different practices for expenditures they can move off-budget in order to meet the requirements of the fiscal rule.

Differences may also arise in countries' experience with debt adjustment and with their debt management capacities. Some countries may be more committed to pursuing debt adjustment than others. The ease of pursuing a policy of attaining sustainable debt will be influenced by how credit rating agencies rate individual countries' debt profiles, for example, DSA will be impacted if a country is transitioning from concessional to market-based debt issuance. The sustainability of a country's debt will be impacted by its external financial position as well as by its liquidity position.

Developments in international debt and financial markets will impact different countries differentially, and they will also respond differently. Hence, while emphasizing a unified framework for DSA (see Chapter 3), nuanced individual country studies can better reflect the differences in country circumstances, histories, and approaches (Chapters 4-6).

\section{Notes}

1 These 24 economies (Brazil; Chile; China, People's Republic of; Colombia; Costa Rica; Arab Republic of Egypt; Hungary; India; Indonesia; Kenya; Malaysia; Mexico; Morocco; Nigeria; Peru; Philippines; Poland; Romania; Russian Federation; South Africa; Sri Lanka; Thailand; Turkey; and Uruguay) accounted for $60 \%$ of the world's population.

2 See also Chalk and Hemming (2000) and IMF (2003b, 2011). For critical reviews of DSA see Wyplosz (2007) and Akyuz (2008). 
3 Fiscal deficit is also sometimes called the "budgetary deficit." The deficit includes servicing of public debt. If interest payment on the public debt is removed, the result is often called the "primary deficit."

4 Wyplosz (2007) argues that when the exchange rate depreciates faster than prices, the domestic currency value of foreign debt rises. A similar conclusion holds for a situation in which interest rates rise faster than inflation and debt servicing becomes a bigger burden.

5 However, debt is not uniformly undesirable at all levels. Adams and Ferrarini (2010) argue that, in developing countries when real interest rates are negative (presumably because of high inflation) and rates of return on public investment are positive, increased debt may well be merited.

6 More recent arguments along the lines suggested by Buiter include those by Easterly (1999), who argues that fiscal adjustment can be illusionary. In particular, this would be the case when such adjustment lowers the public debt but leaves unchanged the net worth of the government. In other words, governments may find ways of maintaining their consumption even when they are actually involved in a process of reducing public debt.

7 Even rapid accumulation of domestic debt, as a result of high fiscal deficits, can have consequences such as the emergence of severe macroeconomic problems, and can impede control of the fiscal deficit. Thus, servicing of the central government debt is one of the largest items in the Government of India's budget, even outstripping major items of expenditure such as defense. High debt repayments can signal that anticipated revenues may be at risk and/or that public expenditures may be higher than anticipated. A perceived drop in government liquidity may lead to a solvency crisis.

8 The IRGD is computed as $\frac{r-g}{1+g}$ where $r$ is the real interest rate and $g$ is the growth rate of real GDP. It is immaterial whether real or nominal interest rates and growth rates are used to compute the IRGD.

9 Defined as all member countries of the Organisation for Co-operation and Development (OECD) except Turkey.

10 See also McKinnon (1973). And, an erroneous belief is that "low" cost of capital will encourage investment. In reality, with low returns, capital becomes even scarcer and the effective price of capital rises above the mandated level.

11 For critical reviews of DSA, see Wyplosz (2007) and Akyuz (2008).

12 This corresponds to the notion of default associated both with risky and risk-free revenue inflows. See also Jha (2004).

13 Another way economists assess debt sustainability using time series methods is to check whether government expenditure and revenue, assuming both are integrated of order 1, (1), follow a common stochastic trend, i.e., they are cointegrated. If this is the case, the cointegrating vector between them should be $[1,-1]$ so that, in the long run, any increase in government expenditure is financed by revenue. Intuitively, then, in such cases the debt should be sustainable.

14 For simplicity, foreign financing of the deficit is excluded.

15 See also Bohn (2007).

16 Along similar lines, IMF (2003a) uses panel data methods on a number of countries to show that many countries do indeed satisfy this criterion. Bohn (2007) provides further support to this argument, and UNCTAD (2009) provides a useful review.

17 The quantity $\tau_{t}$ is a summary variable with temporary factors such as the gap between actual and potential output or temporary changes in government spending, such as due to a natural disaster.

18 Davig and Leeper (2011) study the joint estimation and interaction of monetary and fiscal reaction functions. Sharma and Jha (2012) show that rising fiscal deficit can often lead to reversal of reform in semi-open EMEs. 
19 Explained earlier in this chapter, in the context of the IRGD literature.

20 Abiad and Ostry (2005) provide evidence that the primary budget surplus rises with inflation.

21 Hence, in the face of uncertainty, assessing solvency inherently involves making judgments, which themselves are subject to risk; however, without uncertainty assessing, solvency is only an "arithmetic exercise."

22 An important difference between this fan-chart analysis and that in the previous section is that the frequency distribution of shocks to the right hand side variables is endogenous here and exogenously imposed there.

23 For an exposition of VaR models, see Damodar (2011) and Linsmeier and Pearson (2000).

24 Mendoza and Yue (2011) report three interesting empirical regularities between business cycles and default in a sample of 23 default events during 1977-2009: that default episodes are associated with deep recessions; that interest rates on sovereign debt peak at about the same time as output hits its trough and defaults occur, and these interest rates are negatively related to GDP; and that the external debt/GDP ratio is high on average, and higher than average when countries default.

25 This requires assessing, whether the official debt data includes bills and bonds issued by the country's central bank.

26 This should include covariances between contingent liabilities. Contingent liabilities are typically very important in the areas of pensions and health care, the private financial system, and the nonfinancial state-owned enterprise sector. In addition, explicit or implicit guarantees may be given on private domestic or foreign debt issuance, public investment programs, and public-private partnerships. Moreover, public sector assets in the state-owned enterprise sector could be used to retire debt under privatization programs.

\section{References}

Abiad, A. and Ostry, J. (2005) "Primary Surpluses and Sustainable Debt Levels in Emerging Market Countries" IMF Policy Discussion Papers PDP/05/6, Washington, DC: International Monetary Fund (IMF).

Adams, C. and Ferrarini, B. (2010) "Fiscal Sustainability in Developing Asia" unpublished, Mandaluyong City: Asian Development Bank.

Adams, C., Ferrarini, B. and Park, D. (2010) "Fiscal Sustainability in Developing Asia" ADB Economics Working Paper Series No. 205, Mandaluyong City: Asian Development Bank.

Afonso, A. and Hauptmeier, S. (2009) "Fiscal Behavior in the European UnionRules, Fiscal Decentralization and Government Indebtedness" Working Papers Series, No. 1054, Frankfurt am Main: European Central Bank.

Anderson, P., Silva, A. and Velandia-Rubiano, A. (2011) "Public Debt Management in Emerging Market Economies: Has This Time Been Different?" in C. Baraga and S. Vincelette (eds), Sovereign Debt and the Financial Crisis, Washington DC: World Bank.

Asian Development Bank (ADB) (2009) World Economic Monitor, Mandaluyong City: ADB.

Akyuz, Y. (2008) "Debt Sustainability and Millennium Development Goals in Emerging Market Economies.” New York: United Nations Development Programme. Mimeo.

Baldacci, E., Petrova, I., Belhocine, N., Dobrescu, G. and S. Mazraani (2011) “Assessing Fiscal Stress" IMF Working Paper WP/11/100, Washington DC: International Monetary Fund (IMF). 
Barro, R. (1974) “Are Government Bonds Net Wealth?” Journal of Political Economy, 82: 1095-117.

Berg, A. and Patillo, C. (1999) "Predicting Currency Crises: The Indicators Approach and an Alternative" Journal of International Money and Finance, 18(3): 561-86.

Berg, A., Borensztein, E. and Patillo, C. (2005) “Assessing Early Warning Systems: How Have They Worked in Practice?” IMF Staff Papers, 52(3): 46-502.

Besancenot, D. Huynh, K. and Vranceanu, R. (2004) "Default on Sustainable Public Debt: Illiquidity Suspect Convicted" Economics Letters, 82: 205-11.

Bhatt, A. (2010) "Revisiting Indicators of Public Debt Sustainability: Capital Expenditure, Growth and Public Debt in India" mimeo, Rome: Universita di Roma Tor Vergatta, Dipartimento di Economia e Istituzioni.

Blanchard, O. and Fischer, S. (1989) Lectures on Macroeconomics, Cambridge, MA: MIT Press.

Bohn, H. (1998) “The Behavior of US Public Debt and Deficits" Quarterly Journal of Economics, 113(3): 949-63.

Bohn, H. (2007) “Are Stationarity and Cointegration Restrictions Really Necessary for the Intertemporal Budget Constraint?” Journal of Monetary Economics, 54(6): 1837-47.

Bordo, M. (2008) “An Historical Perspective on the Crisis of 2007-08” NBER Working Paper 14569, Cambridge, MA: National Bureau of Economic Research (NBER).

Budina, N. and Wijnbergen, S. (2008) "Quantitative Approaches to Fiscal Sustainability Analysis: A Case Study of Turkey since the Crisis of 2001" World Bank Economic Review, 23(1): 119-40.

Buiter, W. (1985) “A Guide to Public Sector Debts and Deficits" Economic Policy, 1(1): $13-79$.

(1993) "Measurement of the Public Sector Deficit and Its Implications for Policy Evaluation and Design" in M. Blejer and A. Cheasty (eds), How to Measure the Fiscal Deficit, Washington, DC: International Monetary Fund.

Burger, P., Stuart, I., Jooste, C. and Cuevas, A. (2011) "Fiscal Sustainability and Fiscal Reaction Function for South Africa" IMF Working Paper WP/11/69, Washington DC: International Monetary Fund.

Caner, M., Grennes, T. and Koehler-Geib, F. (2011) "Finding the Tipping Point: When Sovereign Debt Turns Bad" in C. Braga and G. Vincelette (eds) Sovereign Debt and the Financial Crisis, Washington DC: World Bank.

Celasun, O., Debrun, X., and Ostry, J. (2006) "Primary Surplus Behavior and Risks to Fiscal Sustainability in Emerging Market Countries: A 'Fan-Chart' Approach," IMF Staff Papers, 53(3): 401-25.

Chalk, N. and Hemming, N. (2000) "Assessing Fiscal Sustainability in Theory and Practice" IMF Working Paper, WP/00/81, Washington, DC: International Monetary Fund.

Cuddington, J. (1997) “Analysing the Sustainability of Fiscal Deficits in Developing Countries" Washington, DC: World Bank.

Damodar, A. (2011) "Value at Risk" Available HTTP: <http://people.stern.nyu.edu/ adamodar/pdfiles/papers/VAR.pdf $>$ (accessed 27 October 2011).

Das, U., Papaioannou, M., Pedrasw, G., Surti, J. and Ahmed, F. (2011) "Managing Public Debt and its Financial Stability Implications" in C. Baraga and S. Vincelette (eds), Sovereign Debt and the Financial Crisis, Washington DC: World Bank.

Davig, T. and Leeper, E. (2011) "Monetary-Fiscal Policy Interactions and Fiscal Stimulus" European Economic Review, 55(1): 211-57. 
de Haan, J. and Zelhorst, D. (1990) “The Impact of Government Deficits on Money Growth in Developing Countries" Journal of International Money and Finance, 9(3): 455-69.

de Mello, L. (2007) "Estimating a Fiscal Reaction Function: The Case of Debt Sustainability in Brazil" Applied Economics, 40: 271-84.

Easterly, W. and Schmidt-Hebbel, K. (1993) "Fiscal Deficits and Macroeconomic Performance in Developing Countries" World Bank Research Observer, 8(2): 211-37.

Easterly, W. (1999) “When is Fiscal Adjustment an Illusion?” Economic Policy, 28(1): 57-86.

Eaton, J. and Fernandez, R. (1995) "Sovereign Debt" NBER Working Paper, No. 5131, Cambridge, MA: National Bureau of Economic Research.

Eaton, J. and Gersovitz, M. (1981) "Debt with Potential Repudiation: Theoretical and Empirical Analysis" Review of Economic Studies, 48(1): 289-309.

Egert, B. (2010) "Fiscal Policy Reactions to the Cycle in the OECD: Pro or Counter Cyclical" OECD Economics Working Papers, No. 763, Paris: OECD Publishing.

Escolano, J., Shabunina, A. and Woo, J. (2011) “The Puzzle of Persistently Negative Interest Rate-Growth Differentials; Financial Repression or Income Catch Up?" IMF Working Paper, WP/11/260, Washington, DC: International Monetary Fund.

Gemmell, N. (2004) "Fiscal Policy in a Growth Framework" in T. Addison and A. Roe (eds), Fiscal Policy for Development: Poverty, Reconstruction and Growth, forthcoming, Houndmills and New York: Palgrave Macmillan.

Hakkio, G. and Rush, M. (1991) "Is the Budget Deficit 'Too Large'?" Economic Inquiry, 29(3): 429-45.

Hatchondo, J., Martinez, L. and Padilla, C. (2011) "Debt Dilution and Sovereign Default Risk” IMF Working Paper, WP/11/70, Washington, DC: International Monetary Fund. Heller, P. (2004) “Are Governments Overextended?” World Economics, 5(4): 1-31.

International Monetary Fund (IMF) (2003a) "Sustainability Assessment: Review of Application and Methodological Refinements" mimeo, Washington DC: IMF.

- (2003b) World Economic Outlook, Washington DC: IMF. (2007) "Staff Guidance Note on the Application of the Joint Fund-Bank Debt Sustainability Framework for Low-Income Countries" mimeo, Washington DC: IMF. (2008) "Staff Guidance Note on Debt Sustainability Analysis for Market Access Countries," Washington DC: IMF.

(2010) World Economic and Financial Surveys, Fiscal Monitor: Navigating the Fiscal Challenges Ahead, Washington DC: IMF.

(2011) "Modernizing the Framework for Fiscal Policy and Public Debt Sustainability Analysis" mimeo, Washington DC: IMF.

Issler, J. and Lima, L. (2000) "Public Debt Sustainability and Endogenous Seignorage in Brazil: Time Series Evidence from 1947-1992" Journal of Development Economics, 62(1): 131-47.

Jha, R. (2003) Macroeconomics for Developing Countries, 2nd edition, London and New York: Routledge.

- (2004) "The Macroeconomics of Fiscal Policy in Developing Countries" in

T. Addison and A. Roe (eds), Fiscal Policy for Development: Poverty, Reconstruction and Growth, Houndmills and New York: Palgrave Macmillan.

Jha, R. and Sharma, A. (2004) "Structural Breaks, Unit Roots and Cointegration: A Further Test of the Sustainability of the Indian Fiscal Deficit," Public Finance Review, 32(2): 196-219. 
Khalid, M., Malik, W. and Sattar, A. (2007) "The Fiscal Reaction Function and the Transmission Mechanism for Pakistan" The Pakistan Development Review, 46(4): 435-47.

Kraay, A. and Nehru, V. (2006) "When is External Debt Sustainable?" World Bank Economic Review, 20(3): 341-65.

Linsmeier, T. and Pearson, N. (2000) "Value at Risk" Financial Analyst Journal, 56(2): $47-67$.

Liu, L. and Waibel, M. (2011) "Managing Subnational Credit and Default Risk" in C. Baraga and S. Vincelette (eds), Sovereign Debt and the Financial Crisis, Washington DC: World Bank.

Manasse, P. and Roubini, N. (2009) “ 'Rules of Thumb' for Sovereign Debt Crisis” Journal of International Economics, 78(2): 192-205.

McKinnon, R. (1973) Money and Capital in Economic Development, Washington, DC: Brookings Institution.

Mendoza, E. and Yue, V. (2011) "A General Equilibrium Model of Sovereign Default and Business Cycles" IMF Working Paper, WP/11/166. Washington, DC: International Monetary Fund.

Panizza, U. (2006) "Domestic and External Public Debt in Developing Countries" UNCTAD Working Paper, UNCTAD/OSG/DP/2008/3, Geneva: United Nations Conference on Trade and Development (UNCTAD).

Reinhart, C., Rogoff, K. and Savastano, M. (2003) "Debt Intolerance” Brookings Papers on Economic Activity, 1: 1-74.

Sargent, T. (1999) "A Primer on Monetary and Fiscal Policy" Journal of Banking and Finance, 23(8): 1463-82.

Sharma, A. and Jha, R. (2012) "Fiscal Deficits, Banking Crises, and Policy Reversal in a Semi-Open Economy" forthcoming, Economic Modelling.

Tanzi, V. (1993) "Fiscal Deficit Measurement: Basic Issues" in M. Blejer and A. Cheasty (eds), How to Measure the Fiscal Deficit, Washington, DC: International Monetary Fund.

Trehan, B., and Walsh, C. (1991) "Testing Intertemporal Budget Constraints: Theory and Applications to the US Federal Budget and Current Account Deficits" Journal of Money, Credit and Banking, 23(2): 206-23.

Turrini, A. (2008) "Fiscal Policy and the Cycle in the Euro Era: The Role of Government Revenue and Expenditure" European Economy-Economic Papers, Brussels: Directorate General Economic and Monetary Affairs, European Commission.

United Nations Conference on Trade and Development (UNCTAD) (2009) Compendium on Debt Sustainability and Development, New York and Geneva: United Nations.

Wyplosz, C. (2007) "Debt Sustainability Assessment: The IMF Approach and Alternatives" HEI Working Paper No. 03/2007, Geneva: Graduate Institute of International Studies. 


\title{
3 Public debt sustainability assessments for developing Asia
}

\author{
Benno Ferrarini and Arief Ramayandi*
}

\section{Introduction}

This chapter discusses the evolution of fiscal balances and public debt ratios in developing Asia from the mid-1990s to 2010 and investigates the conditions for public debt sustainability in the region through 2016, building on the work of Adams and Ferrarini (2010). Focus is on developing Asia-which denotes the developing member countries (DMCs) of Asian Development Bank (ADB). The assessment mainly comprises the broader trends and outlook for public debt and fiscal indicators in Asia and its subregions, with country-level data aggregated by geographical subdivision. The debt dynamics and prospects of a few selected economies are discussed. An in-depth assessment of three country studies is provided in the following chapters.

The discussion of debt sustainability analysis (DSA) methods evolves from a practical perspective, while Chapter 2 provides a more theoretical exposition. The aspects of fiscal sustainability of public debt, both domestic and foreign currency denominated, are analyzed. (External criteria of debt sustainability are not analyzed, because to do so would involve a broader discussion of the balance-of-payments conditions in Asia, which is beyond the scope of this chapter.) The main emphasis is thus on the historical and prospective evolution of public debt indicators under alternative macroeconomic and fiscal policy assumptions, which constitute the core elements of DSA within the broader context of macroeconomic forecasting. Much of the discussion revolves around the debt sustainability implications of a negative interest rate-growth differential (IRGD), a key characteristic of the macroeconomic environment in Asia during the last two decades. The extent to which responsible fiscal policy by governments in the region has played a role in keeping fiscal position in check and debt ratios comparably low is also analyzed at length. Less attention is devoted to analyzing debt sustainability against thresholds, which was briefly discussed in

\footnotetext{
* This chapter deepens and expands in several directions the empirical work in Adams and Ferrarini (2010). The authors are grateful for helpful comments on an earlier draft by Charles Adams, Richard Hemming, and Raghbendra Jha. However, the authors are solely responsible for the views expressed here.
} 
Chapter 2; this approach is deemed of limited practical interest as the chapter adopts a simple notion of debt sustainability that is premised on the presence of a stable and nonexploding debt path regardless of its position relative to thresholds. Further, Chapter 2's main focus is debt sustainability in countries with access to capital markets, with less emphasis on low-income countries, for which DSA and threshold analysis have a combined role in the multilateral aid allocation process. A discussion of these broader issues is beyond the scope of this chapter.

The next section presents key fiscal indicators in developing Asia and reviews the evolution of public debt ratios from the mid-1990s through 2010. Particular attention is paid to the breakdown of fiscal positions into primary and nonprimary components and the linkages between primary fiscal balances and public debt ratios.

The third section discusses the results from econometric tests of fiscal sustainability, based on panel regression techniques. Estimates of fiscal reaction functions support the notion that Asia has been generally prudent in conducting fiscal policy, with countries tightening their budgets as they see debt stocks rising. The region's record of fiscal rectitude provides the strongest grounds for being confident about the long-run sustainability of public debt in the region.

Section four, on the debt stabilizing primary balance in Asia, discusses the extent to which vastly negative IRGDs have been shaping fiscal dynamics in the region. The concept of debt stabilizing primary balance is introduced, and the impact that less favorable macroeconomic circumstances - whether in the guise of a temporary or structural narrowing of the IRGD — are likely to have on Asia's debt sustainability and on fiscal policy space is also assessed.

Section five, on DSA based on macroeconomic forecast assumptions, projects debt ratios aggregated by Asia's subregions up to the year 2016. Based on the latest $\mathrm{ADB}$ and International Monetary Fund (IMF) macroeconomic forecasts and fiscal policy assumptions for these countries, the results indicate that current forecast assumptions are compatible with continuing debt sustainability in the region. Projections for all the subregions - but not necessarily all their economiessuggest that debt ratios are either stable or declining, and the fiscal outlook for the region is generally benign.

The sixth section conducts stress tests within the standard DSA framework for eight Asian economies, and compares the results with those from stochastic simulation methods. It is argued that stochastic analysis accounts better for the correlation structure among the key variables determining debt dynamics and for the uncertainty surrounding baseline projections than does deterministic analysis. Simulation results suggest that accounting for these factors in most cases does not change the main conclusion about economies' debt sustainability. However, the results suggest that, rather than a single baseline, a whole range of possible outcomes are compatible with a country's macroeconomic track record and the estimated correlation structure among key variables, and not all of them imply a favorable future debt path.

The last section summarizes the findings and concludes. 


\section{Public debt and fiscal performance in developing Asia}

Any assessment of public finances in relation to developing countries faces the challenge of scarce fiscal and public debt data. ${ }^{1}$ The discussion in Appendix 3.1 illustrates that data scarcity is an issue for ADB's developing members, which are analyzed in this chapter. In the fiscal data set for the 45 ADB developing members compiled for this study, 24 economies have consistent yearly data for a comparative review over time of the main fiscal indicators from 1994 to 2010. Data are grouped into five geographical subregions, following the convention of the ADB Asian Development Outlook reports. The subregions and economies within them are Central Asia (Armenia, Azerbaijan, Georgia, Kazakhstan, Kyrgyz Republic, and Tajikistan); East Asia (the People's Republic of China [PRC], the Republic of Korea, and Mongolia); the Pacific (Fiji, Papua New Guinea, Solomon Islands, and Tonga); South Asia (Bangladesh, Bhutan, India, Sri Lanka, Nepal, and Pakistan); and Southeast Asia (Indonesia, Malaysia, the Philippines, Thailand, and Viet Nam). Appendix 3.2, Tables A3.2.1 and A3.2.2 show the data available for ADB's developing members and the data sources used for this chapter.

Table 3.1 summarizes the main fiscal indicators by subregion. The last column indicates the degree of external indebtedness, measured as the ratio of foreign currency denominated debt to total public debt outstanding. All indicators represent simple averages by subregion, which are unweighted for the reasons discussed in Appendix 3.1. Figure 3.1 compares ratios of subregional debt/gross domestic product (GDP) and fiscal revenue/GDP.

To trace the evolution of fiscal indicators over time, Asia's average fiscal data are subdivided into five key periods: 1994-97, to assess fiscal positions prior to the Asian financial crisis (AFC); 1998-99 and 2000-06, to capture the short- and medium-term effects of the AFC on fiscal performance in Asia; and 2007-08 and 2009-10, to compare fiscal positions before and after the global financial crisis $(\mathrm{GFC})^{2}$

The fiscal indicators in Table 3.1 show the following about the fiscal performance in the region:

- Public debt ratios across ADB developing members display considerable heterogeneity and variation over time. According to 1994-2000 averages, South Asia had the highest debt ratios in Asia, averaging nearly 67\%. East Asia, at about half that level, had the lowest debt ratios in the region; average debt ratios in Central Asia, the Pacific, and Southeast Asia were 40-50\% of GDP. By developing countries' standards, public debt in Asia has thus been low, with the notable exception of South Asia.

- The AFC represented a watershed for fiscal policy in the region, as many economies experienced large fiscal slippages. Debt ratios across the region rose substantially during 1998/99 and continued climbing during the early 2000s in the Pacific, South Asia, and Southeast Asia. Subsequently, fiscal consolidation efforts and the support of high rates of economic expansion 
Table 3.1 Fiscal indicators

\begin{tabular}{|c|c|c|c|c|c|c|c|}
\hline \multirow[t]{2}{*}{$\begin{array}{l}\text { Subregion } \\
\text { and period }\end{array}$} & $\begin{array}{l}\text { Public } \\
\text { debt }\end{array}$ & $\begin{array}{l}\text { Primary } \\
\text { balance }\end{array}$ & $\begin{array}{l}\text { Fiscal } \\
\text { balance }\end{array}$ & $\begin{array}{l}\text { Fiscal } \\
\text { expenditure }\end{array}$ & $\begin{array}{l}\text { Fiscal } \\
\text { revenue }\end{array}$ & $\begin{array}{l}\text { Interest } \\
\text { paid }\end{array}$ & $\begin{array}{l}F C D \\
d e b t^{*}\end{array}$ \\
\hline & \multicolumn{6}{|c|}{$(\%$ of $G D P)$} & $\begin{array}{l}(\% \text { of } \\
\text { total })\end{array}$ \\
\hline \multicolumn{8}{|c|}{ Central Asia } \\
\hline $2000-10$ & 40.6 & 0.1 & -0.6 & 24.5 & 23.9 & 0.8 & $\ldots$ \\
\hline $2000-06$ & 47.7 & 0.1 & -0.9 & 22.1 & 21.3 & 1.0 & \\
\hline $2007-08$ & 23.4 & 1.4 & 1.1 & 27.5 & 28.5 & 0.3 & 24.1 \\
\hline 2009-10 & 32.8 & -1.0 & -1.6 & 30.1 & 28.5 & 0.6 & 34.3 \\
\hline \multicolumn{8}{|l|}{ East Asia } \\
\hline 1994-2010 & 34.6 & -0.4 & -1.4 & 23.4 & 22.0 & 1.0 & $\ldots$ \\
\hline 1994-97 & 25.1 & -1.3 & -2.3 & 19.4 & 17.0 & 1.0 & $\ldots$ \\
\hline 1998-99 & 40.7 & -2.9 & -4.5 & 23.0 & 18.5 & 1.6 & $\ldots$ \\
\hline $2000-06$ & 40.9 & 0.4 & -0.6 & 24.1 & 23.5 & 0.9 & $\ldots$ \\
\hline $2007-08$ & 27.5 & 1.1 & 0.4 & 26.0 & 26.5 & 0.7 & 11.6 \\
\hline $2009-10$ & 32.5 & -0.6 & -1.2 & 26.8 & 25.5 & 0.7 & 15.5 \\
\hline \multicolumn{8}{|c|}{ Southeast Asia } \\
\hline 1994-2010 & 42.2 & 0.1 & -2.0 & 21.9 & 19.9 & 2.1 & $\ldots$ \\
\hline 1994-97 & 37.2 & 2.2 & 0.5 & 19.9 & 20.4 & 1.7 & $\ldots$ \\
\hline 1998-99 & 42.6 & -1.1 & -2.8 & 21.0 & 18.1 & 1.7 & $\ldots$ \\
\hline $2000-06$ & 46.0 & -0.2 & -2.7 & 22.3 & 19.6 & 2.5 & $\ldots$ \\
\hline $2007-08$ & 38.4 & 0.3 & -1.6 & 22.6 & 21.0 & 1.9 & 21.8 \\
\hline 2009-10 & 41.9 & -2.2 & -4.5 & 24.7 & 20.2 & 1.8 & 21.7 \\
\hline \multicolumn{8}{|l|}{ South Asia } \\
\hline 1994-2010 & 66.9 & -1.0 & -4.5 & 22.5 & 18.0 & 3.5 & $\cdots$ \\
\hline 1994-97 & 65.2 & -1.0 & -4.3 & 22.9 & 18.5 & 3.4 & $\ldots$ \\
\hline 1998-99 & 65.2 & -1.0 & -4.2 & 21.8 & 17.6 & 3.2 & $\ldots$ \\
\hline $2000-06$ & 71.3 & -1.3 & -4.8 & 22.4 & 17.6 & 3.5 & $\ldots$ \\
\hline $2007-08$ & 62.4 & -0.2 & -3.8 & 22.1 & 18.4 & 3.6 & 32.4 \\
\hline 2009-10 & 61.1 & -0.9 & -4.6 & 23.2 & 18.6 & 3.6 & 31.7 \\
\hline
\end{tabular}

$\ldots=$ data not available, $\mathrm{FCD}=$ foreign currency denominated, GDP $=$ gross domestic product.

$\left(^{*}\right)$ As percentage of total public debt.

Notes: Central Asia data cover only the period 2000-10. A negative sign on the primary or fiscal balance indicates a deficit.

Source: ADB TA7662 Database.

brought debt ratios down throughout the region. By 2007/08, debt ratios were mostly at par with or below levels prior to the AFC.

- The GFC was transmitted to Asia mainly through the trade channel in early 2009. The slump in global demand for Asian exports was met with unprecedented determination by governments mounting large monetary and fiscal stimulus packages to support their economies. ${ }^{3}$ As a result, debt ratios turned up again by $2009 / 10$, albeit less markedly than in the immediate aftermath of the AFC (1998/99) and certainly not uniformly across subregions. ${ }^{4}$ 
a Debt/GDP ratio

के
1
号

1
1
I
I

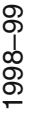

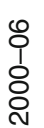

ণ

$\infty$
0
1
$o$
0

Central Asia

East Asia

Pacific

Southeast Asia

South Asia

Developing Asia

Central Asia

East Asia

Pacific

Southeast Asia

South Asia

Developing Asia

Central Asia

East Asia

Pacific

Southeast Asia

South Asia

Developing Asia

East Asia

Pacific

Southeast Asia

South Asia

Developing Asia

Central Asia

East Asia
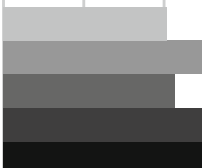

웅

Central Asia

Pacific

Southeast Asia

South Asia

Developing Asia
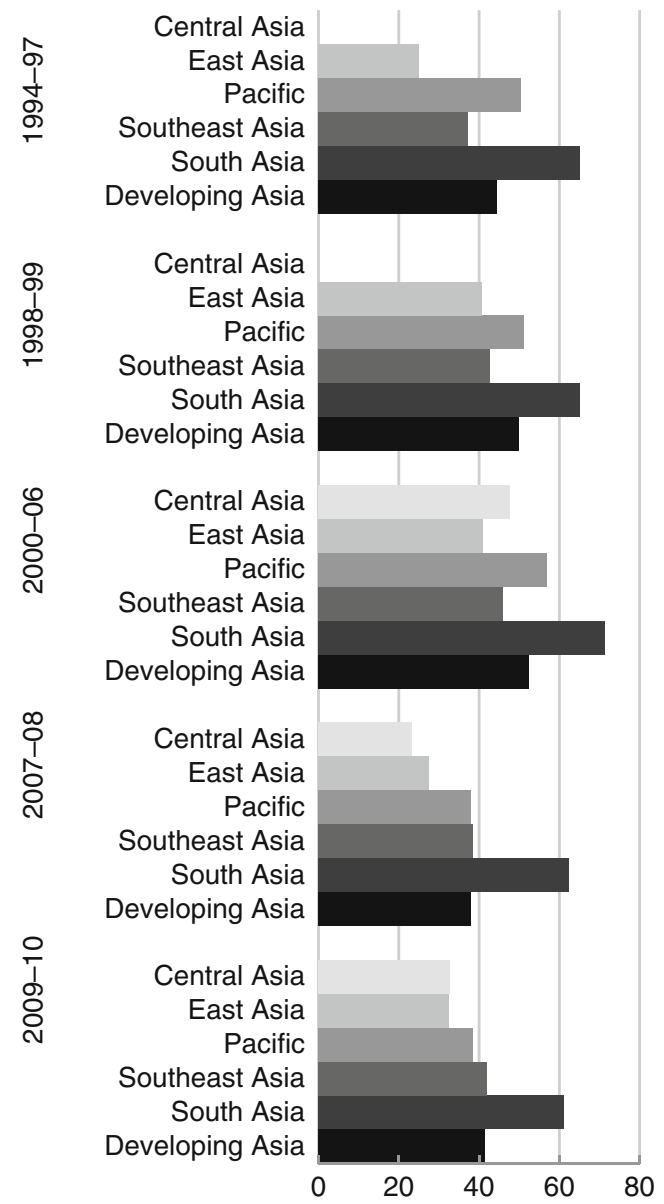

Figure 3.1 Debt indicators (mean values, \%). $\mathrm{GDP}=$ gross domestic product.

Source: Authors' estimates. b Revenue/GDP ratio

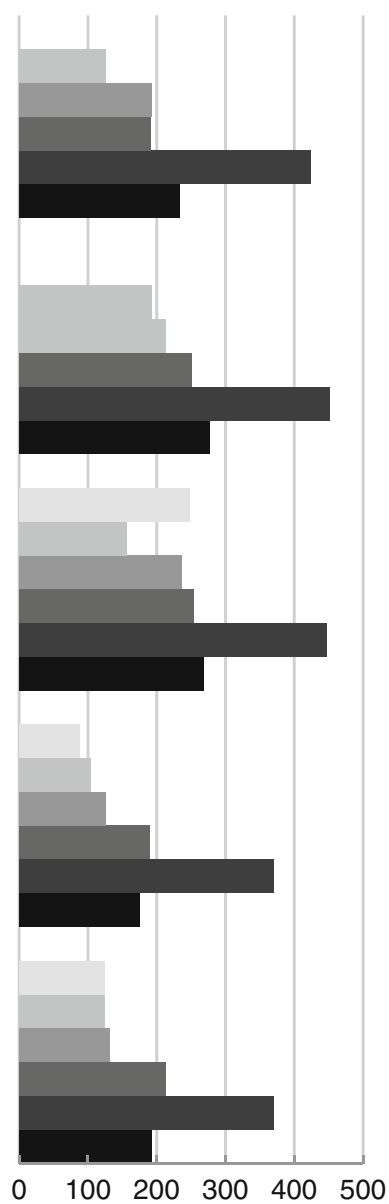


- $\quad$ Fiscal balances across the region were mostly in deficit during 1994-2010. South Asia stands out with a sizeable deficit, averaging $4.5 \%$ over the entire period, followed by Southeast Asia (2.0\%) and East Asia (1.4\%). Fiscal deficits were lower in Central Asia (0.6\%), favored by the price developments in the world commodity markets and debt relief operations since 2000 in relation to Soviet-era liabilities, and in the Pacific (1.1\%), where the debt benefits from a higher grant element than is the case in the rest of Asia.

- The AFC increased fiscal deficits in East and Southeast Asia, which were both at the epicenter of the crisis. Subsequently, fiscal balances improved across the region. By 2007/08, average fiscal balances in East Asia, Central Asia, and the Pacific returned to surplus. Elsewhere, including South Asia, fiscal deficits shrank substantially.

- With the GFC came a dramatic trend reversal in the fiscal stance across the entire region: by 2009-10, South Asia's average fiscal deficit had expanded to $4.6 \%$, Southeast Asia's to $4.5 \%$, and other parts of Asia started recording sizeable deficits from a situation of surplus prior to the crisis.

- By and large, primary balances across the region improved between 1994 and 2008. East Asia managed to turn a 2.9\% average deficit in 1998/99 to a $1.1 \%$ surplus in $2007 / 08$. During the same period, Southeast Asia transformed a $1.1 \%$ deficit into a $0.3 \%$ surplus. Even South Asia managed to rein in its deficits, although it continues to stand out as the subregion with the most persistent primary deficits in Asia, and with the largest interest bills to settle. As will be discussed at length in this chapter, primary balances in the region reflect a fundamental attitude of fiscal responsibility or frugality that has involved fiscal tightening in response to rising debt ratios.

- Average government expenditure and revenue in large parts of Asia are in the range of $20 \%-25 \%$ and thus are lower than in the rest of the emerging world, and substantially lower than in the advanced economies. ${ }^{5}$ The Pacific economies are an exception in this regard, due to relatively large governments and aid financing.

- In the entire region, interest payments on public debt have been low, about $1 \%-3 \%$ of GDP. There is no clear tendency for interest to increase over time. Generally, subregions with the highest debt/GDP ratios also have the highest interest payments/GDP ratios.

- Foreign currency denominated debt (as a share of total public debt) has been generally low in the region. In 2009/10, this share ranged from about $15 \%$ in East Asia to about 34\% in Central Asia.

Figure 3.2 provides another revealing perspective on fiscal positions in the region, displaying time snapshots of the relationship between primary fiscal surplus and debt stocks of each subregion. The movement from period 1 to 2 on the figure corresponds to a substantial worsening of fiscal balances and debt stocks in Asia as a consequence of the AFC. The subsequent shift, from period 3 to 4 , traces the 


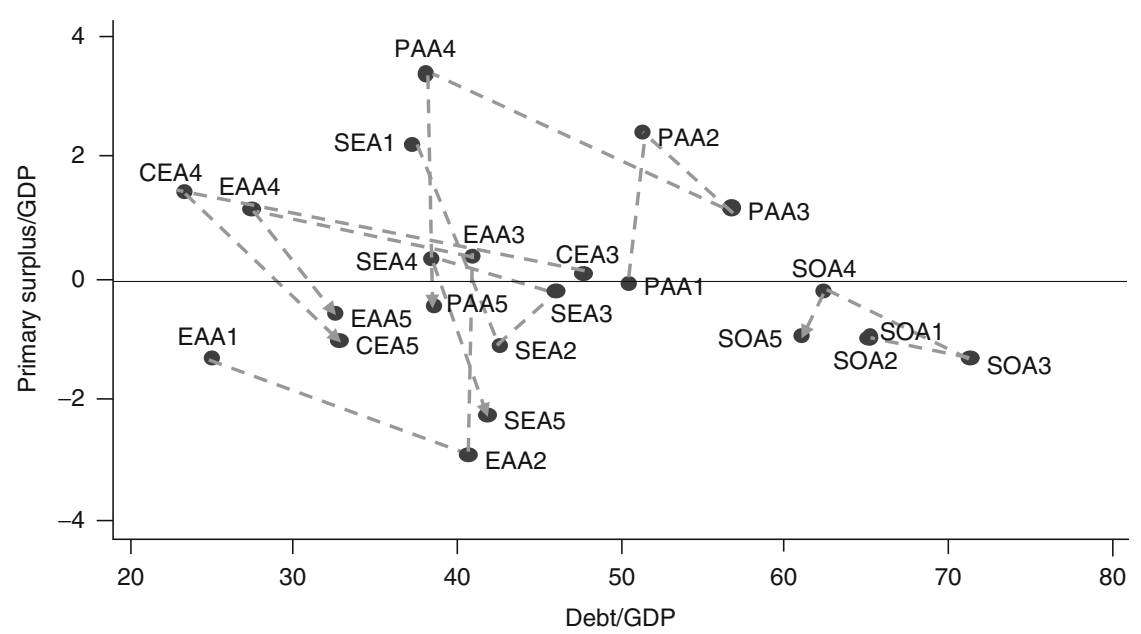

Figure 3.2 Primary balance and public debt (regional period averages).

Periods: $1=1994-97 ; 2=1998-99 ; 3=2000-06 ; 4=2007-08 ; 5=2009-10$.

$\mathrm{CEA}=$ Central Asia, $\mathrm{EAA}=$ East Asia, $\mathrm{GDP}=$ gross domestic product, $\mathrm{PAA}=$ Pacific, $\mathrm{SEA}=$ Southeast Asia, $\mathrm{SOA}=$ South Asia.

Source: Authors' estimates.

fiscal adjustment that gradually took place across the region between the aftermath of the AFC and the onset of the GFC, which for some countries at first involved a further deterioration of fiscal balances and debt ratios well into the early 2000s. By the onset of the GFC, fiscal positions had improved dramatically, but they then deteriorated sharply in period 5, as most governments intervened to rescue their economies with fiscal injections to stem the adverse effects of the global recession.

In Figure 3.2, this pattern is most evident in the East Asia (EAA) and Southeast Asia (SEA) aggregates. Their movements from the first to the second periods (EAA1 to EAA2 and SEA1 to SEA2) show a marked deterioration of primary deficits and public debt ratios due to the AFC. These events were followed by sharp corrections in the economies' balance-of-payments and fiscal accounts, which led to more manageable fiscal balances and lower debt ratios. East Asia, in particular, displays a major policy shift during 2000-06 (EAA3), causing fiscal balances to return to surplus on average across the subregion. By 2007/08 (EAA4), fiscal surpluses had further consolidated in East Asia and the debt ratio had fallen back to just above pre-AFC levels. Figure 3.2 does not show that the fiscal pattern observed for the East Asia subregion is heavily influenced by Mongolia's recovery after a fiscal crisis in the early 2000s.

Compared with East Asia, Southeast Asian countries on average entered the AFC with a higher debt ratio and a fiscal surplus, rather than deficit. By 1998/99, 
that surplus had turned abundantly negative and the debt ratio in most countries kept rising well into the early 2000s. Subsequently, fiscal consolidation efforts combined with favorable debt dynamics based on low interest and high growth rates drove Southeast Asia's average public debt ratio down close to its preAFC level.

Evidence of fiscal consolidation between 2000 and 2008 - that is, a movement upward and leftward on Figure 3.2 - is observed also in relation to South Asia, the Pacific, and Central Asia. As a result, developing Asia was on a sound fiscal footing by the time it faced the GFC: except in a few countries, fiscal balances in the region were generally healthy, and debt ratios were mostly low and declining.

This trend reversed with the GFC. By 2009/10, crisis-related spending, combined with revenue compression due to the slowdown of economic activity, resulted in sizeable fiscal deficits across the region. The unprecedented intensity of the fiscal response by many countries caused subregional deficits to fall below the levels witnessed in connection with the AFC. By contrast, public debt ratios rose as a result of fiscal stimulus, but not to the levels witnessed after the AFC. The profoundly diverse nature of the two crises explains their different impact on the region. Whereas the AFC originated within East and Southeast Asian economies that were facing highly problematic external imbalances and financial fragilities in the years preceding the crisis, the GFC originated in the North Atlantic region and was transmitted to Asia mainly through the trade channel. The prevalence of sound macroeconomic conditions - including huge official foreign currency reserves that had been piling up since the $\mathrm{AFC}$ - helped developing Asia to weather the crisis remarkably well. Economic growth slowed in the region but did not stall, except for a temporary dip in the smaller economies that most heavily rely on foreign trade. Financial markets in the region felt the global credit crunch in 2007 and 2008, but were not left crippled as they were after the AFC, and largely normalized by the second half of 2009. Further, the healthy state of fiscal positions in the region created the policy space necessary for Asian governments, and the PRC in particular, to counter the GFC with large fiscal and monetary stimulus in support of aggregate demand in the region. Although debt ratios rose as a result, strong growth, functioning domestic sovereign bond markets, and low interest rates also prevailing in the international capital markets have been favoring the debt dynamics in the region, keeping debt ratios at a manageable level in most countries.

Subregional averages, which hide a great deal of country heterogeneity, are only roughly indicative of the debt dynamics underlying the individual countries they represent. This is evident in Figure 3.3, which plots individual economies' debt ratios underlying the subregional averages (Figure 3.3 on pp. 56-57). For Central Asia (Figure 3.3a) and the Pacific (Figure 3.3c), the subregional average debt ratios appear to be broadly representative of individual country trends, notwithstanding the occasional outlier. One outlier is Fiji, whose debt ratio has been increasing since the early 2000s, whereas the regional trend indicates a declining ratio for the Pacific more broadly. For the East Asian aggregate, Mongolia's debt pattern 
stands out strongly against that of the PRC and the Republic of Korea, which show roughly similar developments. ${ }^{6}$ Similarly, in Southeast Asia, Indonesia's debt trajectory stands out against that of the other countries in the subregion. ${ }^{7}$ By and large, and notwithstanding the outliers, the subregional averages appear to represent individual countries' public debt patterns sufficiently well and offer useful insights into the broader regional historical patterns as well as differences among Asia's subregions. ${ }^{8}$

\section{Fiscal reaction functions and Asia's fiscal prudence}

The evolution of Asia's fiscal indicators since 1994, discussed in the previous section, provides prima facie evidence of a fundamental pattern of fiscal prudence in the region. Even a crude look at the historical evidence suggests that countries in the region have generally reacted responsibly to increasing debt ratios through fiscal tightening, thus reining in fiscal positions and lowering debt to more manageable levels when necessary. The most recent display of fiscal prudence has been the region-wide fading since 2010 of fiscal stimulus packages enacted in response to the GFC. ${ }^{9}$ Moreover, medium-term fiscal policy plans in the region are testimony to countries' determination to quickly cut back primary deficits to pre-GFC levels in response to higher debt ratios during 2009 and 2010 (ADB 2011a, b).

Responsible, or prudent, fiscal policy constitutes the cornerstone for long-term fiscal sustainability and, as such, assessing the presence of such policy represents the most fundamental of tests in DSA. In contrast to assessment methods centered on accounting identities that link primary fiscal deficits to the evolution of the debt stock ratio - which will be discussed at length below - a most basic test of sustainability consists in determining the behavioral pattern underlying the decision-making process for primary fiscal expenditure and revenue.

Bohn (1998) laid out the theoretical and empirical foundations of the approach, which have since been established firmly in the debt sustainability literature and practice under the labels "fiscal reaction functions" or "primary balance tests" (Chalk and Hemming 2000, IMF 2003, ADB 2010a). Essentially, a fiscal reaction function estimates the relationship between a country's primary surplus and public debt, which is assumed to express a linear decision rule running from the latter to the former. Following Bohn (1998), the basic empirical specification involves the primary surplus $\left(p s_{t}\right)$ and lagged public debt $\left(b_{t-1}\right)$, both as ratios to GDP, as well as temporary factors $\left(\tau_{t}\right)$ impacting the primary balance ratio, such as swings in government spending and the business cycle:

$$
p s_{t}=\rho b_{t-1}+\beta \tau_{t}+\varepsilon_{t} \quad \varepsilon_{t} \sim\left(0, \sigma^{2}\right) .
$$

The vector coefficient, $\beta$, measures the primary surplus' response to the temporary factors included in $\tau_{t}$, and $\varepsilon_{t}$ is an error term with mean 0 and variance $\sigma^{2}$. Central to sustainability in the context of fiscal reaction functions is the coefficient $\rho$, which measures the response of the primary balance to changes in the debt ratio. 


\section{B. Ferrarini and A. Ramayandi}

Bohn (1998) demonstrates that a sufficient condition for fiscal sustainability is that $\rho$ be positive in value and lower than unity:

$$
0<\rho<1
$$

A value of the response parameter between zero and unity implies that the primary surplus increases (on average) with the debt ratio and is taken as evidence of

a Central Asia

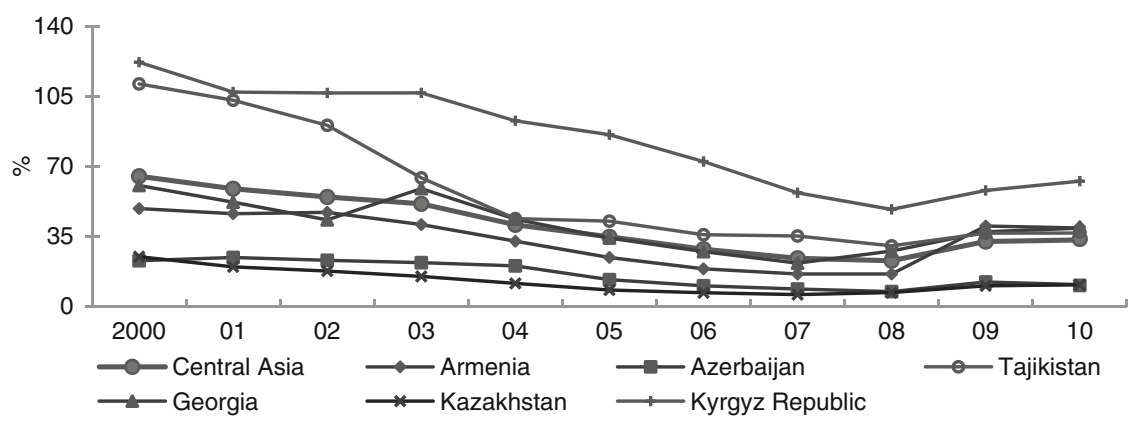

b East Asia

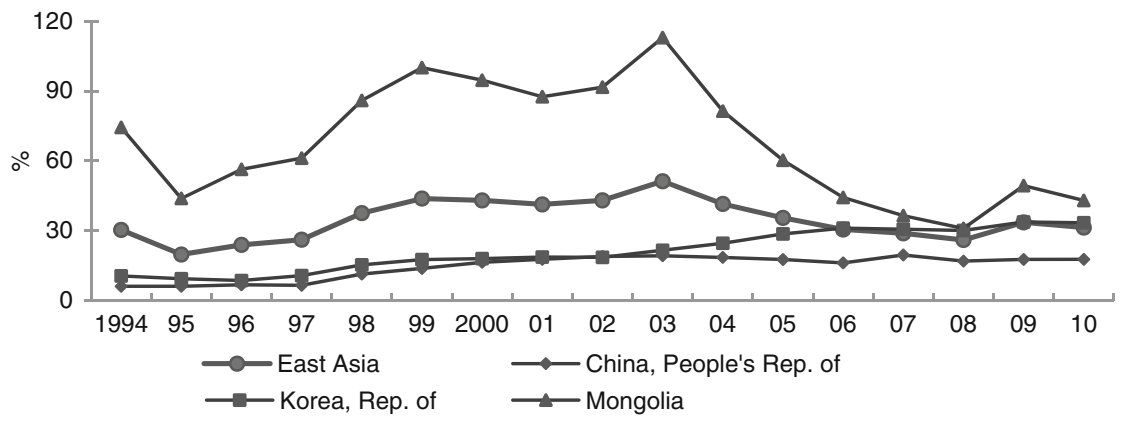

c Pacific

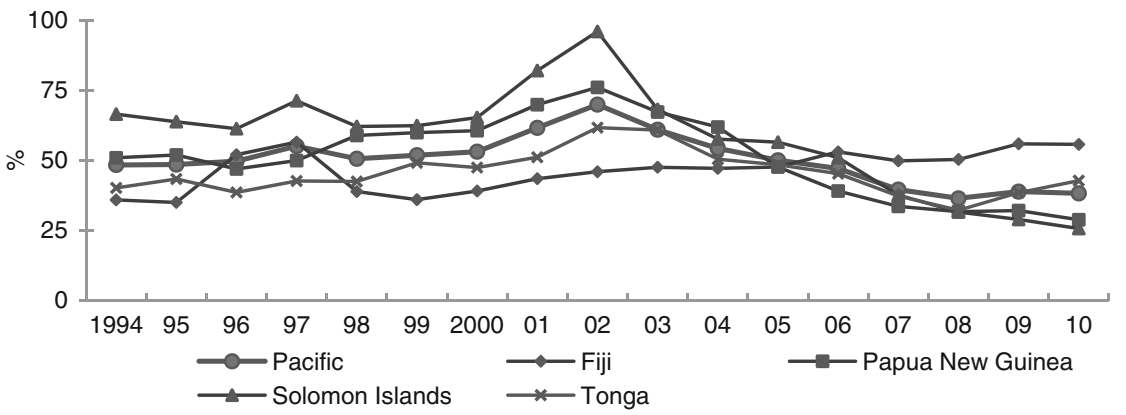

Figure 3.3 (Continued) 


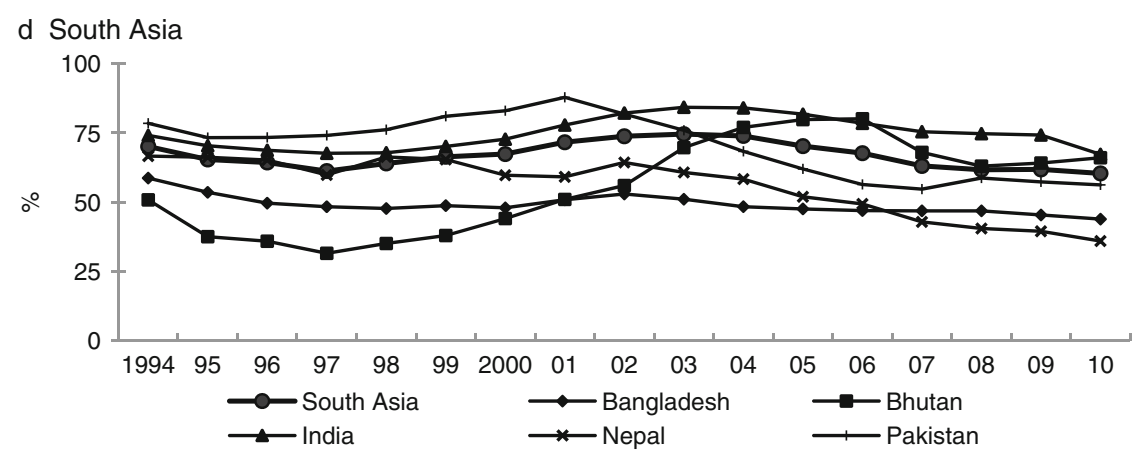

e Southeast Asia

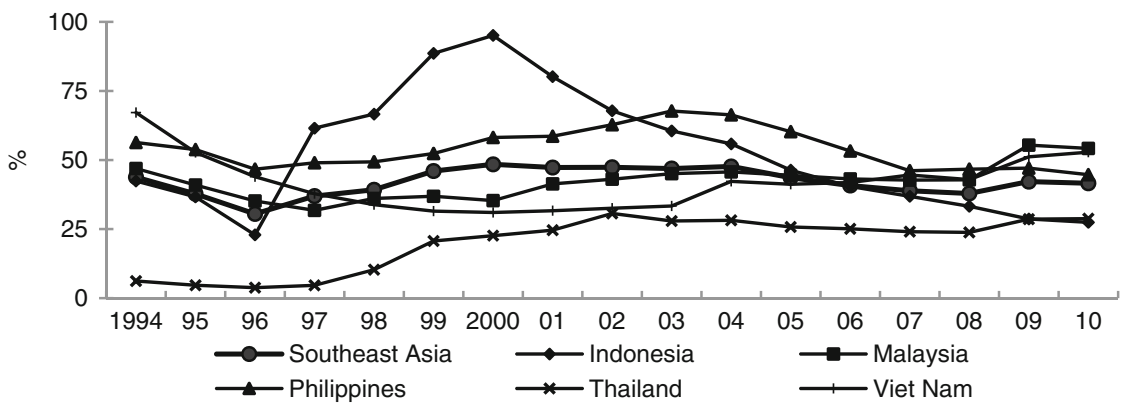

Figure 3.3 Debt/GDP ratios (mean values, \%).

Source: Authors' estimates.

debt sustainability. The closer $\rho$ is to unity, the stronger is the fiscal policy response to increases in the debt ratio. A $\rho$ value close to zero implies that higher debt ratios lead to virtually no response, and when $\rho$ is negative, primary surpluses shrink as a result. In such circumstances, fiscal policy can lead to an explosive debt ratio. ${ }^{10}$

Fiscal reaction functions for selected Asian economies are estimated here for subsets of the data described in Appendix 3.1 for ADB developing members. Results are discussed in relation to a balanced panel of the seven core Asian economies - the PRC, the Republic of Korea, India, Indonesia, Malaysia, the Philippines, and Thailand. For comparison, the results from regressions on a larger, unbalanced panel of 32 economies are reported in Appendix 3.3, Tables A3.3.1A3.3.4. ${ }^{11}$

Table 3.2 summarizes the core results from panel regressions of fiscal policy response functions based on the feasible generalized least squares (FGLS), ordinary least squares (OLS), and system general method of moments (SGMM) estimations. Appendix 3.4 describes the estimation strategy and methods. Linear models, reported in the first three columns of Table 3.2, estimate that the primary deficit in the seven Asian economies on average narrows between $0.036 \%$ and 
Table 3.2 Fiscal reaction functions - panel regression results for seven Asian economies ${ }^{\mathrm{a}}$

\begin{tabular}{|c|c|c|c|c|c|c|}
\hline & $\begin{array}{l}F G L S \\
\text { (1) }\end{array}$ & $\begin{array}{l}\text { Linear OLS } \\
\text { (2) }\end{array}$ & $\begin{array}{l}S G M M \\
\text { (3) }\end{array}$ & $\begin{array}{l}F G L S \\
\text { (4) }\end{array}$ & $\begin{array}{l}\text { Cubic OLS } \\
\text { (5) }\end{array}$ & $\begin{array}{l}S G M M \\
\text { (6) }\end{array}$ \\
\hline \multirow[t]{2}{*}{ Lagged debt } & $0.0361^{* * *}$ & $0.0487^{*}$ & $0.0634^{* * *}$ & $0.160^{* *}$ & $0.215 *$ & $0.206^{* * *}$ \\
\hline & -0.0109 & -0.0257 & -0.022 & -0.0769 & -0.123 & -0.0542 \\
\hline \multirow[t]{2}{*}{ Lagged debt² } & & & & $-0.00334^{*}$ & $-0.00498^{*}$ & $-0.00332^{* *}$ \\
\hline & & & & -0.00183 & -0.00276 & -0.00146 \\
\hline \multirow[t]{2}{*}{ Lagged debt`3 } & & & & $2.61 \mathrm{e}-05^{* *}$ & $3.68 \mathrm{e}-05^{*}$ & $2.15 \mathrm{e}-05^{*}$ \\
\hline & & & & $-1.33 \mathrm{E}-05$ & $-1.89 \mathrm{E}-05$ & $-1.17 \mathrm{E}-05$ \\
\hline \multirow{2}{*}{ Lagged surplus } & & & $0.482^{* * *}$ & & & $0.475^{* * *}$ \\
\hline & & & -0.0909 & & & -0.0863 \\
\hline \multirow[t]{2}{*}{ Real GDP } & $0.209^{* * *}$ & $0.235^{* * *}$ & $0.265^{* * *}$ & $0.151^{* * *}$ & $0.232^{* * *}$ & $0.263^{* * *}$ \\
\hline & -0.0424 & -0.0474 & -0.0604 & -0.0517 & -0.0467 & -0.0617 \\
\hline \multirow[t]{2}{*}{ Real expenditure } & $-0.112^{* * *}$ & $-0.163^{* * *}$ & $-0.155^{* * *}$ & $-0.112^{* * *}$ & $-0.173^{* * *}$ & $-0.158^{* * *}$ \\
\hline & -0.0173 & -0.0193 & -0.0475 & -0.0181 & -0.0201 & -0.0465 \\
\hline \multirow[t]{2}{*}{ Constant } & -0.543 & $-2.141^{* * *}$ & & $-3.409^{* * *}$ & $-3.114^{* * *}$ & \\
\hline & -0.834 & -0.339 & & -1.158 & -0.547 & \\
\hline Dummies & Yes & Yes & Yes & Yes & Yes & Yes \\
\hline Observations & 133 & 126 & 126 & 133 & 126 & 126 \\
\hline Economies & 7 & 7 & 7 & 7 & 7 & 7 \\
\hline $\mathrm{Chi}^{2} / \mathrm{R}^{2}$ _adj & 196.8 & 0.411 & 475.9 & 277.3 & 0.422 & 489.5 \\
\hline A/B Order 1 & $\ldots$ & $\ldots$ & $-1.6445^{*}$ & $\ldots$ & $\ldots$ & $-1.6611^{*}$ \\
\hline A/B Order 2 & $\ldots$ & $\ldots$ & 0.56621 & $\ldots$ & $\ldots$ & 0.68116 \\
\hline
\end{tabular}

${ }^{a}$ Dependent variable: primary fiscal surplus.

A/B Order 1 and 2 = Arellano-Bond test for first-and second-order autocorrelation; CPI = consumer price index; FGLS = feasible generalized least squares estimation; HP = Hodrick-Prescott; OLS = fixed effects ordinary least squares estimation; SGMM = system generalized method of moments Blundell-Bond linear dynamic estimation.

Standard errors in parentheses. Significance levels: ${ }^{* * *} p<0.01,{ }^{* *} p<0.05,{ }^{*} p<0.1$.

$\ldots=$ not available.

Notes:

- The regressions are fitted to a balanced panel of seven economies (the People's Republic of China, the Republic of Korea, India, Indonesia, Malaysia, the Philippines, and Thailand) with data from 1990 to 2010.

- FGLS assuming country-specific heteroskedasticity and AR(1) autocorrelated errors.

- $\quad$ OLS assuming first-order autoregressive errors (AR1).

- $\quad$ SGMM (Arellano and Bond 1991, Blundell and Bond 1998) .

- All variables are expressed as ratio of GDP.

- Lagged debt: MA2 debt stock lagged one year. Lagged debt ${ }^{\wedge} 2$ is squared lagged debt and Lagged debt 3 is cubic lagged debt.

- Real GDP: HP-trend deviation of real GDP.

- Real expenditures: HP-trend deviation of real government expenditure.

- Controls: World oil price indicator, non-food commodity price indicator (deviations from HPtrend), and CPI inflation (two-year moving average). Coefficients not reported.

- Dummies: Country and year dichotomous variables included in regression (coefficients not reported).

- $\quad \mathrm{Chi}^{2}$ /adjusted $R^{2}$ : Overall fit statistics; $\mathrm{Chi}^{2}$ for FGLS maximum likelihood regressions, and adjusted $R^{2}$ for OLS regressions.

- $\mathrm{A} / \mathrm{B}$ Order 1 and 2 indicated are the $z$-statistic and the corresponding probability (Prob $>z$ ).

Source: Authors' estimates. 
$0.063 \%$ in response to a 1 percentage point increase in debt ratios, allowing for a response lag of up to 2 years. The sign and magnitude of these linear point estimates of coefficient $\rho$ are broadly in line with the findings of previous studies and confirm fiscally responsible behavior in the region (IMF 2003, ADB 2010a, IMF 2011a). Moreover, there is no single instance in Table 3.2 of coefficient $\rho$ taking on a negative sign, or of primary fiscal balances in Asia having responded perversely to rising debt.

The statistical significance of the response parameter estimates varies across the alternative specifications in Table 3.2, but always within commonly accepted levels. Significance is highest for the FGLS (column 1) and SGMM (column 3) models, which accommodate the actual time series structure underlying the data better than OLS estimation (column 2). Also consistent across the three models are the estimated coefficients of real GDP and expenditure deviations, which turn out with the expected sign and are both economically and statistically highly significant. That is, a positive shock to the cyclical component of output (real GDP) is found to raise primary surplus by a factor of 0.21 to 0.27 on average, while an increase of real expenditure above its trend is estimated to lower contemporaneous primary fiscal surplus by an average factor of 0.11 to 0.16 .

Specific to SGMM regression is the inclusion of the lagged dependent variable among the regressors. Column 3 of Table 3.2 shows that the coefficient of lagged primary fiscal surplus is estimated at 0.482 and is highly significant. Fiscal policy is thus found to have a strong degree of inertia, causing the sign and magnitude of primary budgets in one year to depend substantially on previous years' budgetary outcome and decisions. This should be no surprise, as government budget plans typically run over several years, and many government revenue and expenditure items are largely fixed or irreversible in the short term. As a result, fiscal responsibility as measured by coefficient $\rho$ typically affects the primary surplus only within the narrow margins of feasible adjustments, except during exceptional periods of fiscal distress that may force governments to abruptly reverse past decisions. ${ }^{12}$

To allow for the possibility that the fiscal reaction function might be nonlinear in shape, columns 4-6 of Table 3.2 report the estimation results of cubic models. ${ }^{13}$ FGLS, OLS, and SGMM estimates again are highly consistent in confirming the existence of nonlinearities in the response function, which causes the intensity of fiscal policy adjustments to vary with the level of debt a country faces. To illustrate this relationship, Figure 3.4 displays the cubic fiscal reaction function estimated by FGLS in column 4, which is shown as a black line relating the primary surplus ratio to the lagged public debt ratio. ${ }^{14}$ In contrast to a linear function, the intensity of fiscal adjustments along the cubic function is shown to first decrease until the debt ratio reaches about $45 \%$, and to then accelerate as the debt ratio approaches higher levels. Put differently, the evidence is that countries facing either low or high debt ratios, such as up to $20 \%$ of GDP and from $70 \%$ up, implement the stronger primary fiscal balance adjustments. By contrast, countries with debt ratios in the medium range tend to react less forcefully to changes in public debt. This particular pattern of fiscal reaction in the region is corroborated 


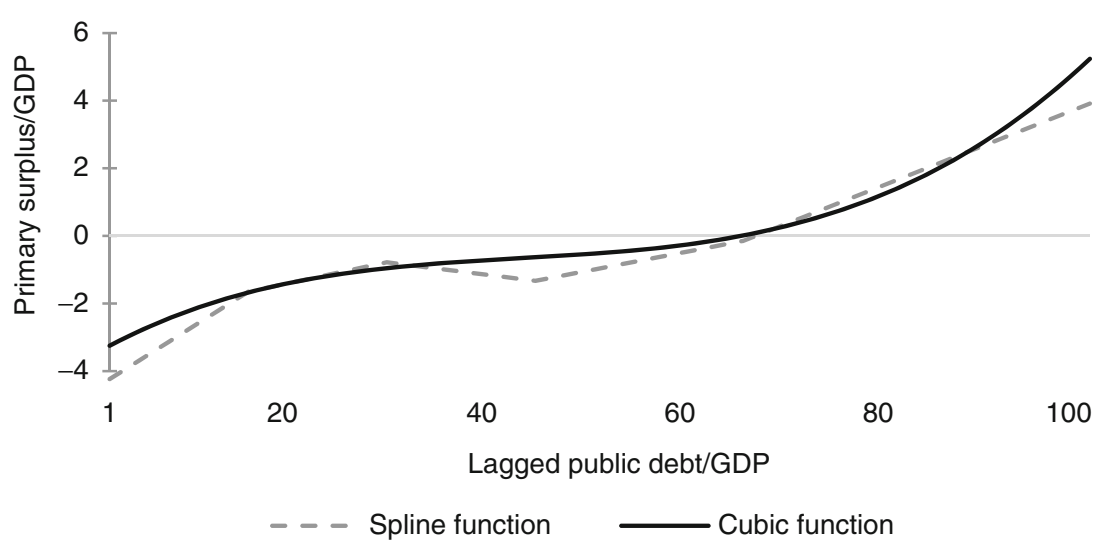

Figure 3.4 Spline and cubic fiscal reaction functions.

$\mathrm{GDP}=$ gross domestic product.

Source: Authors' estimates.

by splined linear regression analysis, shown in Figure 3.4 as the dashed line in light gray. ${ }^{15}$ Intuitively, this finding is compatible with a segmentation of Asian countries into three groups: those that are highly adverse to anything other than extremely low public debt ratios; others that are compelled to forcefully stem high and rising debt ratios that may risk spiraling out of control; and a third group that lies in between, characterized by a more relaxed fiscal response to changes to debt deemed manageable without strong corrective action.

However that may be, the regression analysis in this section unambiguously corroborates the presence of a profoundly responsible and prudent conduct of fiscal policy in the region, which tends to keep debt ratios generally low, or keeps them from rising uncontrollably at higher levels. On average, countries that see their public debt/GDP ratio increase tend to counteract by increasing primary fiscal surpluses or reducing deficits within the following two years. At the same time, primary balances respond in a systematic way to the business cycle, as proxied by output gaps, and to swings in primary government spending relative to trend.

As discussed in Chapter 2 (on concepts and issues), a value for the response parameter $\rho$ between 0 and 1 implies that the primary surplus increases as the debt ratio rises, which is a sufficient condition for (dynamic) sustainability. Therefore, to the extent that past behavior represents a reliable gauge of future fiscal behavior in Asia, this chapter provides ground for optimism about the most fundamental, long-term outlook of debt sustainability in the region.

However, notwithstanding the role the $\rho$ coefficient plays in determining the prospects for dynamic sustainability, the behavior of debt ratios over short- to medium-term horizons also depends importantly on the behavior of the gap between the interest rate on public debt and the growth rate of the economy. 
As noted in the next section, when the growth rate is above the interest rate, the short-term debt/GDP ratio can be stabilized even when the primary balance is in deficit. In such circumstances, if the primary balance fails to increase as debt increases - which is sufficient for sustainability for a very long time when the interest rate is above the growth rate - a stable debt/GDP ratio may still be attained in the near term. Over the longer term, however, fiscal sustainability in Asia will depend on the primary balance increasing as the debt ratio rises.

\section{The interest rate-growth differential and the debt stabilizing primary balance}

The discussion in Chapter 2 emphasizes the crucial role played by the IRGD in determining a country's debt dynamics. Empirically, the impact of the IRGD on debt sustainability in developing Asia arises most clearly in the context of the debt stabilizing primary balance (DSPB). In terms of the notation introduced in Chapter 2, the DSPB derives from the fundamental identity relating changes in a country's public debt ratio $\left(\Delta b_{t}=b_{t}-b_{t-1}\right)$ to the IRGD $\left(\theta_{t}=r_{t}-g_{t}\right)$ and the primary fiscal surplus $\left(p s_{t}\right)$ :

$$
b_{t}-b_{t-1}=\frac{r_{t}}{1+g_{t}} b_{t-1}-\frac{g_{t}}{1+g_{t}} b_{t-1}-p s_{t}
$$

or

$$
\Delta b_{t}=\frac{\theta_{t}}{1+g_{t}} b_{t-1}-p s_{t},
$$

where $b_{t}$ is public debt, $r_{t}$ is the interest rate, $g_{t}$ is the growth rate of GDP, and $\theta_{t}$ is the IRGD (all at time $t$ ).

Against the backdrop of medium-term assumptions about the IRGD $\left(\theta_{t}\right)$ and a country's fiscal policy path $\left(p s_{t}\right)$, debt sustainability is judged according to whether this scenario gives rise to a stable or "explosive" or "snow-balling" debt path over the chosen horizon of analysis. By the same token, the debt stabilizing primary balance $\left(p s^{*}\right)$ is defined as the primary surplus required to keep the debt ratio fixed at its existing level $\left(b_{t-1}^{*}\right)$, given $\theta_{t}$ :

$$
p s^{*}=\frac{\theta_{t}}{1+g_{t}} b_{t-1}^{*} \text {. }
$$

The debt stabilizing primary balance $\left(p s^{*}\right)$ is thus an essential element to inform both DSA and budget plans on to the upper limit to which average primary balances may expand without causing the public debt ratio to rise.

The DSPB approach relates to the short- to medium-term with regard to fiscal policy and thus abstracts from the asymptotic notion of debt sustainability as embodied in the government budget constraint condition, discussed in Chapter 2. Instead, the DSPB approach is firmly anchored in the practical notion that a country's fiscal policy risks spinning out of control eventually, unless it stabilizes the debt ratio over the medium term. 


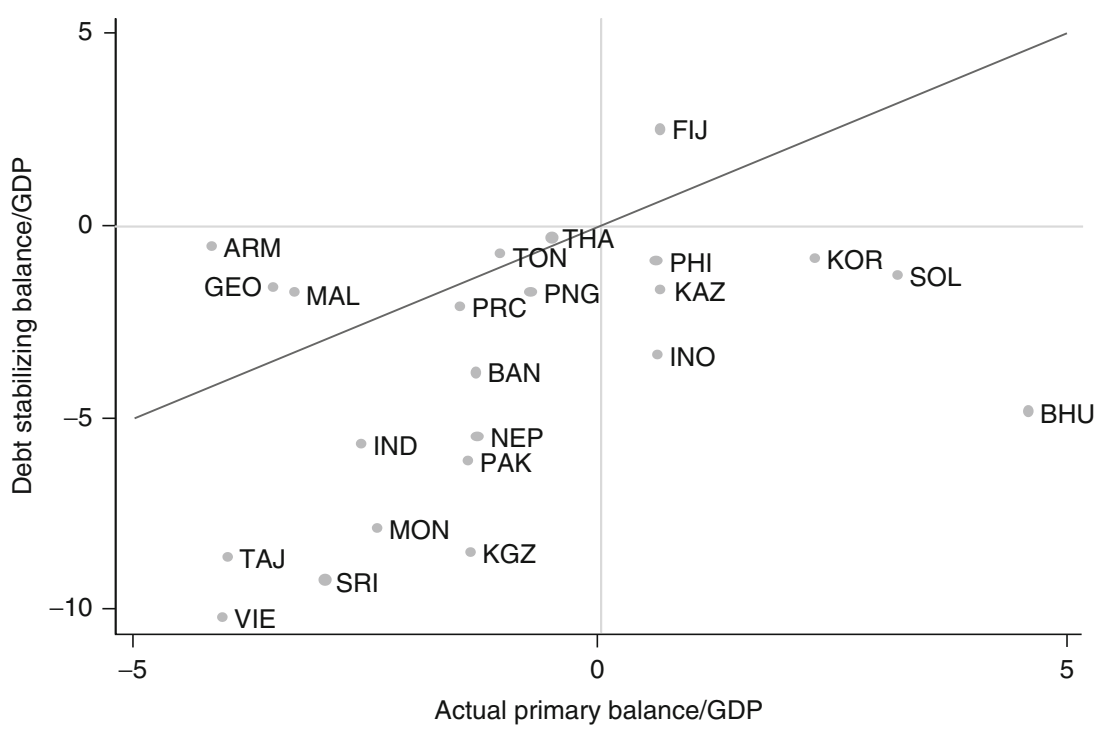

Figure 3.5 Actual and debt stabilizing primary balance (2009-10 average growth and interest rates).

$\mathrm{ARM}=$ Armenia $; \mathrm{BAN}=$ Bangladesh $; \mathrm{BHU}=$ Bhutan; FIJ $=$ Fiji; GDP $=$ gross domestic product; $\mathrm{GEO}=$ Georgia; IND = India; INO = Indonesia; $\mathrm{KAZ}=$ Kazakhstan; $\mathrm{KGZ}=$ Kyrgyz Republic; $\mathrm{KOR}=$ Republic of Korea; MON = Mongolia; $\mathrm{MAL}=$ Malaysia; NEP = Nepal; PAK = Pakistan; $\mathrm{PHI}=$ Philippines $; \mathrm{PNG}=$ Papua New Guinea $; \mathrm{PRC}=$ People's Republic of China $; \mathrm{SOL}=$ Solomon Islands; SRI $=$ Sri Lanka; TAJ $=$ Tajikistan; THA $=$ Thailand; TON $=$ Tonga; VIE $=$ Viet Nam.

Note: Assumed GDP nominal growth rates, interest rates, public debt, and primary balance ratios at 2008-10 average.

Source: Authors' estimates.

The basic intuition behind DSPB is illustrated in Figure 3.5, in relation to the same sample of 24 Asian countries discussed in the first section of this chapter. ${ }^{16}$ The horizontal axis measures countries' actual average primary balance during $2008-10$. The vertical axis indicates the debt stabilizing primary surplus that is compatible with countries' nominal GDP growth and interest rates, which are also kept at 2008-10 average levels. ${ }^{17}$ The line intersecting the chart is the locus of actual primary balances equaling the DSPB. Markers above the line denote situations in which the DSPB is higher than the actual primary surplus. Economies in this position will experience upward pressure on their debt ratio. Conversely, markers below the line correspond to economies with actual primary surplus above the level necessary to stabilize the debt ratio, causing their debt ratios to decline.

Figure 3.5 suggests that the fiscal stance of the majority of Asian countries is sustainable. More precisely, it shows that if countries' growth and interest rates remained unchanged at 2008-10 averages, the debt ratios of all the economies 
scattered below the intersecting line would be expected to decline. This would include economies running large (actual) primary deficits, where the debtincreasing effect of the deficits would be more than outweighed by a large IRGD. ${ }^{18}$ This illustrates the possibility (mentioned in the previous section) for debt ratios to decline despite sizeable primary deficits, as long as the debt dynamics are dominated by a high growth and low interest environment. At least in the short term, then, debt in many of the region's economies would be deemed sustainable regardless of whether they exercise fiscal prudence. However, this does not hold true for countries above the intersecting line in Figure 3.5. For those economies, the IRGD is not adequate to more than outweigh the fiscal stance, and thus they are expected to experience upward pressure on their debt ratios. This is the case for Armenia, Fiji, Georgia, and Malaysia and, to a lesser degree, for Thailand and Tonga, which scatter more closely about the line.

Figure 3.6 confirms that the widespread fiscal comfort in the region derives mostly from an abundantly favorable IRGD, which in 2008-10 was negative for all but one country and exceeded $-10 \%$ for about half the countries in the sample. The role of this IRGD in driving debt dynamics arises most clearly from equation (3.3): when it is negative $\left(\theta_{t}<0\right)$, economic growth erodes the debt ratio more quickly than it is built up through accumulating interest. Moreover, a sufficiently large IRGD erodes the debt ratio by enough to more than offset debt accumulation through fiscal deficits altogether, causing debt ratios to fall, as is the case for the majority of economies in Figure 3.5. ${ }^{19}$ One example is Viet Nam, whose $4.1 \%$ average primary deficit during 2008-10 fell considerably below the

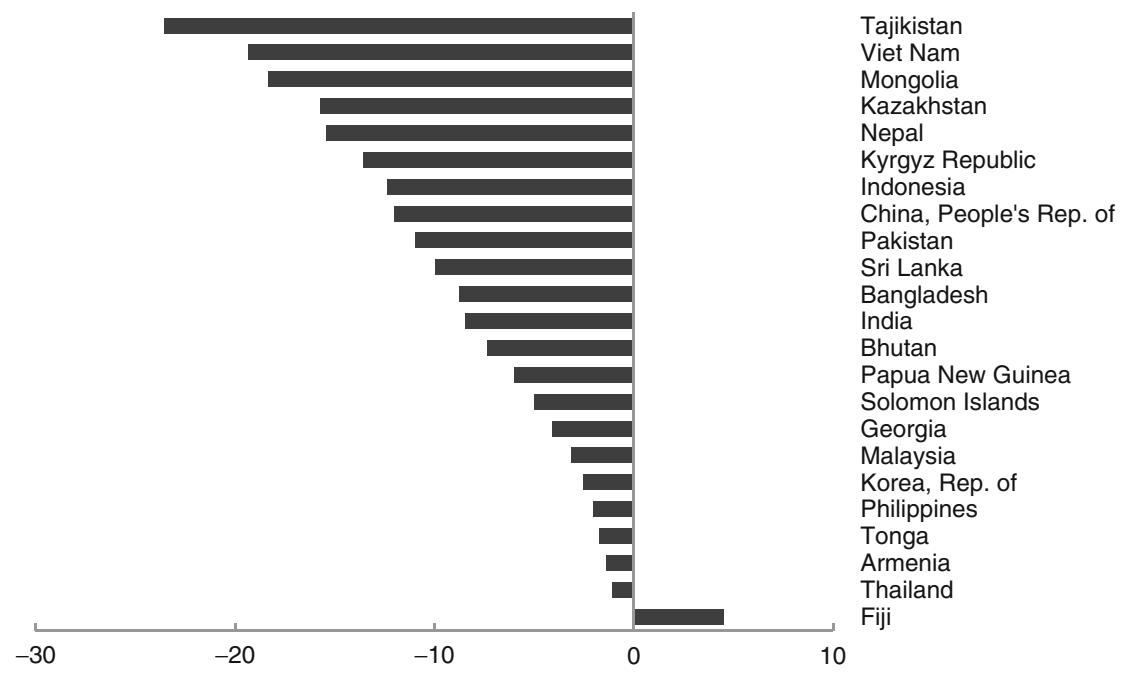

Figure 3.6 Interest rate-growth differential (average \% 2008-10).

Source: Authors' estimates. 
$10.2 \%$ primary deficit it could run and still have its debt ratio stabilized as a result of the large negative IRGD.

By contrast, a positive IRGD $\left(\theta_{t}>0\right)$ pushes up the debt ratio, because economic growth is insufficient to counter cumulating interests. Such a case is Fiji during 2008-10, when its economic growth rate slowed to average $1.8 \%$ while it was facing an effective interest rate of $6.3 \%$ on its public debt outstanding. This explains why Fiji is not within the sustainable zone of Figure 3.5, despite its average primary surpluses of about $0.7 \%$ in the 3 years prior to 2010 .

Adjustments are also required by countries with negative but narrow IRGDs, if they are insufficient to counter sizeable primary deficits. Armenia, for example, would have to narrow its primary deficit from an actual $-4.2 \%$ in $2008-10$ to at least $-0.6 \%$ for its debt ratio to stabilize. Figure 3.5 suggests that similar adjustments would be necessary in Georgia, Fiji, and Malaysia and, to a lesser extent, in Tonga and Thailand.

Although a large negative IRGD favors debt dynamics in the medium term, it usually comes with its own hazards and is bound to narrow and eventually vanish in the longer term. ${ }^{20}$ Periods of large negative IRGDs are typically associated with the development of macroeconomic imbalances in the relevant economies, such as large current account deficits, which frequently lead to the rapid expansion of credit; heightened vulnerability to growth fluctuations; or endogenous reactions by the interest rate to rising default risk, whether actual or perceived. Some economies in the region showed many of these features when the AFC hit in 1998/99. More recent examples are Greece, Ireland, and Spain in 2010/11, when a sudden drop in market confidence caused government bond yields to spike against the backdrop of a sharp slowdown in economic growth. As a result, the IRGD in these countries turned positive after having been negative for the most part since the creation of the euro in 1999, and governments were forced to enact stringent austerity measures and deeply revise fiscal and primary balance targets previously deemed sustainable (Escolano 2010). Except for Greece, perhaps, none of these countries would have appeared to be at particular risk according to the debt indicators informing DSA, but their external imbalances during the run up to the crisis in the 2000s would have indicated risks of imbalance and possible distress in future.

In addition, there are structural reasons for the IRGD to narrow and eventually turn positive as countries reach a certain level of development. Upon reaching a certain level of GDP per capita, the rate of economic expansion slows and domestic interest rates tend to rise as financial repression loosens and financial sectors deepen (Escolano 2010; Eichengreen, Park, and Shin 2011; IMF 2011a). Eventually, dynamic steady-state growth conditions of mature economies will require the IRGD to be positive. ${ }^{21}$

For these reasons, Asian economies will not be able to avoid a structural narrowing of the IRGD over time and, eventually, a sign reversal, upon reaching a certain level of development. In the meantime, these economies will be exposed to an array of temporary shocks to their growth rate, interest rate, 
or both, which may at any time jeopardize debt dynamics previously deemed sustainable.

To assess the region's vulnerability to temporary shocks to the IRGD, Figure 3.7 recomputes debt stabilizing primary balances so as to account for a shock of 1 standard deviation narrowing economies' IRGDs for the period 2000-10. As a result, the DSPB shifts upward in Figure 3.7 (compared to Figure 3.5) for all economies by a distance proportional to 1 standard deviation of their historical IRGDs. To keep the debt ratio stable under this scenario, fiscal policy would have to make up for a less favorable growth performance, higher interest rates, or both. Borderline cases, such as the PRC, India, and Papua New Guinea would first shift outside the sustainability zone because of a narrowing IRGD, and their return to it would require a sufficiently large adjustment to the actual primary balance, implying a movement to the right on Figure 3.7. Other economies, including

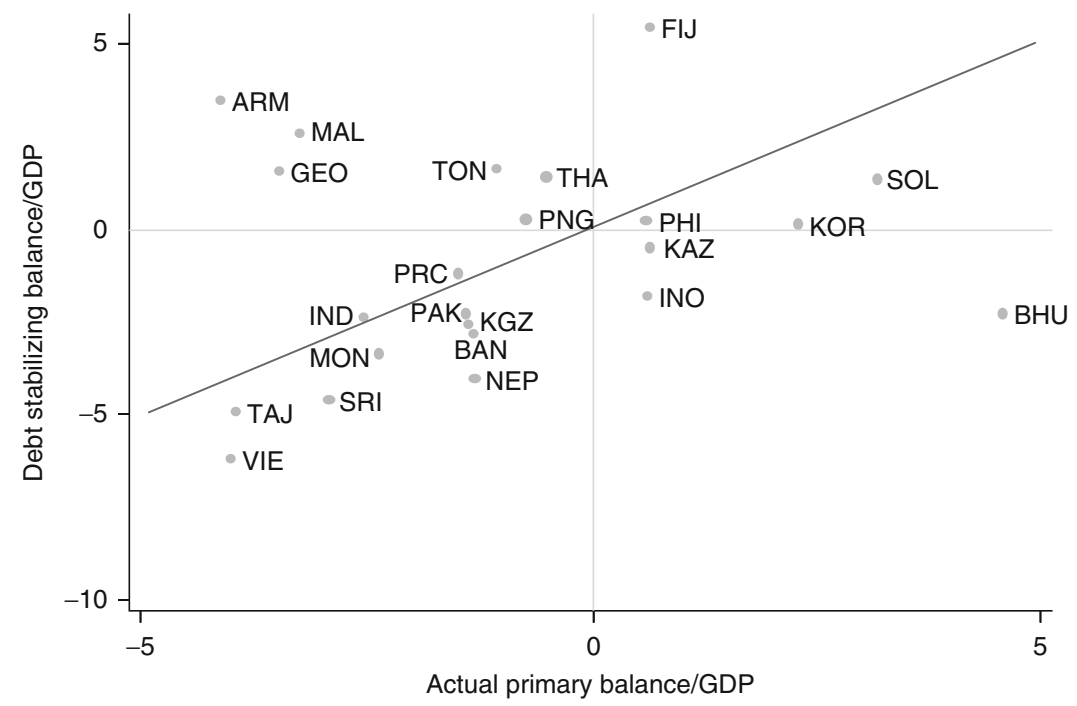

Figure 3.7 Actual and debt stabilizing primary balance with 1 standard deviation shock on the interest rate-growth differential (shock on the interest rate-growth differential).

$\mathrm{ARM}=$ Armenia $; \mathrm{BAN}=$ Bangladesh $; \mathrm{BHU}=\mathrm{Bhutan} ; \mathrm{FIJ}=$ Fiji; GDP = gross domestic product; $\mathrm{GEO}=$ Georgia; IND = India; INO = Indonesia; KAZ = Kazakhstan; KGZ = Kyrgyz Republic; $\mathrm{KOR}=$ Republic of Korea; $\mathrm{MON}=$ Mongolia; $\mathrm{MAL}=$ Malaysia; NEP = Nepal; PAK = Pakistan; PHI = Philippines; PNG = Papua New Guinea; PRC = People's Republic of China; SOL = Solomon Islands; SRI = Sri Lanka; TAJ = Tajikistan; THA = Thailand; TON = Tonga; VIE = Viet Nam.

Note: Assumed GDP growth rates and interest rates at 2008-10 average augmented by one standard deviation of the interest rate-growth differential over the period. Debt and primary balance at 2008-10 average.

Source: Authors' estimates. 
that of Viet Nam, would still see their debt ratios decreasing under the given assumptions, although their fiscal space would be compressed substantially as a result.

The effects of a more drastic scenario are shown in Figure 3.8, which envisages a sign reversal in Asian economies with negative IRGDs, so as to bring it to positive $1 \%$ for all of them. ${ }^{22}$ In such an event - all else being equal-most economies would shift up and out of the sustainability zone in Figure 3.8, their return to sustainability requiring sufficiently sharp fiscal adjustments to cause a wide shift to the right on the graph. ${ }^{23}$ Fiscal surpluses across the region would reflect the new reality of positive IRGDs, with the effect that repeated fiscal slippages would inevitably lead to snowballing debt ratios and the possibility of distress in future. ${ }^{24}$ In such a scenario, fiscal responsibility would play a key role in assuring Asia's continued debt sustainability. Of course, nothing in such a scenario could ensure that the same incentives inducing fiscal responsibility would prevail in an Asia that is likely to find itself economically and socially transformed.

In sum, the DSPB approach suggests that most economies in the region currently fall well within the comfort zone of fiscal sustainability, which is in line with the findings of earlier studies (Horne 1991; IMF 2003; Mendoza and Ostry 2007; Adams, Ferrarini, and Park 2010). The analysis in this section also shows that the prevalence of large negative IRGDs throughout the region has been responsible for highly favorable debt dynamics, which overshadow the dampening effects of Asia's prudent fiscal policy on its debt ratios. However encouraging, these finding should not be seen as grounds for complacency. Economic circumstances, such as the interest rate on public debt being below the growth rate of the economy, are unlikely to hold indefinitely and are subject to sudden temporary reversals. For these reasons, robust debt-stabilizing fiscal policies in the region would have to aim at a stable debt ratio also if the interest rate should rise above the growth rate.

\section{Debt sustainability analysis based on macroeconomic forecasts}

Standard DSA projects the debt ratio based on the latest macroeconomic forecasts and fiscal policy assumptions, typically over a medium-term horizon. ${ }^{25}$ Against the assumptions that concern the domestic and global macroeconomic environments, which are exogenous to the analysis itself, DSA assesses whether the projected path of fiscal policy (the baseline) is compatible with a sustainablethat is, stable - debt ratio over a horizon of usually about five years. ${ }^{26}$ To account for uncertainty in the forecast parameters, DSA involves a number of stress tests. Leaving other variables unchanged, such tests involve raising the interest rate, the growth rate, or both by 1 standard deviation above the historical level observed for a particular country, to assess whether this would significantly alter the debt trajectory and the conclusions about the stability of the ratio. ${ }^{27}$ 


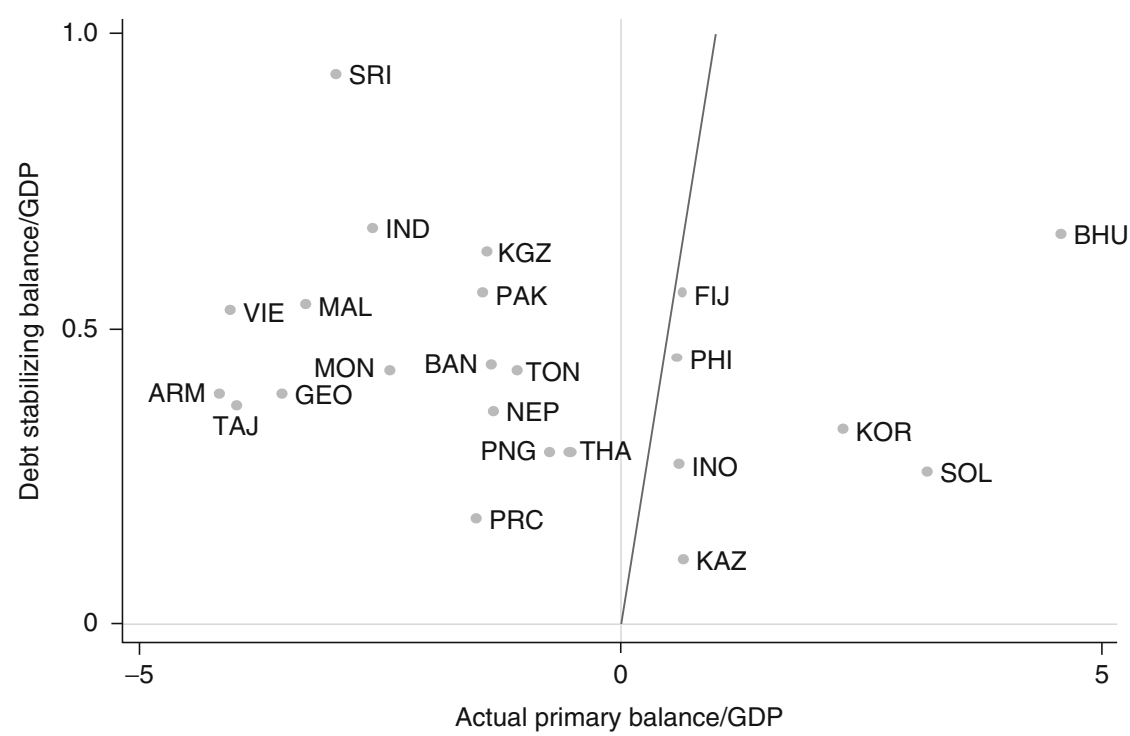

Figure 3.8 Actual and debt stabilizing primary balance with a positive $1 \%$ deviation on the interest rate-growth differential.

$\mathrm{ARM}=$ Armenia BAN $=$ Bangladesh $; \mathrm{BHU}=$ Bhutan; $\mathrm{FIJ}=\mathrm{Fiji} ; \mathrm{GDP}=$ gross domestic product; $\mathrm{GEO}=$ Georgia; IND = India; INO = Indonesia; KAZ = Kazakhstan; KGZ = Kyrgyz Republic; $\mathrm{KOR}=$ Republic of Korea; $\mathrm{MON}=$ Mongolia; $\mathrm{MAL}=$ Malaysia; $\mathrm{NEP}=$ Nepal; $\mathrm{PAK}=$ Pakistan; $\mathrm{PHI}=$ Philippines; $\mathrm{PNG}=$ Papua New Guinea PRC $=$ People's Republic of China $; \mathrm{SOL}=$ Solomon Islands; SRI $=$ Sri Lanka; TAJ $=$ Tajikistan; THA $=$ Thailand; TON $=$ Tonga; VIE $=$ Viet Nam.

Notes: Due to the need for different scales on the vertical and horizontal axes of Figure 3.8, its separating line is drawn more steeply than the same line in Figures 3.5 and 3.7. The interpretation of the line remains the same.

Assumed GDP growth rate at 2000-10 average. Debt and primary balance at 2008-10 average. Interest rate now assumed at $1 \%$ above $2000-10$ growth rate.

Source: Authors' estimates.

As discussed in Chapter 2, the debt accounting mechanism underlying IMFstyle DSA relies on an equation that relates changes in the public debt/GDP ratio $\left(b_{t+1}-b_{t}\right)$ to changes in the real interest rate $\left(r_{t}\right)$, the real growth rate of GDP $\left(g_{t}\right)$, the rate of inflation $\left(\pi_{t}\right)$, the share of debt denominated in foreign currency $\alpha_{t}$, and the exchange rate $\left(\epsilon_{t}\right.$, expressed as local currency units per United States [US] dollar): 28

$$
\begin{aligned}
& b_{t}-b_{t-1}=\frac{r_{t}-\pi_{t}\left(1+g_{t}\right)}{\left(1+g_{t}+\pi_{t}+g_{t} \pi_{t}\right)} b_{t-1}-\frac{g_{t}}{\left(1+g_{t}+\pi_{t}+g_{t} \pi_{t}\right)} b_{t-1}+\frac{\epsilon_{t} \alpha_{t}\left(1+r_{t}\right)}{\left(1+g_{t}+\pi_{t}+g_{t} \pi_{t}\right)} b_{t-1}-p s_{t}+Z_{t} \\
& \text { Change in } \quad \text { (primary (other }
\end{aligned}
$$

Other factors with a bearing on the debt ratio but not pertaining to the debt flow dynamics as such are subsumed in vector $Z_{t}$. Included are mainly off-budget 
(also labeled "hidden" or "below-the-line") operations, such as debt repayments out of financial assets, debt relief operations, implicit liabilities that were previously unbudgeted, or the realization of contingent liabilities adding to a country's debt stock (e.g., a government's bail out of the domestic financial sector). For developing countries in particular, hidden liabilities tend to affect the evolution of the debt ratio heavily and unpredictably. ${ }^{29}$

To provide an overview of IMF-type DSA projection for developing Asia, equation (3.5) is applied to the sample of 24 Asian economies. Average debt ratio projections are summarized in Figure 3.9, for the five subregions and an additional aggregate of seven Asian economies: the PRC, India, Indonesia, the Republic of Korea, Malaysia, the Philippines, and Thailand. ${ }^{30}$

Figure 3.9 shows the evolution of the subregional average debt ratios over historical (2000-10) and projected (2011-16) time periods. Projections are based on the latest ADB and IMF country forecasts of primary fiscal deficits and the rates of economic growth, interest, and inflation, as well as of exchange rates to the US dollar. ${ }^{31}$ Appendix 3.5 lists the average forecast assumptions underlying the 2011-16 baseline projection, as well as historical averages for 2000-10. With few exceptions, the macroeconomic forecast assumptions are roughly in line with 2000-10 historical averages. The outlook for economic growth in the region is thus strongly positive, combined with the expectation of continuing negative real interest rates and moderate inflation pressures in most of the subregions. The assumptions for fiscal policy in the region are somewhat less sanguine, with primary deficits expected to widen slightly in all the subregions except East Asia, which is expected to return to a sizeable surplus during 2011-16.

Based on these assumptions, baseline debt ratio projections are derived and are shown as dashed lines in Figure 3.9. Baseline projections show a declining debt ratio for each subregion, which supports the view that, by and large, public debt is on a firm path of continued consolidation across developing Asia. Notwithstanding the GFC and the region's fiscal response to it, public debt sustainability would not appear to be at risk against the prospects of the region's macroeconomic and fiscal performance during the 5-year horizon, 2011-16. Clearly, average subregional baseline projections do not necessarily reflect how individual economies will fare, and they do not preclude that debt sustainability may very well be at risk in some instances. Moreover, as baselines are premised on the persistence of substantial negative IRGDs, this raises caveats similar to those mentioned in relation to the foregoing DSPB analysis, because nothing in the underlying DSA assumptions would rule out the possibility of a sudden, unexpected narrowing or even reversal of the IRGDs. However, these caveats do not invalidate the main thrust of the DSA analysis illustrated in Figure 3.8, which yields an overly benign outlook about the medium-term fiscal dynamics in the region.

Figure 3.10 reveals the main drivers of the debt ratio in each subregion during 2000-10. The effects on the debt ratio of the primary balance, the real interest rate, the growth rate of real GDP, and the exchange rate are displayed. The percentage change in the debt ratio accounted for by each of these items is measured on the 

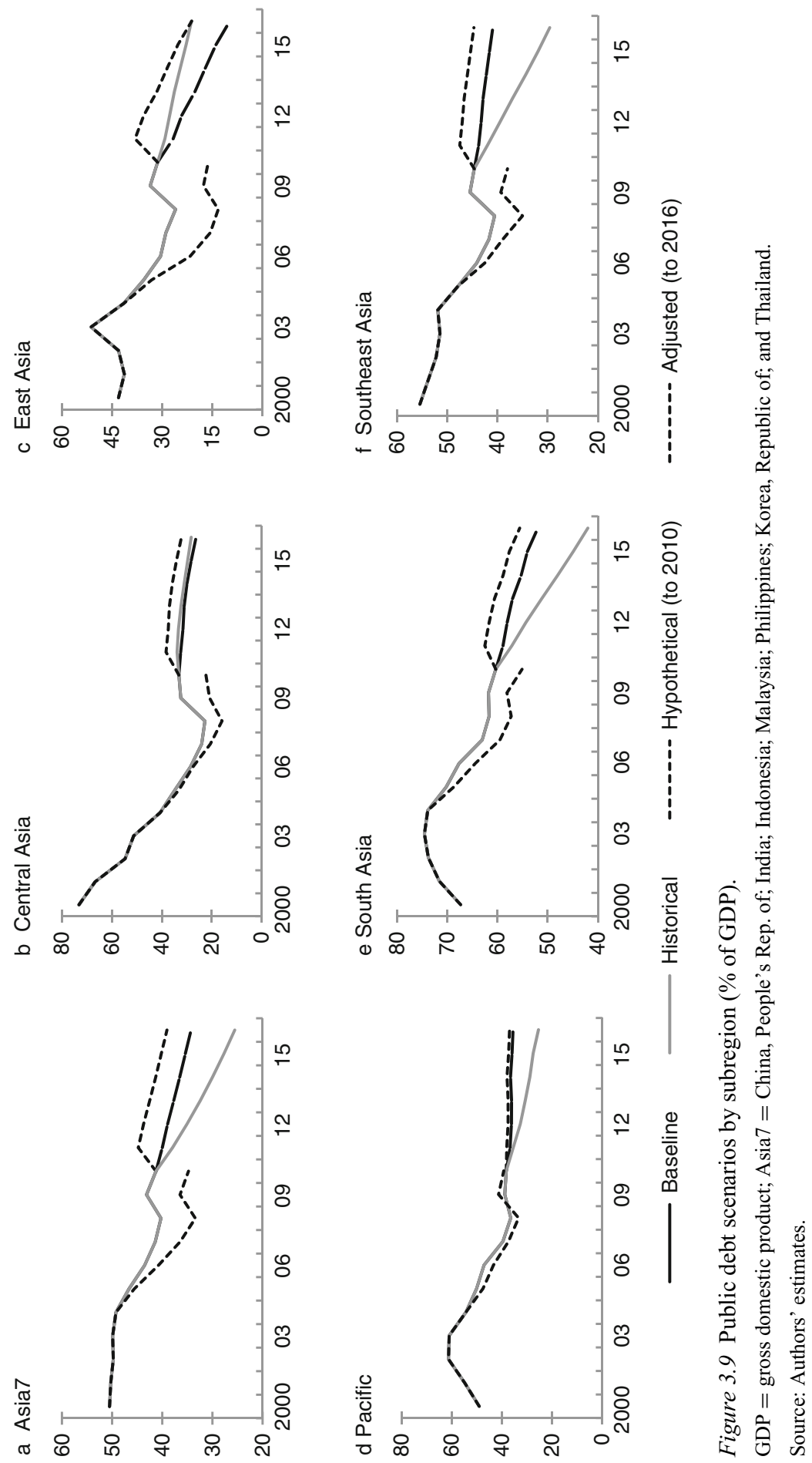


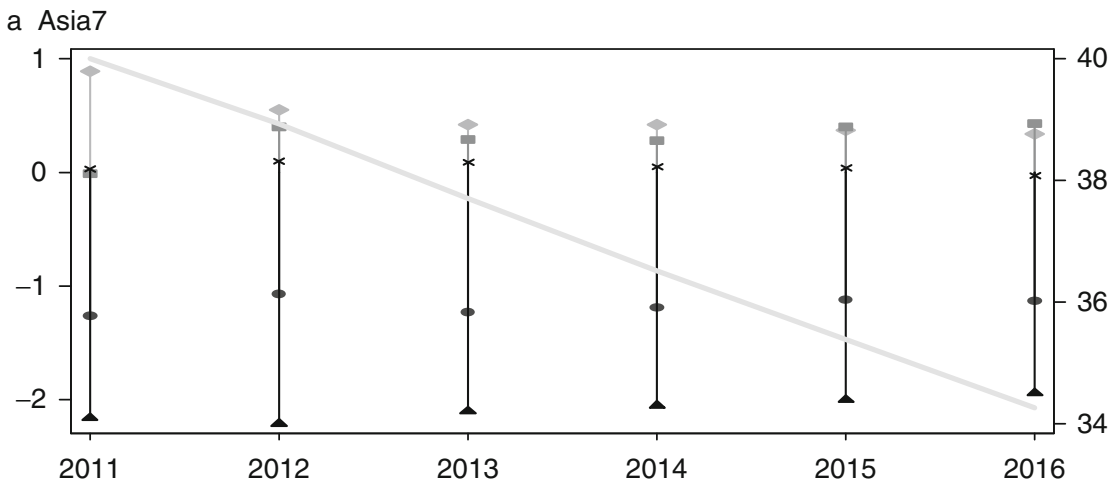

b Central Asia

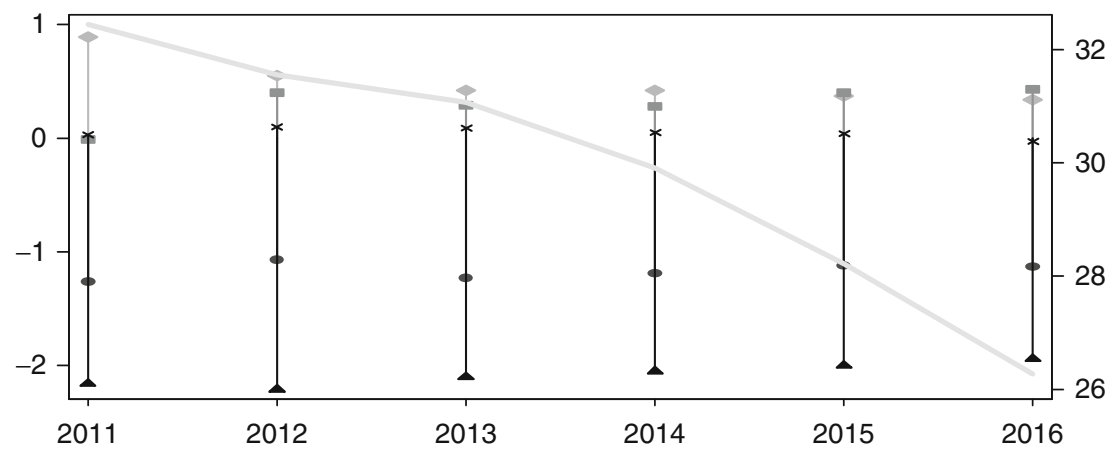

c East Asia

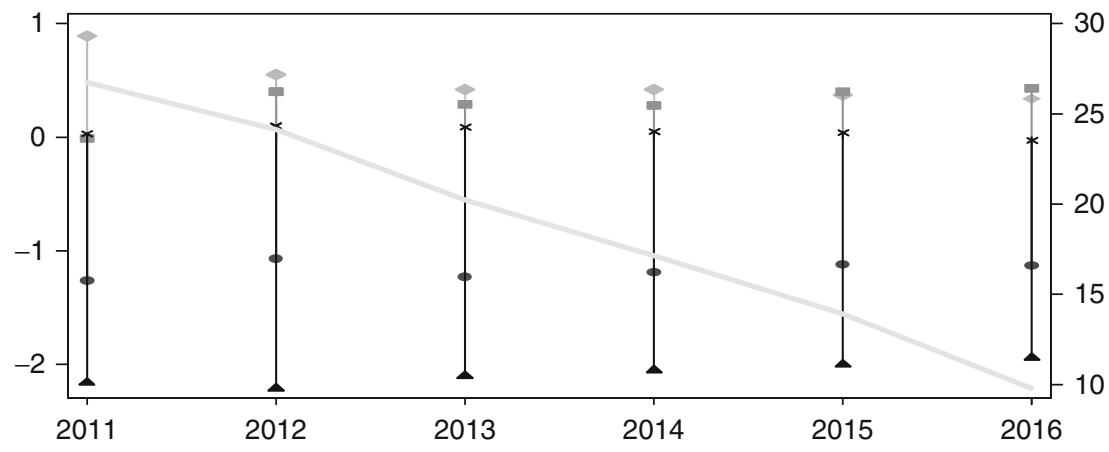

Figure 3.10 (Continued) 
d Pacific

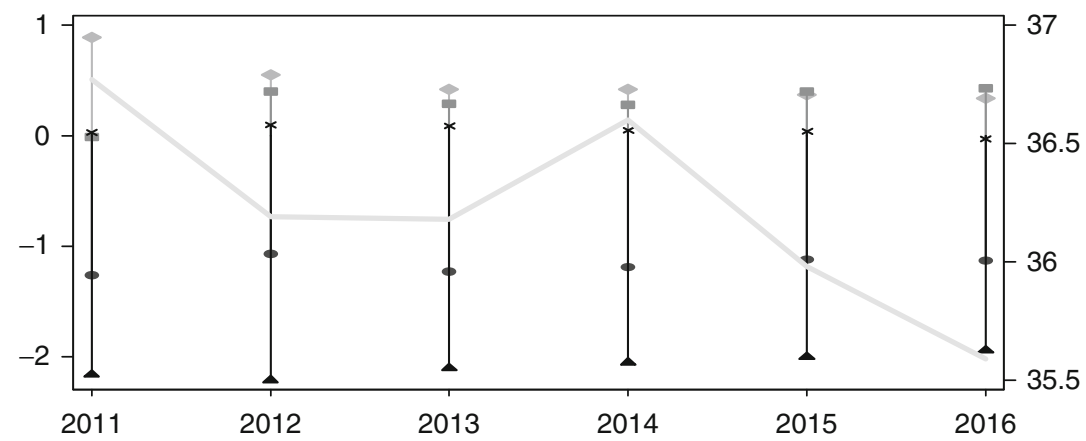

e South Asia

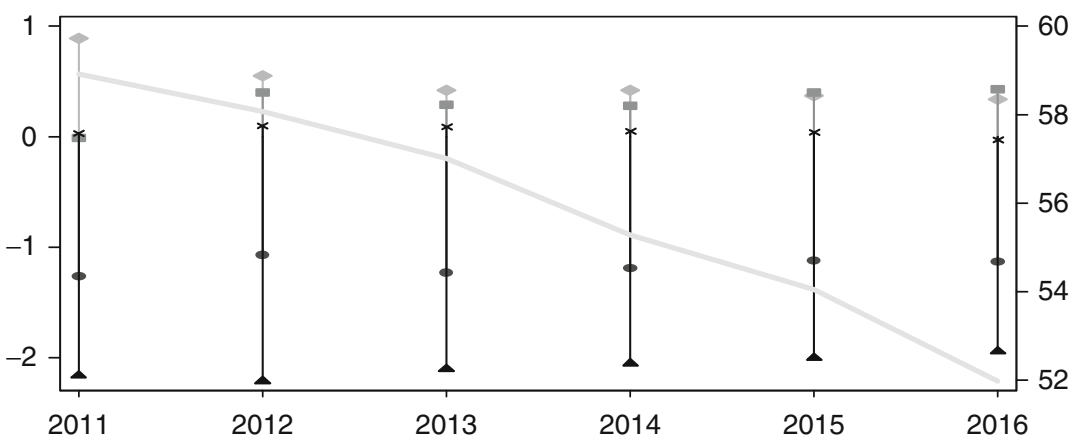

f Southeast Asia

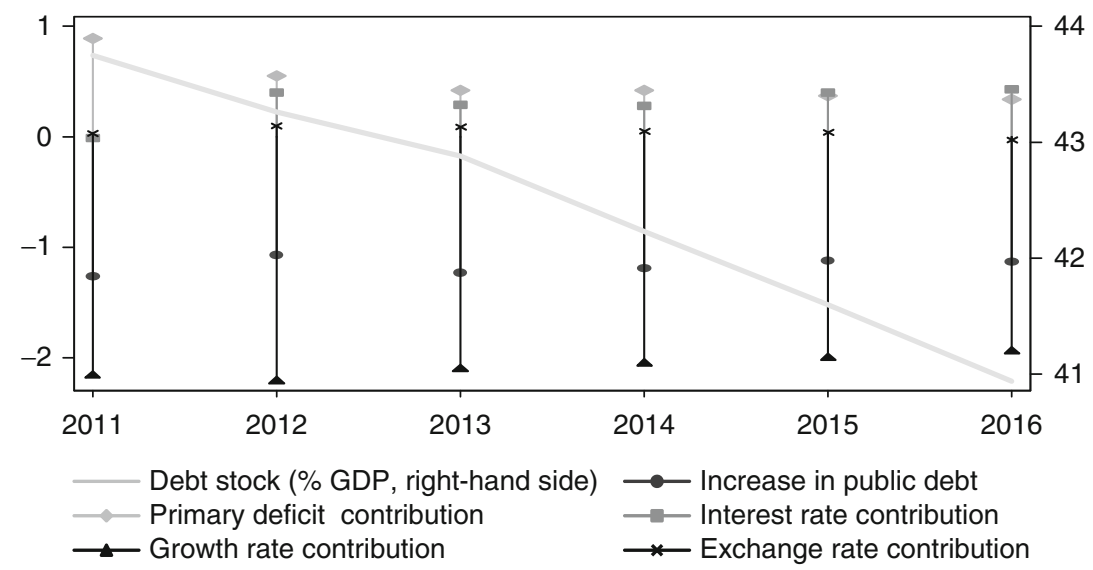

Figure 3.10 Contributions to change in public debt in developing Asia (average \%).

$\mathrm{GDP}=$ gross domestic product; Asia7 $=$ China, People's Rep. of; India; Indonesia; Malaysia; Philippines; Korea, Republic of; and Thailand.

Source: Authors' estimates. 
right-hand side axis by the vertical distance from the zero line of the corresponding marker. Drop lines below (above) the zero line correspond to effects that lower (increase) the debt ratio. The debt/GDP ratio is shown as a line on the graphs, measured on the right-hand side axis. By and large, the evidence emerging from Figure 3.10 is that each subregion's favorable debt dynamics are strongly centered on the assumption of low real interest and high growth rates, which erode debt ratios and more than outweigh the increase in debt from the accumulation of primary deficits and adverse exchange rate developments. Exceptions to this pattern are the aggregate of seven economies (Figure 3.10a), where positive average real interest rates are expected to push up the debt ratio, and the East Asia subregion (Figure 3.10c), where fiscal surpluses are assumed to lower the debt ratio during the projection period.

DSA projections are often accused of erring on the side of optimism regarding the underlying macroeconomic forecast assumptions. ${ }^{32}$ To check the realism of the baseline projections, Figure 3.9 includes a historical scenario (shown as a light gray line) that projects debt ratios with key variables kept at their 200010 historical averages, instead of reflecting the baseline assumptions. A visual comparison between the historical scenario and the baseline indeed suggests that the macroeconomic and fiscal forecasts for East Asian economies on average are more optimistic than what historical records would merit. The opposite appears to be the case for the other subregions, and for Central Asia the two scenarios mostly overlap. By and large, the optimistic outlook for debt sustainability in developing Asia is not premised on overly optimistic assumptions when measured against the region's historical record of macroeconomic and fiscal performance. Of course, past experience is not necessarily a valid guide for expectations about the future, and the baseline assumptions underlying Figure 3.9 may well not be substantiated in the future.

DSA analysis only captures changes to the ratio that are accounted for by the debt-creating flows identified in equation (3.5) and typically does not account for hidden liabilities or other debt/flow reconciliations that are subsumed in factor $Z_{t}$, unless they are explicitly foreseen and accounted for. ${ }^{33}$ The greater these factors' influence on the debt ratio, the less will be the DSA's capacity to correctly project the debt ratio, even if the DSA's other underlying assumptions are accurate. To take this into account, the DSA in Figure 3.9 first computes the hypothetical evolution of the debt ratio during 2004 and 2010, according to the observed primary deficits, interest rate, inflation rate, growth rate, and exchange rate records. In any given year from 2004 to 2010, the vertical distance between the hypothetical debt ratio (shown as a dotted line) and the actual debt ratio thus provides a measure of the factors left unaccounted for by the DSA. ${ }^{34}$ This measure is then added to the baseline from 2011 to 2016, to revise the projection by an amount equal to the average yearly "accounting error" in the previous five years, reversed in sign. In Figure 3.9, the corrected baseline is displayed as a dotted line between 2010 and 2016. Although the baseline correction serves merely an illustrative purpose, it puts into perspective the size of the average margin of inaccuracy in the baseline projections on account of $Z_{t}$. 
Apart from changes to the debt ratio on account of factors that are beyond the debt dynamics accounted for by DSA, there is of course the possibility of shocks to the variables underlying those dynamics. In large part, DSA consists in assessing the likely impact of adverse shocks on the debt path and in judging a country's attainment of debt sustainability after the occurrence of any such shocks. Whereas the standard DSA framework assesses risks around the baseline through deterministic sensitivity analysis involving simple stress tests, a more sophisticated approach involves stochastic simulations that more fully capture the uncertainty surrounding the baseline scenario. These two approaches are discussed in the next section, with application to DSA specifically for selected countries in the region.

\section{Assessing the impact of shocks in the deterministic and stochastic debt sustainability analysis frameworks}

In the standard DSA framework, the impact of specific shocks to key variables underlying the debt dynamics is assessed through so-called "bound" or stress tests. Leaving all the other variables underlying the baseline unchanged, a typical stress test would thus envisage raising by 1 standard deviation above the historical level a country's interest rate, growth rate, or both, in order to ascertain whether this would significantly alter the debt trajectory and the conclusions on the country's debt. The main advantage of stress tests within standard DSA is that they offer a streamlined approach that has a relatively straightforward interpretation and is largely undemanding regarding the data input for analysis. The main disadvantage is that the approach does not take into account the interaction among economic variables. For example, a shock to the exchange rate is assumed to have no effect on output or the interest rate. Further, the approach is unsuitable to account for so-called "tail risks" (risks related to less likely but extreme events), which constitute the main risk factor for debt sustainability.

Recent studies, mostly by IMF staff, have devised stochastic simulation methods to improve estimates of uncertainty about the realization of debt projections within a framework that allows for combined shocks to and feedback among interacting economic variables. Essentially, the stochastic DSA framework consists in a combination of vector autoregression analysis, to estimate the correlation structure of the key macroeconomic variables with a bearing on public debt dynamics, and Monte Carlo analysis to randomly generate frequency distributions of the debt ratio for each year of a projection. In contrast to the deterministic version of stress testing, which merely effects a shift in the debt ratio as any one variable is shocked, the stochastic DSA yields a fan-chart enclosing a range of possible debt projections associated with narrowing levels of likelihood of occurrence.

This section compares standard deterministic with stochastic DSA based on applications with regard to the eight Asian economies listed in Table 3.3. Economies were chosen in order to represent each Asian subregion, within the given constraints of availability of high-frequency data for stochastic simulation. 
Table 3.3 Fiscal characteristics of economies selected for debt sustainability analysis

\begin{tabular}{lll}
\hline $\begin{array}{l}\text { Condition of primary } \\
\text { balance (2011-16) }\end{array}$ & \multicolumn{2}{l}{ Share of foreign currency denominated public debt } \\
\cline { 2 - 3 } & Low & High \\
\hline In deficit & India & Viet Nam \\
Relatively balanced & Chailand & Georgia \\
In surplus & Korea, Rep. of & $\begin{array}{l}\text { Indonesia } \\
\text { Philippines }\end{array}$ \\
\hline
\end{tabular}

Source: Authors' estimates.

This excludes from analysis the countries of the Pacific region. Within the remaining groups, the selected economies reflect different characteristics regarding their fiscal stance and the incidence of foreign currency denominated debt, in order to illustrate a broad range of sensitivities to the scenarios of fiscal and exchange rate shocks in the analysis that follows.

\section{Standard debt sustainability analysis stress tests}

Figure 3.11 shows standard DSA debt ratio projections for each economy in Table 3.3 during 2011-16. Baseline projections reflect the same ADB and IMF macroeconomic country forecasts and fiscal policy assumptions underlying the analysis in the foregoing section and, as before, the historical scenario holds the key macroeconomic variables at their historical 10 -year averages when projecting the debt ratio. A largely benign picture of debt sustainability in the eight economies emerges from the baseline and historical scenarios, much in line with the discussion of subregional trends in the previous section. Indeed, the baseline debt ratio is expected to decline in all economies but Thailand, where it is projected to increase slightly during the 5-year horizon. With respect to the determinants of the projected debt paths, Figure 3.12 reveals that Thailand's debt ratio is mainly under pressure from the persistence of relatively high primary deficits. From 2013 on, Thailand's deficits are expected to more than outweigh the debt erosion from a favorable real IRGD. But in the other economies, highly negative IRGDs dominate the debt dynamics, causing debt ratios to decline throughout $2011-16 .{ }^{35}$ For India and Viet Nam, in particular, favorable interest and growth rates will be key to keep debt ratios from rising against the backdrop of persistently high primary deficits.

Stress tests in Figure 3.11 reflect the outcome of 1 standard deviation increases of the nominal interest rate or rate of inflation above baseline assumptions. Also shown are stress scenarios in relation to a negative 1 standard deviation shock to the rate of real economic growth or the primary surplus. Finally, a foreign exchange rate shock envisages a $20 \%$ nominal depreciation of the domestic currency against the US dollar. Each shock is introduced individually to the DSAs in Figure 3.11, 
that is, affecting one variable at a time while the other variables remain unchanged with respect to the baseline assumptions.

By and large, the evidence from the stress tests is that shocks to output or the nominal interest rate do not alter debt paths significantly in most of the economies. Debt ratios are shifted up slightly as a result of narrowing IRGDs as a result of these shocks, but are not large enough to seriously interfere with the downward sloping trend. ${ }^{36}$ Exceptions are Georgia and Thailand, where debt ratios increase significantly in reaction to a negative output shock.

An increase in inflation generally drives debt ratios down (Figure 3.11), as it reduces the nominal value of outstanding debt. Debt ratio projections appear to be most sensitive to a 1 standard deviation increase in primary deficits. In such a scenario, the debt ratio increases drastically, particularly in countries with relatively higher deficits: Georgia, India, and Thailand. Finally, the effect of a $20 \%$ (permanent) exchange rate depreciation severely jeopardizes public debt sustainability in countries holding high shares of foreign currency denominated debt, such as Georgia and Viet Nam.

In sum, standard stress tests identify some of these economy's vulnerabilities and provide some measures of the direct impact on the debt ratio of some shocks, both of which are useful for DSA and for fiscal planning. However, this framework is largely unsuitable for assessing the fuller impact of shocks on the debt path through economy-wide effects. For example, a shock increasing the interest rate paid on public debt will affect the debt ratio directly by increasing the fiscal expense for the interest bill, and indirectly by inducing a real exchange rate appreciation, deflationary pressures, or slowing growth. The net impact on the debt ratio of the initial shock will depend on a country's specific economic environment and the elasticities involved, but it is likely to diverge strongly from the direct impact on the interest bill alone.

\section{Stochastic simulations}

The shortcomings of simple stress testing are partly overcome in the stochastic approach to DSA, which estimates the correlation pattern among the key macroeconomic variables to account for the basic feedback mechanism and to reflect the uncertainty surrounding baseline debt projections. Essentially, stochastic DSA relies on the estimation of a vector autoregression that captures the correlation pattern of the (nonfiscal) macroeconomic variables underlying the evolution of the debt ratio. This information is then used to implement Monte Carlo simulations. In contrast to the simple stress tests performed in the deterministic version of DSA, the stochastic approach to DSA randomly generates a large sample of stress tests from which frequency distributions of the debt ratio can be derived for each year of the projection. These are then laid out like a fan around the median projection, permitting a probabilistic assessment of sustainability. ${ }^{37}$ (Appendixes 3.6 and 3.7 discuss the data and technical issues related to stochastic DSA.) 


\section{B. Ferrarini and A. Ramayandi}

a China, People's Rep. of

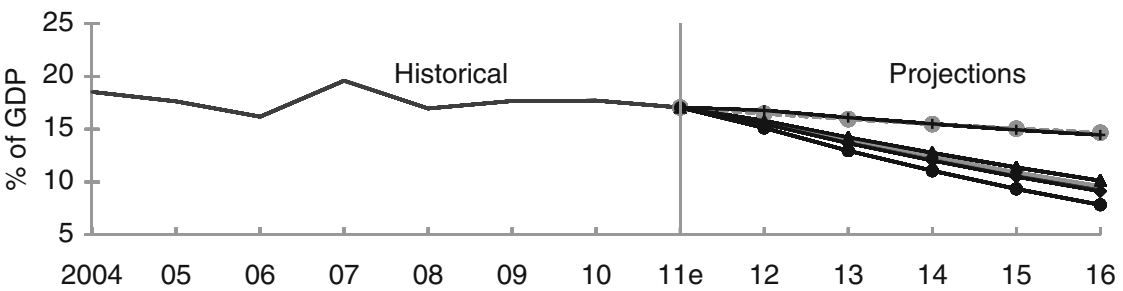

b Georgia
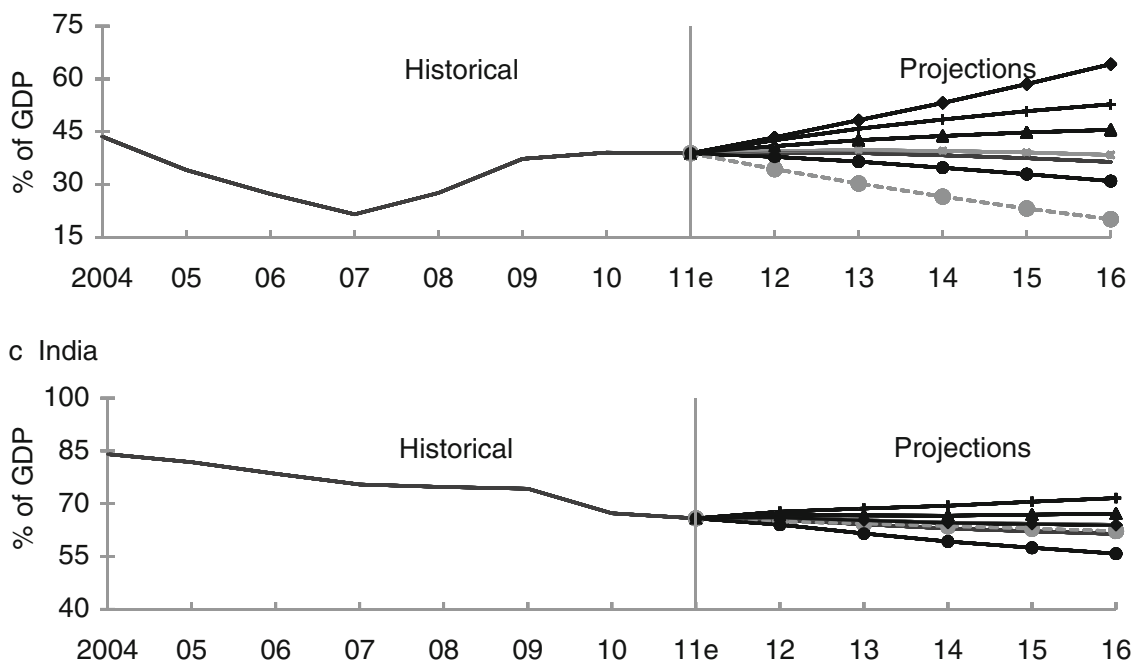

d Indonesia

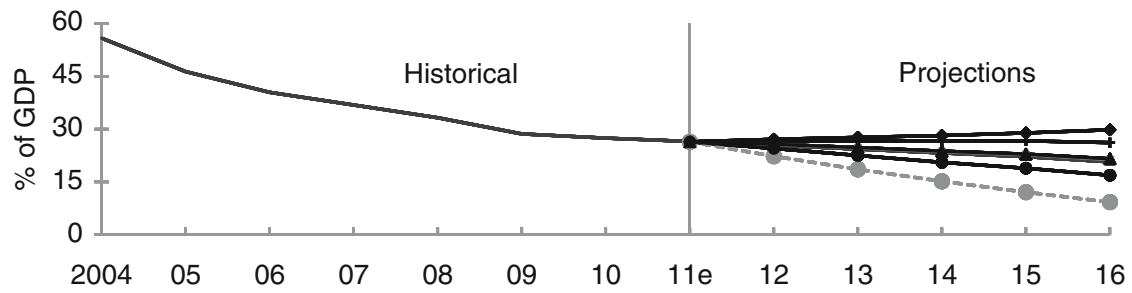

Figure 3.11 (Continued) 
e Korea, Rep. of

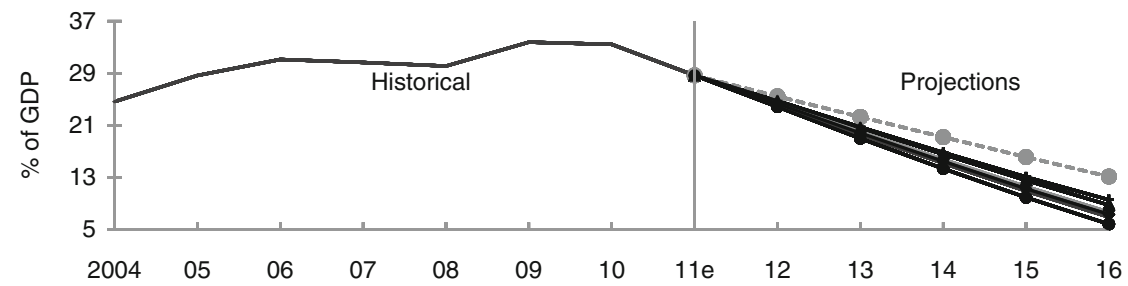

f Philippines

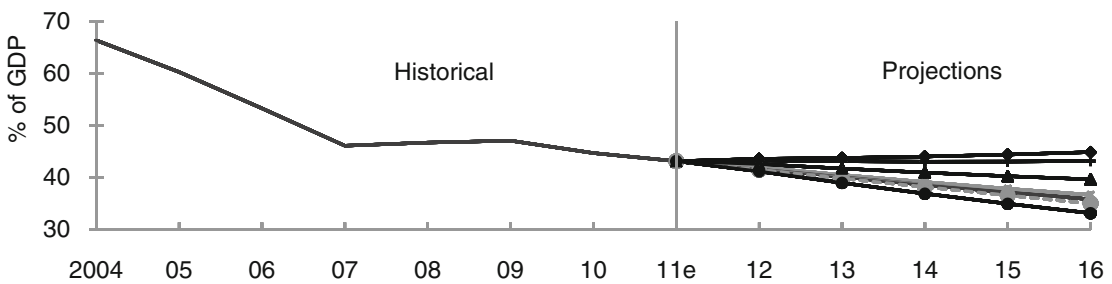

g Thailand

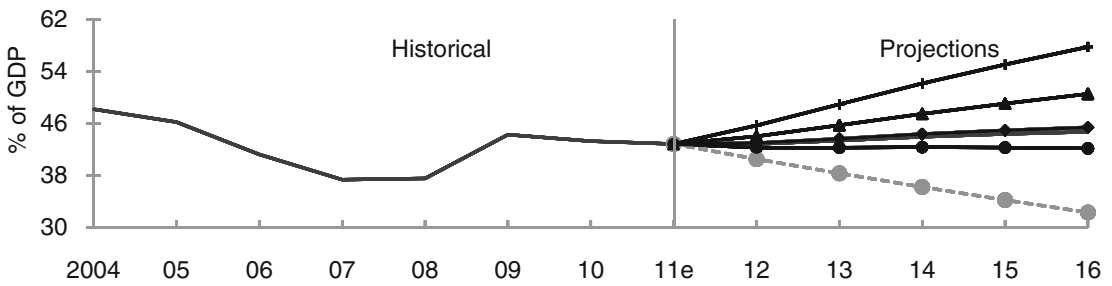

h Viet Nam

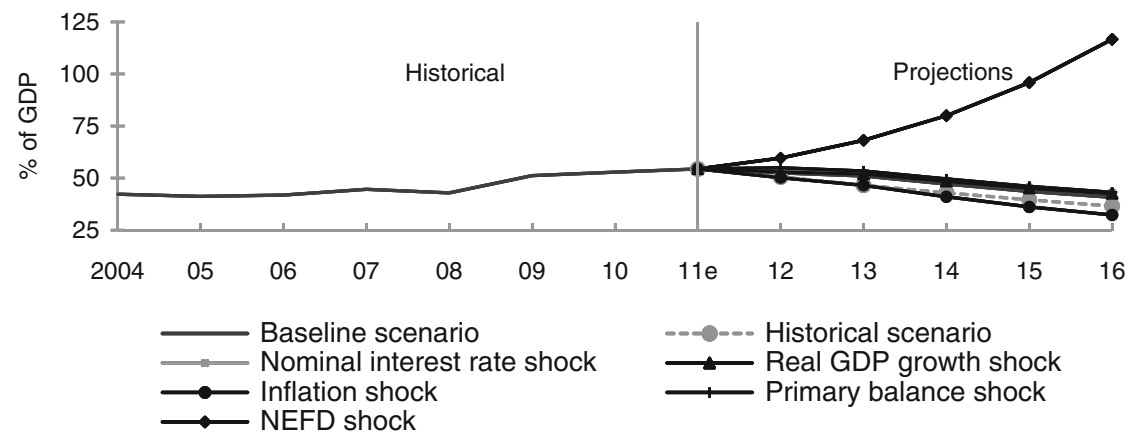

Figure 3.11 The deterministic approach to debt sustainability analysis.

$\mathrm{e}=$ estimate, $\mathrm{GDP}=$ gross domestic product, $\mathrm{NEFD}=$ nominal exchange rate depreciation.

Sources: Asian Development Outlook database; International Monetary Fund. World Economic Outlook database, Article IV Debt Sustainability Assessments and Fiscal Monitor, various years. 
a China, People's Republic of

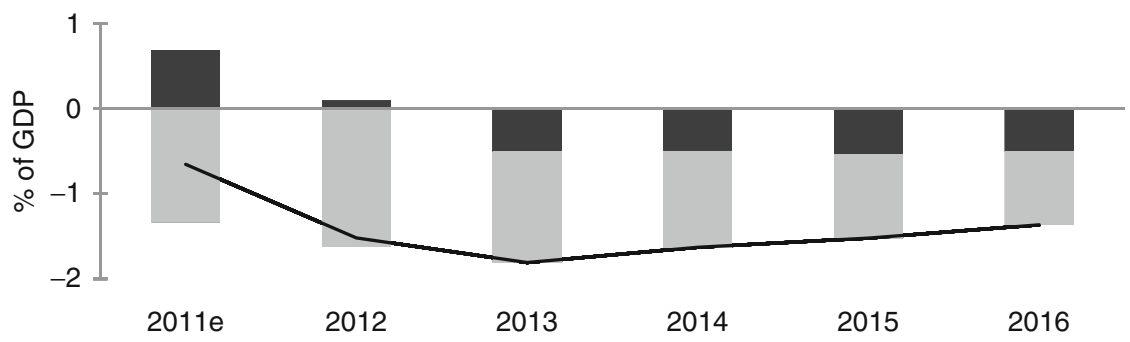

b Georgia
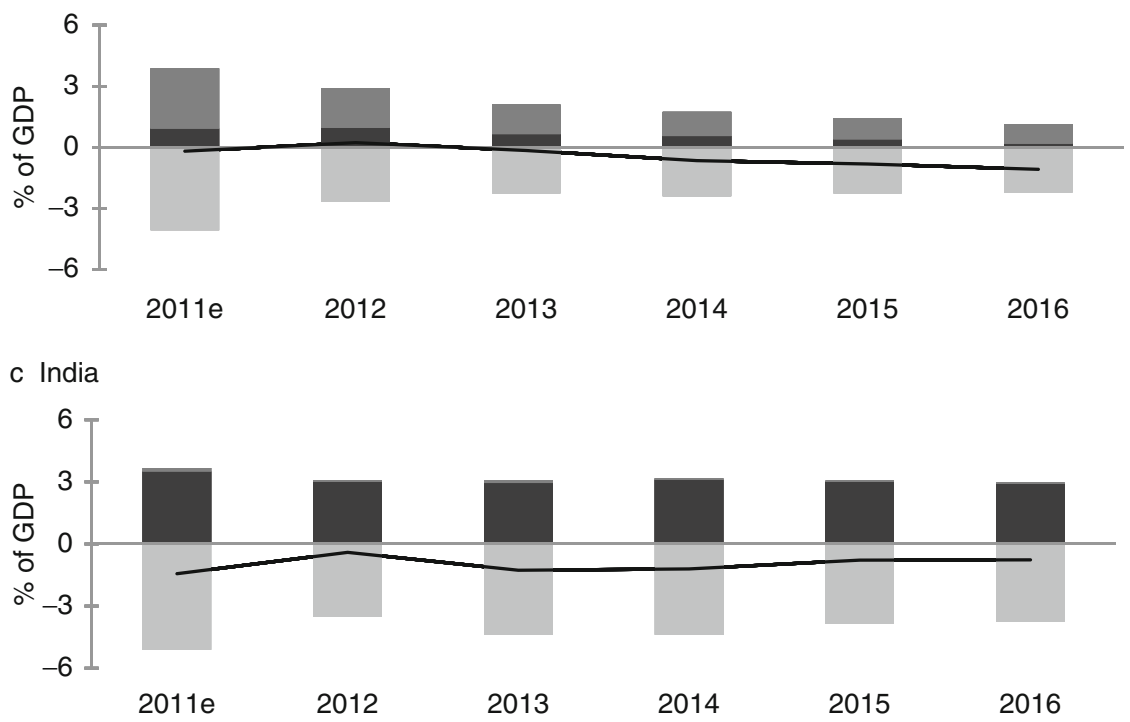

d Indonesia

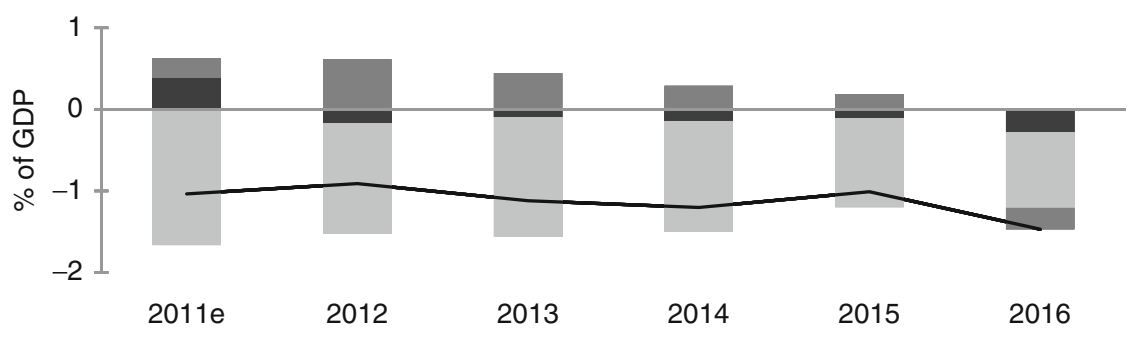

Figure 3.12 (Continued) 
e Korea, Republic of

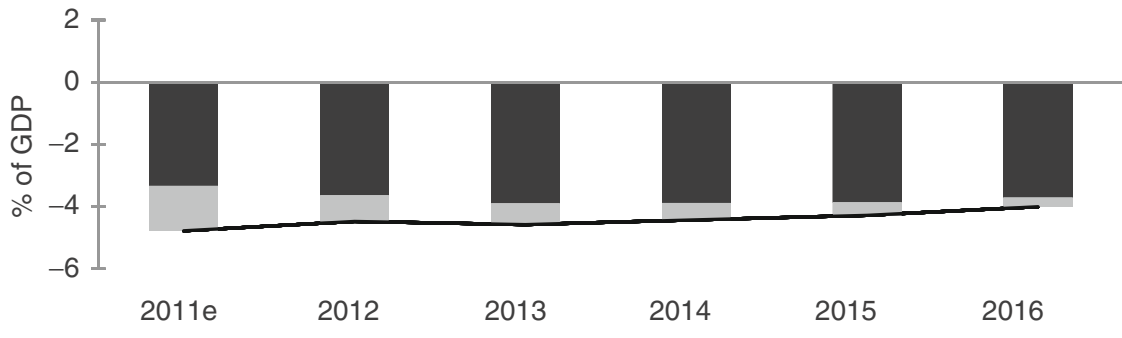

f Philippines

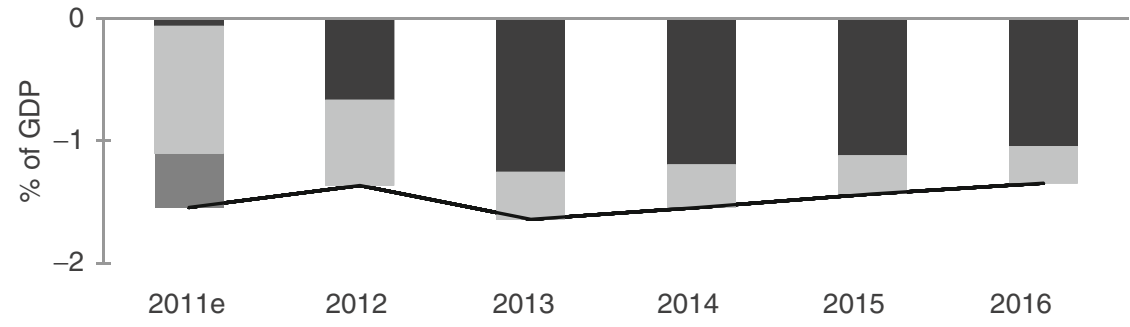

g Thailand

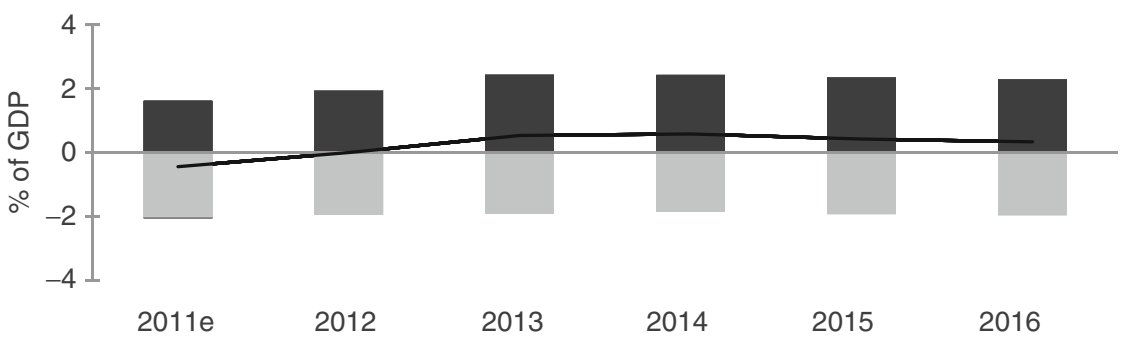

h Viet Nam

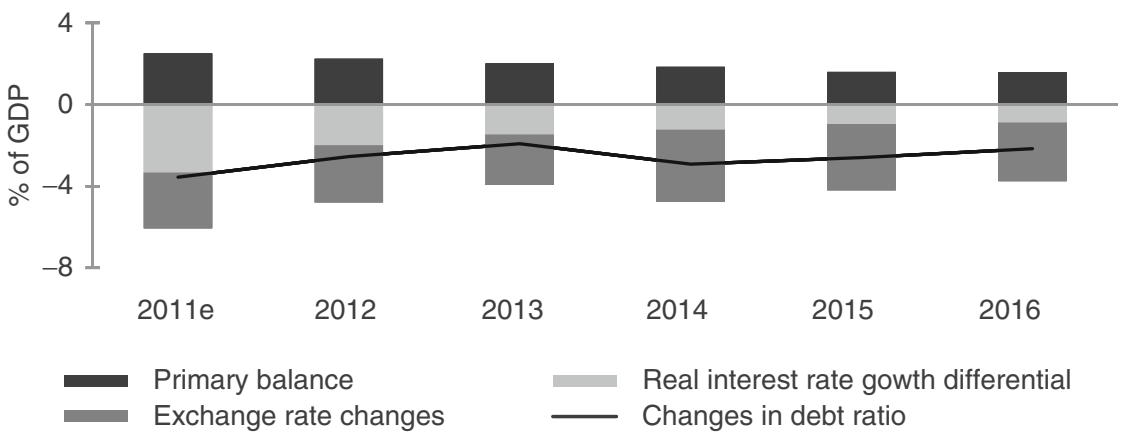

Figure 3.12 Annual changes in the central government debt ratios, 2011-16.

$\mathrm{e}=$ estimate, $\mathrm{GDP}=$ gross domestic product.

Note: Effect of interest rate-growth differential is computed as the difference between the effects of real interest rate and real GDP growth.

Source: Authors' estimates. 
a China, People's Republic of: Assumption-small deficits in the beginning followed by small surpluses towards the end

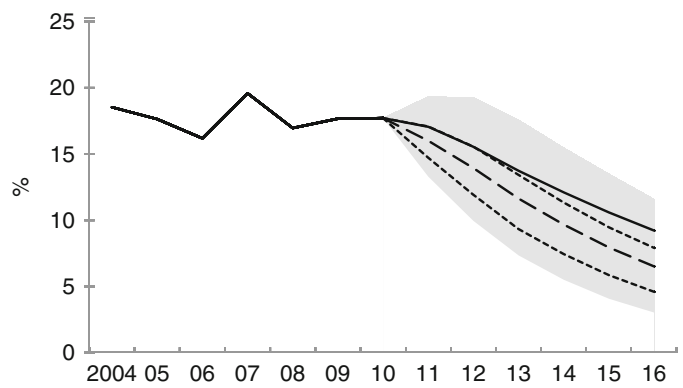

b Georgia: Assumption-running relatively small deficits

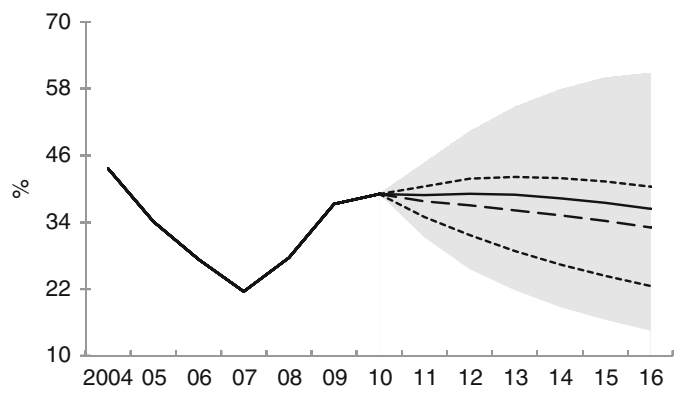

c India: Assumption-running budget deficits

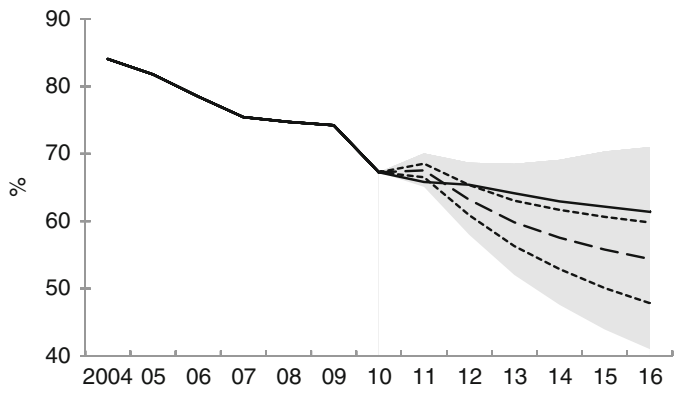

d Indonesia: Assumption-near balanced primary budget with small surpluses

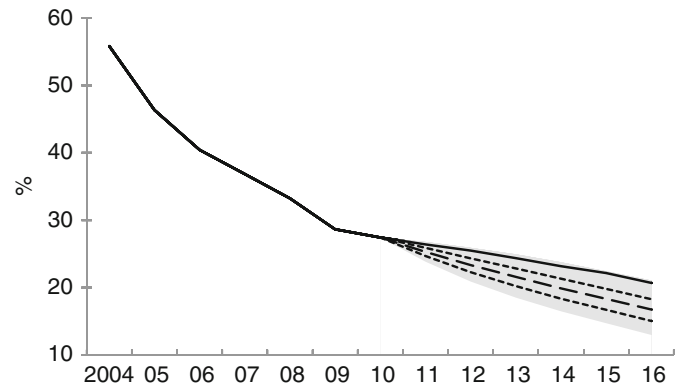

Figure 3.13 (Continued) 
e Korea, Rep. of: Assumption-running primary surpluses

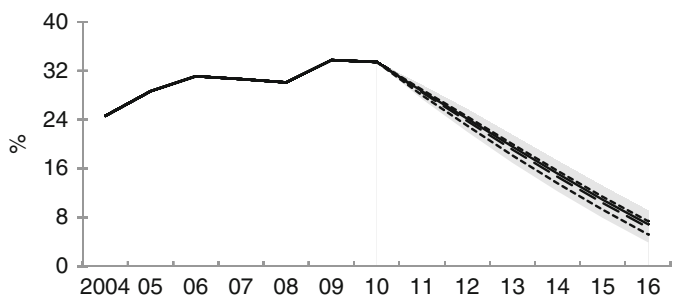

f Philippines: Assumption-running primary surpluses

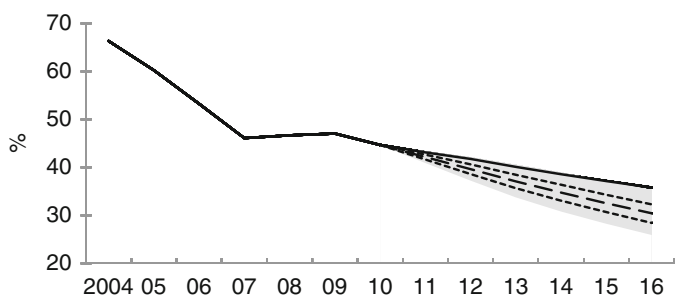

g Thailand: Assumption-running budget deficits

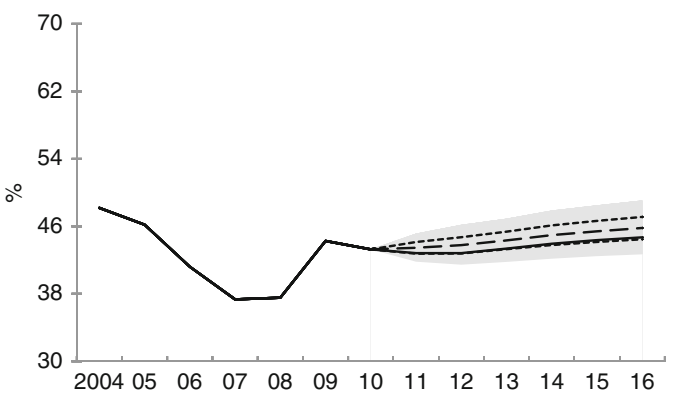

h Viet Nam: Assumption-running primary deficits

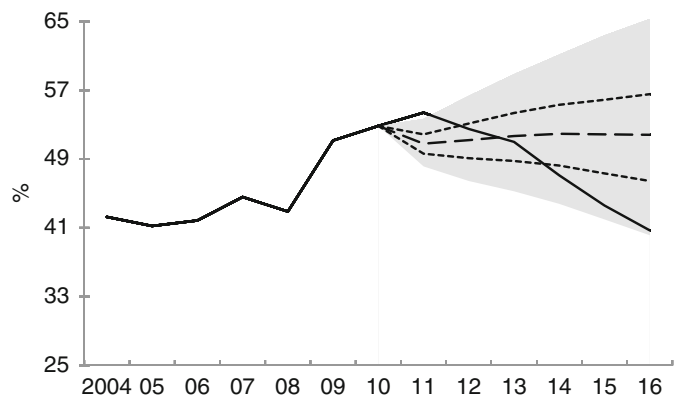

area between the 5 th and 95th percentiles DSA projection

....... limits of the area between the 25th and 75th percentiles - - - Median

Figure 3.13 Stochastic approach to debt sustainability analysis (\% of GDP). $\mathrm{DSA}=$ debt sustainability analysis, GDP $=$ gross domestic product.

Source: Authors' estimates. 
Stochastic DSA simulations for the eight Asian countries in this section are based on quarterly data on real growth $\left(g_{t}\right)$, inflation $\left(\pi_{t}\right)$, the exchange rate $\left(\epsilon_{t}\right)$, and the nominal interest rate $\left(r_{t}\right)$. A four-variable unrestricted vector autoregression system is estimated for each economy, to produce a variancecovariance matrix $(\Omega)$ of the residuals $\left(v_{t}\right)$ :

$$
[I-A(L)] X_{t}=v_{t} ; v_{t} \sim N(0, \Omega)
$$

where $X_{t}=\left[\pi_{t}, \epsilon_{t}, r_{t}, g_{t}\right]$ is the variable matrix, $I$ is an identity vector, $A(L)$ is a vector of lag operators, $v_{t}$ is a vector of residuals that is normally distributed $[N()$.$] with mean 0$ and variance $\Omega$. For each economy and year during 2011-16, a probability distribution is generated from 10,000 random draws on the innovations to each of the variables in $X_{t}$, in correspondence with the variance-covariance structure determined by $\Omega$ and by taking fourth-quarter 2010 data as the initial values.

To derive fan-charts for the DSA, the quarterly frequency distributions in relation to the system of macroeconomic variables are first annualized and then combined with the baseline fiscal policy assumptions to yield yearly frequency distributions of the simulated debt ratio projections. The resulting fan-charts are shown in Figure 3.13 (see pp. 80-81), for each of the eight economies. Both 50\% and $90 \%$ confidence intervals are displayed about the median of the projected government debt ratio. For example, India's median debt ratio is projected to decline to about $54 \%$ in 2016 , down from $67 \%$ in 2010 . However, the $90 \%$ confidence interval marked by the graph's shaded area suggests a $10 \%$ combined probability that India's debt ratio by 2016 will either have climbed to $71 \%$ or plunged as low as $41 \%$ of GDP. Put differently, the broad range of possible outcomes suggests that India's estimated macroeconomic historical record gives rise to a significant degree of uncertainty about whether the variables driving its debt dynamics will eventuate. Indeed, the range of outcomes within the $90 \%$ interval is such that an increase in India's debt ratio during 2010-16 could not be excluded entirely. Other country fan-charts suggest that the same is true also for Georgia, Thailand, and Viet Nam.

In terms of the sign of the projected changes in public debt ratios, the stochastic projections broadly validate the realism of a country's nonstochastic baseline assumptions. (Baselines are shown as solid lines in Figure 3.13.) Indeed, median stochastic debt paths and baselines mostly point in the same direction, which would lead to roughly similar conclusions at least regarding the fundamental judgment of a country's debt sustainability. The only exception is Viet Nam, which displays a baseline projection that slopes downward and a median stochastic projection that slopes upward. Although the baseline falls well within the shaded area and is thus consistent with the $90 \%$ confidence interval of the stochastic distribution, the standard DSA for Viet Nam appears to rest on overly optimistic assumptions regarding its future economic development. From 2012 on, the fan-chart attributes less than a $25 \%$ probability that the assumptions underlying Viet Nam's baseline will be realized. By contrast, baseline assumptions appear pessimistic for the PRC, 
India, Indonesia, and the Philippines, which are closely within the upper edge of the confidence interval. The implications for the four economies' fiscal plans are that they should strengthen their fiscal positions in order to account for a macroeconomic environment that may fall short of expectations.

The fan-charts are also useful for assessing the degree of association between central government debt dynamics and changes in the structural feature of the economy, such as medium- to long-term changes in the fiscal policy stance. Figure 3.14 illustrates this point by imposing primary budget balance throughout the projection period - that is, forcing more stringent fiscal discipline on economies' running primary deficits (e.g., India and Viet Nam), and relaxing the fiscal position of economies with primary surpluses (such as the Republic of Korea and the Philippines).

More fiscal discipline in India significantly changes the prospects of its mediumterm debt dynamics. With increased fiscal discipline, the path of India's debt ratio is likely to be brought down consistently from 2012 to 2016 for any possible realization of the underlying macroeconomic variables within the horizon. The case of Viet Nam also shows that more stringent fiscal discipline is required to drive down the debt path, suggesting that the country needs more budgetary discipline in order to lower its government debt ratio. The exercise on the Republic of Korea strongly suggests that the decline in its debt path hinges heavily on its ability to realize the projected primary surplus assumed in its baseline. ${ }^{38}$ A more relaxed budgetary position would derail the country's attempt to sharply reduce its central government debt ratio. The Philippine case, on the other hand, suggests that the country still has room to increase its central government spending, as a more relaxed primary budget position does not seem to alter the country's target for reducing its debt ratio in the medium term.

In sum, stochastic DSA analysis broadly confirms the conclusions based on standard DSA in the preceding section. The outlook for debt dynamics in developing Asia is mostly benign, and among the economies considered in this section there is no evidence of debt ratios that suggest a clear danger of spinning out of control during the horizon of projection. This is not, however, reason for complacency. Stochastic DSA highlights quite clearly that the spectrum of possible or indeed likely outcomes is substantially broader than what simple baseline analysis and related stress tests show. Indeed, even within the small sample of eight economies considered in this section, fan-charts include instances where an increase of the debt ratio is fully plausible on the basis of the underlying macroeconomic forecasts and fiscal policy assumptions.

\section{Conclusion}

This chapter reviews the historical development of fiscal indicators in developing Asia since the early 1990s and analyzes the main factors that will determine the region's fiscal performance during the next few years, up to 2016. The chapter has attested to a pattern of fiscal responsibility among the economies in the region. Regression analysis estimating fiscal reaction functions for a sample of 


\section{B. Ferrarini and A. Ramayandi}

a Korea, Republic of

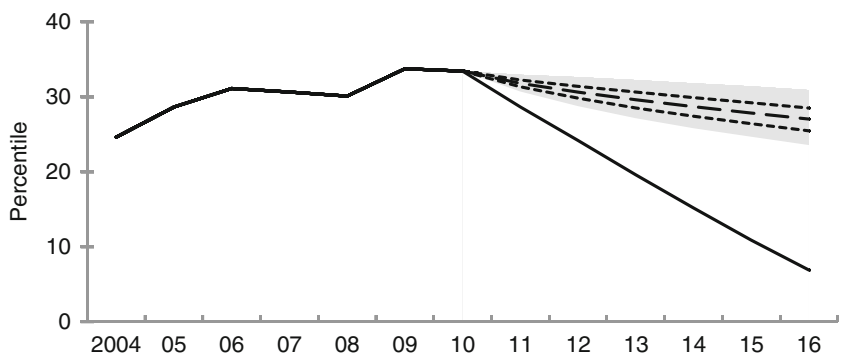

b India

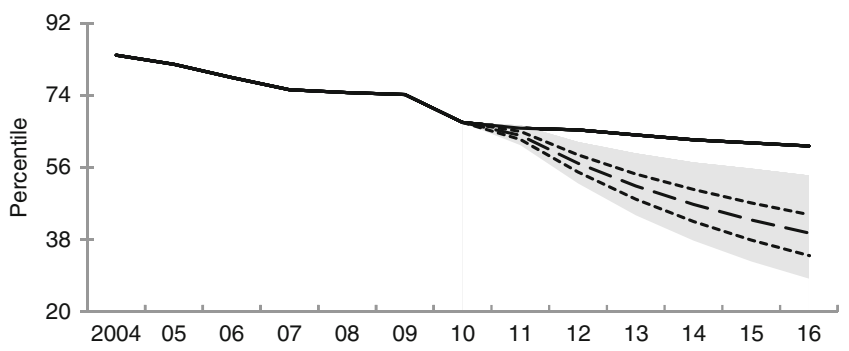

c Philippines

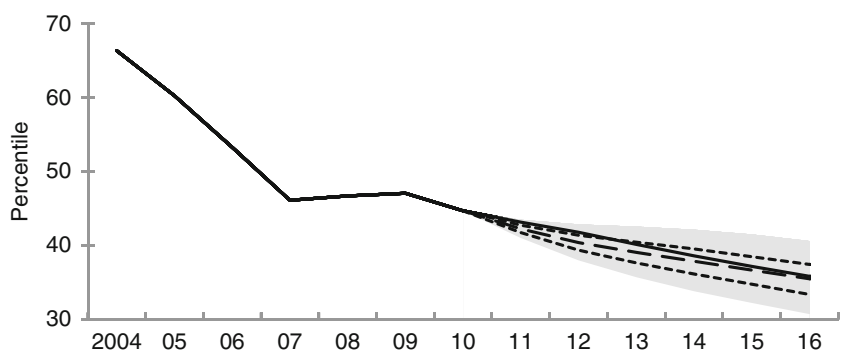

d Viet Nam

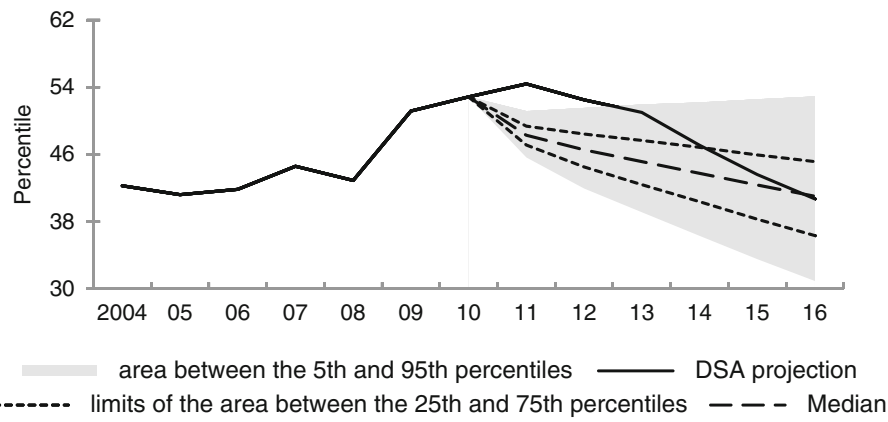

Figure 3.14 Stochastic approach to debt sustainability analysis - primary budget balanced. $\mathrm{DSA}=$ debt sustainability analysis, GDP $=$ gross domestic product.

Source: Authors' estimates. 
24 economies confirms previous findings about governments' tendency to tighten fiscal policy to counter rising debt ratios. This display of prudence has served Asia well by keeping debt ratios under control, which constitutes the most fundamental of determinants to ensure debt sustainability in the region over the longer termassuming this prudence persists despite the profound social and economic changes Asia is undergoing.

The analysis has also highlighted the profound benefits economies in the region derive from having relied on rapid economic growth and low interest rates, which together have tilted the debt dynamics in their favor by exerting a persistent downward pressure on debt ratios. Under such conditions, even a less prudent fiscal stance or the occurrence of occasional shocks increasing debt ratios temporarily are unlikely to overturn the benign outlook on debt sustainability. However, one cannot assume that negative IRGDs will persist for the longer term. IRGDs inevitably will shrink and eventually turn positive as growth in the region will have to slow at some point, and rapid development of the region's economies will have to lead to a gradual easing of the structural constraints and policies that have been keeping domestic interest rates artificially low. Simple graphical simulations of such a narrowing of countries' IRGDs have shown an environment that would be much less forgiving of the conduct of fiscal policy and the absorption of macroeconomic shocks than has hitherto been the case for the region. In such a scenario, Asia's fiscal prudence will have to be the ultimate guarantor of fiscal sustainability, as advanced countries facing positive IRGDs have been witnessing particularly during recent times.

The discussion then moves on to highlight the main elements of IMF-style deterministic DSA analysis, focusing on subregional aggregates rather than individual economies. Based on the latest macroeconomic and fiscal policy forecasts, DSA analysis yields overwhelming evidence of a generally benign outlook for public debt sustainability in the region. All of Asia's subregions (although not necessarily each economy in the subregions) are associated with declining or stable debt paths up to 2016, premised on the assumption of continuing strong growth, low interest rates, moderate inflationary pressures, and the gradual normalization of fiscal policy after regionwide expansion in relation to the 2008/09 GFC.

Finally, the results of standard DSA are compared with stochastic DSA, which more fully accounts for the interrelations among the variables driving debt dynamics and improves the estimates of uncertainty surrounding baseline assumptions. The evidence arising from comparative analysis involving eight economies in the region supports the conclusion that the fiscal outlook for the region is generally benign. More generally, the findings from stochastic DSA broadly align with those of standard DSA, thus validating the baseline assumptions underlying the latter. At the same time, however, the stochastic simulations highlight a large spectrum of likely outcomes regarding the macroeconomic realizations driving debt ratios, not all of which are compatible with stable or declining debt ratios as suggested by the baseline assumptions. The implication for countries with higher risk profiles of public debt is thus to revise fiscal policy 
to be able to accommodate a future macroeconomic environment that may be less favorable than that reflected in the baseline assumptions.

\section{Appendix 3.1: Data issues}

Assessing public finances in the region is a daunting challenge and huge difficulties are encountered in assembling a comprehensive set of fiscal and public debt data for all the developing members of the Asian Development Bank (ADB). To the familiar problems of occasional missing observations over time and across countries are added a number of serious shortcomings in the availability of consistent and comprehensive fiscal data in some countries and, in particular, pertaining to public debt obligations. In addition, only a very limited number of countries publish public sector asset positions (as well as public debt data). Consequently, fiscal sustainability analysis needs, for the most part, to be based on only one part of the fiscal picture (liabilities rather than assets). Even in the case of countries that report interest payments on debt, consistent data are not generally available for the actual interest rates on public debt and the extent to which debt may be serviced at concessional or market interest rates. Moreover, to the extent that some countries issue public debt to "captive" local buyers (such as local banks and pension funds), the true economic costs of servicing that debt may be quite different from the recorded costs.

Another problem is that countries do not generally report contingent and other hidden (off-balance-sheet) liabilities. Based on experience, these are often the key factors in influencing fiscal sustainability over time, and are where the "fiscal surprises" often occur. For example, much of the deterioration in fiscal positions during the Asian financial crisis was associated with bailouts of distressed banks and other financial institutions. The omission of contingent fiscal liabilities implies that the approach adopted arguably represents the "best case" in so far as the accounting for hidden liabilities would likely lead to the possibility of higher rather than lower future debt ratios, and potentially larger threats to fiscal sustainability. (Chapter 4 discusses at length the implications of hidden liabilities for public debt sustainability for the case of the People's Republic of China [PRC]).

At the most fundamental level, there is also the issue of how broadly or narrowly the public sector should be defined. Ideally, fiscal sustainability analysis should cover all aspects of public sector operations and activities that have fiscal implications, suggesting a very broad and comprehensive approach. Such comprehensiveness is probably best achieved by focusing on the overall public sector (including all actual and quasi state-owned enterprises and governmentlinked companies), but it is frequently difficult to draw the line in defining the public sector, and comprehensive data for the entire public sector are frequently difficult to obtain. Even in cases where only the (formal) government sector can be covered, there are often issues related to the availability of data for different levels of government (central, state, and local) and data consistency over time. There are no simple solutions to these and related "boundary" problems in defining the public sector. And, frequently, it is necessary to base the analysis on a "narrow" 
definition of government because data are not available for broader definitions of the public sector.

For the purposes of this chapter, annual data were assembled on government fiscal positions and debt (and other variables) for 45 ADB developing members, from the early 1990s through 2010. The data were assembled from various International Monetary Fund (IMF) country publications and reports, such as IMF Article IV documents and Statistical Appendixes. Where possible, data for the general government were used but, in several cases, central government data had to suffice. Government debt and fiscal time series were integrated with additional data drawn from the IMF Government Finance Statistics database and from national sources. Data coverage varies across countries and spans a maximum of 21 years, 1990-2010. Macroeconomic variables were drawn from the ADB Asian Development Outlook database, the IMF International Financial Statistics, and the World Bank's World Development Indicators databases. Appendix 3.2, Table A3.2.2 provides a detailed description of the data sources underlying this chapter.

In some cases, series had breaks or gaps, causing the panel data to be somewhat unbalanced, with the most comprehensive time series coverage generally occurring in the more developed economies. To avoid inconsistencies from changing compositions of the subregional data aggregations over time, only 24 economies were retained for the descriptive analysis in this chapter. For the regression analysis, an unbalanced panel of 32 economies was retained after excluding those with interruptions in any of the time series underlying the analysis. The panel was further narrowed to 7 core economies, for which a fully balanced data set that includes all the relevant variables is available for regression analysis.

The descriptive overview relies mostly on country data grouped into five subregional aggregates, defined according to ADB's geographical subdivisions of its developing members: Central Asia, East Asia, the Pacific, South Asia, and Southeast Asia. One key question that arises when presenting and discussing the large amounts of country data concerns the way in which subregional aggregates are compiled. For example, ADB's Asian Development Outlook follows the practice of weighting relevant country measures by gross national income. Although this is appropriate when, for example, summarizing gross domestic product or average annual growth rates across the region, it obviously causes averages to represent mostly the largest economies in the region, such as the PRC (for East Asia) and India (for South Asia). For example, as a result of gross national income weighting, an economy like the PRC inevitably ends up representing more than $40 \%$ of the regional average. By contrast, without applying a concept of region-wide fiscal positions, it is not clear whether there is a meaningful way to devise weights in relation to fiscal variables, where economy size, however measured, has no evident bearing on its representativeness within some broader subregional or regional aggregate. Based on these considerations, all the fiscal aggregates for Asia presented in this chapter refer to unweighted simple arithmetic averages of data of individual economies by subregion or developing Asia as a whole, unless specified otherwise. 


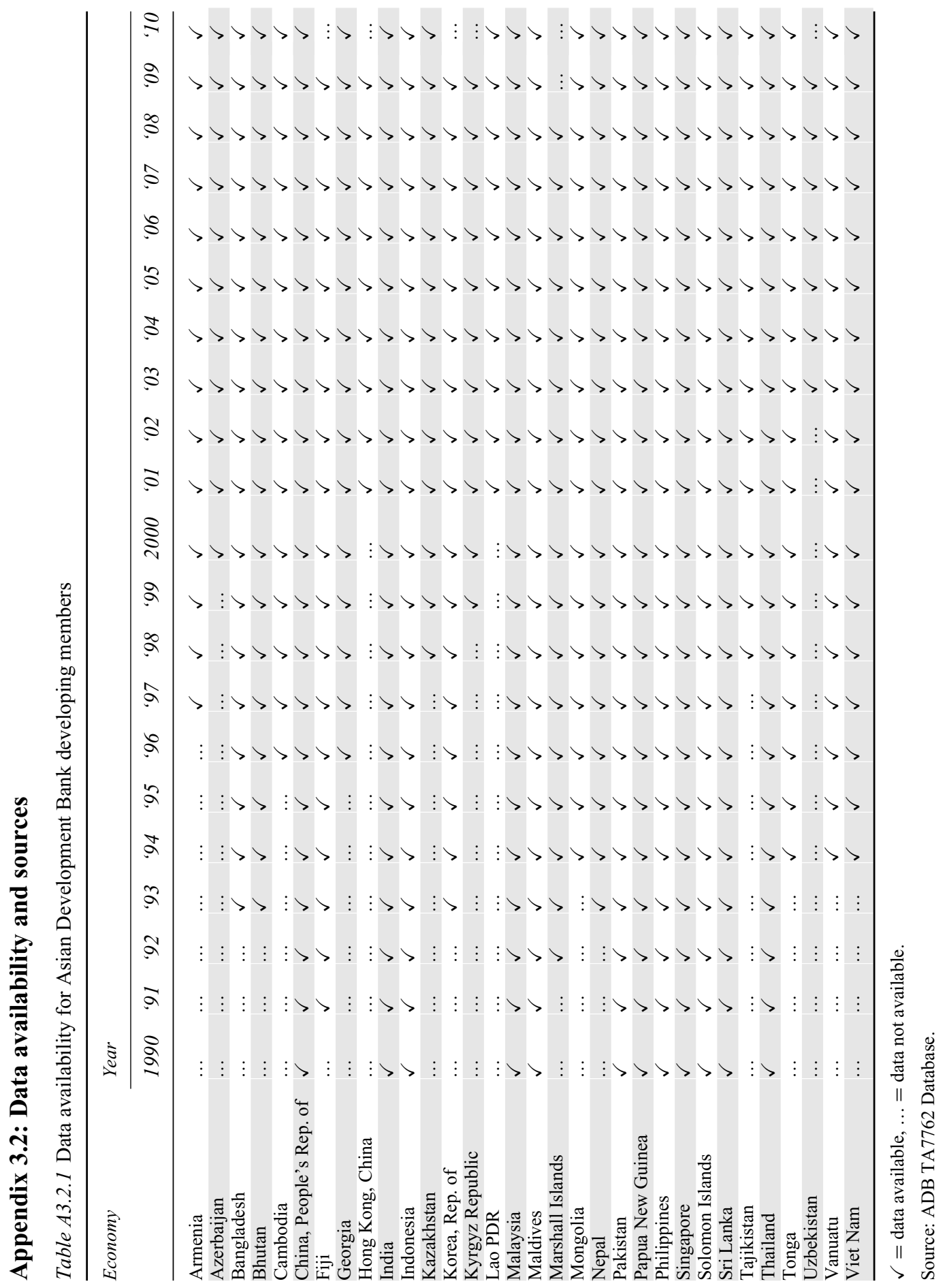




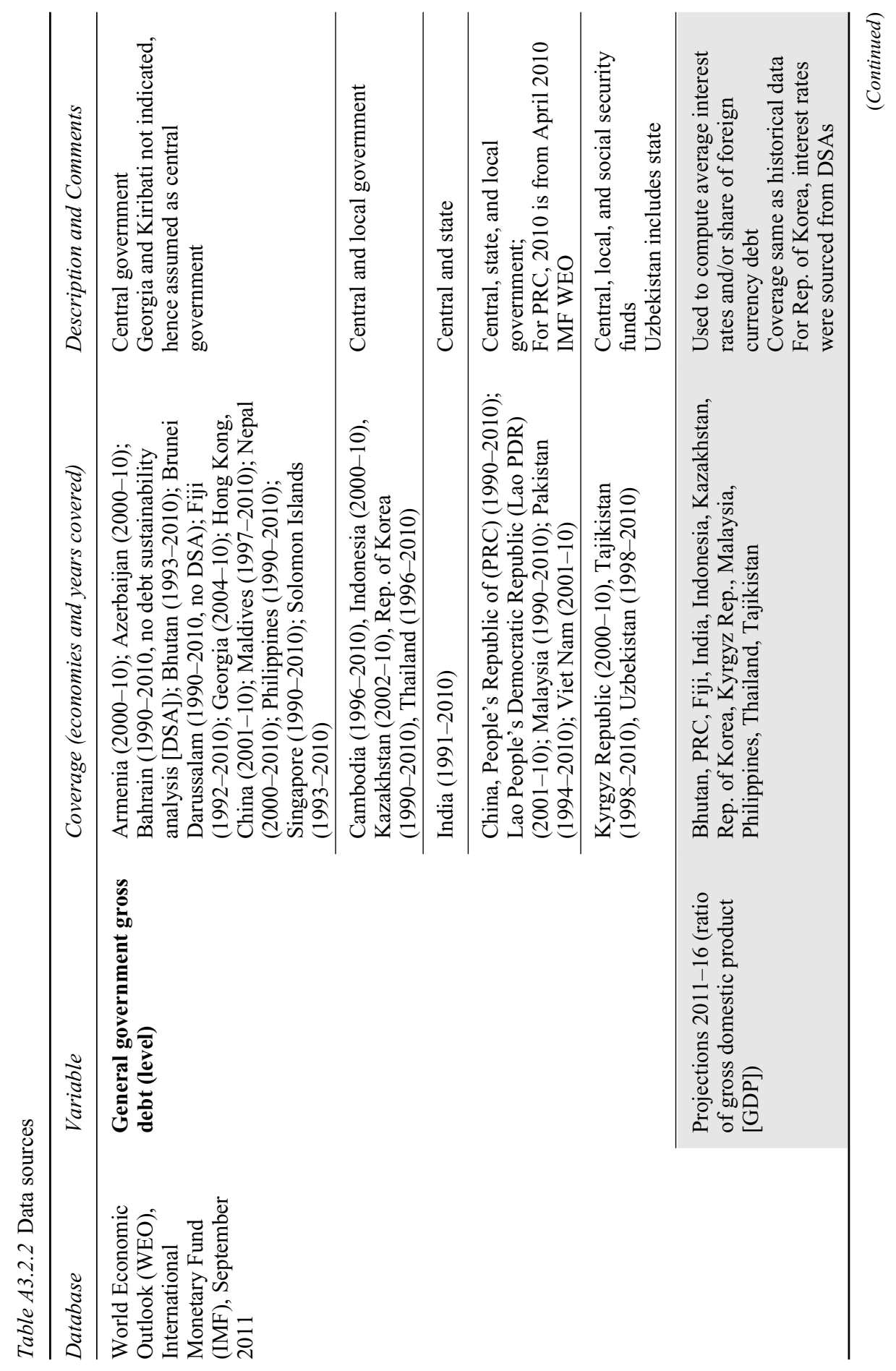




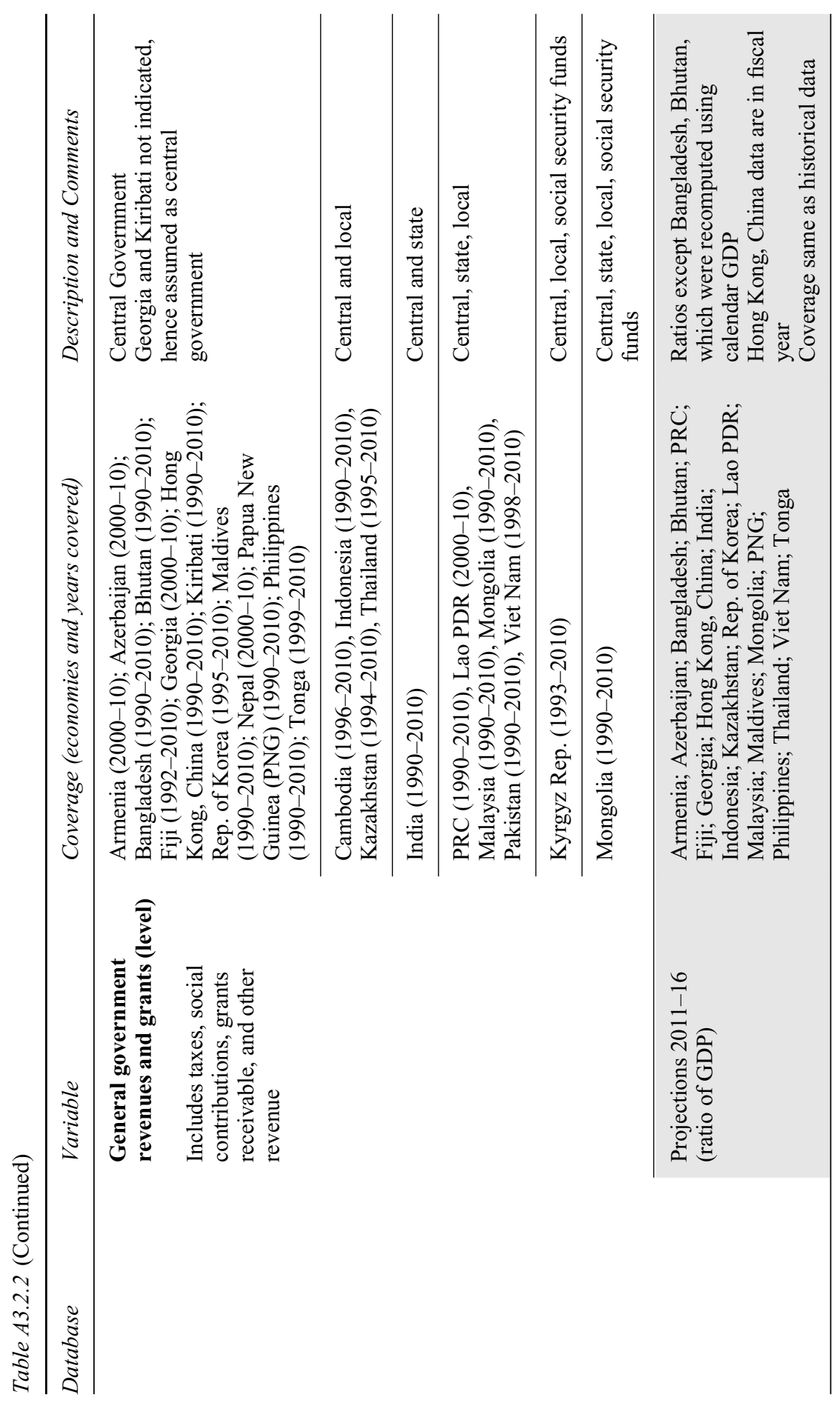




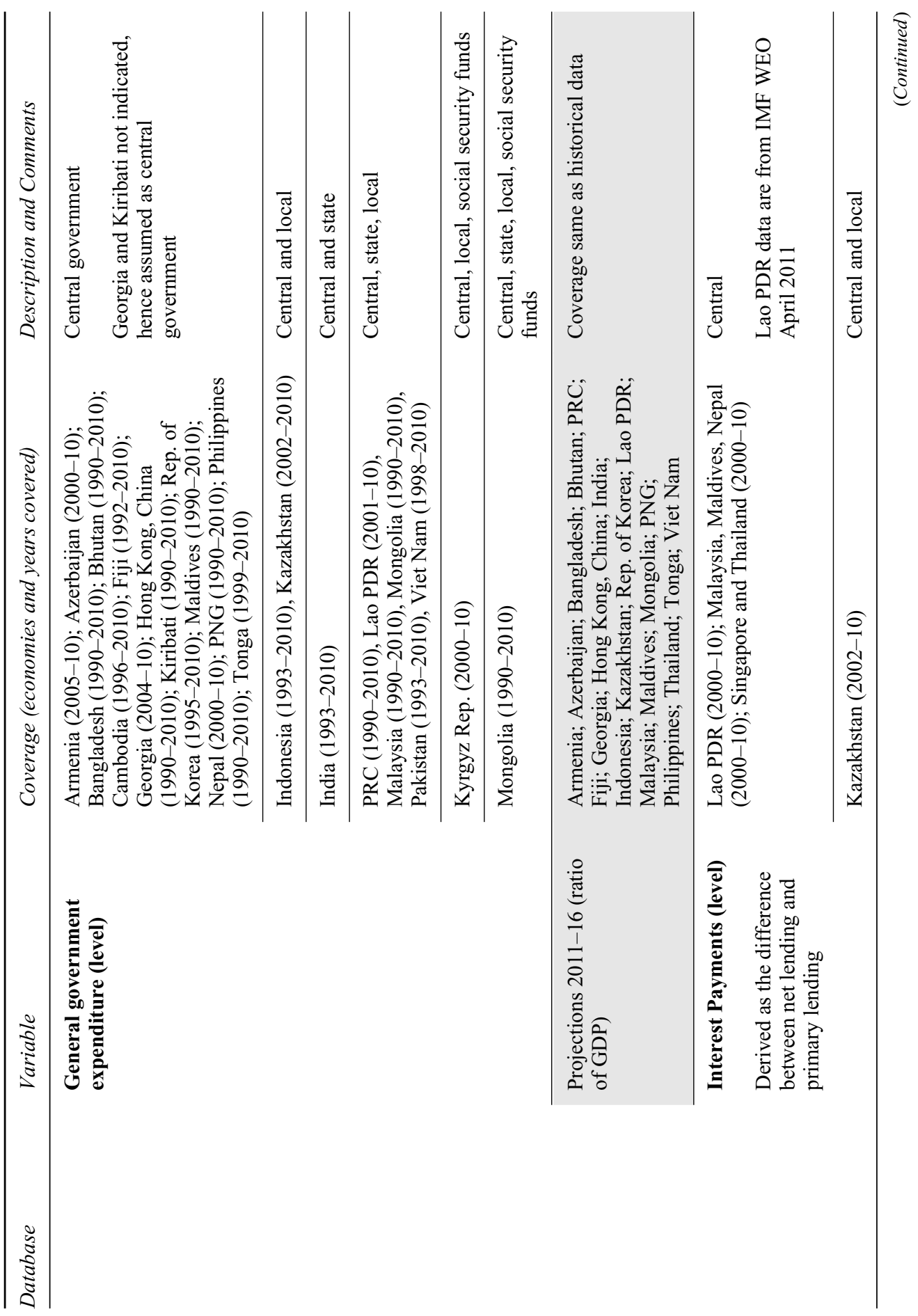




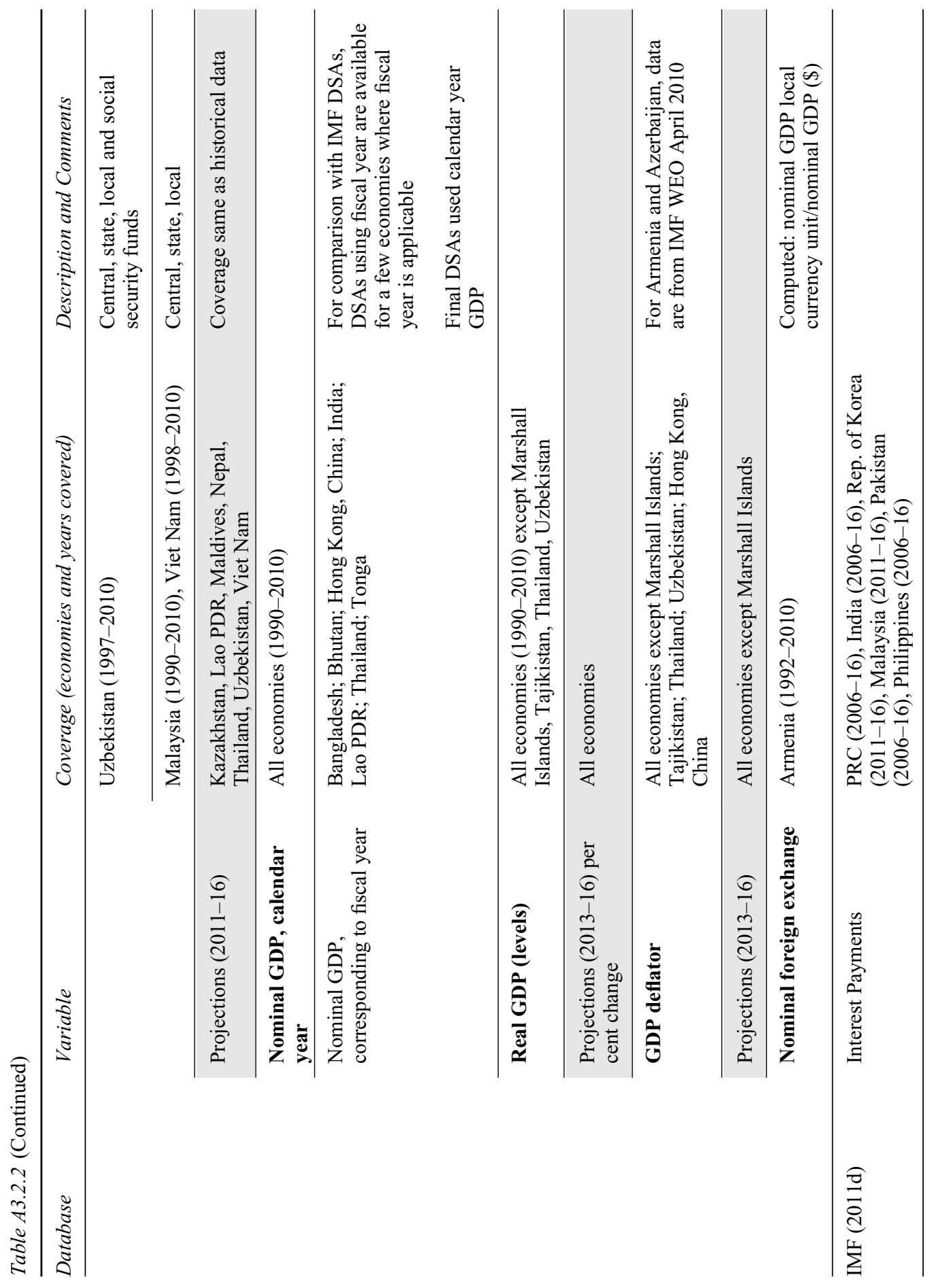




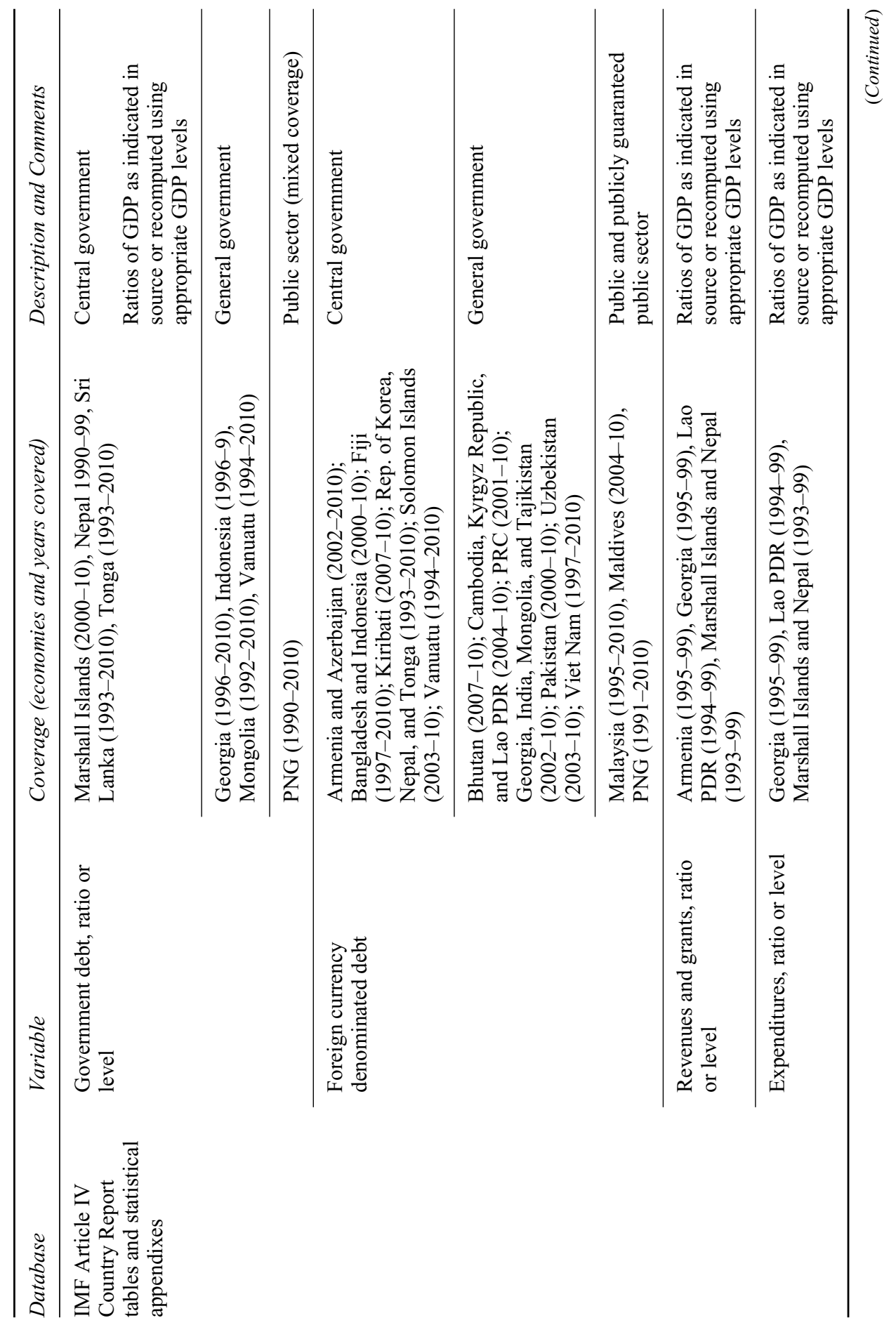




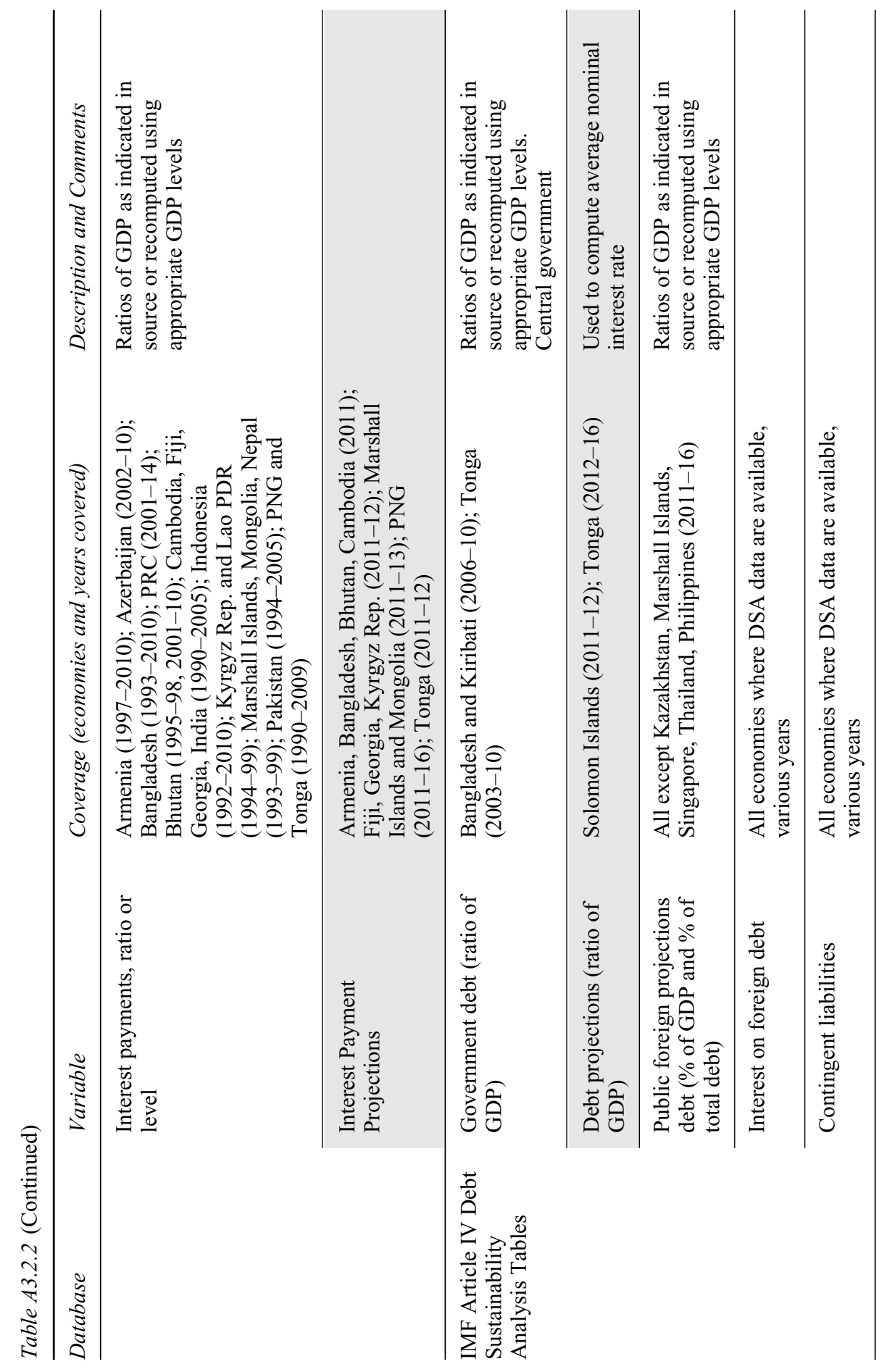




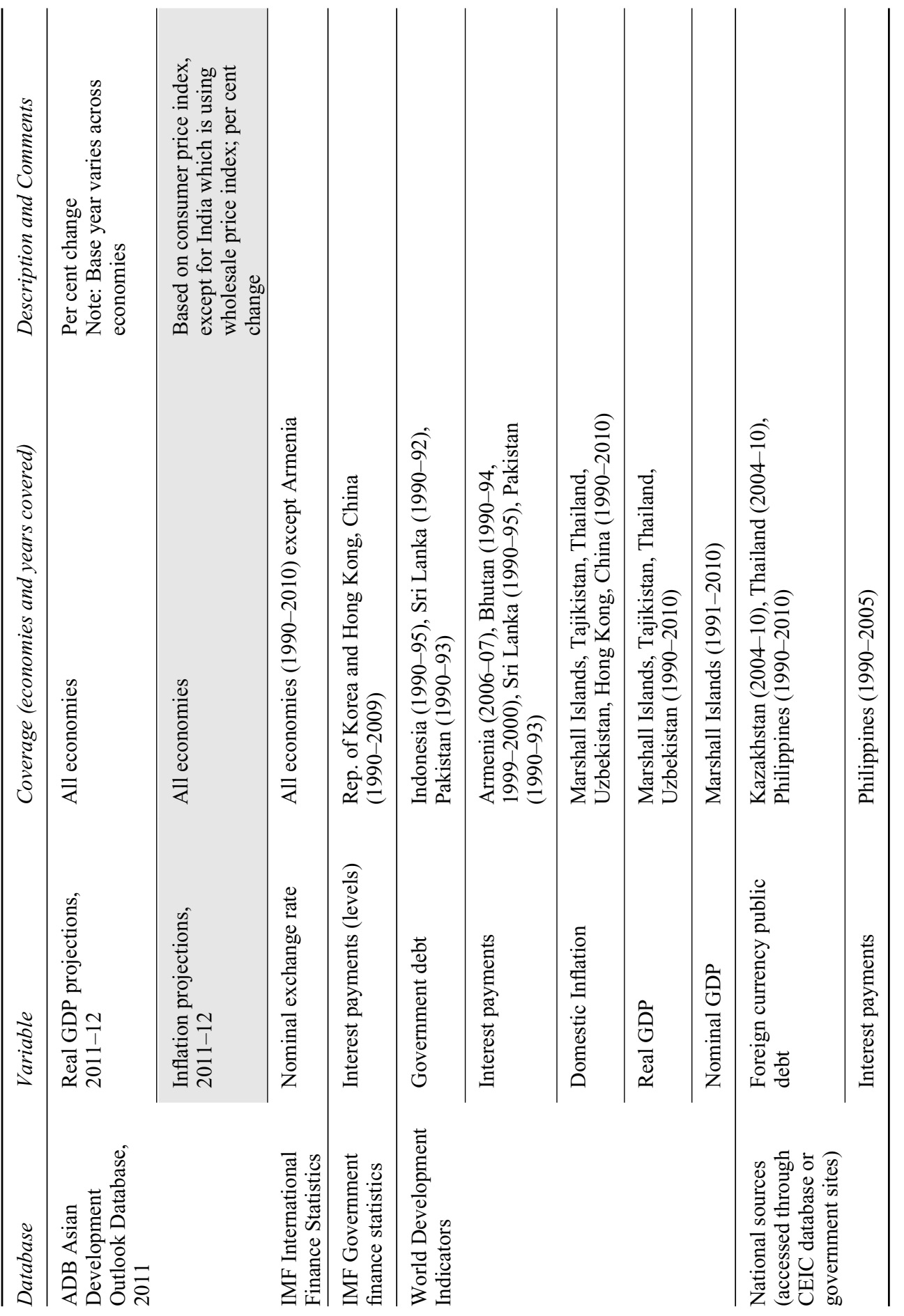




\section{Appendix 3.3: Regression analysis samples and functions}

Table A3.3.1 Samples for regression analysis

\begin{tabular}{lll|lll}
\hline Subregion/economy & Asia32 & Asia7 & Subregion/economy & Asia32 & Asia7 \\
\hline Central Asia & & & South Asia & & \\
Armenia & $\checkmark$ & & Bangladesh & $\checkmark$ & \\
Azerbaijan & $\checkmark$ & & Bhutan & $\checkmark$ & \\
Georgia & $\checkmark$ & & India & $\checkmark$ & $\checkmark$ \\
Kazakhstan & $\checkmark$ & & Sri Lanka & $\checkmark$ & \\
Kyrgyz Republic & $\checkmark$ & & Maldives & $\checkmark$ & \\
Tajikistan & $\checkmark$ & & Nepal & $\checkmark$ & \\
Uzbekistan & $\checkmark$ & & Pakistan & $\checkmark$ & \\
East Asia & & Southeast Asia & & \\
China, People's Rep. of & $\checkmark$ & $\checkmark$ & Cambodia & $\checkmark$ & \\
Hong Kong, China & $\checkmark$ & & Indonesia & $\checkmark$ & $\checkmark$ \\
Korea, Rep. of & $\checkmark$ & $\checkmark$ & Lao PDR & $\checkmark$ & \\
Mongolia & $\checkmark$ & & Malaysia & $\checkmark$ & $\checkmark$ \\
Pacific & & Philippines & $\checkmark$ & $\checkmark$ \\
Fiji & & Singapore & $\checkmark$ & \\
Marshall Islands & $\checkmark$ & & Thailand & $\checkmark$ & $\checkmark$ \\
Papua New Guinea & $\checkmark$ & & Viet Nam & $\checkmark$ & \\
Solomon Islands & $\checkmark$ & & & \\
Tonga & $\checkmark$ & & & \\
Vanuatu & $\checkmark$ & & & \\
\hline
\end{tabular}

$\checkmark=$ included; Asia32 $=32$ Asian economies, Asia7 $=7$ Asian economies, Lao PDR $=$ Lao People's Democratic Republic.

Source: Authors' listing.

Table A3.3.2 Fiscal reaction functions-panel regression results for 32 Asian economies ${ }^{\mathrm{a}}$

\begin{tabular}{|c|c|c|c|c|c|c|c|c|}
\hline & $\begin{array}{l}\text { FGLS } \\
\text { Linear } \\
\text { (1) }\end{array}$ & $\begin{array}{l}F G L S \\
\text { Linear } \\
\text { (2) }\end{array}$ & $\begin{array}{l}\text { OLS } \\
\text { Linear } \\
\text { (3) }\end{array}$ & $\begin{array}{l}\text { OLS } \\
\text { Linear } \\
\text { (4) }\end{array}$ & $\begin{array}{l}S G M M \\
\text { Linear } \\
\text { (5) }\end{array}$ & $\begin{array}{l}\text { FGLS } \\
\text { Cubic } \\
\text { (6) }\end{array}$ & $\begin{array}{l}\text { OLS } \\
\text { Cubic } \\
\text { (7) }\end{array}$ & $\begin{array}{l}\text { SGMM } \\
\text { Cubic } \\
\text { (8) }\end{array}$ \\
\hline Lagged & $0.0237^{* * *}$ & $0.0247^{* * *}$ & 0.0302 & 0.0339 & $0.0285^{* *}$ & -0.0818 & 0.0223 & 0.0312 \\
\hline $\begin{array}{l}\text { debt } \\
\text { Lagged }\end{array}$ & & & $(0.0216)$ & $(0.0214)$ & $(0.0120)$ & $\begin{array}{l}(0.0546) \\
0.00226^{* *}\end{array}$ & $\begin{array}{l}(0.147) \\
0.000184\end{array}$ & $\begin{array}{l}(0.113) \\
6.25 \mathrm{e}-05\end{array}$ \\
\hline debt² & & & & & & $(0.000964)$ & $(0.00261)$ & $(0.00207)$ \\
\hline Lagged & & & & & & $-1.35 \mathrm{e}-05^{* *}$ & $-1.19 \mathrm{e}-06$ & $-1.08 \mathrm{e}-06$ \\
\hline debt 3 & & & & & & $(5.27 \mathrm{e}-06)$ & $(1.46 \mathrm{e}-05)$ & $(1.15 \mathrm{e}-05)$ \\
\hline $\begin{array}{l}\text { Lagged } \\
\text { surplus }\end{array}$ & & & & & $\begin{array}{l}0.596^{* * *} \\
(0.0566)\end{array}$ & & & $\begin{array}{l}0.550^{* * *} \\
(0.0521)\end{array}$ \\
\hline Real GDP & $\begin{array}{l}0.258^{* * *} \\
(0.0303)\end{array}$ & $\begin{array}{l}0.239^{* * *} \\
(0.0312)\end{array}$ & $\begin{array}{l}0.216^{* * *} \\
(0.0516)\end{array}$ & $\begin{array}{l}0.164^{* * *} \\
(0.0514)\end{array}$ & $\begin{array}{l}0.259^{* * *} \\
(0.0556)\end{array}$ & $\begin{array}{l}0.262^{* * *} \\
(0.0313)\end{array}$ & $\begin{array}{l}0.216^{* * *} \\
(0.0518)\end{array}$ & $\begin{array}{l}0.257^{* * *} \\
(0.0491)\end{array}$ \\
\hline $\begin{array}{l}\text { Real } \\
\text { expenditure }\end{array}$ & $\begin{array}{l}-0.160^{* * *} \\
(0.00986)\end{array}$ & $\begin{array}{l}-0.160^{* * * *} \\
(0.00995)\end{array}$ & $\begin{array}{l}-0.175^{* * *} \\
(0.0169)\end{array}$ & $\begin{array}{l}-0.168^{* * *} \\
(0.0165)\end{array}$ & $\begin{array}{l}-0.197^{* * *} \\
(0.0330)\end{array}$ & $\begin{array}{l}-0.159^{* * *} \\
(0.00995)\end{array}$ & $\begin{array}{l}-0.175^{* * *} \\
(0.0171)\end{array}$ & $\begin{array}{l}-0.212^{* * *} \\
(0.0303)\end{array}$ \\
\hline Constant & $\begin{array}{l}-1.737^{* *} \\
(0.721)\end{array}$ & $\begin{array}{l}-1.811^{* *} \\
(0.719)\end{array}$ & $\begin{array}{l}-1.397^{* * *} \\
(0.391)\end{array}$ & $\begin{array}{l}-1.859^{* * * *} \\
(0.382)\end{array}$ & & $\begin{array}{l}-0.291 \\
(1.152)\end{array}$ & $\begin{array}{l}-1.312 \\
(0.941)\end{array}$ & \\
\hline Controls & No & Yes & No & Yes & No & No & No & No \\
\hline Dummies & Yes & Yes & Yes & Yes & Yes & Yes & Yes & Yes \\
\hline
\end{tabular}


Table A3.3.2 (Continued)

\begin{tabular}{lllllllll}
\hline & $\begin{array}{l}\text { FGLS } \\
\text { Linear } \\
(1)\end{array}$ & $\begin{array}{l}\text { FGLS } \\
\text { Linear } \\
(2)\end{array}$ & $\begin{array}{l}\text { OLS } \\
\text { Linear } \\
(3)\end{array}$ & $\begin{array}{l}\text { OLS } \\
\text { Linear } \\
(4)\end{array}$ & $\begin{array}{l}\text { SGMM } \\
\text { Linear } \\
(5)\end{array}$ & $\begin{array}{l}\text { FGLS } \\
\text { Cubic } \\
(6)\end{array}$ & $\begin{array}{l}\text { OLS } \\
\text { Cubic } \\
(7)\end{array}$ & $\begin{array}{l}\text { SGMM } \\
\text { Cubic } \\
(8)\end{array}$ \\
\hline Observations & 488 & 488 & 456 & 456 & 481 & 488 & 456 & 456 \\
Economies & 32 & 32 & 32 & 32 & 32 & 32 & 32 \\
Chi $^{2} / R^{2}$ _adj & 975.4 & 956.4 & 0.165 & 0.210 & 368.5 & 857.6 & 0.161 & 413.2 \\
A/B Order 1 & $\ldots$ & $\ldots$ & $\ldots$ & $\ldots$ & $-2.4729^{* *}$ & $\ldots$ & $\ldots$ & $-2.4549^{* *}$ \\
A/B Order 2 & $\ldots$ & $\ldots$ & $\ldots$ & $\ldots$ & 0.5098 & $\ldots$ & $\ldots$ & 0.50868 \\
\hline
\end{tabular}

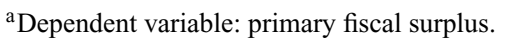

$\ldots=$ data not available, $\mathrm{AR}=$ autoregressive, $\mathrm{CPI}=$ consumer price index, FGLS $=$ feasible generalized least squares estimation, GDP $=$ gross domestic product, HP $=$ Hodrick-Prescott, OLS = fixed effects ordinary least squares estimation, SGMM = system generalized method of moments Blundell-Bond linear dynamic estimation.

Standard errors in parentheses. Significance levels: ${ }^{* *} p<0.01,{ }^{* *} p<0.05,{ }^{*} p<0.1$.

Notes:

- The regressions are fitted to an unbalanced panel of 32 economies with data from 1990 to 2010 (depending on data availability for individual economies; see Table A3.2.2).

- FGLS assuming country-specific heteroskedasticity and AR(1) autocorrelated errors.

- OLS: assuming first-order autoregressive errors (AR1).

- $\quad$ SGMM: (Arellano and Bond 1991; Blundell and Bond 1998).

- All variables are expressed as ratio of GDP.

- Lagged debt: MA2 debt stock lagged one year. Lagged debt 2 is squared lagged debt and lagged debt $^{\wedge} 3$ is cubic lagged debt.

- Real GDP: HP-trend deviation of real GDP.

- Real expenditure: HP-trend deviation of real government expenditure.

- Controls: World oil price indicator, non-food commodity price indicator (deviations from HPtrend), and CPI inflation (two-year moving average). Coefficients not reported.

- Dummies: Country and year dichotomous variables included in regression (coefficients not reported).

- $\quad \mathrm{Chi}^{2} / R^{2}$ adj: Overall fit statistics; $\mathrm{Chi}^{2}$ for FGLS maximum likelihood regressions, and adjusted $R^{2}$ for OLS regressions.

- Controls is a vector of control variables, including oil price and non-fuel commodity price indexes, computed as deviations from the HP filter. Both variables are interacted with a dichotomous variables taking value 1 for oil and non-fuel commodity exporting countries in the region, and zero otherwise. As a further control, also included are CPI ratios, computed as two-year moving averages.

Source: Authors' estimates.

Table A3.3.3 Fiscal reaction functions-spline regressions for seven Asian economies ${ }^{\mathrm{a}}$

Feasible generalized least squares estimation

2 splines 5 splines

(1)

$\begin{array}{ll}\text { Lagged debt S1 } & 0.0800^{* *} \\ & (0.0382) \\ \text { Lagged debt S2 } & 0.0638^{* * *} \\ & (0.0197)\end{array}$


Table A3.3.3 (Continued)

Feasible generalized least squares estimation

2 splines

(1)

Lagged debt S1

Lagged debt S2

Lagged debt S3

Lagged debt S4

Lagged debt S5

Real GDP

Real expenditures

Constant

Controls

Dummies

Observations

Number of economies

$\mathrm{Chi}^{2}$
5 splines

(2)

$0.185^{* *}$

$(0.0743)$

0.0621

$(0.0661)$

$-0.0365$

(0.0604)

$0.0563^{*}$

$(0.0320)$

$0.116^{* * *}$

(0.0358)

$0.128^{* *}$

(0.0557)

$-0.114^{* * *}$

(0.0177)

$-4.426^{* * *}$

(1.338)

No

Yes

133

7

302.2

${ }^{a}$ Dependent variable: primary fiscal surplus.

$\mathrm{AR}=$ autoregressive, $\mathrm{FGLS}=$ feasible generalized least squares, $\mathrm{GDP}=$ gross domestic product.

Standard errors in parentheses. Significance levels: ${ }^{* * *} p<0.01,{ }^{* *} p<0.05,{ }^{*} p<0.1$.

Notes:

- FGLS: assuming country-specific heteroskedasticity and AR(1) autocorrelated errors.

- 2 splines: the distribution of the public debt ratio is split once, at the median (38.48\%) of the data.

- 5 splines: the distribution of the public debt variable is split at the 20th, 40th, 60th, and 80th percentiles of the data. The corresponding knots are $15.70 \%$ (20th), 29.03\% (40th), $44.68 \%$ (60th), $65.04 \%$ (80th).

- This table reports the results from estimating two such spline regressions. The first column divides the sample of seven observations in two, according to whether they are associated with a debt ratio below or above the median. The coefficient estimates reported in the first two rows of the table suggest that fiscal response at 0.080 on average is higher in the below-median section than it is above, at 0.064 . However, more nuanced is the results of the spline regression in column 2, where the debt ratio is split into five sections, divided by the 20th, 40th, 60th, and 80th percentiles of the distribution of debt ratios in the sample. What emerges is a clear pattern of increasing coefficient estimates in relation to higher debt ratio segments, which roughly corresponds with the pattern of the cubic function estimated earlier. Indeed, Figure 3.4 shows the two estimated functions to largely overlap. The difference in the splined regression is that the fiscal response is estimated to take a negative sign over the median (3rd) segment, while the cubic function is strictly monotonic; however, the spline estimate in relation to that particular section lacks precision. The lack of statistical significance in some segments along the spline (the 2nd and 3rd in this case) is rather unsurprising given the limited sample size of 133 observation that is split into 5 segments each with a proportionally lowered number of degrees of freedom.

Source: Authors' estimates. 
Table A3.3.4 Fiscal reaction functions - spline regressions for 32 Asian economies $^{\mathrm{a}}$

Feasible generalized least squares estimation

$\begin{array}{ll}2 \text { splines } & 5 \text { splines } \\ (1) & (2)\end{array}$

\begin{tabular}{lll}
\hline Lagged debt S1 & 0.00522 & \\
Lagged debt S2 & $(0.0206)$ & \\
& $0.0331^{* * *}$ & \\
Lagged debt S1 & $(0.0106)$ & -0.00837 \\
& & $(0.0285)$ \\
Lagged debt S2 & & 0.0268 \\
& & $(0.0421)$ \\
Lagged debt S3 & & 0.00499 \\
Lagged debt S4 & & $(0.0467)$ \\
& & $0.0495^{*}$ \\
Lagged debt S5 & & $(0.0285)$ \\
& & -0.00377 \\
Real GDP & $0.259^{* * *}$ & $(0.0168)$ \\
& $(0.0310)$ & $0.259^{* * *}$ \\
Real expenditures & $-0.162^{* * *}$ & $(0.0314)$ \\
Constant & $(0.0100)$ & $-0.159^{* * *}$ \\
& -1.195 & $(0.0100)$ \\
Controls & $(0.944)$ & -0.922 \\
Dummies & No & $(1.059)$ \\
Observations & Yes & No \\
Number of economies & 488 & Yes \\
Chi ${ }^{2}$ & 32 & 488 \\
\hline
\end{tabular}

${ }^{\mathrm{a}}$ Dependent variable: primary fiscal surplus.

$\mathrm{AR}=$ autoregressive, $\mathrm{FGLS}=$ feasible generalized least squares, $\mathrm{GDP}=$ gross domestic product.

Standard errors in parentheses. Significance levels: ${ }^{* * *} p<0.01,{ }^{* *} p<0.05,{ }^{*} p<0.1$

Notes:

- FGLS: assuming country-specific heteroskedasticity and AR(1) autocorrelated errors.

- 2 splines: the distribution of the public debt ratio is split once, at the median $(46.00 \%)$ of the data.

- 5 splines: the distribution of the public debt variable is split at the 20th, 40th, 60th, and 80th percentiles of the data. The corresponding knots are $28.52 \%$ (20th), $41.38 \%$ (40th), $51.47 \%$ (60th), and $71.04 \%$ (80th).

Source: Authors' estimates.

\section{Appendix 3.4: Estimating fiscal reaction functions}

The regression specification applied in this chapter is guided by optimal taxation theory, as in Bohn (1998). Simply put, this theory postulates that temporary government spending and declines in income cause budget deficits to temporarily rise above normal levels and to revert to their optimal trend thereafter. In addition to assuming a linear relationship between debt stock and primary deficit ratios, 
we test for the possibility that this relationship takes a nonlinear form, evidence for which has been found in other studies, such as IMF (2003), ADB (2010a), or IMF (2011a). The Bohn-type regression equation augmented by quadratic and cubic debt regressors and a set of dichotomous variables specific to the panel setting takes the form:

$$
\begin{aligned}
p s_{i t} & =\rho_{1} b_{i t-1}+\rho_{2} b^{2}{ }_{i t-1}+\rho_{3} b^{3}{ }_{i t-1}+\beta_{1} \tilde{y}_{i t}+\beta_{2} \tilde{g}_{i t}+\beta_{3} c_{i t}+\beta_{4} d_{i t}+\varepsilon_{i t} \\
\varepsilon_{i t} & =\varphi \varepsilon_{i t-1}+\gamma_{i t} \quad \text { and } \quad \gamma_{i t} \sim\left(0, \sigma_{\gamma}^{2}\right),
\end{aligned}
$$

where:

- $\quad$ all variables are expressed as a ratio of gross domestic product (GDP);

- $\quad$ subscript $i$ is a country (panel) indicator, and $t$ indicates time, measured in years;

- $\quad p s_{i t}$ is the primary fiscal surplus, defined as government fiscal income minus expenditure;

- $\quad b_{i t-1}$ is the two-year average debt stock lagged one year with respect to the primary balance;

- $\quad b_{i t-1}^{2}$ and $b_{i t-1}^{3}$ are the quadratic and cubic debt stock ratios, respectively.

- $\rho_{1}$ is the key coefficient of interest in this regression when it is estimated in its linear form, i.e., excluding quadric and cubic debt: $\rho_{1}$ measures the sign and intensity of the fiscal reaction across countries and time;

- $\quad \rho_{2}$ and $\rho_{3}$ are the core coefficients defining the fiscal reaction function, jointly with $\rho_{1}$, when it is estimated as a cubic relationship;

- $\quad \tilde{y}_{i t}$ is the output gap or business cycle, measured as the deviation from trend of real GDP, whereby the trend is determined by the Hodrick-Prescott filter; ${ }^{1}$

- $\quad \tilde{g}_{i t}$ is temporary fiscal outlays, measured as the deviation from trend of real government expenditure, whereby the trend is determined by the HodrickPrescott filter;

- $\quad c_{i t}$ are control variables, including oil and non-food commodity prices-both measured as trend deviations - and average CPI inflation rates;

- $d_{i t}$ is a matrix including country dichotomous variables, a time trend, and the regression constant;

- $\quad \beta_{1}$ to $\beta_{4}$ are the additional coefficients estimated; and

- $\varepsilon_{i t}$ is a first-order autoregressive error term, $\operatorname{AR}(1)$, which in the feasible generalized least squares (FGLS) estimation also allows for cross-sectional correlation and heteroskedasticty.

Equation (A4.1) is estimated by FGLS. Compared to ordinary least squares (OLS), the FGLS method allows for a variance-covariance matrix that accounts for correlation and heteroskedasticity across countries as well as for countyspecific autocorrelation. Put differently, FGLS accommodates the possibility that the relationship between fiscal policy and the variables influencing it may be 
correlated, and that variances across these variables as well as autocorrelation structures be not the same across countries. To check the robustness of the estimates to changes in the estimation method, we estimate equation (A4.1) also by OLS. The latter also allows for AR(1) disturbances across panels, but not for heteroskedasticity and country-specific correlation of the error terms, as within-estimates are now produced through OLS, not FGLS. ${ }^{2}$

In addition to the static model specification, we estimate equation (A4.1) as a system general method of moments (SGMM) dynamic panel model, the dynamism or feedback mechanism of which derives from including lagged primary fiscal surplus as an additional regressor, shown on the right hand side of equation A4.3. More specifically, the latter enters the regression as the so-called general method of moments (GMM)-type instrument, $\left(a s_{t-i}\right)$, which captures the dynamics of the primary fiscal surplus variable and its dependence on itself through time, as well as the system-type instruments, which are the debt, GDP, and expenditure ratios taken in differences (signed by a dot). Omitting the cubic specification of the debt stock ratio for simplicity, the SGMM is estimated as ${ }^{3}$ :

$$
\begin{aligned}
p s_{i t} & =\alpha s_{i t-1,2}+\rho b_{i t-1}+\beta_{1} \tilde{y}_{i t}+\beta_{2} \widetilde{g}_{i t}+\rho \dot{b}_{i t-1}+\beta_{1} \dot{y}_{i t}+\beta_{2} \dot{g}_{i t}+\varepsilon_{i t} \\
\varepsilon_{i t} & =\varphi \varepsilon_{i t-1}+\gamma_{i t} \text { and } \gamma_{i t} \sim\left(0, \sigma_{\gamma}^{2}\right)
\end{aligned}
$$

The main advantage of SGMM estimation is its explicit accounting for the inertia of primary fiscal deficits. For example, government fiscal reaction may be constrained when current outlays are largely predetermined by extant commitments for multiyear investment projects or government consumption, such as public sector payrolls. To the extent that current fiscal revenue and expenditure (net of interest payments) tend to correlate to those of the previous years, SGMM adds an important dynamic element that increases the regression fit and hence its accuracy above that of FGLS and OLS.

However popular a tool of cross-country analysis may be, a number of caveats and qualifications need mentioning in relation to the results presented in this section. In view of serious data limitations and the considerable heterogeneity within the region, the econometric results are to be treated with care. Indeed, although a fully balanced set of data allows robust panel estimation for the sample of 7 Asian economies, the results are far less robust across alternative samples including larger groups of economies. This arises from Appendix 3.3, Tables A3.3.2-A3.3.4, summarizing the outcomes from regressions on the sample of 32 economies. Whereas the large-sample results can be seen to qualitatively overlap with those of the sample of 7 economies, the economic and statistical significance of the fiscal reaction coefficients tends to be lower for the former. However, differences in outcomes are most pronounced in the cubic regressions, which present different signs on the key parameters, implying a shape of the reaction curve that would be different from that in Figure 3.4.

The sensitivity of the regressions to sample inclusion derives from the dominance of single country experiences in the results during certain years, which 
is felt particularly strongly when estimating small samples. Lest outliers are to drive the results, regression analysis has to make do with a small subsample of countries for which a full series of data of sufficient quality are available, as was done in this chapter. Even then, however, panel regressions of fiscal reaction functions are best interpreted as a pattern indicative of a regional context such as for Asia, and not as proof of a consistent fiscal response function specific to any individual country. To achieve country-specific conclusions, the empirical strategy would have to take exclusive focus on countries one by one, studying the time series properties and unit roots of the relevant variable over an extended period of time, probably not less than 40-50 years. Whereas Bohn's groundbreaking work in the estimation of fiscal reaction functions could rely on roughly two centuries of data on fiscal policy in the United States (Bohn 1998), such a rich data set is usually not available for emerging economies. Thus, researchers are regularly forced to use a panel setting across countries, although the concept is strictly country-specific and its hypotheses can ultimately only be refuted against country data series spanning a reasonably long time period.

\section{Appendix 3.4 notes}

1 The Hodrick-Prescott filter removes the trend $\gamma$ from $y$ (or $g$ ) by minimizing with respect to $\gamma_{t}: \min \sum_{t=1}^{T}\left\{\left(y_{t}-\gamma_{t}\right)^{2}+\varphi\left[\left(\gamma_{t+1}-\gamma_{t}\right)-\left(\gamma_{t}-\gamma_{t+1}\right)\right]^{2}\right\}$, where $y_{t}-\gamma_{t}$ is the business cycle component or temporary output gap that is assumed to affect the primary surplus.

2 The interested reader can find a discussion about the differences between these methods in Greene (2012).

3 SGMM builds a system of two equations including the original equation as well as the transformed equation, in differences. It rests on the assumption that first differences of the instrument variables are uncorrelated with the fixed (country) effects. See Arellano and Bond (1991) and Blundell and Bond (1998) for a discussion of the SGMM method.

\section{Appendix 3.5: Assumptions underlying the 2011-16 baseline projections}

Table A3.5.1 Assumptions underlying the 2011-16 baseline projection

\begin{tabular}{|c|c|c|c|c|c|c|c|}
\hline \multirow[t]{2}{*}{$\begin{array}{l}\text { Subregion and } \\
\text { period }\end{array}$} & \multirow{2}{*}{$\begin{array}{l}\text { GDP } \\
\text { growth } \\
\text { rate }\end{array}$} & $\begin{array}{l}\text { Inflation } \\
\text { rate }\end{array}$ & $\begin{array}{l}\text { Average } \\
\text { interest } \\
\text { rate }\end{array}$ & Revenue & Expenditure & $\begin{array}{l}\text { Average } \\
\text { share of } \\
\text { FCD debt }\end{array}$ & $\begin{array}{l}\text { Primary } \\
\text { deficit }^{*}\end{array}$ \\
\hline & & $(\%)$ & $(\%)$ & $\begin{array}{l}(\% \text { of } \\
\text { GDP })\end{array}$ & $\begin{array}{l}(\% \text { of } \\
\text { GDP) }\end{array}$ & $\begin{array}{l}(\% \\
\text { total } \\
\text { debt }) \\
\end{array}$ & $\begin{array}{l}(\% \text { of } \\
\text { GDP) }\end{array}$ \\
\hline \multicolumn{8}{|l|}{ Central Asia } \\
\hline $2000-10$ & 0.081 & 0.111 & 0.026 & -0.081 & 0.023 & 0.809 & -0.033 \\
\hline $2011-16$ & 0.049 & 0.071 & 0.027 & -0.044 & 0.030 & 0.759 & 0.054 \\
\hline
\end{tabular}


Table A3.5.1 (Continued)

\begin{tabular}{|c|c|c|c|c|c|c|c|}
\hline \multirow[t]{2}{*}{$\begin{array}{l}\text { Subregion and } \\
\text { period }\end{array}$} & \multirow{2}{*}{$\begin{array}{l}\text { GDP } \\
\text { growth } \\
\text { rate } \\
(\%)\end{array}$} & \multirow{2}{*}{$\begin{array}{l}\text { Inflation } \\
\text { rate }\end{array}$} & \multirow{2}{*}{$\begin{array}{l}\text { Average } \\
\text { interest } \\
\text { rate }\end{array}$} & \multirow{2}{*}{$\begin{array}{l}\text { Revenue } \\
\text { (\% of } \\
\text { GDP) }\end{array}$} & \multirow{2}{*}{$\begin{array}{l}\text { Expenditure } \\
(\% \text { of } \\
\text { GDP) }\end{array}$} & \multirow{2}{*}{$\begin{array}{l}\text { Average } \\
\text { share of } \\
\text { FCD debt } \\
(\% \\
\text { total } \\
\text { debt })\end{array}$} & \multirow{2}{*}{$\begin{array}{l}\begin{array}{l}\text { Primary } \\
\text { deficit }^{*}\end{array} \\
\text { (\% of } \\
\text { GDP) }\end{array}$} \\
\hline & & & & & & & \\
\hline \multicolumn{8}{|l|}{ East Asia } \\
\hline $2000-10$ & 0.073 & 0.065 & 0.033 & -0.032 & 0.004 & 0.328 & -0.330 \\
\hline $2011-16$ & 0.088 & 0.048 & 0.031 & -0.017 & 0.022 & 0.302 & -1.532 \\
\hline \multicolumn{8}{|l|}{ Pacific } \\
\hline $2000-10$ & 0.020 & 0.058 & 0.044 & -0.012 & 0.020 & 0.543 & -1.256 \\
\hline $2011-16$ & 0.041 & 0.068 & 0.047 & -0.021 & 0.027 & 0.613 & 0.634 \\
\hline \multicolumn{8}{|l|}{ South Asia } \\
\hline $2000-10$ & 0.059 & 0.068 & 0.053 & -0.014 & 0.026 & 0.512 & 1.199 \\
\hline $2011-16$ & 0.064 & 0.076 & 0.063 & -0.014 & 0.046 & 0.492 & 1.413 \\
\hline \multicolumn{8}{|l|}{ Southeast Asia } \\
\hline $2000-10$ & 0.053 & 0.060 & 0.049 & -0.010 & 0.008 & 0.371 & 0.476 \\
\hline $2011-16$ & 0.057 & 0.048 & 0.047 & -0.001 & 0.019 & 0.300 & 1.263 \\
\hline
\end{tabular}

$\mathrm{FCD}=$ foreign currency denominated, GDP $=$ gross domestic product.

Note $:-$ sign $=$ deficit in the Primary deficit column.

Source: Authors' estimates.

\section{Appendix 3.6: Data issues in stochastic debt sustainability analysis}

Stochastic debt sustainability analysis (DSA) relies on country time series of the key macroeconomic variables, from which to estimate the variance-covariance matrix as a gauge of the basic correlation structure underlying debt dynamics. As is the case for all analysis involving time series data, for vector autoregression (VAR) analysis to yield meaningful results, estimations must rely on a minimum number of observations. Although no clear rule exists in this regard, a typical rule of thumb for VAR regressions would indicate 40 as the minimum number of observations, below which the time series properties of the underlying data series cannot be adequately established and estimates tend to lack the minimum degree of precision and reliability required. Without consistent annual data series spanning at least 40 years or so, researchers and analysts often resort to using quarterly or monthly data. The higher frequency of such data more easily fulfills the minimum data requirement, reducing by a factor of 4 or 12 the number of years that historical data series are required to go back in time.

Unfortunately, the data available for developing countries, and low-income countries in particular, often do not meet the minimum requirements for this type of analysis. For many of these countries, fiscal and debt data are typically available for a short time series and exclusively with annual frequency. Further, in the exceptional instances, when long enough time series are available for all the variables to be analyzed, the data tend to be inconsistent because of 
significant structural shifts - such as in relation to the Asian financial crisiswhich significantly complicates estimation on technical grounds.

Recent attempts to circumvent these difficulties include Garcia and Rigobon (2004), who estimate a VAR system for Brazil based on monthly observations of debt stocks, the real interest rate, inflation, and the exchange rate. In this approach, the data gap pertaining to primary fiscal balances and gross domestic product, which are not available on a monthly basis, is closed by deriving suitable series from quarterly data adjusted for inflation. An alternative approach, also followed in this chapter, uses quarterly macroeconomic data to estimate a VAR system from which to derive a quarterly probability distribution. The latter is then annualized for the construction of fan-charts, which are easily reconciled with the annual frequency of the usual DSA framework (Ferrucci and Penalver 2003; Celasun, Debrun, and Ostry 2006).

For the stochastic analysis in this section, quarterly data for each of the eight economies on real growth, inflation, and the exchange rate were drawn from national sources. Quarterly data for the nominal effective interest rate on central government debt are not available in the DSA data set of any of these economies and had to be generated instead. This process involved identifying, for each economy, the annual interest rate series among those available in the International Monetary Fund's International Financial Statistics database that most strongly correlates with the interest rate series of the annual DSA data set. The difference between the annual International Financial Statistics series and the effective rate of interest applied in country DSAs was then used to proportionally adjust the corresponding quarterly International Financial Statistics series, to ensure it corresponds with the DSA annual effective rate of interest when annualized after simulations.

\section{Appendix 3.7: The stochastic simulation analysis}

Stochastic simulation is performed according to equation (3.5), defining the debt dynamics, and equation (3.6), representing the vector autoregression (VAR) system of the macroeconomic variables affecting the debt dynamics. The VAR system in equation (3.6) can also be expressed as a reduced form VAR as follows:

$$
X_{t}=A_{0}+\sum_{k=1}^{p} A_{k} X_{t-k}+v_{t}, \quad v_{t} \sim N(0, \Omega)
$$

where $X_{t}$ is a vector of variables, $A_{0}$ is a vector of constraints, $k$ and $p$ are the beginning and ending lagged values, $t$ is time and $v_{t} \sim N(0, \Omega)$ is a vector of residuals that are normally distributed with mean 0 and variance $\Omega$. The residuals contained in $v_{t}$ may be contemporaneously intercorrelated as characterized by the structure of its variance-covariance matrix $(\Omega)$ Thus, $\Omega$ provides the contemporaneous joint statistical properties of the macroeconomic disturbances affecting the debt dynamics. 
Alternative paths for each of the macroeconomic variables are simulated by using the estimated VAR in (A7.1), taking lagged values of $X$ as the initial condition and the draws of the corresponding residuals for each period. An appropriate correlation matrix is needed to ensure that the draws are consistent with the estimated distribution of the residuals to reflect the underlying properties of the data. To that end, a Cholesky decomposition is applied to $\Omega$, to derive a consistent correlation that determines the random draws on the residuals.

The simulations involve 10,000 draws on the stochastic residuals, from which the distributions of $X$ over the projection period are derived. These projections of $X_{t}$ are first annualized, to produce an annual spectrum of values for the macroeconomic variables determining debt dynamics over the horizon of projection. The spectrum of the corresponding debt paths is then computed recursively according to equation (3.5), assuming a certain path of primary budget balance and the share of foreign currency denominated debt over the projection period, together with the spectrum of annualized macroeconomic variables projected from the quarterly VAR above.

\section{Notes}

1 The data cut-off date for this chapter is 30 September 2011, at which time the fiscal data for the year 2010 were mostly preliminary. Data for some countries have been revised frequently.

2 Consistent data for Central Asian countries are available only from 2000 on.

3 For a summary of fiscal stimulus measures in the region in response to the GFC, see the Appendix in Chapter 1.

4 For example, South Asia's average debt ratio actually declined in 2009 and 2010, despite fiscal interventions. As discussed in Chapter 5 in relation to India, South Asia's robust growth during and since the GFC helped drive down debt ratios in a large part of the subregion.

5 In 2009/10, average general government expenditure was $29.4 \%$ and revenue was $25.0 \%$ in emerging economies, and $37.5 \%$ and $35.4 \%$, respectively, in advanced economies (IMF 2011b: 125-6).

6 Underlying Mongolia's particularly challenging debt pattern within East Asia is its late transition to a market economy, combined with weak fiscal government and an unfavorable external environment that jointly led to a massive buildup of public debt in the late 1990s and early 2000s. Major structural reform efforts, fiscal discipline, debt relief (including the Russian Federation's writing off most of Mongolia's Soviet-era debts), and favorable commodity price developments jointly brought the country back from the brink of default and, by 2008, down to a debt ratio that was roughly in line with the subregional average.

7 Indonesia stands out as the country most heavily hit by the AFC, which, among other things, led to the nationalization of Indonesia's banking sector. Subsequently, in the decade since 2000, major reforms and solid economic growth amid a favorable external environment - including high international commodity prices-resulted in the country's debt ratio being drastically reduced to a level substantially beneath the subregional average.

8 As discussed in Appendix 3.4, an alternative choice to using simple averages to derive subregional aggregates would be to weight debt ratios by countries' economic sizes. For example, in that case, the East Asian aggregate would be less reflective of Mongolia's vicissitudes, and would closely resemble the PRC's debt ratio instead. However, there 
is no obvious reason to prefer such a weighted average, as long as individual economies are considered equally representative of the region as a whole.

9 The Appendix in Chapter 1 lists fiscal stimulus packages in Asia, outlining their main features and period of application.

10 This is most certainly the case for countries facing interest rates that are higher than their rate of economic expansion. By contrast, when the rate of economic growth exceeds the interest rate, the debt ratio may be stabilized, even when the primary balance is in deficit. As noted in the next three sections of this chapter, many countries in Asia have indeed been benefitting from a persistently negative IRGD that has played a key role in keeping debt ratios in check.

11 Appendix 3.3, Table A3.3.2 shows that the findings for the larger panel of 32 countries largely mirror those of the Asia7 panel discussed in this section, although the accuracy of the estimates tends to be lower due to the strong presence of outliers in the data.

12 Also specific to SGMM estimation is the Arellano-Bond autocorrelation test reported in the last two rows of Table 3.2. First-differenced errors of orders 1 and 2 show no sign of violating the model assumptions, and the model appears to be sufficiently well specified.

13 In the cubic model, equation (A4.3) in Appendix 3.4 includes on the right-hand side both the quadratic and the cubic form of lagged average debt stock ratio $\left(b_{i t-1}^{2}\right.$ and $\left.b_{i t-1}^{3}\right)$.

14 The estimated function is strictly monotonic, which implies that the primary surplus continuously increases (and never falls) as the debt ratio grows larger.

15 The estimation results of spline regression analysis are reported in Appendix 3.3, Tables A3.3.3 and A3.3.4. The estimation technique is described in Appendix 3.4 and essentially consists of dividing the sample into five subsamples ordered according to increasing debt ratios, for which equation (A4.3) of Appendix 3.4 is then estimated separately.

16 As noted in the first section of this chapter, the advantage of this sample of countries is the availability of a consistent set of comparable macroeconomic and fiscal data.

17 In Figure 3.5, the DSPB is computed so as to stabilize the public debt ratio at its 2010 level. More generally, the assumptions underlying the DSPB in Figure 3.5 are made to roughly assess the sustainability of fiscal policy in the region during, for example, 2011-13, if countries' growth, interest rates, and fiscal policy turn out to be similar to the levels observed during 2008-10. Arguably, the volatile macroeconomic environment and quick reversal of the fiscal stance since the GFC provides a plausible scenario, which well reflects the fundamental uncertainty underlying macroeconomic forecasts for the next few years.

18 As previously mentioned, the prevalence of large average primary deficits during 2008-10 mostly reflects the strong fiscal stimulus packages enacted in response to the GFC.

19 Further, the discussion in Chapter 2 shows that when $\theta_{t}<0$, the debt ratio converges to zero asymptotically and debt sustainability no longer requires a government to abide by the transversality condition and the government budget constraint. Essentially, in the "court of debt sustainability," a country can "get away with murder" as long as $\theta_{t}<0$, in that it may run sizeable fiscal deficits up to any point in time and yet have its debt ratio decline to zero eventually. (For a more comprehensive discussion on the implications of a negative IRGD, see Escolano 2010.)

20 In addition, in the presence of negative real interest rates, the actual interest rates in the region may not reflect the true shadow price of debt, thus involving substantial economic costs and distortions, which themselves pose a significant risk to fiscal sustainability and macroeconomic stability more broadly (Adams, Ferrarini, and Park 2010).

21 Akin to the "modified golden rule" in Blanchard and Fischer (1989), efficiency conditions associated with long-term economic growth and the intertemporal allocation 
of consumption by welfare-maximizing private agents require $\theta_{t}>0$ to hold for any economy close to its steady state. Otherwise, welfare-maximizing agents would have an incentive to borrow at low interest rates and raise present consumption, and roll over their debts indefinitely (up until $\theta_{t}>0$ ) in view of a declining ratio of debt to income (see Blanchard and Fischer 1989; Escolano 2010).

22 This roughly reflects the average $\theta$ for advanced economies of the G20 and represents a typical scenario assumption for this type of exercise (IMF 2011a: 52).

23 Due to the need for different scales on the vertical and horizontal axes of Figure 3.8, its separating line is drawn more steeply than the same line in Figures 3.5 and 3.7. The interpretation of the line remains the same.

24 The only exception among the 24 countries is Fiji, which would benefit from this scenario because it involves a positive IRGD that is narrower than what it has actually been facing.

25 DSA is routinely implemented by ADB, the IMF, the World Bank, and other organizations in the context of country economic and financial reports, lending operations, and country assistance programs. The IMF has been leading the conceptualization and implementation of DSA for both market-access and poorer countries. It publishes debt sustainability assessments for its member countries, typically in the context of annual Article IV country consultations or IMF program reports.

26 This applies to countries with access to the international financial markets. A slightly different analysis is applied for low-income countries, which are mainly recipients of concessional loans, characterized by long grace periods and a high grant element. To reflect these features of public debt, DSA for poorer countries is conducted on the basis of net present value of debt over longer horizons of up to 20-30 years. See IMF and IDA (2010) for guidelines of their joint Debt Sustainability Framework for Low-Income Countries.

27 See IMF (2008) for an outline of the stress tests typically conducted in relation to market-access countries.

28 Equations (3.3) and (3.5) express the same accounting identity (apart from $Z_{t}$ ), showing the evolution of the debt ratio to depend on the real interest rate, the real growth rate, and the primary fiscal balance. Equation (3.3) subsumes inflation into the nominal growth rate and the interest rate, whereby the latter reflects the local currency equivalent of effective interest paid on both domestic and foreign-currency denominated debt. Equation (3.5) more explicitly accounts for these individual factors, although a clean separation is not possible. For example, the denominator $\left(1+g_{t}+\pi_{t}+g_{t} \pi_{t}\right)$ of the first three items of the right-hand side of equation (3.5) is a decomposition of the nominal growth rate in its real and nominal components, and the numerators of the first and third items include variables other than the interest rate and the exchange rate, respectively.

29 Unfortunately, the higher the stock-flow reconciliations are through $Z_{t}$, the lower the usefulness of DSA is as an ex-post accounting tool of the changes in the debt stock by means of flow accounting alone.

30 The aggregate of seven Asian economies was introduced in relation to the regression analysis in the first section of this chapter. The aggregate is included because it represents a largely representative sample of core Asian countries from the East, South, and Southeast Asian subregions, for which a consistent set of data is available.

31 The forecasts are as of 30 September 2011. ADB macroeconomic forecasts are drawn from the Asian Development Outlook 2011 Update (ADB 2011b). ADB forecasts are integrated with IMF forecasts, as reflected in the World Economic Outlook September 2011 (IMF 2011c) and in IMF country documents. The data sources underlying Figure 3.8 are described in Appendix 3.2, Table A3.2.2. For a detailed discussion of country-specific DSAs, rather than subregional aggregates, see the next section in this chapter. 
32 See, for example, IMF (2011a; 2011b: 10-11).

33 For a discussion of hidden liabilities, see Chapter 2. For an example of DSA that explicitly accounts for hidden liabilities, see Chapter 4 on the PRC.

34 Any discrepancy between the two lines in any given year will accumulate over the years. This explains why, except for the Pacific, the two lines diverge quite strongly at some point, particularly for Central Asia and East Asia. The causes of large discrepancies are manifold and specific to individual countries. On the causes underlying large stock-flow reconciliation in the Republic of Korea, see the discussion in Box 7.1 (Chapter 7).

35 The only exception is Georgia, for which projections show a slight increase in the debt ratio in 2012 and a decline thereafter.

36 The size of the shock is country-specific, depending on the standard deviation of the country's interest and growth rate during 2001-10.

37 For a review of the application of stochastic DSA to emerging economies, see Ferrucci and Penalver (2003), Garcia and Rigobon (2004), and Celasun, Debrun, and Ostry (2006).

38 This is in line with the observation in Figure 3.12, which suggests that high primary fiscal surplus is the main factor lowering debt ratios in the Republic of Korea.

\section{References}

Adams, C., and Ferrarini, B. (2010) "Fiscal Sustainability in Developing Asia," Background paper for Asian Development Outlook, Unpublished, Mandaluyong City: Asian Development Bank.

Adams, C., Ferrarini, B., and Park, D. (2010) "Fiscal Sustainability in Developing Asia," ADB Economics Working Paper Series No. 205, June 2010, Mandaluyong City: ADB.

Asian Development Bank (ADB) (2010a) Asian Development Outlook 2010, Asian Development Bank.

- (2010b) Asian Development Outlook Update 2010, Mandaluyong City: ADB.

(2011a) Asian Development Outlook 2011, Mandaluyong City: ADB.

(2011b) Asian Development Outlook Update 2011, Mandaluyong City: ADB.

Arellano, M., and Bond, S. (1991) "Some Tests of Specification for Panel Data: Monte Carlo Evidence and an Application to Employment Equations," Review of Economic Studies 58: 277-97.

Blanchard, O., and Fischer, S. (1989) Lectures on Macroeconomics, Cambridge, MA: MIT Press.

Bohn, H. (1998) "The Behavior of US Public Debt and Deficits," Quarterly Journal of Economics, 113(3): 949-63.

Blundell, R., and Bond, S. (1998) "Initial Conditions and Moment Restrictions in Dynamic Panel Data Models," Journal of Econometrics 87: 115-43.

Celasun, O., Debrun, X., and Ostry, J. (2006) "Primary Surplus Behavior and Risks to Fiscal Sustainability in Emerging Market Countries: A 'Fan-Chart' Approach," IMF Working Papers 06/67, Washington, DC: International Monetary Fund.

Chalk, N., and Hemming, R. (2000) "Assessing Fiscal Sustainability in Theory and Practice," IMF Working Paper, WP/00/8, April 2000, Washington, DC: International Monetary Fund.

Eichengreen, B., Park, D., and Shin, K. (2011) "When Fast Growing Economies Slow Down: International Evidence and Implications for the People's Republic of China," Economics Working Paper Series, No. 262, June 2011, Mandaluyong City: ADB. 
Escolano, J. (2010) “A Practical Guide to Public Debt Dynamics, Fiscal Sustainability, and Cyclical Adjustment to Budgetary Aggregates,” International Monetary Fund Technical Notes and Manuals, January 2010, Washington, DC: IMF.

Ferrucci, G., and Penalver, A. (2003) "Assessing Sovereign Debt Under Uncertainty," Financial Stability Review, Bank of England, December: 151-59.

Garcia, M., and Rigobon, R. (2004) “A Risk Management Approach to Emerging Market's Sovereign Debt Sustainability with an Application to Brazilian Data," NBER Working Papers 10336, Cambridge, MA: National Bureau of Economic Research.

Greene, W. (2012) Econometric Analysis, 7th ed. Upper Saddle River, NJ: Prentice Hall.

Horne, J. (1991) "Indicators of Fiscal Sustainability," International Monetary Fund Working Paper No. 91/5, Washington, DC: IMF.

International Monetary Fund (IMF) (2003) Public Debt in Emerging Markets, World Economic Outlook, September 2003, Available HTTP: < http://www.imf.org/external/ pubs/ft/weo/2003/02/index.htm > (2008) "Staff Guidance Note on Debt Sustainability Analysis for Market Access Countries," 3 July 2008, Available HTTP: < http://www.imf.org/external/np/pp/eng/ 2008/070308a.pdf>

(2011a) "Fiscal Monitor, Shifting Gears-Tackling Challenges on the Road to Fiscal Adjustment," April 2011, Washington, DC: IMF.

- (2011b) "Modernizing the Framework for Fiscal Policy and Public Debt Sustainability Analysis," 5 August 2011, Available HTTP: <http://www.imf.org/ external/np/pp/eng/2011/080511.pdf> IMF.

IMF and the International Development Association (IDA) (2010) "Staff Guidance Note on the Application of the Joint Bank-Fund Debt Sustainability Framework for LowIncome Countries," 22 January 2010, Available HTTP: < http://www.imf.org/external/ np/pp/eng/2010/012210.pdf>

Mendoza, E., and Ostry, J. (2007) "International Evidence on Fiscal Solvency: Is Fiscal Policy 'Responsible'?” Journal of Monetary Economics, 55(6): 1081-93. 


\title{
4 Public debt sustainability and hidden liabilities in the People's Republic of China
}

\author{
Richard Hemming*
}

\section{Introduction}

As this chapter was being written, during the latter part of 2011, global financial markets were in turmoil following a sovereign downgrade in the United States and there were worries that the debt crisis in Europe was spreading from the periphery to the core. Against this background, government debt in the People's Republic of China (PRC), which official numbers suggest is well below $20 \%$ of gross domestic product (GDP), would hardly seem to merit a second glance. Yet concern about sovereign debt in the PRC has been growing, with the possibility that official numbers significantly understate the government's true indebtedness.

This is not the first time that such a concern has been voiced. Lardy (2004) explains how nonperforming loans (NPLs), prompted by a sharp increase in bank lending in the early 2000s combined with poor risk management by banks, can impose a fiscal burden that is not reflected in debt statistics but is nonetheless a potential threat to debt sustainability. The issue now is similar-rapid growth in bank lending for the last few years, specifically to finance local government investment in infrastructure. This investment and the associated borrowing are off-budget, and the quality of many projects, and by implication the soundness of bank assets is questionable. For these reasons, government debt in the PRC could be as high as in countries where the possibility of default is being openly discussed, and there has been speculation that a debt crisis is more than a remote possibility for the PRC.

Clearly, this is an opportune time to have a closer look at debt and debt sustainability in the PRC, and to provide answers to the following questions:

- What is the PRC's true debt position? Answering this question requires understanding what is included in official debt numbers and deciding whether the government has hidden liabilities that should be counted as debt and included in headline debt numbers. ${ }^{1}$

\footnotetext{
*This chapter has benefitted from comments by discussants (Mark Kruger and Louis Kuijs) and participants at a technical workshop held in Beijing on 22 July 2011 where preliminary findings were presented. Claire Ying Shi provided valuable research assistance. However, the author is solely responsible for the views expressed here.
} 
- Does the government have other hidden liabilities that may not count as debt but should be taken into account in assessing debt sustainability? To answer this question, the nature and consequences of all hidden liabilities have to be identified.

- How should the way that debt sustainability is assessed be modified to reflect hidden liabilities? One possibility is to include them in an augmented total debt measure, as is done by people who have produced much higher debt numbers for the PRC. However, an alternative approach, based on assessing the fiscal risk associated with hidden liabilities, provides a basis for more helpful insights about debt sustainability.

- When all hidden liabilities are taken into account, does the PRC have a sovereign debt problem? If so, what should be done? Even if not, hidden liabilities can pose fiscal and other macroeconomic management challenges that have to be addressed.

\section{What do official debt numbers say?}

Figure 4.1 describes the evolution of government debt. The data are from the International Monetary Fund (IMF) World Economic Outlook (WEO) database, and they refer to gross debt incurred from the budgetary operations of central and local government. Local government comprises provinces, municipalities, and counties. Off-budget borrowing to finance local government infrastructure investment is not included. The WEO numbers are very close to the official PRC government numbers, and are widely accepted headline numbers.

The debt ratio rose steadily through the late 1990s and early 2000s and reached just over $19 \%$ of GDP in 2003, then fell back (albeit erratically) to $17 \%$ of GDP in $2010 .^{2}$ The spike in 2007 is due to CNY1.6 trillion in bonds issued to establish the China Investment Corporation, while the pickup in 2008 and

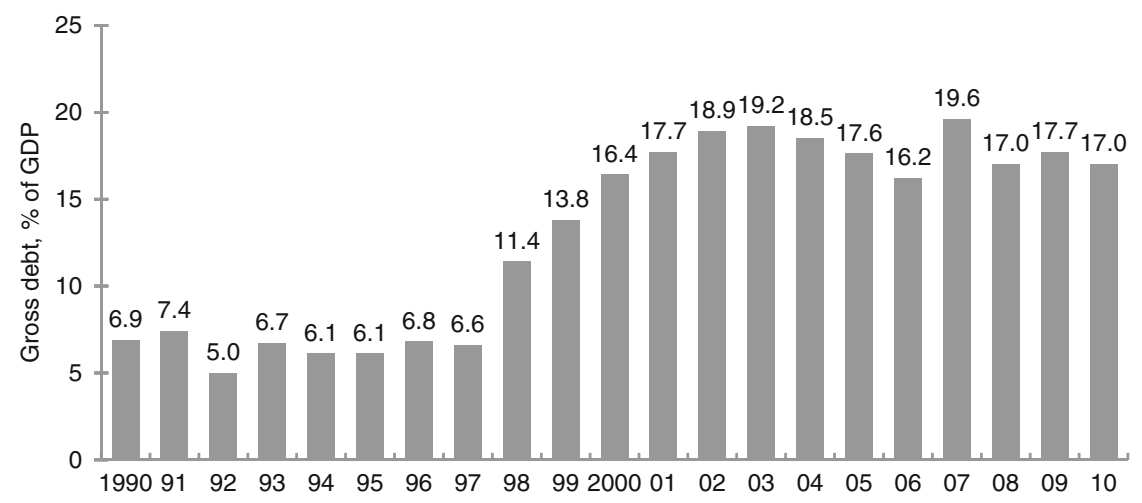

Figure 4.1 General government debt, 1990-2010.

$\mathrm{GDP}=$ gross domestic product.

Source: IMF World Economic Outlook database. 


\section{R. Hemming}

2009 reflects borrowing associated with fiscal stimulus spending in response to the global financial and economic crisis. The fall in 2010 reflects the withdrawal of stimulus.

In general, debt developments have been heavily influenced by the government's activist approach to fiscal policy, where government plans have been characterized by Lida (2007) and others as proactive (meaning expansionary), tight or moderately tight, or prudent (meaning neutral). ${ }^{3}$ However, as Dunaway and Fedelino (2006) explain, the announced and actual fiscal stances differ, due to deviations of revenue and expenditure outturns from budget plans. Revenue is generally underestimated; excess revenue used to be overspent and fiscal policy was often looser than planned, but more recently part of excess revenue has been saved and fiscal policy has tended to be tighter than planned. For this reason, and as can be seen in Figure 4.2, while fiscal stimulus was supposed to continue in 2010 before being withdrawn starting in 2011, withdrawal actually began in 2010 owing to unanticipated revenue growth.

The IMF (2011b) projection in Figure 4.3 shows the debt ratio falling through to 2016 based on assumptions that fiscal stimulus would be withdrawn further in 2011; the primary balance will improve through to 2013 due to increasing revenue collections before stabilizing with a primary surplus of $0.5 \%$ of GDP (which would mean a 2.5\% of GDP improvement from 2010); and the interest rate-growth differential (IRGD) will average about -9 percentage points. By 2016 , debt will have fallen to $9.3 \%$ of GDP.

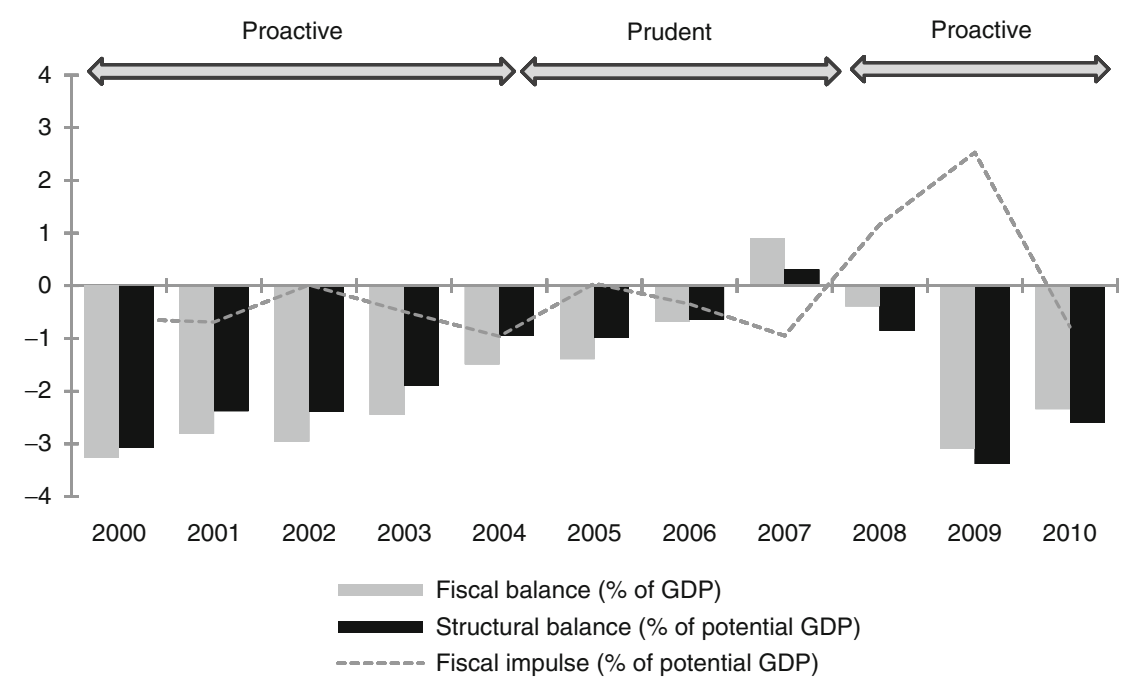

Figure 4.2 Fiscal stance, 2000-10.

$\mathrm{GDP}=$ gross domestic product.

Source: IMF World Economic Outlook database. 


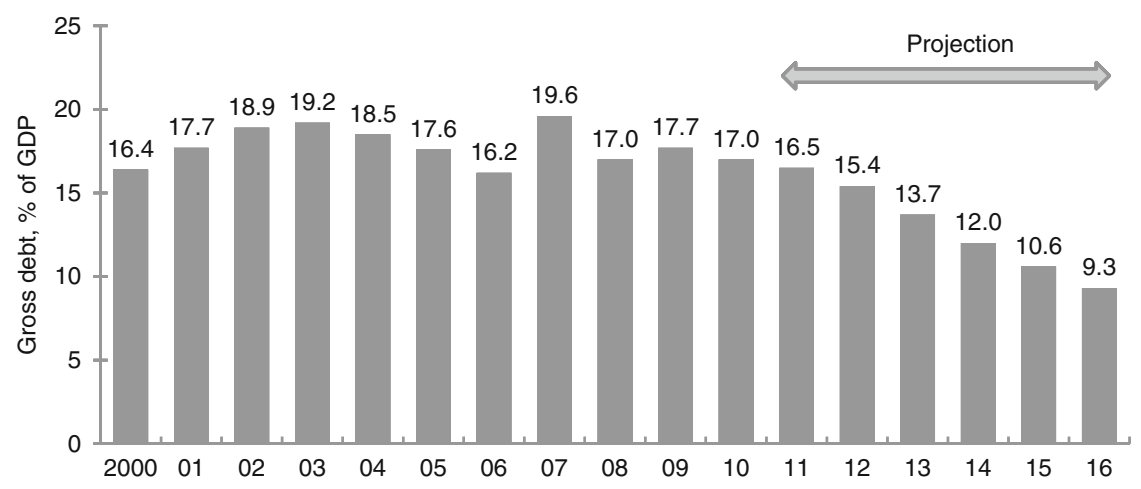

Figure 4.3 General government debt, 2000-16.

Source: IMF World Economic Outlook database.

International comparison also presents government debt in the PRC in a good light. Indeed, Figure 4.4 shows that debt in most emerging markets, including those that have experienced debt crises in the past, is significantly lower than in industrial countries where debt is a current concern. Moreover, debt in the PRC is half the emerging market average, with only Chile, Kazakhstan, Nigeria, the Russian Federation, and Saudi Arabia, all resource-rich countries, having less debt than the PRC. That said, emerging markets have in the past defaulted with quite low debt ratios, but this is because their debt structures were risky. Unlike countries that borrowed mainly short term and in foreign currency, and were therefore exposed to interest rate and exchange rate risk, the PRC hardly any foreign currency government debt, while the maturity structure of the debt is well balanced.

Not surprisingly, markets seem unconcerned about the PRC's sovereign debt. Figure 4.5 depicts a steadily improving credit rating, except for a single "technical" downgrade in 1997. The alternative market indicators shown in Figure 4.6 give the same benign impression. All in all, debt in the PRC does not appear to be anything to fret about. Appearances, however, can be deceptive.

\section{Are hidden liabilities masking a more serious debt problem?}

"Government debt, including hidden liabilities, could reach RMB 39.8 trillion or $96 \%$ of GDP in 2011. The worst case is a pretty large-scale financial crisis around 2012. The slowdown would last at least two years and maybe longer" (V. Shih, quoted on Bloomberg 2010).

If Shih is correct, government debt in PRC is of the same magnitude as that in Iceland or Ireland, and is exceeded in only a few highly indebted industrial countries (Italy, Greece, and Japan). However, while alarm bells are already being 


\section{R. Hemming}

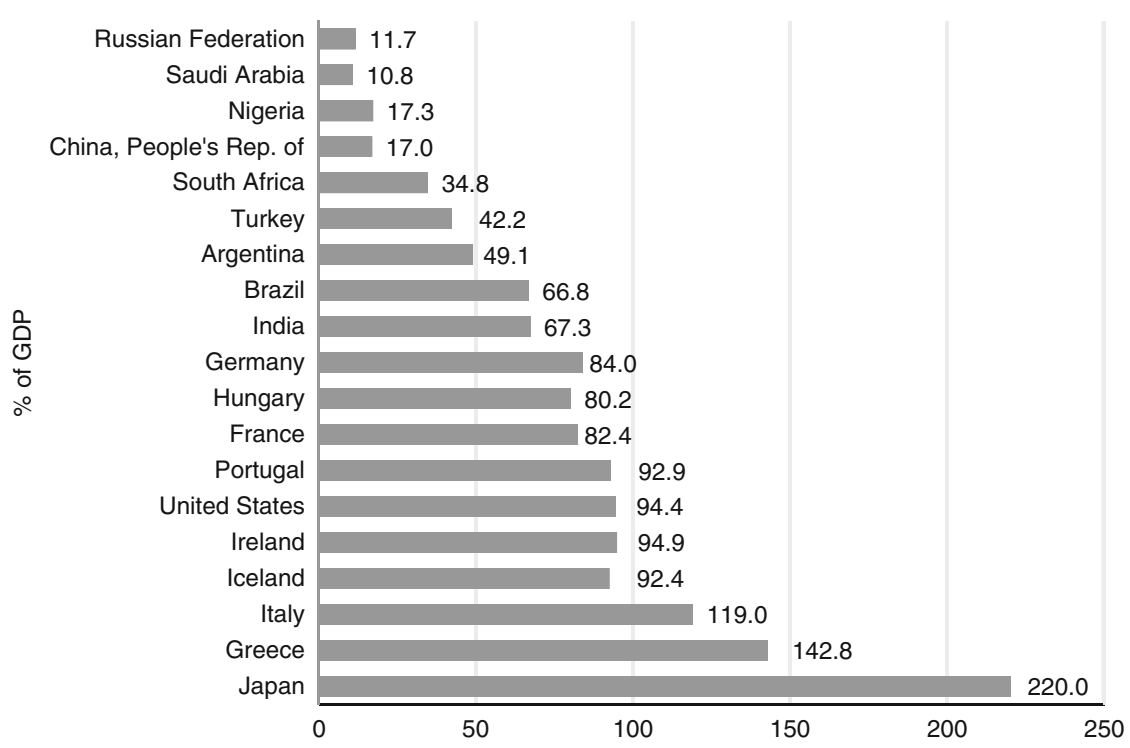

Figure 4.4 Gross debt by economy, 2010.

$\mathrm{GDP}=$ gross domestic product.

Source: IMF World Economic Outlook database.

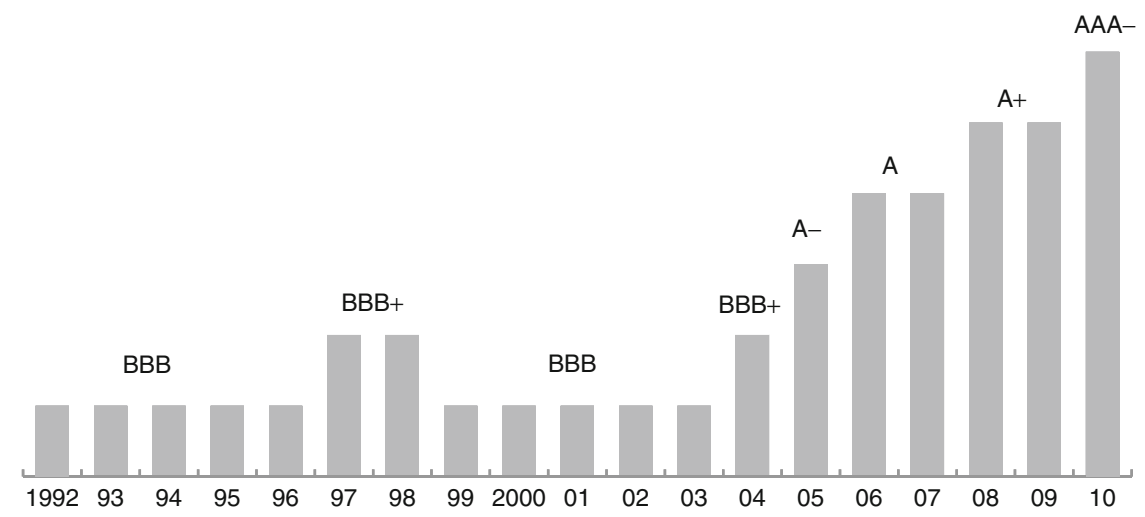

Figure 4.5 Standard \& Poor's sovereign bond rating, 1992-2010.

Source: Standard \& Poor's, cited in Roubini Global Economics (2010). 


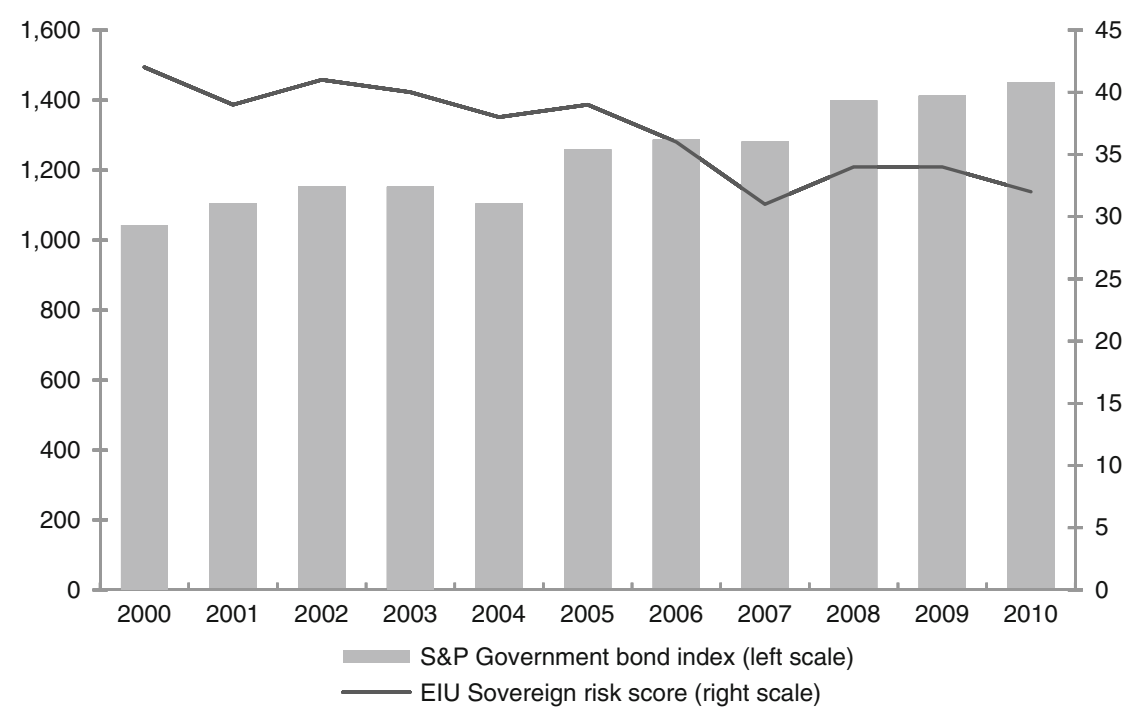

Figure 4.6 Government bond index and sovereign risk score.

EIU $=$ Economist Intelligence Unit, $\mathrm{S} \& \mathrm{P}=$ Standard \& Poor's.

Source: Standard \& Poor's, cited in Roubini Global Economics (2010); Economist Intelligence Unit.

sounded more widely (see The Economist 2011: 86), it is important to understand the sort of liabilities that $96 \%$ of GDP and similar numbers count as debt. While the detail underlying such numbers is often lacking, it is quite easy to produce a disturbingly high number, although not one quite as high as 96\% of GDP. Table 4.1, which includes many of the sources of hidden liabilities mentioned by people who have discussed the issue, illustrates this. ${ }^{4}$ The debt of local investment companies (LICs) merits some explanation in view of its size, and the recent attention it has attracted from Shih and others. (The individual items in this table will be discussed later.)

LICs are off-budget special purpose entities set up by local governments to finance infrastructure investment and other urban development projects. ${ }^{5}$ The LICs' main source of finance is bank loans, which are partly collateralized by land and other local government assets, and LICs depend heavily on land sales for revenue. The number of LICs, their borrowing, and their reliance on land sale revenue have all expanded rapidly with the government's fiscal stimulus program, given its heavy emphasis on infrastructure spending. ${ }^{6}$ So too have concerns about the quality of the projects that the LICs are financing, the possibility that land prices will retreat from current levels, and the implications for banks should a sizable number of LICs run into repayment difficulties. It is widely assumed that lending to LICs is either explicitly or implicitly guaranteed by government, in which case widespread loan delinquency would likely have a significant fiscal cost. 
Table 4.1 Total government debt, 2009

\begin{tabular}{lc}
\hline Debt & \% of GDP \\
\hline 1. Commercial bank NPLs & 1.5 \\
2. ABC NPLs & 2.5 \\
3. Asset management company bonds & 2.9 \\
4. Policy bank bonds & 13.3 \\
5. PBOC bonds & 12.4 \\
6. Local investment company debt & 33.5 \\
7. Ministry of Railways bonds & 0.9 \\
Hidden liabilities & $\mathbf{6 7 . 0}$ \\
Official government debt & 17.7 \\
Total government debt & $\mathbf{8 4 . 7}$ \\
\hline
\end{tabular}

$\mathrm{ABC}=$ Agricultural Bank of China, GDP $=$ gross domestic product; $\mathrm{NPL}=$ nonperforming loan, $\mathrm{PBOC}=$ People's Bank of China.

Sources: IMF World Economic Outlook Database; China Banking Regulatory Commission; ABC Annual Report; CEIC Data Co. Ltd.; PBC, Victor Shih (various reports); Trusted Sources (2010).

Putting aside momentarily the numbers in Table 4.1, it is interesting to ask whether the approach the table embodies is a useful starting point for thinking about government debt and its sustainability. More specifically, is it meaningful to add a mix of hidden liabilities — bank NPLs, bonds issued by public financial institutions, and off-budget debt of government entities - to official debt? Are they equivalent, or should they be treated differently? And what about other hidden liabilities (e.g., rising pension costs and bailouts of state-owned enterprises [SOEs])? Answering these questions is key to understanding whether the PRC faces a serious debt problem, and to developing an appropriate approach to managing both official debt and hidden liabilities.

\section{Standard debt sustainability analysis}

A useful starting point for analyzing the issues raised by the foregoing questions is the debt sustainability analysis (DSA) routinely undertaken by international organizations, rating agencies, and others. Figure 4.7 provides the results of the standard approach for the PRC, which involves preparing a baseline scenario based on a set of policy and economic assumptions, alternative policy scenarios, and sensitivity analysis with respect to policy and economic assumptions. The 2010 and 2011 figures are treated as estimated outturns and the projection period is 2012-16. During this period, the primary balance improves precisely as assumed in IMF (2011b) and in producing in Figure 4.3, while the IRGD averages about $-8.5 \%$ percentage points, based on Asian Development Outlook projections (ADB various years). Although this is a slightly smaller difference than assumed by the IMF, the baseline scenario in Figure 4.7 shows a similar decline in the debt ratio as does Figure 4.3.

Alternative policy scenarios assume that all variables are at their historical average for the period 1999-2009, with a primary deficit of $1.2 \%$ of GDP, and 


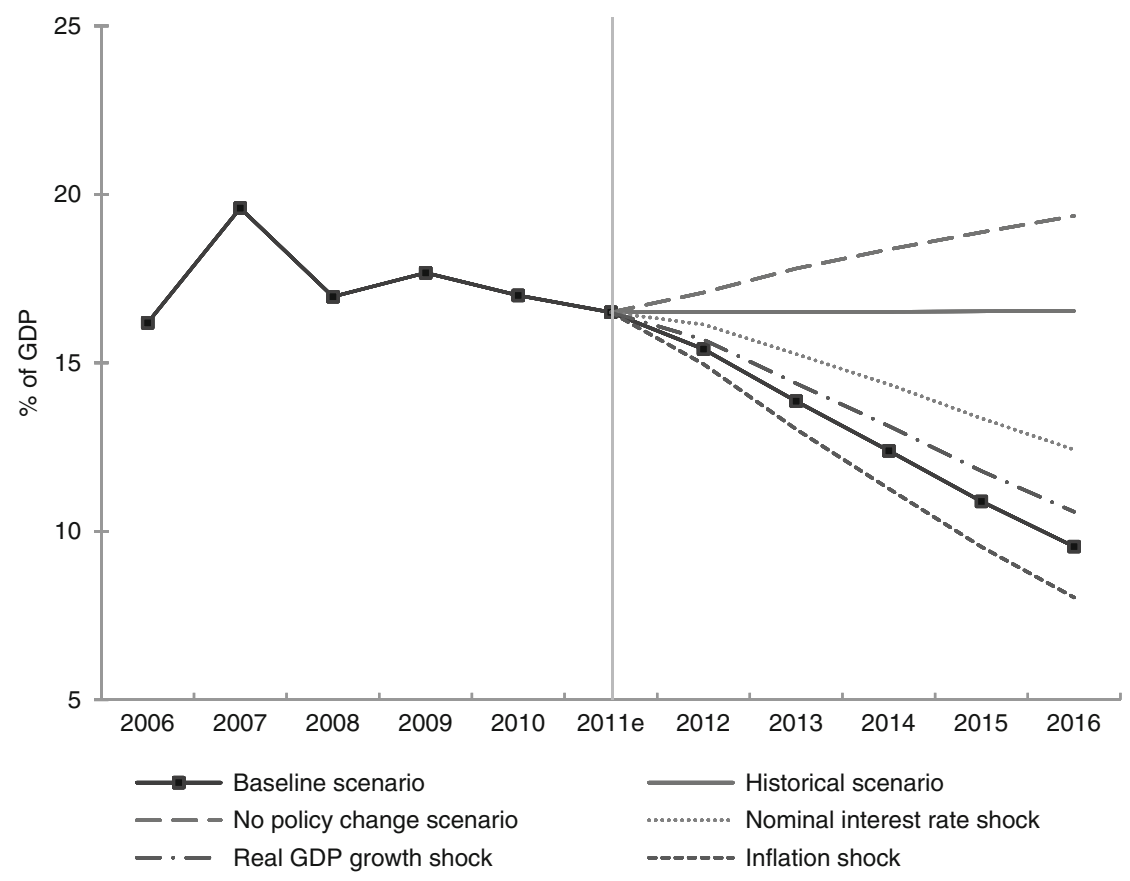

Figure 4.7 Debt scenarios and sensitivity analysis, 2006-16.

$\mathrm{e}=$ estimate, $\mathrm{GDP}=$ gross domestic product.

Source: ADB based on IMF World Economic Outlook database, and Asian Development Outlook assumptions.

that the primary deficit stays at its 2009-11 average of 2\% of GDP (i.e., no policy change). Sensitivity tests report the independent effects of 1 standard deviation permanent shocks to the real GDP growth rate, the nominal interest rate on government debt, and the inflation rate. An exchange rate shock is usually also included, but this has no effect given that the PRC has very little foreign currency debt. ${ }^{7}$ The debt ratio could end up on an upward rather than a downward path, especially with a combination of looser-than-planned fiscal policy and adverse economic shocks. But how much can be read into this?

It is important to note that Figure 4.7 does not depict a central projection of the debt ratio with a reasonably high probability of being the actual outcome, flanked by increasingly less likely outcomes. In fact, the baseline scenario is highly unlikely to materialize, and the other scenarios are no more or less likely to do so. They are simply guesses about how future public finances might evolve in different states of the world, which is why they are sometimes referred to, more appropriately, as illustrative scenarios (see IMF 2011d). ${ }^{8}$ Moreover, such scenarios convey little information about the likelihood of debt sustainability problems. 


\section{R. Hemming}

One can safely conclude that if the debt ratio looks set to increase continuously, then the government will eventually be unable to finance flow deficits and retire or roll over existing debt. ${ }^{9}$ The government will then have little choice but to default on debt service payments and/or other obligations (including by inflating them away), or to embark on a sizeable fiscal correction that could create a debt spiral where default is delayed but a recurring cycle of slower growth, deteriorating debt dynamics, and further fiscal correction eventually make default unavoidable. However, default or near default could be a long time coming, and so it would be useful to know when debt enters a danger zone where default risk becomes unacceptably high. Unfortunately, it is far from straightforward to establish a benchmark, or debt limit, that distinguishes a safe debt ratio from a dangerous one. Such a benchmark should reflect a country's debt tolerance-its capacity to successfully manage fiscal policy as debt rises - but debt tolerance depends on a wide array of country-specific factors (including debt structure, hidden liabilities, economic volatility, institutional quality, adjustment record, and default history) that are hard to translate into a benchmark. ${ }^{10}$ Thus, a reliance on rule-of-thumb debt limits is understandable. ${ }^{11}$

The limitations of debt scenarios and sensitivity analysis notwithstanding, they illustrate possible outcomes that can usefully inform policy decisions. Knowing the trend in the debt and its underlying determinants is an essential starting point for thinking about fiscal policy choices. However, care is always needed in interpreting DSA results and a large element of judgment is required in doing so. Moreover, while the sophistication of DSA has been improved, especially through the use of stochastic simulations to generate alternative outcomes and fiscal reaction functions to forge a link between debt and fiscal policy responses, this probably calls for even greater caution. For example, the "state of the art" is currently represented by fan-charts, and it is tempting to interpret them as showing the probability attached to different debt paths. But fan-charts in fact show the probability of deviations from a baseline for which the probability of occurrence is unknown. Again, fan-charts can be useful in thinking about fiscal policy, but the process of producing them has to be well understood before too much is read into them.

What are the implications of this discussion of DSA for the PRC? Certainly, the discussion points to the need to think about whether the DSA as shown in Figure 4.7, even on its own terms, tells the whole story about the debt outlook. Two things come immediately to mind in this connection. First, what should reasonably be assumed about future fiscal policy? On the one hand, the government is facing pressure to step up social and rural development spending. On the other hand, there is considerable scope to increase revenue collections, and the government's stated objective is to achieve broad budget balance, which it believes is necessary to provide room (or fiscal space) to respond to future fiscal challenges. Second, is it reasonable to assume that the IRGD will continue to remain so negative? Maybe the possibility of a sharp growth slowdown (which the evidence suggests is usual for middle-income countries and could happen to the PRC before 2016) ${ }^{12}$ and significantly higher interest rates (due to short-term monetary tightening and 
longer term financial liberalization) should be considered. However, at the current low debt level, even reasonable pessimism about these things cannot produce a troubling debt outlook. ${ }^{13}$

This conclusion might change, however, if debt is in fact higher than the official numbers suggest. As previously noted, hidden liabilities influence debt tolerance, the point being that, all other things being equal, a country with sizeable hidden liabilities is less debt-tolerant because such liabilities can create a future fiscal burden and future debt. The approach adopted in Table 4.1, where hidden liabilities are counted in a measure of total debt, simply means that debt levels are initially higher. Either way, whether through increases in future spending or a higher starting debt ratio, DSA is affected, and the assumptions made about future fiscal policy and key macroeconomic variables could then matter much more.

\section{Hidden liabilities and the measurement of government debt}

\section{Government obligations}

Figure 4.8 classifies government obligations from hard to soft, with official debt being "hard" in the sense that debt interest and amortization payments are certain in their timing and reasonably certain as to their amount. ${ }^{14}$ Arrears are also quite hard, being fairly certain in terms of amount but less so in timing. Contingent liabilities arising from explicit guarantees, deposit insurance, and the like must be honored if triggered, although being of uncertain timing and amount. They are somewhat harder than contractual obligations, such as government and social security pensions or the purchase of services under public-private partnership (PPP) arrangements, which the government may have every intention of honoring in full but policy decisions can be taken to change this. ${ }^{15}$ "Stand behind obligations" refers to implicit guarantees, where experience may suggest that the government will step in to bail out the financial sector and to provide disaster relief, but will not make this explicit because of moral hazard concerns. Finally, at the "soft" end, come constructive obligations, which refer to the services that government is confidently expected to provide, but for which there is no contractual backing.

Arrears, contingent liabilities, contractual obligations, and "stand behind obligations," have all at some time been referred to as hidden liabilities. Constructive obligations, on the other hand, relate to the government's spending commitments, and few people would argue that these obligations create a liability. But what determines whether a hidden liability is a debt? Statistical standards provide some guidance on this, because they define debt as follows: "Total gross debt consists of all liabilities that are debt instruments. A debt instrument is defined as a financial claim that requires payment(s) of interest and/or principal by the debtor to the creditor at a date, or dates, in the future" (IMF 2011c: 3). On the face of it, this definition provides little scope to include hidden liabilities as part of debt. While insurance, pension, and standardized 


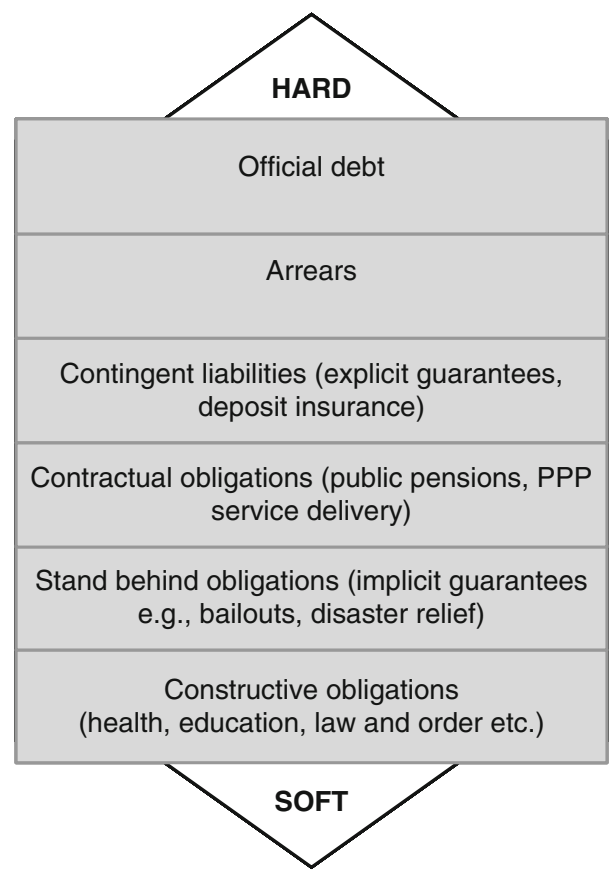

Figure 4.8 The spectrum of government obligations.

$\mathrm{PPP}=$ public-private partnership.

Source: Author, drawing on Heller (2004).

guarantee schemes are treated as debt instruments, this only provides a basis for counting government pensions and small guarantees issued in large numbers (e.g., export credit guarantees), the costs of which can be reliably estimated, as debt. Social security pensions and most contingent liabilities would be excluded. ${ }^{16}$ However, statistical standards also define the institutional coverage of debt statistics, providing more scope for including hidden liabilities as debt. This will be explained in the following section by specific reference to hidden liabilities in the PRC.

\section{Hidden liabilities}

\section{Nonperforming loans}

At the end of the 1990s, the four big state-owned commercial banks-Agricultural Bank of China, Bank of China, China Construction Bank, and Industrial and Commercial Bank of China - had nonperforming loans (NPLs) of $42 \%$ of loans, 
or about $30 \%$ of GDP. Much of the buildup in NPLs had occurred in the second half of the 1990s, even though three special purpose banks - the Agricultural Development Bank, China Development Bank, and Ex-Im Bank-had been set up in 1994 to take over responsibility for policy lending, which had previously accounted for about one-third of the lending of the big four. In 1999, an asset management company (AMC) was paired with each of the four banks, ${ }^{17}$ and in 1999 and 2000 they assumed CNY1.4 trillion of NPLs, including CNY100 billion from China Development Bank. These were taken on at par, financed by cash provided by the Ministry of Finance, People's Bank of China (PBOC) credit, and (for the most part) by issuing 10-year AMC bonds. ${ }^{18}$ By 2006, the AMCs had disposed of CNY1.2 trillion in NPLs (through auction, recovery action, rescheduling, and debt-for-equity swaps with SOEs) with a recovery rate of about $21 \%$. The poor quality of remaining assets, disputes over the ownership of collateral, and other issues have prevented significant further sales, and AMCs have resorted to trading bad assets among themselves. The balance sheets of AMCs are clearly fragile, with what good assets they have being needed simply to ensure that interest is paid on AMC bonds.

In the meantime, as Figure 4.9 shows, by the year 2010, NPLs had fallen sharply to CNY429 billion, or just over 1\% of loans and of GDP in absolute terms, due to write-offs and improved lending standards, and relative to total loans and GDP, due to stepped up lending that financed rapid growth. Also, in 2008, CNY800 billion of Agricultural Bank of China NPLs was transferred to a special fund as part of the bank's restructuring. Despite lower NPLs, having AMC bonds on their balance sheets clearly exposes banks to the risk that AMCs may default on their bonds. For this reason, and maybe because banks want to keep AMCs in business should there be a further buildup of bank NPLs, banks have been providing financial support to AMCs. NPLs at policy banks are modestfor the largest bank, China Development Bank, they are less than $1 \%$ of loans (although, as previously noted, this is after some of its NPLs were taken over by AMCs).

What is the hidden liability associated with NPLs? In the worst case, the government could be faced with the full cost of cleaning up NPLs. Based on the figures in Table 4.1 (p. 115), as of the end of 2009 this would cost just under $7 \%$ of GDP. However, commercial bank and policy bank NPLs are modest and risks are manageable, especially given recent increases in provisioning. However, NPLs held by AMCs are a different proposition, given the fragility of their balance sheets. If AMCs were to default on their bonds and other loans, banks and other creditors may be able to manage this on their own, or AMC debt may have to be assumed by the government because it is implicitly guaranteed. This discussion suggests that the government's expected liability due to NPLs in 2009 was less than 7\% of GDP, and probably no more than half that if the only significant risk is posed by AMCs. That said, NPLs could have a much larger downside, for example, if a significant share of bank lending to LICs were to go bad. ${ }^{19}$ 


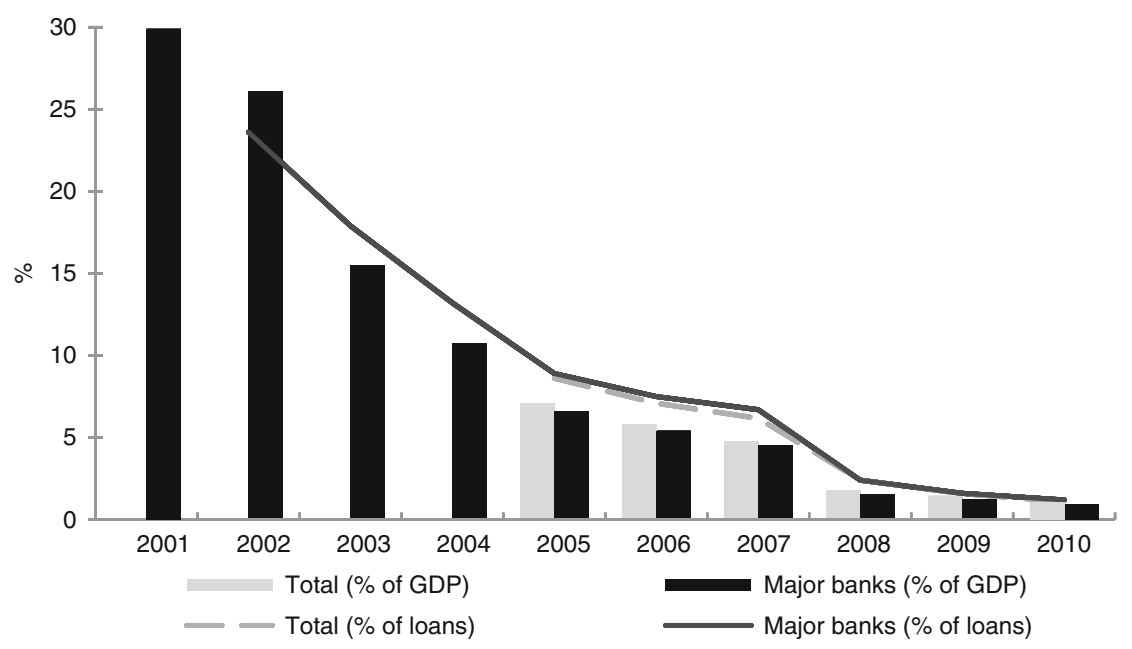

Figure 4.9 Commercial bank nonperforming loans, 2001-10.

$\mathrm{GDP}=$ gross domestic product.

Source: China Banking Regulatory Commission.

\section{Local investment companies}

Local governments are responsible for spending on regional economic and social development and on local administration, which accounts for about threequarters of general (central, provincial, municipal, and county) government budget spending. This is paid for by local taxes and nontax charges, and more recently from land sale proceeds. Local governments are not supposed to run deficits and cannot issue bonds, but in the last few years the central government has issued bonds on their behalf to cover budget gaps. However, as already noted, local governments also undertake off-budget spending on infrastructure and urban development. While local governments have some sources of off-budget revenue to cover this spending (mainly fees collected by funds and other off-budget entities), they use LICs to sidestep borrowing restrictions. Estimates suggest that there are 8,000-10,000 LICs; while the larger ones are known, many smaller LICs operate completely "under the radar." Outside speculation that LIC borrowing is a threat to debt sustainability has of late turned into official concern that they may indeed pose a problem for financial stability.

Of course, properly assessing LIC borrowing is difficult in the absence of good information about all aspects of their operations, although more financial data are beginning to emerge. With the ramping up of infrastructure spending as part of the government's fiscal stimulus, LIC borrowing has risen significantly in recent years. In 2009, LICs borrowed CNY1.3 trillion from banks, which was a third of bank lending. The China Banking Regulatory Commission estimates that the bank debt of LICs was CNY7.7 trillion as of mid-2010, while unofficial estimates 


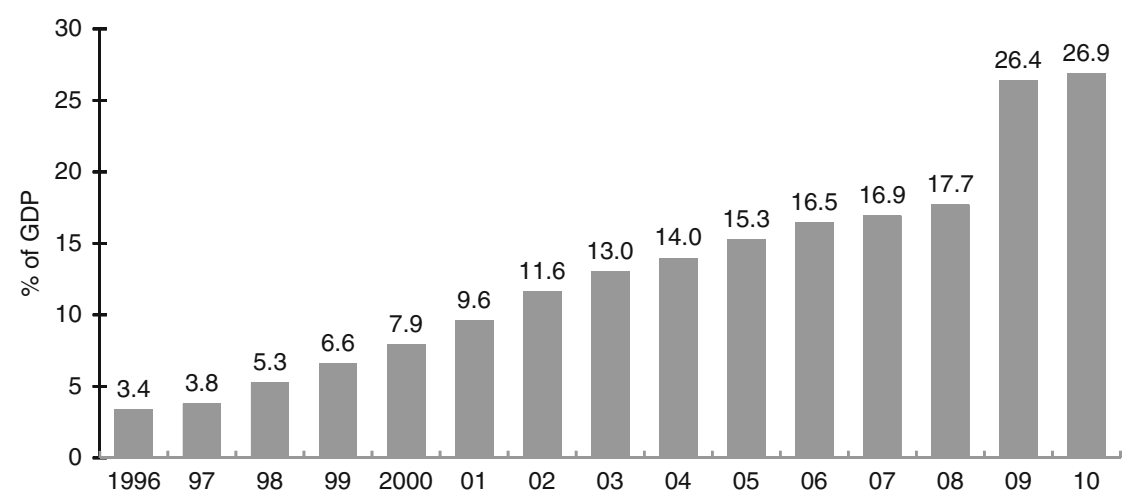

Figure 4.10 Local government debt, 1996-2010.

$\mathrm{GDP}=$ gross domestic product.

Source: The People's Republic of China's National Audit Office.

suggest that their total debt was as high as CNY11.4 trillion at the of end 2009 (when bank debt was CNY7.4 trillion). This is the basis of the LIC debt number reported in Table 4.1. However, the PRC's National Audit Office recently issued a report that estimates that local government debt was CNY10.7 trillion in 2010 (CNAO 2011). But this number is difficult to assess. The explicit debt of local governments of CNY6.7 trillion in 2010, including LIC debt of only CNY3.1 trillion in 2010, seems very low, with LIC debt in particular coming out well below other unofficial and official estimates. ${ }^{20}$ At the same time, bonds the central government issued on behalf of local governments, and possibly some other debt, are included in both the local government and official debt numbers. Moreover, the overall number includes CNY4 billion of guaranteed debt and unspecified borrowing, neither of which is clearly explained. In the final analysis, it is difficult to say exactly how much debt local governments (including LICs) have incurred, but for now it is assumed that CNY10.7 trillion, which has been highly publicized, is correct. Based on this number and other information in PRC's National Audit Office report, Figure 4.10 shows that, after increasing fairly steadily for a number of years (by slightly more than 1\% of GDP on average), local government debt accumulation accelerated sharply in 2009, reflecting the LIC borrowing binge, then slowed in $2010 .^{21}$

What should be made of numbers such as these? One possibility is to think of LICs as local SOEs, in which case the issue is what happens if LICs get into trouble and default on their bank debt. The answer is that bad LIC debts are added to bank NPLs, and the government's hidden liability is the expected fiscal cost associated with increased NPLs, plus the cost of any subsidies that have to be provided to keep troubled LIC-financed projects afloat. Following this approach, local government debt should exclude that of LICs, and would be quite 


\section{R. Hemming}

small (although local government guarantees of LIC debt may be large). Another possibility is to treat LICs as part of local government, because they are controlled by them, and to consolidate LIC operations with local government budgetary operations. LIC debt would then be counted as local government debt, and as general government debt. Statistical standards support this treatment: "Special purpose entities undertaking fiscal and/or quasi-fiscal activities and not bearing the risk associated with (their) assets and liabilities are part of general government" (IMF 2011c: 16). Because LIC borrowing, and the projects it finances, are to all intents and purposes backstopped by the government, this would seem to be the correct approach to take.

Whatever the treatment of LIC debt, it is necessary to form a view on how much LIC debt will go bad, but this is difficult given that the true riskiness of LIC borrowing is unclear. ${ }^{22}$ The degree of riskiness depends on the quality of projects that are financed. In all likelihood, LIC borrowing has so far been fairly low risk, in that it has financed investment to fill critical gaps in economic infrastructure and has generated high returns in terms of growth and government revenue. However, these returns do not generate the resources LICs use to service their bank debt; rather, the returns accrue to the government. So, if investment returns are lower than they might be because the quality of some projects is in doubt or, as is likely, they begin to fall as essential economic infrastructure projects give way to less profitable economic and social infrastructure, this creates problems for government. The principal risk facing LICs is that land sale revenue declines as the property market cools, which is beginning to happen in response to government containment measures. However, if lower property prices, higher interest rates, or some other development were to create problems for LICs, the ability of the government to respond could also be affected by lower investment returns and revenue.

\section{Other sources of hidden liabilities}

PBOC bonds. While PBOC bonds may be implicitly guaranteed by the government, statistical standards do not call for including the central bank in the general government (it is part of the financial corporation sector), and in practice this would only be justified where central bank policies are driven by fiscal policy objectives, that is, there is fiscal dominance (Anand and van Wijnbergen 1988). Because PBOC bonds are issued for monetary policy purposes, and given that the PBOC balance sheet is strong, they are not a hidden liability of government; the possibility that the PBOC could at some time require fiscal support creates a hidden liability, but this is highly unlikely and the associated hidden liability is very small. A related concern is the impact of accumulating depreciating dollars on the value of PBOC assets. Clearly, such an exchange rate movement weakens the PBOC balance sheet, but the way that the government is managing financial policy does not suggest that the exchange rate movement could lead the PBOC to need recapitalizing in the foreseeable future, and certainly not that it could result in insolvency. 
Ministry of Railways bonds. The PRC is investing heavily in the rail sector and much of its borrowing for this purpose is extrabudgetary. Here statistical standards are clear: "General government entities with individual budgets not covered by the general budget are considered extrabudgetary" (IMF 2011c: 10). Extrabudgetary entities are part of general government. Hence, Ministry of Railways (MOR) liabilities should count as debt, and not just the bonds it has issued, which is all that is in Table 4.1 .

State-owned enterprises. SOEs, of which there are well over 100,000 in the PRC, still play a major role in the economy. In many countries, loss-making and bankrupt SOEs are a major drain on fiscal resources. In the most extreme cases, where SOEs are controlled by government and engage in extensive fiscal (or quasi-fiscal) activities, the IMF has in the past called for consolidating the nonfinancial public enterprise sector with the general government and analyzing fiscal policy at the level of the public sector. Thus, for DSA purposes, the focus would shift from government to public sector debt, including SOE debt. Statistical standards provide some justification for this: "The [Government Finance Statistics] system covers all entities that materially affect fiscal policy...fiscal policy may be carried out by government-owned or controlled enterprises that engage mainly in commercial activities...these enterprises are not considered part of government" (IMF 2001d: 6). "Statistics should be compiled for the public sector as well as for the general government sector" (Ibid: 14). While this falls short of what the IMF has called for, and there is clear justification for paying more attention to SOE finances, making the public sector the focus of fiscal policy analysis is neither widely accepted nor especially compelling. Doing so would limit meaningful dialogue about fiscal policy that is formulated at the government level, the relevance of fiscal accounts that are influenced by commercial activities is unclear, and focusing on the public sector could hamper reforms to reduce the dependence of SOEs on government.

In the PRC case, SOEs are assigned fiscal and quasi-fiscal objectives and, for this and other reasons, some SOEs are loss makers. SOEs are also a source of bank NPLs, and defaults and bailouts, while rare, are not unknown. This means that SOEs could require subsidies or, in extreme circumstances, bailouts, which makes them a source of contingent liabilities. However, SOEs in the PRC are primarily commercial in orientation, and the SOE sector is not only profitable but also achieves a reasonable rate of return on assets, and so contingent liabilities arising for SOE operations do not seem to be a serious threat to debt sustainability. That said, some of the largest SOEs are state monopolies that can be highly profitable despite considerable inefficiency, and the sources and consequences of SOE inefficiency are a concern. ${ }^{23}$

Public-private partnerships. Most infrastructure investment in the PRC is financed by the government, and by local governments in particular, using some internal resources but mainly through borrowing. After some early forays in the power and water sectors in the 1980s and 1990s, PPP investment picked up in the 2000s. The Beijing Olympic venues may be the highest profile PPP projects, 


\section{R. Hemming}

but transport projects, especially road building, have been the most numerous. And PPPs are found across many sectors. Little has been written about PPPs in the PRC, but a weak legal framework, a lack of competitive bidding, bureaucratic intervention, and corruption seem to have led some projects to fail, although recent projects (e.g., the Beijing metro extension) appear to be more like model PPPs. While some projects have government guarantees, their extent and purpose is unclear. But if the guarantees are extensive, or are likely to become so as PPPs expand, there is a potentially significant contingent liability. Some PPPs will also involve the government in signing long-term service delivery contracts. While these do give rise to a contractual obligation, spending on them is small relative to total expenditure and the resulting hidden liability is also small.

Pension liabilities. The PRC faces significant pension challenges owing to the legacy costs of the pension system that was replaced in the 1997 reform, the cost of ongoing reform to address the limited coverage of the working population, and a rapidly aging population. This means that the social security pension system has an unfunded liability, but the size of this liability is far from clear. The legacy costs are in fact quite modest: in 2003 they were estimated at 7\% of GDP. The problem is determining the size of the overall unfunded liability. The estimates, which range from a low of $10 \%$ of GDP to a high of $141 \%$ of GDP for 2001 , are unhelpfully wide. In principle, the unfunded pension liability is the present value of future pensions less the sum of existing pension fund assets and the present value of future contributions, all based on the current pension system and announced reforms. A World Bank estimate of the pension financing gap for 2001, $95 \%$ of GDP, seems to be measuring the right thing, but is so out of date that it excludes the impact of significant reforms, especially the launch of a rural pension scheme that aims to achieve universal coverage by 2020 and the introduction of social pensions for the urban population. It is important to estimate the current unfunded liability, because it has a significant bearing on taxation and spending going forward (Sin 2005). The unfunded liability is a hidden liability, but its size is far from clear given that pension reform is in a state of flux and what pension provision will look like in the future is unknown, including the extent to which there will be more of a shift to a funded system.

\section{Augmented debt and hidden liabilities}

Based on the preceding discussion, a strong case can be made for augmenting the official debt number by adding local government debt and MOR debt to produce a comprehensive headline government debt number. Using the PRC's National Audit Office report numbers for local government debt and MOR numbers for its total liabilities, this would give the estimates in Table 4.2. Looking back at Figure 4.4 reveals that the numbers in Table 4.2 push debt in the PRC out of what is clearly the comfortable zone. ${ }^{24}$ And while debt is not clearly in the critical zone, the possibility that debt is significantly higher than current official numbers suggest argues for a more thorough investigation of its precise level and proper scrutiny of its implications. 
Table 4.2 Augmented total government debt, 2009 and 2010 (\% of GDP)

\begin{tabular}{lcc}
\hline Debt & 2009 & 2010 \\
\hline Official government debt & 17.7 & 17.0 \\
Local government debt & 25.5 & 26.9 \\
Ministry of Railways liabilities & 3.8 & 4.8 \\
Total government debt & $\mathbf{4 7 . 0}$ & $\mathbf{4 8 . 7}$ \\
\hline
\end{tabular}

Sources: IMF World Economic Outlook database; National Audit Agency; and Ministry of Railways, People's Republic of China.

Turning to hidden liabilities, the focus should be on contingent liabilities. Most obviously, NPLs and AMC losses merit the closest attention, but all sources of contingent liabilities should be considered, including explicit and implicit guarantees, insurance programs, bailouts, disaster spending, environmental cleanup, legal action against government, indemnities, uncalled capital, etc. The idea is to treat contingent liabilities as a source of fiscal risk, and to incorporate fiscal risk into DSA. The following section discusses how to do this.

\section{Debt sustainability analysis and fiscal risk}

\section{Revisiting standard debt sustainability analysis}

In the first instance, the standard DSA can be modified to reflect the inclusion of local government debt and MOR debt in augmented total government debt. For direct comparison with the earlier DSA results, a starting level of total government debt for 2011 must be established and new local government borrowing projected for the period 2012-16. On the assumption that new borrowing continued to slow in 2011 as it did in 2010, and given that official debt is projected to fall, it is assumed for illustrative purposes that total government debt rose only modestly in 2011, to 50\% of GDP. Projecting what will happen to borrowing in the future is fraught with problems. The pace of the government's railway modernization must slow, as must investment in other areas of economic infrastructure. But social infrastructure needs are enormous, and the first step in meeting these needs appears to be an ambitious social housing program that will be financed by local governments and could require them to raise $2 \%-3 \%$ of GDP yearly in financing during the next 5 years. If this occurs, new borrowing by local governments, almost all of it through LICs, could be quite large, and, while not as high as in 2009 , it is likely to be well above the longer term average.

The central scenario in Figure 4.11 assumes that local government and MOR activities will add 4\% of GDP a year to primary spending during 2012-16 (compared to the baseline projection in Figure 4.7), and the alternative scenarios describe the impact of higher or lower spending. Although the central scenario's debt ratio is higher than in Figure 4.7, the scenario is characterized by a slowly falling debt ratio. This reflects the basic arithmetic of debt dynamics. With a $50 \%$ 


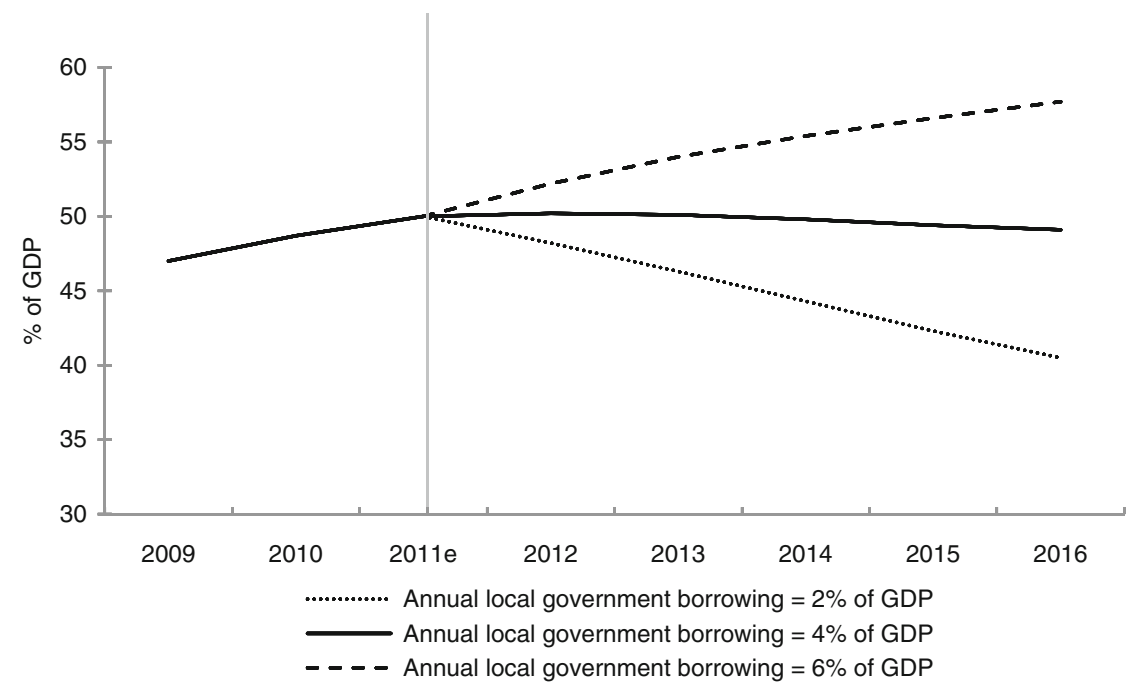

Figure 4.11 Revised debt scenario and sensitivity analysis, 2009-16.

$\mathrm{e}=$ estimate, $\mathrm{GDP}=$ gross domestic product.

Source: Author's assumptions.

of GDP debt ratio, nominal GDP growth of $10 \%$ would accommodate an overall deficit of close to $5 \%$ of GDP without adding to the debt. In the central scenario, the higher debt ratio due to the inclusion of local government and MOR debt combines with high growth to provide the room to reflect LIC and MOR spending in the primary balance while holding the debt dynamics in check. However, the situation is precarious, in that higher spending (by LICs, the MOR, or other parts of government) could easily produce a debt explosion. The issue of whether a debt ratio of about $50 \%$ of GDP is too high is taken up later.

\section{Contingent liabilities, fiscal risk, and debt sustainability analysis}

According to Brixi and Schick (2002), fiscal risk is concerned with potential sources of future fiscal stress, especially contingent liabilities and off-budget fiscal activities. The term "fiscal risk" has been used more broadly to cover all sources of deviation between fiscal outcomes and plans. While the present concern is the fiscal consequences of contingent liabilities, DSA tries to take account of a wider range of fiscal risks.

The fiscal risk from contingent liabilities can be incorporated into DSA. Figure 4.12 indicates the stages involved. The idea is that contingent liabilities have to be identified and the nature of the fiscal risks they pose determined. Some may have flow implications, mainly in the form of higher spending, for example to honor guarantees. Others may have only stock implications, for example, if 


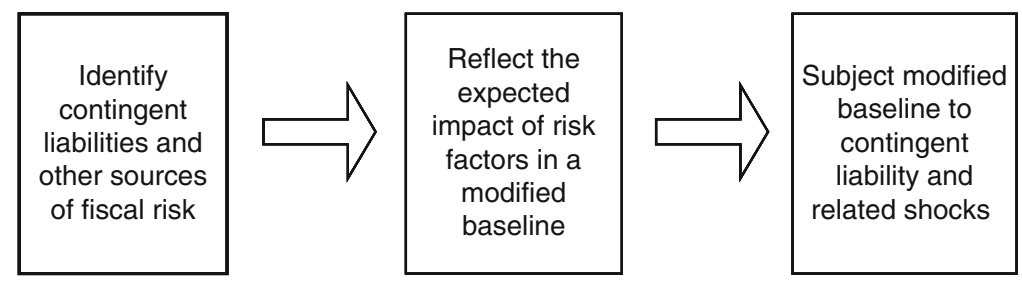

Figure 4.12 Integrating fiscal risk into debt sustainability analysis.

Source: Author.

a bailout involves an assumption of debt. One issue is whether flows should in fact be converted to stocks, so that the expected future flow costs of contingent liabilities are discounted to the present and included in an augmented debt figure for DSA purposes. While turning contingent debt into an equivalent amount of actual debt may be appealing, it would be better to work with a debt measure that meets statistical standards, and to treat the consequences of contingent liabilities as exactly what they are, expenditures or stock adjustments. ${ }^{25}$ In this way, contingent liabilities can be incorporated into a modified DSA baseline. This baseline can then be subjected to the same sensitivity tests as in Figure 4.7, with the addition of a contingent liability shock. This is the sense in which DSA looks at a wider range of fiscal risks, such as errors in macroeconomic and fiscal forecasts and policy uncertainty. ${ }^{26}$

The DSA in IMF (2011b) actually does something along these lines in that it includes an alternative scenario in which "contingent debt" arising from current and future NPLs, AMC losses, and unfunded pension liabilities is recognized. As previously noted, treating unfunded pension liabilities as contingent debt may be merited. The alternative scenario assumes that contingent debt is recognized in full in 2011 , adding about $68 \%$ of GDP to the debt stock, with a sensitivity test adding $10 \%$ of GDP to the original debt stock rather than this larger figure. This approach would add the flow costs of contingent liabilities to future spending, which in turn would be reflected in future primary balances (as is done above with local government spending financed through LICs). Figure 4.13 does this, on the assumption that contingent liabilities impose a fiscal cost of $3 \%$ of GDP a year, using the central scenario in Figure 4.11 as a starting point. The alternative scenario is the government taking a larger $20 \%$ of GDP in 2012 in the form of a debt stock adjustment (e.g., due to recapitalization or debt assumption related to a banking crisis), while the fiscal cost of remaining contingent liabilities is $2 \%$ of GDP a year. ${ }^{27}$ Naturally, this results in higher debt levels, but the arithmetic of debt dynamics just discussed again prevents a debt explosion.

The scenarios in Figure 4.13 are subject to all the caveats about DSA discussed earlier. Indeed, because they are based on assumptions about things that are even more speculative than with the standard DSA, interpreting outcomes merits 


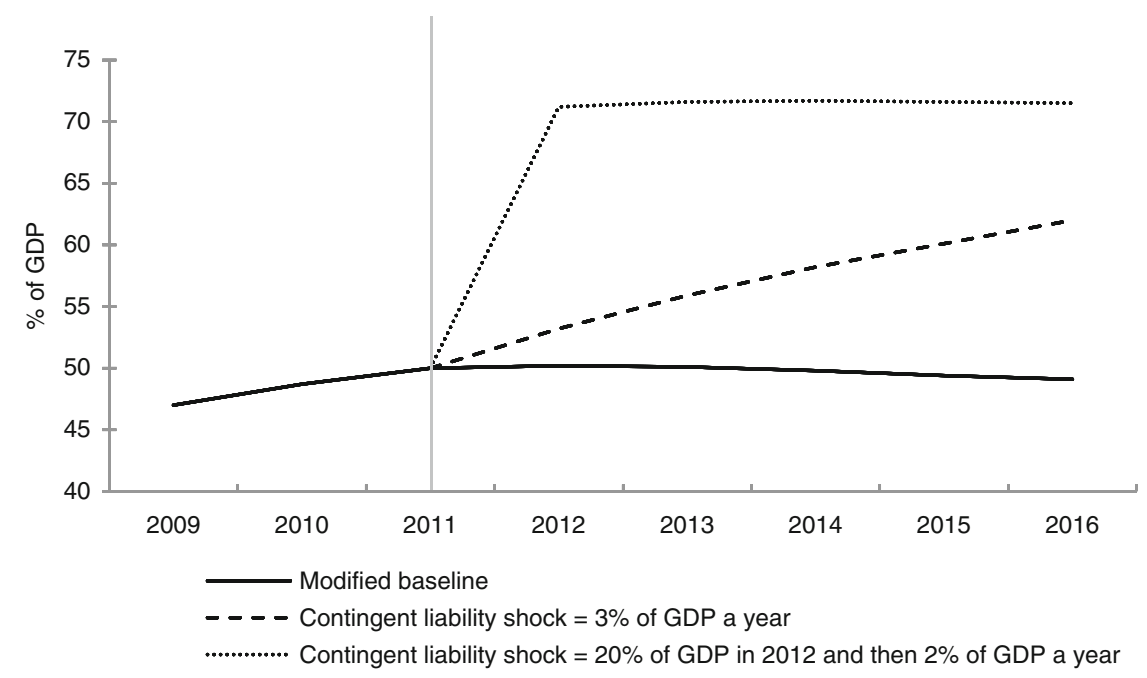

Figure 4.13 Debt sustainability and contingent liabilities, 2009-16.

$\mathrm{e}=$ estimate, GDP $=$ gross domestic product.

Source: Author's assumptions.

even greater care. That said, it should be possible to improve the quality of the assumptions about local government and MOR borrowing, and about contingent liabilities, on which Figure 4.13 is based. However, this requires greater clarity about government spending plans and the contingent liabilities that the government has taken on. ${ }^{28}$

\section{Fiscal management and policy issues}

\section{Debt sustainability, fiscal vulnerability, and government assets}

The foregoing discussion focuses on developing a better understanding of the way debt should be measured in the PRC, fiscal risks that could result in higher debt in the future, and the evolution of the debt under different circumstances. While debt could be pushed onto an upward path by some combination of fiscal laxity (especially at the local government level) and contingent liability and macroeconomic shocks, a view has not been offered as to when debt becomes too high. IMF (2011d) uses a 40\% of GDP debt limit to assess fiscal adjustment needs in emerging market countries, and the same limit has also been used more widely. However, the use of rule-of-thumb debt limits is perhaps the most significant shortcoming of DSA and of the fiscal policy recommendations that follow from it. As already noted, there is a need to establish a benchmark or debt limit based on a country's debt tolerance. 
While factors point to the PRC being more debt-tolerant than many other emerging market economies (e.g., its debt structure is favorable), other factors may suggest the opposite. Recent work on fiscal vulnerability, while not coming up with a benchmark or debt limit, throws light on factors affecting the risks associated with sovereign debt. For example, Ghezzi, Keller, and Wynne (2010) have produced an index of fiscal vulnerability, which incorporates debt tolerance considerations by looking at five components of vulnerability: solvency (basic debt dynamics, i.e., whether the debt ratio is stable or increasing); fiscal financing needs and debt composition; external financing dependence; financial sector health; and institutional strength. The idea is that a judgment as to whether the debt dynamics point to a possible default depends in part on the other factors. The fiscal vulnerability index is reported as country $z$-scores, which are highly correlated with 5-year credit default swap spreads across 47 industrial and emerging market economies. The PRC ranks 11 th best of 47 economies, and its $z$-score is as close to that of the least vulnerable economy-Hong Kong, China — as is Portugal's to that of the most vulnerable - Greece. The PRC's favorable debt dynamics and limited financing requirements distinguish it from many other economies, and more than compensate for its financial sector weaknesses and ineffective institutions (as reflected in World Bank governance indictors).

Of course, the five components of $z$-scores do not exhaust all factors that may be relevant, and they may not focus on those that are most important. More recently, BlackRock (2011) has reported sovereign risk scores based on four factors: fiscal space (debt level and structure, demography, default history, etc.); the external finance position; financial sector health; and willingness to pay (political and institutional factors). This index is also highly correlated with five-year credit default swap spreads, and the PRC ranks 18th best of 44 economies. In this case, the PRC's index is quite different from those of the least risky economies (which are mainly industrial countries), but it is surrounded (in terms of its index) by a large group of countries where sovereign debt distress is not very likely. ${ }^{29}$ The fiscal vulnerability $z$-scores and sovereign risk scores add support to the view that the PRC does not have a significant debt problem. However, a key factor is clearly not taken into account in these scores - hidden liabilities, and especially LIC debt and contingent liabilities. Taking the hidden liabilities into account would make the PRC look more vulnerable or risky. But another key factor, the size of the government's assets, clearly reduces fiscal vulnerability and sovereign risk in the PRC.

At the end of 2009, the government had deposits at the PBOC and commercial banks totaling $15.3 \%$ of GDP. It also issued bonds in 2007 to capitalize the China Investment Corporation, equivalent to $4.5 \%$ of GDP, against which it has matching claims. The gross debt of $47 \%$ of GDP for 2009 reported in Table 4.2 therefore translates into a net debt of $27.2 \%$ of GDP. On top of this, the SOE sector has net assets totaling about $50 \%$ of GDP, and the government still has large landholdings, so that privatization and further land sales (even if land prices retreat from their current high levels) offer considerable scope to meet debt obligations if necessary. The exact state of the government's balance sheet is not known, but there is reason to believe that it is reassuringly strong. 


\section{R. Hemming}

\section{Local investment platforms, local government finances, and expenditure prioritization}

Even if LICs are not the source of an overall debt problem in the PRC, the LICs' activities pose challenges for economic management. Official concern focuses on the risk that LIC borrowing could at some time lead to another wave of NPLs. To contain this risk, the government has already called for closer scrutiny of LIC loans and collateral, especially by smaller regional banks where close ties to local governments result in laxer lending standards. This explains why bank lending to LICs started to slow in 2010. The government also seems prepared to go further if need be, although its precise response, which could involve regulation, consolidation, and/or new AMCs, has yet to be decided. But there are also bigger issues to address.

Current financial arrangements at the local government level do not seem to be sustainable. At present, local governments are responsible for spending that they cannot pay for, given their limited revenue sources and ability to borrow. They should not need to borrow to cover current spending, other than temporarily, and they should not have to set up off-budget entities to borrow to pay for infrastructure. Rather, they should be given a wider range of independent revenue sources, with the rolling out of the property tax being the highest priority in this regard. At the same time, they should reduce their dependence on land sales, so that there is less pressure to keep land prices high (which would make providing affordable housing easier).

LICs should also be brought on-budget, making them formally part of local and general government. ${ }^{30}$ Future LIC-financed spending will then be subject to the same budget scrutiny as other spending programs; current and capital spending could be properly coordinated (e.g., to ensure adequate provision for investment maintenance); and assurances could be given that debt and debt service of all general government entities is manageable. Transfers from central to local governments should reflect the social returns to investments mandated by the central government and economic returns accruing to the central government rather than local governments, so that infrastructure investment can be selffinancing at the local government level. Finally, the absence of a local bond market makes it difficult for local governments to fulfill their responsibility for infrastructure investment. LICs have requested permission to issue bonds, but they cannot yet do so. Letting creditworthy LICs issue bonds could be a first step in creating a well-functioning local bond market (as part of a general shift toward more nonbank financial intermediation) where local governments can also raise capital subject to appropriate prudential controls and financial markets can play more of a role in disciplining the behavior of local governments, LICs, and other local public entities. Clarity about guarantees is essential if this is to happen. ${ }^{31}$

There is also a pressing need to think more broadly about spending prioritization, especially in view of the PRC's large social expenditure needs (pensions, housing, health, education, unemployment benefits, and other social transfers) and planned rebalancing in favor of private consumption. To this end, the government should 
consider implementing medium-term budgeting, with resources constrained by borrowing capacity and revenue potential, spending priorities guided by strategic objectives, and budgets increasingly results-driven. Such a framework keeps governments focused on the need for fiscal discipline and spending efficiency, in that they have to think about whether the medium-term payoff from spending justifies borrowing to finance it, and whether public money is being wasted on unnecessary and ineffective programs. Medium-term budgeting should also force governments to pay attention to and (to the extent possible) quantify fiscal risk, and to ensure that there are short-term budget resources and longer term fiscal space to handle the risks. Of course, where local governments are responsible for a large share of spending, both the central and local governments need to adopt medium-term budgeting. Whether this is the highest budget reform priority given the PRC's other budgeting problems (Deng and Peng 2011) has to be established in the context of formulating longer term budget reform strategy.

\section{Conclusions}

This chapter starts by asking whether there is more to the PRC's government debt position and outlook than the official numbers suggest, and in particular if they are masking a debt problem that poses a serious threat to financial stability and growth. The answer provided suggests that official numbers do understate government debt, and that the government is exposed to fiscal risks that could increase debt in the future. However, the debt appears to be sustainable in that there is little likelihood of a debt explosion, while the government's fiscal position provides room to handle reasonable risks and its asset position provides an additional cushion should more extreme risks materialize. That said, the principal source of concern about the PRC's debt—borrowing by LICs - raises broader issues about local government finances and government spending that need to be addressed. These should be priority areas for reform.

The discussion in this chapter also highlights another priority reform areafiscal transparency. Much of the speculation about government debt is badly informed about both the nature of the government's liabilities and the proper way to think about different liabilities, as illustrated in Table 4.1. This chapter contributes to fiscal transparency by distinguishing between hidden liabilities that should be included as part of government debt and those that are contingent in nature and therefore a source of fiscal risk that could lead to higher debt in the future. However, the chapter has made only a limited contribution to increased transparency about contingent liabilities and their implications for debt sustainability, because the information necessary to go much further is not readily available. Meeting the disclosure requirements for contingent liabilities in IMF (2007) would be a good start, but work will need to be done, including the collection of relevant data, to determine their quantitative significance and impact and whether steps need to be taken to control the fiscal risks they pose. Doing this should be part of a concerted effort to provide more information about fiscal policy and government operations. 


\section{R. Hemming}

\section{Notes}

1 Headline numbers are those most widely quoted in official statements and public commentary on fiscal policy.

2 However, both the latest version of the WEO database and the most recent IMF Fiscal Monitor (IMF 2011a) report a higher debt number for 2010 than in the WEO database of only a few months previously, the preceding Fiscal Monitor (IMF 2010d), and the latest IMF Country Report for the PRC (IMF 2011b). The higher number for 2010, $33.8 \%$ of GDP as opposed to $17 \%$ of GDP, includes local government debt that was previously excluded. Because the proper measurement of government debt is discussed in detail in the following text, and given that revised data for previous years are not reported, the lower number is included in Figure 4.1.

3 For a discussion of the role of proactive fiscal policy in the PRC, see Jia (2002).

4 Lardy (2004) produces a figure very close to that in Table 4.1, viz. $85 \%$ of GDP, but his figure is for 2003, when NPLs were much higher and LIC debt was virtually nonexistent. He also excludes some of the hidden liabilities included in Table 4.1. Krumm and Wang (2002) described a range of hidden liabilities in the PRC, but they did not attempt to come up with a comprehensive estimate.

5 LICs are also referred to as "local government investment platforms" and "urban development and investment companies."

6 Wong (2011) provides a detailed discussion of the role of LICs in the context of the PRC government's fiscal stimulus program.

7 Value-at-risk shocks, which are concerned with the joint effects of 1 standard deviation temporary shocks to key variables, are not reported, but in this case an exchange rate shock has an effect via other economic variables that is almost identical to the historical scenario.

8 This is the term used in IMF (2011d).

9 Defined in this way, DSA is more about assessing liquidity than solvency, especially given that the timeframe is 5 years, when it is unlikely that major shifts in policies or policy regimes are feasible. Solvency is concerned with the government's ability to satisfy its intertemporal budget constraint over the long term, when there is more scope for policy and regime changes. Sustainability should be about both solvency and liquidity, but it is very difficult to determine whether a government is in fact solvent.

10 Wyplosz (2007) concludes that the combination of an unknowable debt path and unknown debt limit means that judgments about debt sustainability simply cannot be made. He refers to this as the "impossibility principle."

11 Rules of thumb include stabilizing the debt ratio at the current level, which is presumed safe if debt problems have so far been avoided, or adopting a widely used limit such as the euro-area's $60 \%$ of GDP convergence target. A $40 \%$ of GDP limit is often thought to be more appropriate for emerging market economies in view of their lower debt tolerance. IMF (2011d) bases its medium-term fiscal adjustment scenarios on a $60 \%$ of GDP debt target for advanced economies (except Japan) and a 40\% of GDP target for emerging markets.

12 See Eichengreen et al. (2011).

13 However, extreme assumptions can produce apparent policy challenges. For example, the fiscal adjustment scenario in IMF (2011d) suggests that, to stabilize debt at its 2010 level, the PRC needs to undertake a fiscal adjustment of similar size to that required in G20 countries on average during 2010-20. However, this assumes an IRGD of 0 up to 2015 and is 1 thereafter.

14 The domestic currency cost of servicing foreign currency debt depends on exchange rate movements, which adds some uncertainty to interest and amortization payments. 
15 In the case of government pensions, provisions are written into formal employment contracts, while social security can be characterized as an informal contract between successive working generations.

16 This treatment is consistent with the Government Finance Statistics Manual (IMF 2001). In the case of social security pensions, it could be argued that the government's contractual obligation to provide pensions is indistinguishable from its constructive obligation to provide health care. Indeed, the provision of pensions and health care to the elderly is often discussed as if they are much the same, which seems quite reasonable, not because current levels of health care for the elderly are guaranteed, but rather because it has been clearly demonstrated that pension promises can be altered. Thus, while providing social security pensions may be a contractual obligation of government, the basis on which the size of pensions is determined is not covered by the contract.

17 The AMCs are the Great Wall with Agricultural Bank of China, Orient with Bank of China, China Cinda with China Construction Bank, and China Huarong with Industrial and Commercial Bank of China.

18 AMCs may also have assumed another CNY1 trillion of NPLs in 2003, but reporting of this is sporadic.

19 For further discussion of NPLs and the role of AMCs, see Bottelier (2004).

20 CNY6.7 trillion is the amount used to produce the higher 2010 debt number in IMF (2011b).

21 The PRC's National Audit Office report does not include a time series for local government debt, but it does report growth rates. Figure 10.3 is based on the 2010 figure and reported growth rates. Local government debt for 2009 is estimated at CNY8.7 trillion.

22 In August 2010, Roubini Global Economics suggested that CNY400 billion of CNY7.7 trillion LIC bank debt would have to be written off by the end of 2012 . However, other reports have suggested that maybe $25 \%$ of LIC bank debt should be classified as NPLs.

23 As, for example, Chang (2011) has claimed.

24 The comparisons in Figure 4.4 may change somewhat if the debt numbers for other countries are examined as closely as those for the PRC have been and are modified as needed.

25 What is done does not matter analytically, in the sense that stabilizing any measure of debt at the current level will require the same amount of adjustment to the primary balance (measured in a way corresponding to the chosen debt measure).

26 While the focus here is on contingent liabilities, the approach can be extended easily to other hidden liabilities, such as unfunded pensions (when, unlike in the PRC, future pension provision is reasonably clear). Perhaps, since hidden liabilities are being revealed, some other less judgmental term, such as "nondebt liabilities," should be used to describe them.

27 The alternative scenario may look less drastic than that of IMF (2011b), with its $68 \%$ of GDP contingent debt shock. While details of the IMF estimate of contingent debt are not available, pension liabilities are undoubtedly the biggest item, and these are more likely to be "recognized" through future expenditure than through prefunding.

28 Approaches to improving the analysis of fiscal risks in DSA are discussed in IMF (2011c).

29 IMF (2011d) includes a fiscal sustainability risk map with six dimensions — core fiscal indicators, long-term fiscal challenges, liability structure, macroeconomic uncertainty, financial sector risks, and policy implementation risk - but country-specific information is not reported. IMF (2011a) discusses fiscal fundamentals in the PRC: debt, gross financing, short-term debt, cyclically adjusted primary balance, pension spending, 
health spending, and the IRGD. The PRC's fiscal fundamentals look a lot stronger than in those of most other countries, although the presentation of separate data on each fundamental does not make it easy to compare across countries.

30 An issue is what this would mean for the banks that have already lent to LICs. While LIC debt could be backed unconditionally by government, there is no reason why banks that have made bad lending decisions should be bailed out in the event of an LIC default. Rather, banks should be required to assess the riskiness of LIC loans and provision for them appropriately.

31 These very general recommendations will need to be supported by specific institutional reforms. Liu (2010) draws on international experience to suggest a range of market and nonmarket measures that could help to discipline local government and LIC borrowing.

\section{References}

Agricultural Bank of China (ABC) (2011) 2010 Annual Report. Available HTTP: $<$ http://www.abchina.com/en/about-us/annual-report/> (accessed March-May 2011).

Anand. R., and S. van Wijnbergen (1988) "Inflation, External Debt and Financial Sector Reform: A Quantitative Approach to Consistent Fiscal Policy with an Application to Turkey," NBER Working Paper No. 2731, Cambridge, MA: National Bureau of Economic Research.

Asian Development Bank (ADB) (various years) Asian Development Outlook. Mandaluyong City: ADB.

BlackRock (2011) "The BlackRock Sovereign Risk Index: A Performance Assessment and Update," October 2011. Available HTTP: <https://www2.blackrock.com/ webcore/litService/search/getDocument.seam?venue=PUB_IND\&source=GLOBAL\& contentId=1111150649> (accessed March-May 2011).

Bloomberg (2010) "China's Hidden Debt Risks 2012 Crisis, Northwestern's Shih Says." 3 March 2010. Available HTTP: <http://www.bloomberg.com/apps/news?pid= newsarchive\&sid=aN94MF7BDx_A $>$ (accessed March-May 2011).

Bottelier, P. (2004) “China's Emerging Domestic Debt Market," Stanford Center for International Development Working Paper No. 202, Stanford, CA: Stanford Center for International Development.

Brixi, H., and Schick, A. (2002) "Introduction" to H. Brixi and A. Schick (eds.) Government at Risk: Contingent Liabilities and Fiscal Risk, New York: World Bank and Oxford University Press.

CEIC Data Co. Ltd. Available HTTP: <www.ceicdata.com/> (accessed March-May 2011).

Chang, G. (2011) "Is the People's Bank of China Insolvent?" Forbes 17 April 2011, Available HTTP: <http://www.forbes.com/sites/gordonchang/2011/04/17/is-thepeoples-bank-of-china-insolvent/> (accessed March-May 2011).

China Banking Regulatory Commission (CBRC). Available HTTP: <www.cbrc.gov.cn>

CNAO (China National Audit Office) (2011) “Audit Findings on China's Local Government Debts," No. 35 of 2011 (General Serial No. 104). Beijing: CNAO.

Deng, S., and Peng, J. (2011) "Reforming the Budgeting Process in China," OECD Journal of Budgeting, 11(1): 75-89.

Dunaway, S., and Fedelino, A. (2006) "Fiscal Policy in China," in J. Aziz, S. Dunaway, and E. Prasad (eds), China and India Learning from Each Other: Reforms and Policies for Sustained Growth, Washington, DC: International Monetary Fund. 
The Economist (2011) "Coming Clean," 4 June.

Economist Intelligence Unit. Available HTTP: <www.eiu.com> (accessed March-May 2011).

Eichengreen, B., Park, D., and Shin, K. (2011) "When Fast Growing Economies Slow Down: International Evidence and Implications for China," NBER Working Paper No. 16919, Cambridge, MA: NBER.

Ghezzi, P., Keller, C., and Wynne, J. (2010) "Our Measure of Fiscal Vulnerability: A Systematic Global Approach," Barclays Capital Economic Research, 10 September 2010.

Heller, P. (2004) “Are Governments Overextended?” World Economics, 5(4): 1-31.

International Monetary Fund (IMF) (2001) Government Finance Statistics Manual, Washington, DC: IMF.

(2007) Manual on Fiscal Transparency, Washington, DC: IMF.

(2008) Fiscal Risk—Sources, Disclosure and Management, Washington, DC: IMF.

(2011a) "Addressing Fiscal Challenges and Reducing Economic Risks," Fiscal

Monitor, World Economic and Financial Surveys, Washington DC, September 2011.

(2011b) "People's Republic of China: IMF Country Report" No. 11/192, Washington, DC: IMF, July 2011.

Draft.

(2011c) Public Sector Debt Statistics. Washington, DC: IMF, Pre-Publication

(2011d) "Shifting Gears: Tackling Challenges on the Road to Fiscal Adjustment," Fiscal Monitor, World Economic and Financial Surveys, Washington, DC: IMF, April 2011.

World Economic Outlook database. Available: HTTP: <http://www.imf.org/ external/pubs/ft/weo/2011/02/weodata/index.aspx > (accessed March-May 2011).

Jia, K. (2002) "Proactive Fiscal Policy in China since 1998: Background and Its Emphasis in Practice," Journal of Asian Economics, 13: 615-22.

Krumm, K., and Wang, P. (2002) "Analyzing Government Fiscal Risk Exposure in China," in H. Brixi and A. Schick (eds.) Government at Risk: Contingent Liabilities and Fiscal Risk, Washington, DC: World Bank and Oxford University Press.

Lardy, N. (2004) "State-Owned Banks in China," in G. Caprio, J. Fiechter, R. Litan, and M. Pomerleano (eds.) The Future of State-Owned Financial Institutions, Washington, DC: Brookings Institution Press.

Lida, L. (2007) "The Fiscal Policy Framework in China," in Fiscal Policy: Current Issues and Challenges, papers presented at the Banca D'Italia Research Department Workshop, Perugia, Italy, 2007.

Liu, L. (2010) "Strengthening Subnational Debt Financing and Managing Fiscal Risks," Review of Economic Research. Beijing: Ministry of Finance.

Ministry of Railways of PRC. Available (in Chinese) HTTP: <http://www.china-mor. gov.cn> (accessed March-May 2011).

People's Bank of China (PBOC). Available HTTP: <www.pbc.gov.cn/> (accessed MarchMay 2011).

Roubini Global Economics (2010) “Crouching Local Debts, Hidden Risks: How Exposed are China's Banks?” 27 August.

Sin, Y. (2005) "Pension Liabilities and Reform Options for Social Insurance," China Working Paper Series, No. 2005.1, Washington, DC: World Bank.

Trusted Sources (2010) Is China's Local Government Debt a Serious Problem? 28 April 2010. 


\section{R. Hemming}

Wong, C. (2011) "The Fiscal Stimulus Programme and Public Governance Issues in China," draft.

Wyplosz, C. (2007) "Debt Sustainability Assessment: The IMF Approach and Alternatives," HEI Working Paper No. 03/2007. Geneva: Graduate Institute of International Studies. 


\title{
5 Public debt sustainability and fiscal management in India
}

\author{
Mukul G. Asher*
}

\section{Introduction}

In the aftermath of the 2008/09 global financial crisis (GFC), severe income disparities and chronic fiscal imbalances have emerged as among the major risks facing the global economy (WEF 2012). As financial and capital markets have become more focused on fiscal risks, the prospects of debt sustainability in countries at all income levels have become a major concern of the policymakers. At the minimum, perceptions of unsustainable fiscal deficits and debt levels raise risk premiums for rolling over and for issuing public debt, thereby potentially crowding out growth and equity-enhancing use of budgetary resources.

The guiding principles for managing sovereign risk and high levels of public debt (the Stockholm principles) for sound sovereign debt management state that debt portfolio risks should be kept at prudent levels, while funding costs need to be minimized over the medium to long term (IMF 2012).

Managing fiscal imbalances and debt sustainability prospects are among the key macroeconomic management issues in India. These have been recurrent themes of the Article IV consultations of the International Monetary Fund (IMF) with India and of academic writings and commentaries by financial sector economists. Thus, Singh and Srinivasan (2004: 31) argue that “... India's fiscal situation requires immediate attention: high growth and low interest rates will not take care of the problem of long run sustainability of the debt, nor the risks of a crisis in the short or medium run." Topalova and Nyberg (2010) find that, among a sample of 27 emerging countries, India's general government debt ratio was among the highest, and between 2003 and 2008 the reduction in India's public $\mathrm{debt} /$ gross domestic product (GDP) ratio, at $9.2 \%$, was lower than for the sample as a whole, at $15.5 \%$.

\footnotetext{
* This chapter has benefitted greatly from the comments by the participants at the workshop organized by the Asian Development Bank on India's Debt Sustainability in Singapore on 21 November 2011. Thanks are also due to Subbaiah Singala for research assistance. I alone, however, am responsible for any remaining errors.
} 
Ahya (2012) argues that unless a credible plan is implemented to address India's high national deficit, primarily arising from increasing government consumption expenditure (including on subsidies), India will continue to experience high real interest rates, low productivity of investments, and slow growth, and will be vulnerable to adverse global shocks. The central government expenditure on subsidies in fiscal year 2009/10 (FY2010) ${ }^{1}$ was $2.3 \%$ of GDP, nearly the same as in FY1991 (2.4\%), when India experienced a major macroeconomic crisis (Chakravarty 2012). This has also been emphasized in the Reserve Bank of India (RBI) review of monetary policy for the third quarter of FY2012, which stated that "At the current juncture when there is a need to boost private investment, the increase in fiscal deficit could potentially crowd out credit to the private sector. Moreover, slippages in the fiscal deficit have been adding to inflationary pressures and it continues to be a risk for inflation" (RBI 2012: 12). Narrowing the differential between the interest rate and GDP growth in turn would adversely impact the sustainability of India's public debt.

In addition to persistently large fiscal deficits (Table 5.1 and Figure 5.1), India needs to simultaneously address the current account deficits in the balance of payments. The deficits have shown a rising trend since 2004, reaching nearly 3\% of GDP in FY2011 (Malik 2011). The factors contributing to India's current account deficits have included persistently high oil prices despite diminished growth prospects globally as well as in India. During April-September 2011, India's current account deficit was equivalent to $3.6 \%$ of GDP (RBI 2012: 7). The depreciation of the Indian rupee in recent months has been one of the corrective consequences of the higher current account deficits and elevated inflation. In 2009, the domestic inflation based on the GDP deflator was $10.2 \%$, and in 2010 it was 9.3\% (Table 5.1). Due to India's fiscal and current account deficits, monetary policy has been overextended in managing the macroeconomy.

As the RBI (2012: 15) argues:

strong signs of fiscal consolidation, which will shift the balance of aggregate demand from public to private and from consumption to capital formation, are critical to create the space for lowering the policy rate without the imminent risk of resurgent inflation. In the absence of credible fiscal consolidation, the RBI will be constrained from lowering the policy rate in response to decelerating private consumption and investment spending. The forthcoming Budget must exploit the opportunity to begin this process in a credible and sustainable way.

In the foregoing context, this chapter analyzes the dynamics and prospects for the sustainability of India's public debt for the next several years. India is a federal country with a population (according to the 2011 census) of 1.2 billion. India has established constitutional and other provisions for fiscal powers and for centerstate relations. This chapter is based on the premise that, to understand dynamics of public debt and its sustainability in India, one must grasp the constitutional and 
institutional aspects of fiscal arrangements and debt management, as well as major components of budgetary revenue and expenditure that impact fiscal balance, in addition to standard IMF-style debt sustainability analysis (DSA) focusing on key macroeconomic variables.

The rest of the chapter is structured as follows. The next section analyzes recent trends in the level and composition of India's public debt and their implications for India's debt sustainability. The aggregate debt, fiscal, and macroeconomic data used are from IMF sources to ensure compatibility with the DSA in the fourth section. For more detailed micro-level analysis, however, official Indian government sources are used. ${ }^{2}$ As fiscal deficits financed by borrowing add to the stock of public debt, trends in fiscal deficits of the central government, and the cost of debt and composition of holders of government securities with implications for debt rollover risk, are discussed in the third section. Section four provides IMFstyle standard DSA for India. Such standard DSA is an accounting framework that does not incorporate endogenous behavioral responses - a major limitation of the standard DSA. The chapter then discusses the constitutional and institutional framework for debt management in India. Measures that could help address fiscal deficits that contribute to debt accumulation and assist in better debt management are discussed in the sixth section. The final section concludes.

\section{Trends in the level and composition of public debt}

Table 5.1 provides selected public debt, fiscal, and macroeconomic indicators for India in 1999-2010. The trends observed from the data and their implications for India's public debt sustainability are noted below.

First, the public sector debt as a percentage of GDP increased sharply between 1999 and 2003 , from $68.0 \%$ to $81.7 \%$, but then dropped to $64.1 \%$ by 2010 . $^{3}$ The fiscal correction implied by the reduced debt levels has been a result of several initiatives. In 2003, India adopted a rules-based fiscal framework by passing the Fiscal Responsibility and Budget Management (FRBM) Act at the central government level and since then all but three states have passed similar acts. As noted in the 13th Finance Commission ${ }^{4}$ Report, which makes recommendations for the period 2010-15, the 12th Finance Commission had suggested a detailed reform for the states to achieve a target level of revenue balance by 2008-09. All but three states had achieved this target by FY2008. The 13th Finance Commission commended the states for their extraordinary performance in deficit management (FCI 2009: Chapters 1, 2, 4, 7, and 13).

The central government also initiated several measures to ease the debt burden of the states:

- the Debt Swap Scheme (FY2003-05);

- the Debt Consolidation and Relief Facility, effective in FY2006, which allowed central government loans to be rescheduled at a reduced rate of interest of $7.5 \%$ and debt to be waived (subject to enactment of fiscal 
responsibility legislation [RBI 2005] and adherence to revenue deficit reduction targets); and

- reduction of the interest rate on securities issued to the National Small Savings Fund (NSSF) during FY2000-02, which carried interest rates of $10.5 \%-13.5 \%$, effective from FY2008.

Further, in accordance with the National Development Council's decision, the states' obligatory share in the NSSF has been reduced from $100 \%$ to $80 \%$ from FY2008.

The foregoing initiatives suggest that the Indian government can undertake major fiscal correction when conditions demand it. But the aftermath of the GFC shows that a systematic rather than a reactive approach is required to forestall severe crisis.

Second, the overwhelming proportion of India's debt is internal, and this has been growing. Thus, in 2010 the internal debt was $93.3 \%$ of the total, compared with $84.9 \%$ in 1999 . As a result, India is not very vulnerable to external sentiments in managing and sustaining its public debt. However, to the extent that internal borrowings by the public sector crowd out private sector domestic borrowings, the country's vulnerability to external developments may grow as the private sector's external debt increases. Indian companies will need to repay $\$ 11.4$ billion of dollar bonds in 2012, double the five-year average of $\$ 5.6$ billion (LiveMINT 2011). According to the Crisil Ratings, the Indian corporate sector's debt servicing capacity, measured by the interest coverage ratio, declined to 4.8 times in September 2011, compared with the five-year average of 8.4 times (LiveMINT 2012a).

The central government's internal debt largely consists of fixed tenure and fixed rate government papers (dated securities and Treasury bills) that are issued through auction (GI 2010). In FY2011, dated securities financed about $90 \%$ of the fiscal deficit.

According to official sources, the vulnerability indicators for the external debt deteriorated slightly between September 2009 and September 2010 (RBI 2011c). Thus, the ratio of short-term debt to total debt, based on the original maturities, rose from 17.5\% in September 2009 to 22.3\% in September 2010; while the corresponding figures for the ratio of foreign exchange reserves to total debt declined from 115.9\% in September 2009 to 99\% in September 2010. Nevertheless, external public debt is not a significant source of concern for India's debt sustainability.

Third, total interest payments as a share of GDP have ranged from a low of $4.7 \%$ in 2010 to a high of $10.4 \%$ in 2002. Even the 2010 figure is of sufficient magnitude to constrain fiscal flexibility, that is, reallocating government expenditure toward growth and equity-enhancing directions. This situation has arisen in spite of the fact that the nominal GDP growth rate has in most years exceeded the average interest rate. The interest rate-growth differential (IRGD) has been quite substantial since 2004. Until 2007, the high real GDP growth rate contributed significantly to the 


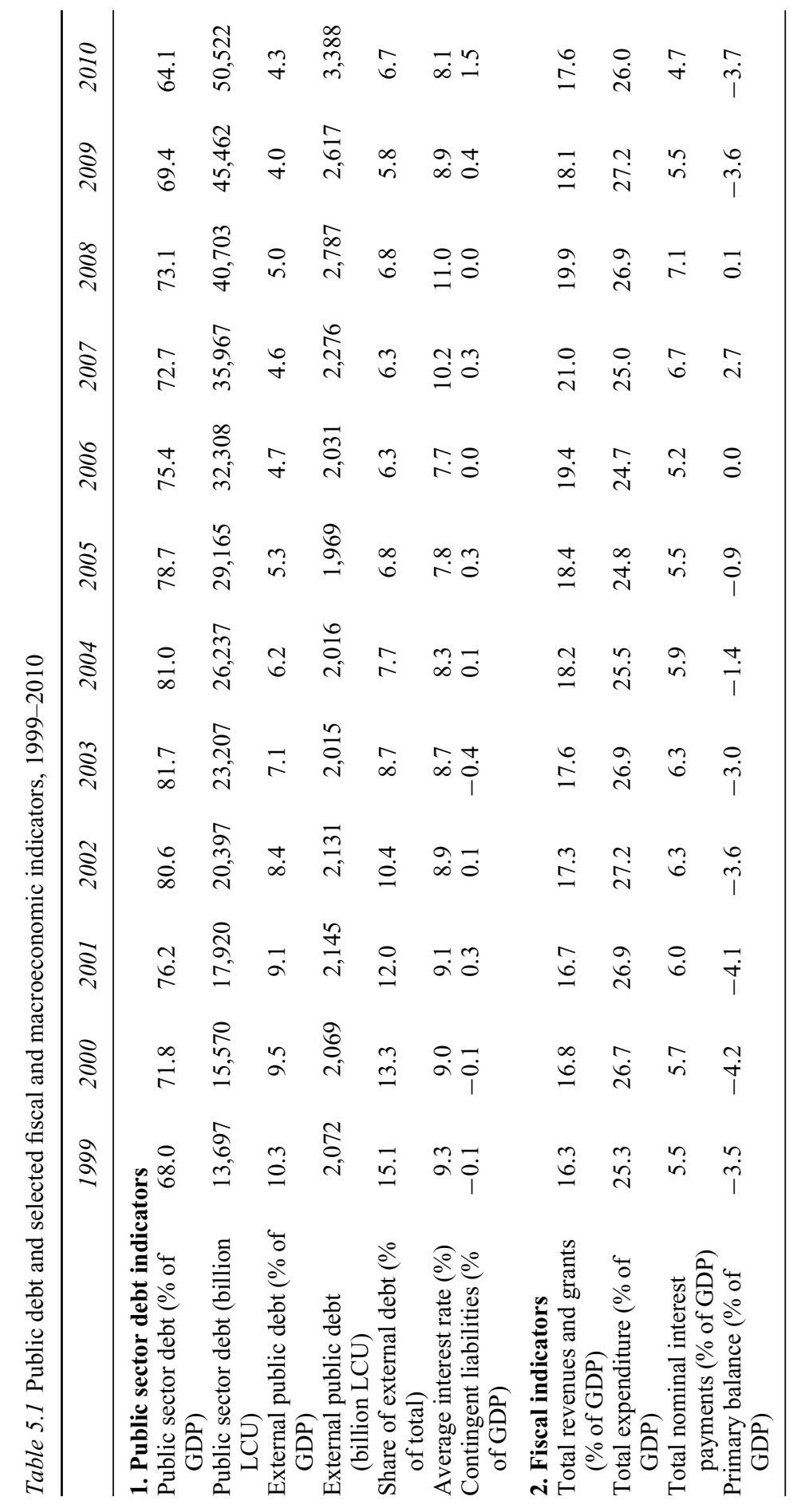




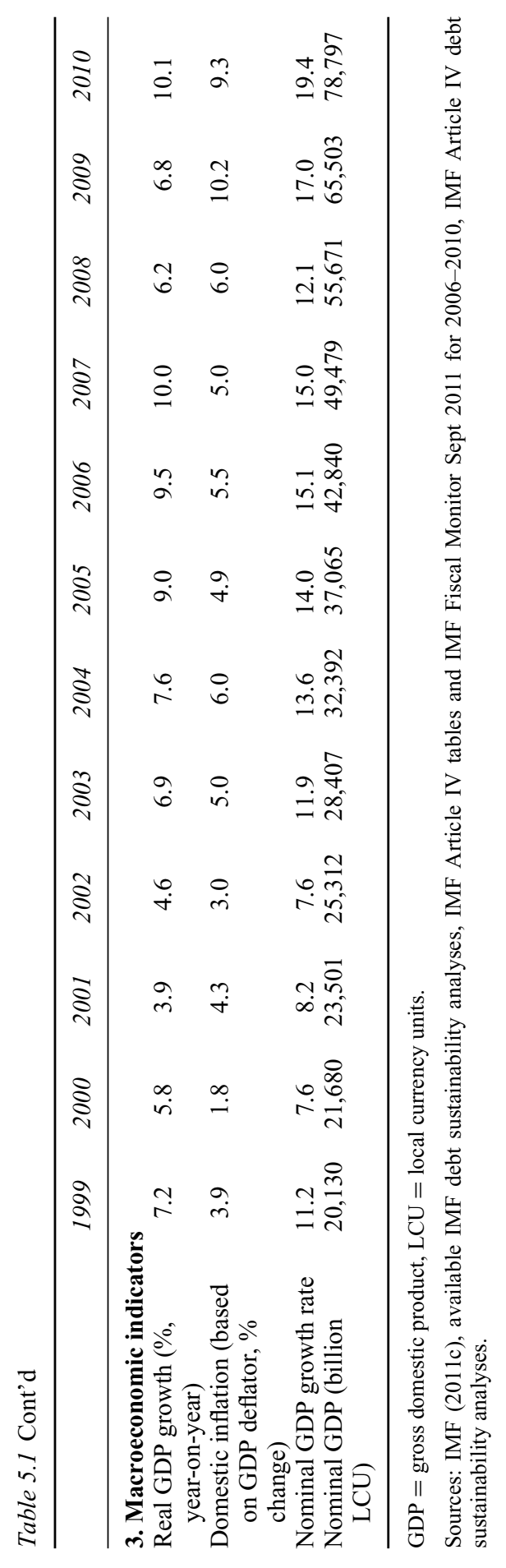


IRGD but, since then, high domestic inflation has been the main contributor. Restoring the pre-2007 composition between the real GDP growth and domestic inflation, without extensive financial repression, would enable India to improve its debt sustainability capacities without compromising broader developmental objectives.

Fourth, the differential between total revenue and grants and total expenditurethat is, the overall fiscal deficit — has been substantial throughout the period. The differential narrowed between 2004 and 2007 when India experienced higher real GDP growth rates, but has widened considerably since then. In 2010, the differential between the two was $8.4 \%$ of GDP. As overall deficit adds to the stock of outstanding public sector debt, it needs to be lowered for debt sustainability.

In all but three years during 1990-2010, India also experienced a primary deficit - overall deficit less debt repayment. The primary deficit has widened substantially since the GFC in 2008/09, suggesting an urgent need for fiscal correction.

\section{Trends in fiscal debt, and cost and ownership patterns of Indian government securities}

The previous sections have strongly suggested the need for fiscal correction for better macroeconomic management, including managing India's public debt dynamics. This section provides an overview of trends in the fiscal deficits of India's central and state governments, the cost of issuing government securities, and the ownership patterns of government securities. Implications for the sustainability of India's public sector debt are also briefly noted.

The data used in this section, which enable a more detailed micro-level and institutional analysis, are based on official Indian government sources. The gross fiscal deficit for FYs 1990-2010 reported by the IMF is higher by an average of $0.76 \%$ of GDP per year and the primary balance is higher by an average of $0.55 \%$ of GDP per year (see endnote 2 regarding the treatment of small savings and other deposits in the Public Account).

Figure 5.1 provides trends in the combined deficits of India's central and state governments and in total liabilities of the Indian government for the FY1991 to FY2010 period. Persistent fiscal deficits in India have resulted in a sustained increase in the government's total liabilities. Fiscal deficits and increased combined liabilities (external and internal) of the central and the state governments showed a high correlation of 0.95 during 1984-2010.

Throughout the period under consideration, India's fiscal system has had a revenue deficit (i.e., current receipts were insufficient to finance current expenditure), severely constraining the flexibility to reallocate expenditure toward public infrastructure and other investments. The minimum goal of fiscal consolidation should thus be to eliminate revenue deficits. The gross fiscal deficit accelerated particularly noticeably in FY2009-10, a trend that is not sustainable and may portend difficulties in debt management (RBI 2010). 


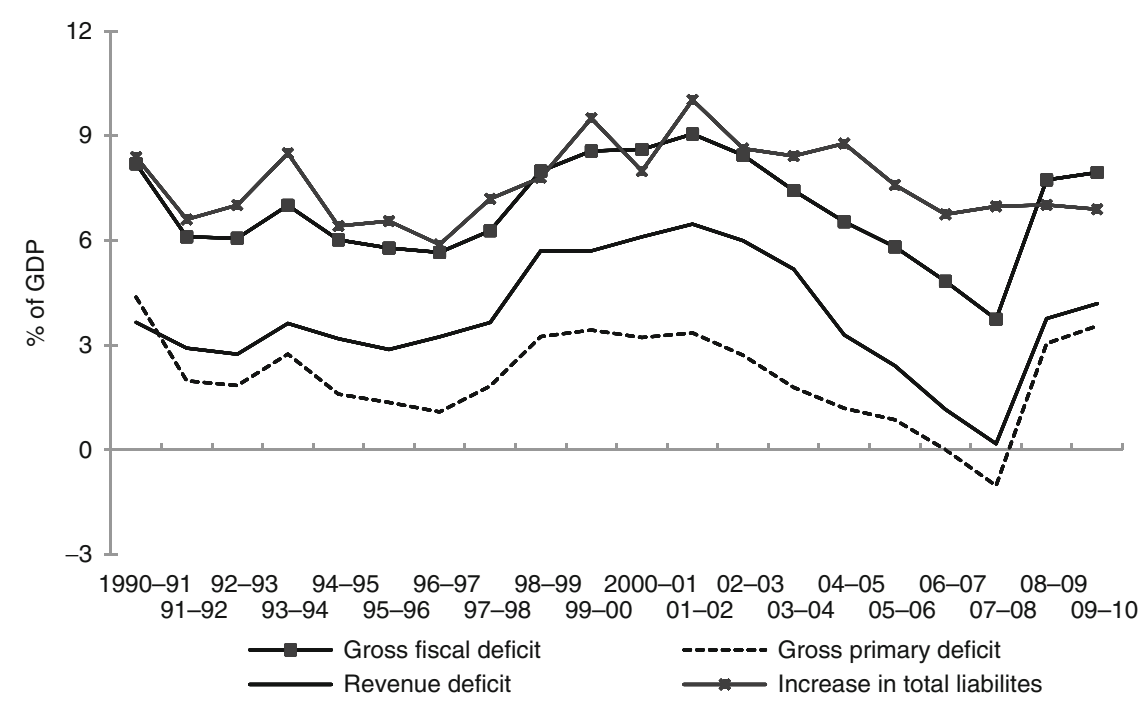

Figure 5.1 Combined deficits of central and state governments and increase in total liabilities, 1990-2010.

$\mathrm{GDP}=$ gross domestic product.

Notes: Gross fiscal deficit (GFD) is the excess of total expenditure (including loans net of recovery) over revenue receipts (including external grants) and nondebt capital receipts. Since 1999-2000, GFD excludes states' share in small savings.

Gross primary deficit is defined as GFD minus interest payments. Revenue deficit is the difference. Between the revenue receipts and revenue expenditure.

Increase in total liabilities refers to increase in total claims from domestic and external sources on the government.

Source: Estimated from RBI (2011b).

\section{Government securities market: evolution and reforms}

The previous section noted that the predominance of internal debt in India's total public sector debt has been a major factor in containing India's vulnerability to developments beyond its borders. The predominant instrument for financing India's deficit has been dated government securities. This section discusses the evolution and reforms of the government securities market and their implications for debt sustainability.

The Indian government securities market has been transformed in the last 15 years. Prior to the 1991 reform period, the market was characterized by administered (and often artificially low) rates of interest; the participants were captive investors (mostly banks) due to high statutory liquidity ratio requirements; and there was no liquid and transparent secondary market for government securities, resulting in the lack of a smooth and robust yield curve for pricing the instruments. Low coupon rates were offered on government securities to keep 
government borrowing costs down, which made real rates of return negative for several years until the mid-1980s. During the 1980s, the volume of debt expanded considerably, particularly of short-term debt, due to the RBI's automatic accommodation of the central government, through issuing ad-hoc Treasury bills. With a captive investor base and interest below the market rate, the secondary market for government bonds remained dormant. Yields not related to the market for government securities affected the yield structure of financial assets in the system, and led to higher lending rates. Thus, the RBI's monetary management was dominated by a regime of administered interest rates, and raising the cash reserve ratio and statutory liquidity ratio prescriptions. High cash reserve ratios and statutory liquidity ratios left little room for monetary policy flexibility.

Reforms in the government securities markets were initiated in the early 1990 s as part of a broader set of economic reforms. The most compelling factors for initiating reforms were: (1) the government's increased borrowing requirements, due to the burgeoning fiscal deficit; (2) the need to keep the cost of borrowing reasonable; (3) the need to develop a benchmark for other fixed income instruments for the purposes of pricing and valuation, and to act as a conduit for convergence of interest rates in other markets; (4) the need to operate monetary policy through indirect instruments such as open market operations and repurchase agreements, which requires an active secondary market for government securities; and (5) the need to improve the overall efficiency of financial markets (Mohan 2004).

As a result of the reform measures, the Government of India's securities market has become one of the most liquid markets in Asia, thus paving the way for an efficient debt market. The fiscal deficits are now funded at reasonable nominal interest rates and through long duration debt. Thus, in 2009-10, the weighted average coupon rate on the outstanding stock of government securities was $7.89 \%$ and the maturity period was 9.67 years (Table 5.2). Indeed, only about $30 \%$ of the total government securities had a maturity period of 5 years or less (Table 5.3). This makes India's debt refinancing fairly resilient to short-term volatilities in interest rates.

Data on the composition of holders of Government of India securities (Figure 5.2) suggest that commercial banks and insurance companies combined hold more than three-fifths of Government of India securities. As the public sector owns a high share of these financial institutions, debt refinancing and management are facilitated. This in turn has helped to insulate public debt management in India from the full discipline of market forces and sentiments. Such insulation is, however, not without opportunity costs in terms of developing more dynamic and sophisticated financial and capital markets, where credit and access to savings are based on economic returns rather than public ownership or statutory requirements.

BCA Research (2011) uses reasoning similar to the foregoing to explain why India's public debt situation has not been perceived as alarming despite high debt levels. The report argues that, considering the nature of India's public liabilities 
Table 5.2 Maturity and yield of central government securities

\begin{tabular}{|c|c|c|c|c|}
\hline \multirow[b]{2}{*}{ Year } & \multicolumn{2}{|c|}{ Issued during the year } & \multicolumn{2}{|c|}{ Outstanding stock ${ }^{*}$} \\
\hline & $\begin{array}{l}\text { Weighted } \\
\text { average yield } \\
(\%)\end{array}$ & $\begin{array}{l}\text { Weighted } \\
\text { average } \\
\text { maturity } \\
\text { (years) }\end{array}$ & $\begin{array}{l}\text { Weighted } \\
\text { average } \\
\text { coupon (\%) }\end{array}$ & $\begin{array}{l}\text { Weighted } \\
\text { average } \\
\text { maturity } \\
\text { (years) }\end{array}$ \\
\hline $2003-04$ & 5.71 & 14.94 & 9.30 & 9.75 \\
\hline $2004-05$ & 6.11 & 14.13 & 8.79 & 9.63 \\
\hline $2005-06$ & 7.34 & 16.90 & 8.75 & 9.92 \\
\hline $2006-07$ & 7.89 & 14.72 & 8.55 & 9.97 \\
\hline $2007-08$ & 8.12 & 14.90 & 8.50 & 10.59 \\
\hline 2008-09 & 7.69 & 13.81 & 8.23 & 10.45 \\
\hline $2009-10$ & 7.23 & 11.16 & 7.89 & 9.67 \\
\hline 2010-11 Q1 & 7.61 & 10.45 & 7.85 & 9.71 \\
\hline 2010-11 Q2 & 7.97 & 12.17 & 7.79 & 9.83 \\
\hline 2010-11 Q3 & 8.11 & 12.35 & 7.81 & 9.71 \\
\hline $2010-11(\mathrm{Q} 1-\mathrm{Q} 3)$ & 7.87 & 11.54 & 7.81 & 9.71 \\
\hline
\end{tabular}

* End of financial year or quarter (Q).

Source: GI (2011a).

Table 5.3 Maturity profile of central government securities (billion rupees)

\begin{tabular}{lccccc}
\hline Maturity buckets & \multicolumn{2}{l}{ End Dec. 2010 } & & \multicolumn{2}{l}{ End Sep. 2010 } \\
\cline { 2 - 3 } \cline { 6 - 6 } & Amount & Share (\%) & & Amount & Share (\%) \\
\hline Less than 1 year & 995.09 & 4.67 & & 878.87 & 4.32 \\
1-5 years & $5,438.92$ & 25.54 & & $5,301.39$ & 26.08 \\
5-10 years & $7,203.81$ & 33.82 & & $6,903.81$ & 33.97 \\
10-20 years & $4,370.66$ & 20.52 & & $4,080.66$ & 20.08 \\
20 years and over & $3,289.94$ & 15.45 & & $3,159.94$ & 15.55 \\
Total & $21,298.43$ & 100.00 & & $20,324.67$ & 100.00 \\
\hline
\end{tabular}

Source: GI (2011a).

and its strong repayment capabilities, the country's current public debt levels can safely be termed sustainable:

- First, only about half of India's general government debt is subject to any market refinancing risk.

- Second, the share of external debt (at about $4 \%$ ) is small, and nearly all of the government debt is in fixed interest rate loans. In an inflationary environment, as is currently the case in India, the real value of the debt will be eroded.

- Third, the average residual maturity of the central government debt is about 10 years, so the immediate refinancing risk is low.

- Fourth, "hidden" liabilities in the form of guarantees for other government agencies are relatively low and are already included in the debt levels. 


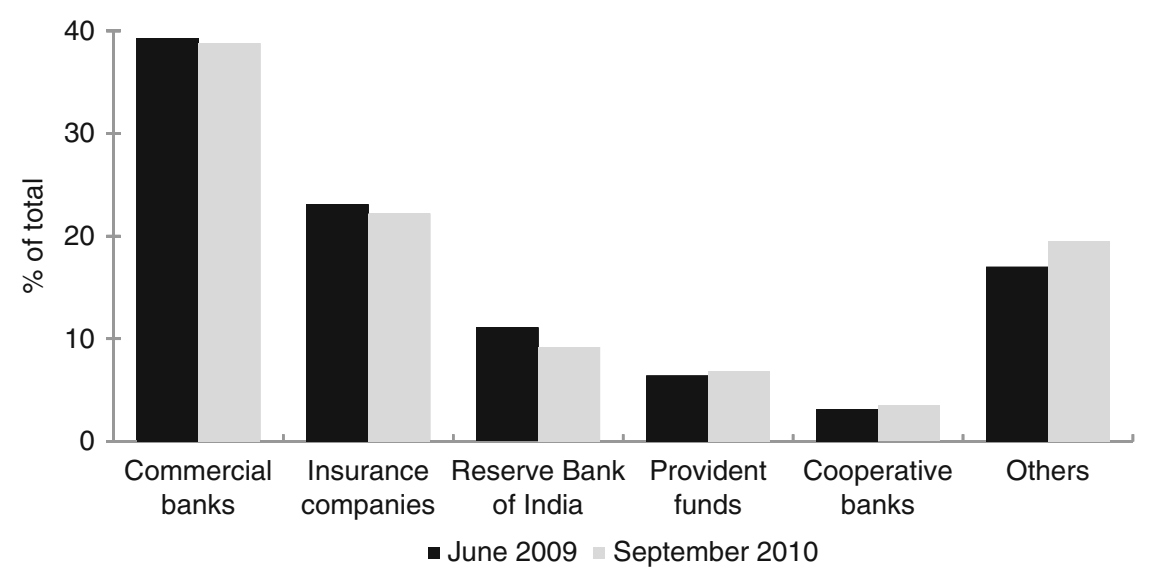

Figure 5.2 Composition of the holders of Government of India securities.

Source: Estimated from GI (2011a).

\section{Debt sustainability analysis}

The standard DSA analysis emphasizes historical and prospective evolution of a medium-term public debt ratio for a country based on macroeconomic forecasts and fiscal policy assumptions. The main focus in this analysis is on whether the debt/GDP ratio is sustainable - that is, stable over the medium term, usually 5 years. In the Asian context, the implications of a negative IRGD for debt sustainability are emphasized (see Chapter 3 ).

The stress tests in the standard DSA framework usually envisage altering a country's interest rate or growth rate by 1 standard deviation above the historical level. A main limitation of projections based on the standard DSA and the stress tests is that they do not take into account interactions among the variables.

The limitations of the simple stress testing can be partly overcome by the stochastic approach to DSA, which estimates the correlation pattern among the key macroeconomic variables to account for basic feedback mechanisms and to reflect the uncertainty surrounding baseline debt projections. Such simulation thus permits a probabilistic assessment of sustainability. As may be expected, such simulations usually result in more nuanced understanding of vulnerabilities in sustaining public sector debt.

The DSA projections of India's public debt/GDP ratio (including contingent liabilities) are presented in Table 5.4. The contingent liabilities included are in the Public Account, where provident fund and other such balances are deposited. While central government explicit guarantees are included in contingent liabilities, it appears that state and local government liabilities are not. In general, only explicit guarantees are included and not implicit guarantees. Implicit liabilities may arise from recapitalization of weak banks, financial institutions, and public enterprises; 
Table 5.4 Medium-term deterministic debt sustainability analysis projections (public debt/GDP ratio, $\%$, with contingent liabilities)

\begin{tabular}{llllllll}
\hline & 2010 & $2011 e$ & 2012 & 2013 & 2014 & 2015 & 2016 \\
\hline Baseline scenario & 64.1 & 63.7 & 64.0 & 63.3 & 62.6 & 61.9 & 61.2 \\
Historical scenario & 64.1 & 63.7 & 63.0 & 62.3 & 61.7 & 61.0 & 60.4 \\
No policy change scenario & 64.1 & 63.7 & 63.4 & 62.2 & 60.9 & 59.8 & 58.7 \\
Nominal interest rate shock & 64.1 & 63.7 & 64.6 & 64.4 & 64.2 & 64.0 & 63.8 \\
Real GDP growth shock & 64.1 & 63.7 & 65.2 & 65.7 & 66.1 & 66.6 & 66.8 \\
Inflation shock & 64.1 & 63.7 & 62.7 & 61.0 & 59.3 & 57.8 & 56.2 \\
Primary balance shock & 64.1 & 63.7 & 66.2 & 67.6 & 68.8 & 70.0 & 71.0 \\
Nominal foreign exchange & 64.1 & 63.7 & 64.6 & 64.4 & 64.1 & 64.0 & 63.7 \\
$\quad$ depreciation shock & & & & & & & \\
\hline
\end{tabular}

$\mathrm{e}=$ estimate, $\mathrm{GDP}=$ gross domestic product.

Note: The values are for fiscal year.

Source: Author's estimates.

the write-off of past tax obligations; debt relief; development support to less developed regions; and bail-outs of unviable public enterprises. The contingent liabilities included thus represent only a part of the potential government liabilities that could incur fiscal risk.

Potentially, however, larger fiscal risk may arise from the cash accounting system used by public sector organizations in India rather than the accrual accounting system. The cash accounting system does not take into account already-earned pension, health care, and other benefits of public sector employees. Actuarial deficits of publicly managed social security organizations are also not taken into account. Thus, the Employee Pension Scheme of the Employees Provident Fund Organization is projected to have an actuarial deficit of over Rs250 billion (Asher 2009: 8) and growing, and this is not an isolated case.

The baseline scenario projections of India's debt/GDP ratio in Table 5.4 assume that the real GDP growth and inflation levels will moderate from the current levels, while the nominal interest rate will continue to be around the current levels. The rupee is assumed to be depreciating at moderate rates during 2010-16.

The baseline scenario projects that India's public debt/GDP ratio will decline from $64.1 \%$ of GDP in 2010 to $61.2 \%$ in 2016 (Table 5.4). Based on a historical scenario using a 10-year historical average for all variables and assuming a "no policy change" scenario, the projections exhibit a similar declining ratio (Figure 5.3a). The differences in the public debt/GDP ratio among the three scenarios are relatively small. The main variable tending to reduce the debt/GDP ratio is the IRGD, while the primary balance has tended to increase the debt ratio. ${ }^{5}$ The projections lead to a relatively optimistic view of India's public debt sustainability, and are consistent with Topalova and Nyberg's (2010) finding that India's public debt could be sustainable even at a level of $60 \%-65 \%$ while permitting counter-cyclical fiscal response. 
a Public debt/GDP ratio under different scenarios, standard deterministic DSA approach

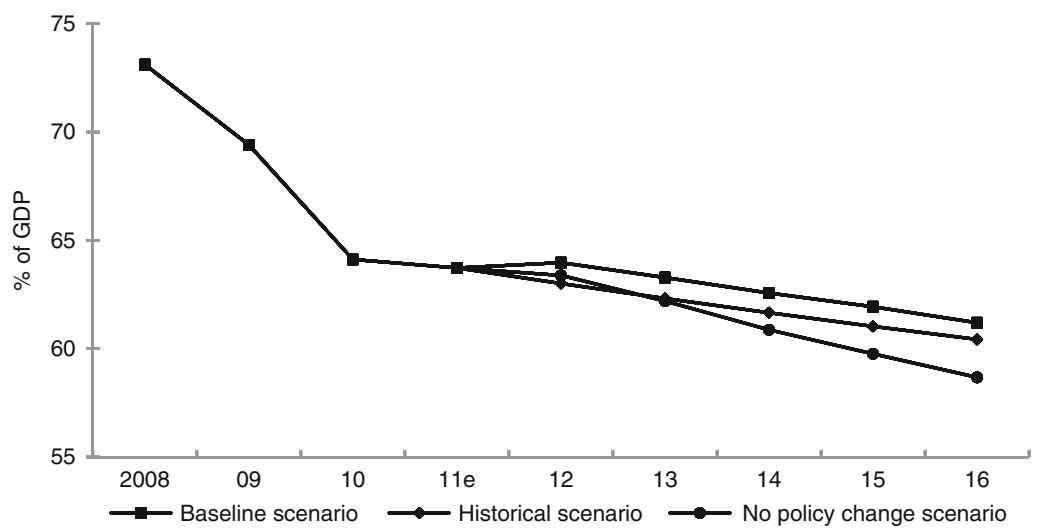

b Impact of shocks on public debt/GDP ratio, standard deterministic DSA approach

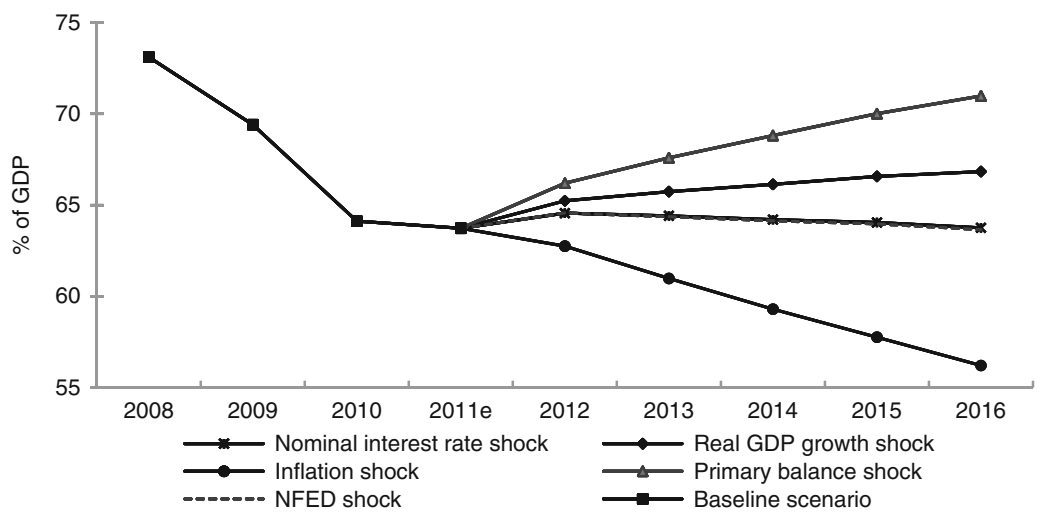

c Stochastic approach to DSA for India

(DSA assumption: running budget deficits)

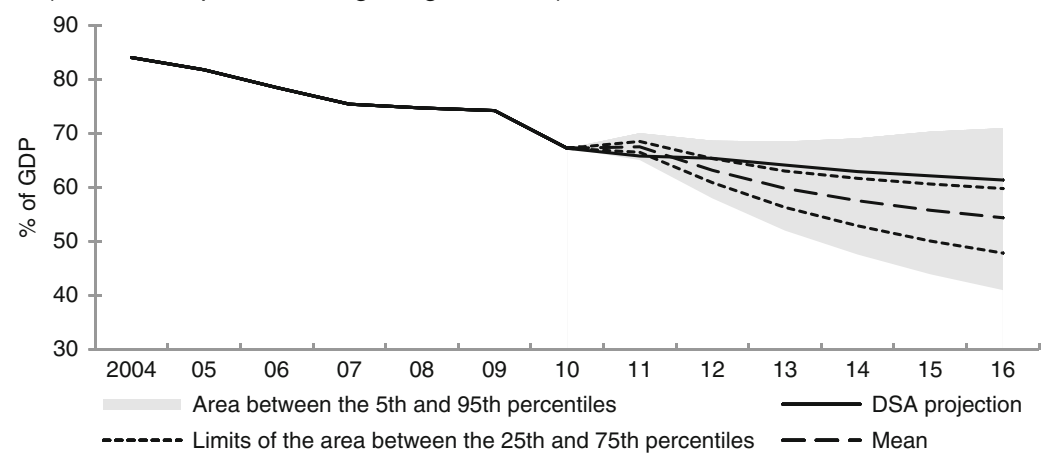

Figure 5.3 Scenarios of India's public debt/GDP ratio.

$\mathrm{e}=$ estimate, $\mathrm{DSA}=$ debt sustainability analysis, GDP $=$ gross domestic product, $\mathrm{NFED}=$ nominal foreign exchange depreciation.

Source: Author's estimates and Chapter 3 of this book. 
Figure $5.3 \mathrm{~b}$ provides the results of stress tests applied using a standard deterministic DSA approach. As may be expected, the projections in Figure 5.3b are quite sensitive to a primary balance shock (debt level rising to $71.0 \%$ of GDP by 2016); and a real GDP growth shock (debt level rising to $66.8 \%$ of GDP by 2016). The debt/GDP ratio will be moderately higher if there is a nominal interest rate shock and a nominal currency depreciation shock. The debt/GDP ratio, however, will be sharply lower if there is an inflation shock (56.2\% of GDP by 2016).

If the IRGD is positive by $1 \%$, India's debt stabilizing primary balance will need to be about $+0.7 \%$ of GDP, implying unrealistically sharp fiscal consolidation. ${ }^{6}$ Thus, India must maintain a large IRGD, and do so without financial repression and without high inflation. This suggests that economic policies should focus on sustaining high real growth. The projections also suggest the importance of fiscal consolidation to ensure that the primary balance does not deteriorate. The stress tests thus point to potential vulnerabilities in sustaining India's public sector debt.

Figure 5.3c provides a probabilistic assessment of India's debt sustainability around baseline projections assuming India continues to run budget deficits. Thus, the medium-term debt ratio (excluding contingent liabilities) for India is projected to decline to about $54 \%$ in 2016 , down from $67 \%$ in 2010 . However, the $90 \%$ confidence interval suggests a $10 \%$ combined probability that India's debt ratio in 2016 will either go up to $71 \%$ or fall to $41 \%$ of GDP. The $2008 / 09$ GFC has underlined the importance of heeding the tail risks. The stochastic simulations, which assume that India has a primary budget that is balanced rather than in deficit, yields declining debt/GDP ratios under all probabilistic assessments. ${ }^{7}$

The stochastic analysis suggests that India must strengthen its efforts at fiscal consolidation to guard against an adverse macroeconomic environment, particularly a real economic growth rate falling below the projections. The stochastic analysis thus provides policy messages consistent with those from the standard deterministic DSA approach.

To summarize, India's current and projected public debt levels are broadly sustainable, though not without greater focus on fiscal consolidation, more competent public financial management, and broader economic reforms designed to revive public and private sector investments and to maintain good quality high growth.

In particular, India will need to avoid severe primary balance and real GDP growth shocks. Reversing fiscal slippages of the last 2-3 years should clearly be a high policy priority, but will be politically challenging given unfavorable election outcomes for the ruling party in important states during the FebruaryMarch of 2012, the general election to be held before May 2014, and continuing uncertainty in the global economy.

India will also need to address fiscal risks that are not captured in standard DSA, whether deterministic or stochastic. One set of such risks arises from the very slow progress in moving government accounts from the current cash-based accounting toward accrual-based accounting, at least for selected commercially oriented government organizations. For example, already accrued future pension and health care liabilities of government organizations are not recognized under 
the current cash accounting system, and no assets are being set aside to meet them. Additional fiscal risks arise from the increasing shift toward rights-based or entitlement-based access to employment and social services, which will make expenditure management difficult, particularly during adverse macroeconomic shocks.

Notwithstanding these significant fiscal risks, Moody's, the credit rating agency, unified the Indian government's local and foreign currency bond ratings at Baa3 (investment grade) on 21 December 2011. Moody's assigned a Baa2 (investment grade) rating to India's foreign currency bank deposit, and A1 to local currency bonds and bank deposits. Moody's has thus upgraded them from "not prime" to "investment grade." Moody's reasons included a large diversified economy, robust medium-term prospects, and a strong domestic savings pool. Nevertheless, it is premature to draw comfort from the upgrade in managing India's fiscal risks and public debt sustainability. Moody's observed that “.... material decline in fiscal deficit and government debt ratios, as well as in their vulnerability to growth and political cycles would improve India's credit metrics relative to peers" (Moody's 2011).

\section{Constitutional and institutional framework for debt management}

This section discusses the constitutional and institutional framework for debt management in India and the implications for public sector debt sustainability. As the predominant share of India's public sector debt is internal, the framework governing its level and the cost of government securities can be impacted by the constitutional and institutional framework for debt management. India's central bank, the RBI, has traditionally pursued a more conservative stance in macroeconomic management (particularly fiscal and debt management) than has the executive branch of the government. This sets the context for the debate on the location of the debt management office (DMO), which is discussed in this section.

The primary objective of debt management in India is to raise the required amount of funding in an effective way. The overall objective of the government's debt management policy is to meet the central government's financing need at the lowest possible long-term borrowing cost and to keep the total debt within sustainable levels. Additionally, the government aims to support development of a well-functioning and vibrant domestic bond market (GI 2010). Other objectives of sovereign debt management are to achieve an optimal balance between the costs and risks of the debt and development and to maintain an efficient market for government securities.

\section{Constitutional provisions}

The Constitution of India has adopted a federal system of polity and governance, originally envisaging a two-tier structure: central (i.e., federal) and state 
(i.e., provincial) governments. ${ }^{8}$ With the Constitution's 73rd and 74th Amendment Acts (1992), local self-governing institutions (i.e., rural and urban local bodies), have been accorded constitutional status as the third tier of government. The Constitution provides for preparation of annual budgets and borrowings by the center under Articles 112 and 292 and by the states under Articles 202 and 293.

Under the Constitution, Union (i.e., central) Government debt is a "Union subject," and Article 246(1) of the Constitution gives the Parliament exclusive power to make laws regarding the public debt of India and foreign loans. However, State Government debt is a "State subject," and Parliament cannot legislate on state borrowings. Article 246(3) of the Constitution provides that state legislatures have the exclusive power to make laws regarding their public debts. The issue of developing municipal bond markets and its implications are discussed later in the subsection on subnational debt.

Under the Constitution, all public debt is charged to the Consolidated Fund of India and can be redeemed without a vote of Parliament. Article 112(3)(c) provides that the expenditure on "debt charges for which the Government of India is liable, including interest, sinking fund charges and redemption charges and other expenditure relating to the raising of loans and the service and redemption of debt" will be charged on the Consolidated Fund of India.

The government may borrow on the security of the Consolidated Fund of India. The borrowing powers conferred on the central government in terms of Article 292 can be limited by Parliament only by law. Presently, the only restriction the law imposes on the central government's borrowing power is the Fiscal Responsibility and Budget Management (FRBM) Act, although the Constitution provides for other restrictions. The FRBM Act was enacted by the Parliament in 2003, and the rules were notified in 2004. At the time, the targets were to reduce the revenue (operating) deficit by $0.5 \%$ of GDP per year and to eliminate it by FY2009. The overall fiscal deficit was to be reduced to $3.0 \%$ of GDP by FY2009. The FRBM Act was prompted partly by indicators such as the share of taxes being used to pay interest on past borrowings. These targets have, however, been missed. The 2008/09 GFC has contributed to missing the targets, but so has lax fiscal management.

Article 293 of the Indian Constitution restricts borrowing by the state governments. The Article stipulates that a state may not, without the consent of the central government, raise any borrowings if it has any loan outstanding that is repayable to the central government. Further, under the Constitution, state governments were not allowed to borrow in other countries. The central government used to be the intermediary in the transfer of external borrowings to states. Following the 12th Finance Commission's recommendations, states have started borrowing in foreign currency directly and are thus now exposed to foreign currency risk. This has implications for the overall macroeconomic management and for debt management. Several states have passed their own acts that are broadly similar to the FRBM Act of 2003. 


\section{Institutional framework}

An institutional framework assigns specific roles and responsibilities relating to debt management functions to specified agencies. The institutional arrangements for subnational debt management in India are as follows:

- The central government decides on resource allocation, the policy for consolidation of central debt, debt swap schemes, buybacks of debt, allocation criteria under the NSSF, etc.

- The RBI raises market borrowing, acts as registrar, handles debt service payments on market loans, invests surplus cash, provides ways and means, and administers the Consolidated Sinking Fund and Guarantee Redemption Fund.

- The Comptroller and Auditor General ${ }^{9}$ and/or the Controller of Aid, Accounts and Audit in the Ministry of Finance maintain accounts and make debt service payments on loans from line ministries.

- State governments decide policy for debt management and its execution, decide the institutions from which to borrow and the rate at which to borrow, pay debt service costs, and maintain debt and guarantee data.

The front office functions are performed by the RBI. Back office functions are performed by the RBI (with regard to depository functions) and accounting is done by the Comptroller and Auditor General. The middle office function is performed by the finance department of the concerned government.

\section{Subnational debt}

The Reserve Bank of India Act, 1934, stipulates that the RBI is the fiscal agent and debt manager for the Government of India and for state governments through mutual agreement. Accordingly, the RBI is the banker to 26 states and the debt manager to all the states. During the 1990s, the RBI used to complete the combined borrowing program of all the states generally in two or more tranches by issuing bonds with a predetermined coupon and pre-notified amounts for each state (the "Traditional Tranche Method"). High statutory liquidity ratios and the small size of state government borrowings ensured the success of these primary issues. In 1997, state governments were given the option to enter the market individually to raise resources. As the municipal bond market gradually develops, it would be useful to create a constitutional framework for such bonds, particularly for the urban development authorities that span more than one municipality or state, such as in the National Capital Region.

\section{Municipal bond market-current status and prospects}

Conventionally, the infrastructure of the Indian urban local bodies (ULBs) has been financed through transfers from the central and state government and 
state-owned institutions, and a small proportion through assistance from bilateral and multilateral agencies. However, by the mid-1990s, the ULBs realized that these funds were no longer sufficient to cater to the increasing infrastructure requirements. Additionally, as a consequence of the 74th Amendment of the Indian Constitution in 1992, ULBs had been given the responsibility of service provision. The growing fiscal imbalance between function and finance (Ventakachalam 2005) prompted policymakers to consider alternative sources of funds, such as commercial borrowing (including municipal bond financing), which was recommended by the Rakesh Mohan Committee on Infrastructure Financing in 1996.

A total of 25 municipal bond issues have taken place in India since 1997. They have included taxable and tax-free bonds and pooled financing issues mobilizing nearly Rs14 billion (approximately \$3 million). Only a few ULBs have issued the bonds, with a quarter raised by the Ahmadabad Municipal Corporation and about one-sixth each by Nashik Municipal Corporation and by ULBs around Bangalore. The trend in the value of municipal bond issues from 1997 to 2010 showed much enthusiasm for them until 2005, then a sharp fall in the value of issues in the past few years (Vaidya and Vaidya 2008, Srikumar 2010).

Recent estimates suggest that India's urban population increased from 290 million in 2001 to 340 million (about one-third of the total population) in 2008 , and is projected to be 590 million by 2030. Further, urban India is expected to create $70 \%$ of all new, more productive, jobs over the next 20 years, which will contribute to a substantial increase in India's per-capita income. Such a rapid pace of urbanization requires a significant level of investment in urban infrastructure, estimated at about $\$ 1,200$ billion (Sankhe et al. 2010).

For financing of such a scale, fiscal transfers to the ULBs from the higher levels of government, while critical, are not sufficient, and the importance of other modes of finance is rising. While the municipal bond market remains in a nascent stage, the Government of India recognizes that the debt route might become increasingly important in the future (Sheikh 2011).

As a part of the Jawaharlal Nehru National Urban Renewal Mission, the Government of India has tried to enable ULBs to access the bond market. Credit ratings for the municipal corporations and councils of the 63 cities covered under this Urban Renewal Mission are being released regularly, and, in April 2010, nearly $40 \%$ of them were rated as investment grade (MUD 2010).

However, none of these ULBs have accessed the bond market recently, which implies that much remains to be done. Most importantly, policy initiatives need to address the supply constraints (i.e., constraints ULBs face in issuing municipal bonds) and demand constraints (i.e., constraints individual and institutional investors face in participating in the municipal bond market) that limit the market for municipal bonds. Developing the municipal debt market is essential for managing India's rapid urbanization. But the debt raised is likely to remain at very modest levels, about 3\%-5\% of GDP. Guarantees and potential contingent and noncontingent fiscal liabilities could be higher, however, if the public-private 
partnerships for the urban amenities and services are not designed and managed competently.

Thus, while the current municipal debt levels are not substantial enough to impact the overall sustainability of public sector debt in India, increasing use of public-private partnerships to finance urban services and infrastructure could create substantial contingent liabilities over time. ${ }^{10}$ FRBM acts of the states and of the central government should incorporate the level of such contingent liabilities in their targets to avoid medium-term stress on India's public debt sustainability.

\section{A debt management office}

The Union Budget (2007/08) proposed establishing a full-fledged autonomous debt management office (DMO). As a precursor, an office was set up in the Ministry of Finance in 2008. The Union Budget 2011/12 announced: "The Government has been in the process of setting-up an independent Debt Management Office in the Finance Ministry. A Middle Office is already operational. As a next step, I propose to introduce the Public Debt Management Agency of India Bill in the next financial year. There has however been various perspectives on whether the DMO should be based in the Ministry of Finance or in the Reserve Bank of India (RBI), India's central bank" (GI 2011b).

RBI Governor Subbarao (2011) argues for continuing to entrust debt management responsibilities to the RBI. His reasoning is that

- $\quad$ public debt management in India has been effective because the RBI, which is the monetary authority, is also entrusted with the task;

- the government's progress with fiscal consolidation in the years before the GFC suggested that operational efficiencies could be gained by shifting debt management to a separate DMO, but the content and pace of this process should be reconsidered in view of the changed circumstances since the GFC;

- only the RBI has the requisite market pulse and instruments to aid in making contextual assessment, which an independent debt agency, driven by narrow objectives, will not be able to do;

- the states' borrowing has attained a critical mass vis-à-vis the absorptive capacity of the market, making it imperative to harmonize the market borrowing programs of the center and the states, which could be difficult if the center's debt management function is separated from the central bank; and

- internationally, the emerging post-GFC wisdom recognizes the interdependence between the functions of monetary policy, financial stability, and sovereign debt management and the need for the central bank to be closely associated with sovereign debt management.

There is another compelling case to reexamine the costs and benefits of setting up a DMO. While managing the sovereign debt may involve a trade-off with the 
monetary management function of the central bank, the alternative of a government department or division (such as the DMO) managing it could result in conflict of interest, when the government is both a borrower from and the owner of the major investors - the public sector banks.

The country has many years of expertise in handling the monetary and debt management trade-offs, and the experience has been institutionalized in the RBI. Testing a new institutional framework involving a new conflict of interest (government as borrower and owner of the investing firms) could prove to be much more risky, particularly from a macro-prudential perspective involving financial stability considerations.

The 13th Finance Commission, which covers 2010-15, has supported the move to create a national debt management agency. The commission's report argues that the Ministry of Finance "... as the main force behind the fiscal responsibility and budget management process, has to calibrate and implement an increasingly sophisticated roadmap for future fiscal consolidation. This requires considerably enhanced policy formulation and analysis capabilities and a more horizontal and integrated approach to the task than has historically been the case" (FCI 2009: 257). The 13th Finance Commission argues that such a restructured Ministry of Finance is essential if the proposed establishment of a fiscal council and council of finance ministers is to steer India toward a path of greater fiscal and debt sustainability, while sustaining broad-based high growth. The foregoing suggests that institutional development and greater competency and coordination in fiscal management involving India's federal structure are essential for fiscal consolidation and therefore public debt sustainability.

\section{Rationalization of small savings schemes}

The Government of India, in consultation with the RBI, has increased its market borrowing size for FY2012, mainly due to the shortfall in collections under the small savings scheme. The shortfall raises questions about the existing approach to managing the small savings schemes in the context of debt sustainability. Unless measures are taken to broadly align the interest rates on small savings with the secondary market yields of the central government dated securities, managing the shortfall or excess collections in the small savings is going to weaken the existing transparency and disclosure arrangements, such as the half-yearly borrowing calendar, and distort the price discovery process.

The central government had constituted the Expert Committee under the chairpersonship of then RBI Deputy Governor Gopinath, for a comprehensive review of the NSSF. The Expert Committee recommended (1) rationalizing the small savings instruments; (2) making the secondary market yields on central government securities of comparable maturities the benchmarks for the various small savings instruments (other than savings bank deposits, which do not have a fixed maturity) with a reset period of one year and with a positive spread of 25 basis points; (3) placing a cap of 100 basis points so that the administered rates are neither raised nor reduced by more than 100 basis points from one 
year to the next, even if the average benchmark interest rates rise or fall by more than 100 basis points (this would reduce the year-to-year volatility in the administered rates); and (4) equally sharing the borrowings from the NSSF between the sovereign and the subsovereign governments. The Expert Committee felt that, to the extent that the rates of interest on borrowings from the NSSF are higher than the market rates, the 50:50 arrangement would ensure equitable burden sharing. These recommendations could facilitate rationalizing the cost and volatility of the collections under the small savings schemes.

\section{Deregulation of savings bank interest rates}

In 2011, the RBI announced that it would deregulate the savings bank deposit interest rate with immediate effect (RBI 2011d). Banks are free to determine their savings bank deposit interest rates, subject to two conditions:

- $\quad$ First, each bank will have to offer a uniform interest rate on savings bank deposits up to Rs0.1 million, irrespective of the amount in the account within this limit.

- Second, for savings bank deposits over Rs0.1 million, a bank may provide differential rates of interest, if it so chooses. However, the interest rates for similar amounts on deposit should be the same for all customers.

The decision could increase the cost of funds to banks and in turn lead to an increase in the interest rates across the yield curve and overall in the cost of government borrowings.

\section{Measures to address fiscal deficits and public debt sustainability}

In addition to initiatives discussed in the previous section, other measures could help address the slippages in fiscal deficit of the last three years, and thereby enhance public debt sustainability in India. These measures range widely and will require political management. While it is not feasible to quantify the extent to which each measure will help improve India's capabilities to sustain its public debt, the cumulative impact of the measures would significantly improve the prospects that India could do so. This is consistent with the argument in this chapter that wideranging reforms in public financial management at all levels of government will be essential to address the sustainability of India's public sector debt.

The measures discussed in the following subsections are in addition to two widely expected major fiscal reform initiatives. One is the introduction of a Goods and Services Tax designed to unify India's internal markets, widen the tax base by including services, and reduce administration and compliance costs of sales taxation. The other initiative is the passage of the Direct Taxes Code, which will replace the current Income Tax Law of 1961. These reforms should be regarded as national projects, albeit with some suitable modifications to their provisions. 
Table 5.5 Residual maturity profile of the outstanding state development loans and power bonds (billion rupees)

\begin{tabular}{lrcccrr}
\hline Year of maturity & SDL & $\begin{array}{c}\text { \% change } \\
\text { in SDL }\end{array}$ & $\begin{array}{l}\text { Power } \\
\text { bonds }\end{array}$ & $\begin{array}{l}\text { \% change in } \\
\text { power bonds }\end{array}$ & Total & $\begin{array}{c}\text { \% change } \\
\text { in total }\end{array}$ \\
\hline $2011-12$ & 219.9 & n.a. & 14.5 & n.a. & 234.4 & n.a. \\
$2012-13$ & 306.3 & 39.3 & 28.7 & 97.9 & 334.9 & 42.9 \\
$2013-14$ & 320.8 & 4.7 & 28.7 & 0.0 & 349.5 & 4.4 \\
$2014-15$ & 333.8 & 4.1 & 28.7 & 0.0 & 362.5 & 3.7 \\
$2015-16$ & 351.9 & 5.4 & 27.9 & -2.8 & 379.8 & 4.8 \\
$2016-17$ & 315.2 & -10.4 & 15.8 & -43.4 & 330.9 & -12.9 \\
$2017-18$ & 677.8 & 115.0 & $\ldots$ & n.a. & 677.8 & 104.8 \\
$2018-19$ & 1181.4 & 74.3 & $\ldots$ & n.a. & 1181.4 & 74.3 \\
$2019-20$ & 1306.2 & 10.6 & $\ldots$ & n.a. & 1306.2 & 10.6 \\
$2020-21$ & 1045.4 & -20.0 & $\ldots$ & n.a. & 1045.4 & -20.0 \\
Total (2011-12 & 6058.7 & 479.6 & 144.2 & n.a. & 6202.9 & 493.4 \\
$\quad$ to 2020-21 & & & & & & \\
\hline
\end{tabular}

$\ldots=$ not available, n.a. $=$ not applicable, $\mathrm{SDL}=$ state development loans.

Source: Estimated from RBI (2011a).

\section{Variation in public debt sustainability among the states}

While the general government debt appears to be sustainable, there are wide variations in the individual states' abilities to sustain their debts. The states are increasingly relying on market borrowings to finance their fiscal deficits. Table 5.5 suggests that, beginning in FY2018, repayment of the State Development Loans increases rapidly and, if the collections under the small savings schemes are not as expected, the states' debts could be difficult to roll over.

Rajaraman, Bhide, and Pattnaik (2005) had recommended a comprehensive cap on borrowing by each state, which is formula-driven and objective, as market perceptions of the risk attached to state government loans are critical. Though the 13th Finance Commission put a cap of $25 \%$ of GDP as the ceiling on the outstanding debt of any state, a huge increase in the maturity profile of the debt is likely after the 13th Finance Commission period ends in 2015. The 13th Finance Commission, therefore, recommended that the central government set net borrowing limits for states based on the fiscal deficit path outlined by the commission.

As market loans are increasing in amount and importance, the state governments may be well served if market loans receive more policy attention. The issues for policy focus are accessing the market across the year uniformly in view of the difficulty of timing the market; better use of "Ways and Means Advances"11 as a cash management tool; issuance of securities with different maturities; passive consolidation of State Development Loans; preparation of an advance indicative calendar; buildup of sizeable balances in reserves such a consolidated sinking fund, ${ }^{12}$ Guarantee Redemption Fund, and State Revolving Fund; and enhancement of the investors' base through retail investment. Capacity building for effective 
debt management, including a strong risk assessment and monitoring mechanism at the state government level, merits serious consideration.

The fiscal conditions of the state of West Bengal illustrate the continuing urgent need for greater fiscal discipline in some states if they are to avoid pressure on the sustainability of their public debt. The reports indicate that for FY2012 West Bengal state exhausted its borrowing limits 2 months before the end of the fiscal year on 31 March. This reportedly contributed to serious concerns about the state's ability to pay salaries and pensions for February and March 2012 (LiveMINT 2012 b). Moreover, the slowdown in economic growth will impact the size of the fiscal deficit at the central government level, and in the states. This is because the amount of taxes devolved from the center to the states declines as slower growth reduces central government revenue.

\section{Tax arrears}

Table 5.6 provides data on tax arrears in India. Tax arrears arise when the taxpayers refuse or fail to pay the demands of the Income Tax Department, either due to disputes about the demands, which may go into appeal, or through an undisputed demand for which the assessment officers have to initiate the recovery process through the Tax Recovery Office.

In FY2010, for example, the uncollected portion of the tax demand was $67 \%$ of the direct tax revenue and $2.8 \%$ of GDP. Even a small portion of these arrears can make a significant difference to the debt situation. The table also highlights that the tax arrears persisted during 2005-10, and increased by $135 \%$ from FY2006 to FY2010. An analysis of the tax arrears in demand for the quarter ending September 2010, as estimated from the Comptroller and Auditor General's report, showed that $60 \%$ were related to Individuals and Hindu Undivided Families and 34\% were related to companies (CAG 2011). Conversely, the trends in tax collection indicate that the share of corporate tax collected is about twice that collected from individuals.

Table 5.6 Tax arrears as a percentage of gross domestic product

\begin{tabular}{llllll}
\hline Financial year & $\begin{array}{l}\text { Tax } \\
\text { arrears }\end{array}$ & Direct tax & $\begin{array}{l}\text { Arrears as } \% \\
\text { of direct } \\
\text { tax revenue }\end{array}$ & GDP & $\begin{array}{l}\text { Arrears as \% } \\
\text { of GDP }\end{array}$ \\
\hline $2005-06$ & 772 & 1,207 & 64 & 36,925 & 2.1 \\
$2006-07$ & 862 & 1,697 & 51 & 42,937 & 2.0 \\
$2007-08$ & 869 & 2,315 & 38 & 49,864 & 1.7 \\
$2008-09$ & 933 & 2,482 & 38 & 55,826 & 1.7 \\
$2009-10$ & 1,816 & 2,716 & 67 & 65,503 & 2.8 \\
Average (2005-06 & 1,050 & 2,083 & 51 & 50,211 & 2.1 \\
$\quad$ to 2009-10) & & & & & \\
\hline
\end{tabular}

$\mathrm{CAG}=$ Comptroller and Auditor General, GDP $=$ gross domestic product.

Source: Estimated from CAG (2011), RBI (2011b). 
Table 5.7 Estimates of tax expenditures (billion rupees)

\begin{tabular}{|c|c|c|c|c|}
\hline \multirow[t]{2}{*}{ Category } & \multicolumn{4}{|l|}{$2009 / 10$} \\
\hline & Tax expenditure & $\%$ of total & $\begin{array}{l}\% \text { of the actual } \\
\text { tax collections }\end{array}$ & $\%$ of $G D P$ \\
\hline Total & $5,258.1$ & 100.0 & n.a. & 9.4 \\
\hline Corporate income tax & 728.8 & 13.9 & 29.8 & 1.3 \\
\hline Personal income tax & 451.4 & 8.6 & 34.0 & 0.8 \\
\hline Excise duty & $1,691.2$ & 32.2 & 164.4 & 3.0 \\
\hline Customs duty & $1,952.9$ & 37.1 & 227.5 & 3.5 \\
\hline \multirow[t]{3}{*}{ Export promotion } & 433.8 & 8.3 & n.a. & 0.8 \\
\hline & \multicolumn{4}{|l|}{ 2010/11 } \\
\hline & Tax expenditure & $\%$ of total & $\begin{array}{l}\text { \% of the actual } \\
\text { tax collections }\end{array}$ & $\%$ of $G D P$ \\
\hline Total & $5,702.2$ & 100.0 & n.a. & 8.7 \\
\hline Corporate income tax & 882.6 & 15.5 & 29.8 & 1.3 \\
\hline Personal income tax & 506.6 & 8.9 & 34.0 & 0.8 \\
\hline Excise duty & $1,982.9$ & 34.8 & 148.8 & 3.0 \\
\hline Customs duty & $1,744.2$ & 30.6 & 132.3 & 2.7 \\
\hline Export promotion & 585.9 & 10.3 & n.a. & 0.9 \\
\hline
\end{tabular}

$\mathrm{GDP}=$ gross domestic product, n.a. $=$ not applicable.

Source: Estimated from RBI (2011b).

\section{Tax expenditures}

Table 5.7 estimates the tax expenditure pattern for FY2010 and FY2011 and indicates that revenue foregone accounted for about 9.4\% of GDP in FY2010 and $8.7 \%$ in FY2011. In both years, the revenue foregone was primarily attributable to the excise and customs duties, which together account for $69 \%$ of the total revenue foregone in FY2010 and 65\% in FY2011. This is almost 6.5\% of GDP in FY2010 and 5.7\% in FY2011. Excise revenue foregone includes area-based concessions, and the customs duty concessions are given to industries such as crude oil and mineral oils; machinery; diamonds, gold, and jewelry; edible vegetables, fruits, cereals, and oils; chemicals and plastics; and primary metals. The costs of these concessions against the benefits could be usefully examined.

\section{Divestment receipts}

The central government has also been using divestment receipts as ordinary receipts that reduce the fiscal deficit, rather than treating them as extraordinary receipts that help finance the deficit. For FY2012, the central government is attempting to meet the divestment target of Rs 400 billion $^{13}$ through methods such as the rich public sector enterprises buying back shares, and pledging stocks the 
government holds in nonstate companies. These are extraordinary ad hoc methods, when more systematic and sustained measures are needed. A strong argument can be made that an improved investment and business environment brought about by economic and regulatory reforms is likely to generate significant divestment receipts.

\section{Using government assets more productively}

Government is the largest owner of landed property in India. ${ }^{14}$ The government is in the process of creating a more complete asset registry and developing a formal policy of asset use, including selling and leasing of land, with a view to generating additional revenue in new ways and using assets more productively. Monetizing these assets in an economically sound manner could assist in fiscal management and debt sustainability (Economic Times 2012).

\section{Cost recovery}

The cost of recovering social and economic services provided by the governments at all levels has been low (RBI 2011a). Thus, according to revised budget estimates for FY2010, cost recovery, defined as a ratio of nontax revenue to nonplan expenditure, was $3.0 \%$ for education, $4.6 \%$ for health, $17.7 \%$ for irrigation, $22.6 \%$ for power, and $5.8 \%$ for roads. While the cost recovery rates have improved, they are considerably lower than the levels needed for financial viability, ${ }^{15}$ adversely impacting the budgetary deficits. The 13 th Finance Commission's report indicates that receipts from the irrigation sector do not even cover the expenditure on operation and maintenance of irrigation projects. The cost recovery issues are part of a larger set of issues involving design and implementation of economic and social sector goods and services and how to price them in accordance with their scarcity.

\section{Liabilities of the state-level public sector undertakings}

State-level "public sector undertakings" (PSUs) remain a drag on state government finances. Cumulative financial support by contribution to equity, loans, and subsidies to state PSUs stood at Rs919 billion, Rs1705 billion, and Rs250 billion, respectively, at the end of March 2008. Outstanding state guarantees on the loans raised by PSUs amounted to Rs1,127 billion and constituted $60 \%$ of the total outstanding guarantees of all states at the end of March 2008. Information received from states indicated that PSUs' dividend and interest payments were Rs1.7 billion and Rs 17 billion, respectively, in FY2008: dividends amounted to $0.18 \%$ of equity, and interest payments amounted to $0.99 \%$ of the outstanding loans. These shares are abysmally low and nowhere near the desired levels of $5 \%$ return on equity and $7 \%$ interest on outstanding loans suggested by the 12th Finance Commission (FCI 2009). 


\section{Corporate debt market}

A critical challenge to sustaining India's sovereign debt could come from one of its internal market segments. Most Indian banks are holding the Government of India debt at much higher levels than required, suggesting, among other things, a lack of adequate quality corporate debt paper. ${ }^{16}$ The situation is bound to change as the banks' risk aversion (particularly among public sector banks) decreases, the regulatory environment for a more favorable investment climate for the corporate debt market improves, and the economic capital base of the banks increases. Consequently, the government may not be able to roll over its debt with the same ease it has been used to. Regardless of where the DMO is established, the regulator will be more objective in its treatment of the investments in the government securities, which could increase the risk perception about and pricing of the government securities. Both could increase the yields on the government securities and thus increase the gross borrowing requirements.

\section{Concluding remarks}

This chapter has analyzed prospects for the sustainability of India's public sector debt in the medium term, that is, until 2016. This issue is of increasing concern to Indian policymakers due to the persistence of high fiscal and current account deficits, and because the GFC has substantially raised the risks for countries perceived to be pursuing unsustainable fiscal policies.

The standard IMF-style DSA for India suggests that, under a baseline scenario, the public debt/GDP ratio will fall from $64.1 \%$ in 2010 to $61.2 \%$ in 2016 . A large negative IRGD will be the major factor in this outcome. The predominant share of public sector debt has been internal, with public sector financial institutions being the major holders of government debt. These characteristics, combined with financial repression, have enabled the government to be relatively less exposed to market risks in rolling over debt and in issuing new debt. This helps to explain India's success at debt sustainability despite relatively high levels of public sector debt and persistent fiscal deficits, including deficits in the primary balance.

The DSA projections, however, suggest that a severe primary balance shock (which could arise if recent fiscal slippages are not addressed) and a real GDP growth shock (which could arise not just from global slowdown, but more importantly from failure to pursue pro-growth policies with sufficient vigor) could lead to a less sanguine view of India's public debt sustainability. Given India's persistent primary deficit, maintaining a large differential between the real interest rate and real GDP growth, without undue financial repression, will be essential. Stochastic projections present a wide range in which the debt/GDP ratio may fall. This suggests that tail risks, which may lead to much higher public debt/GDP ratios than those reported, should not be ignored, particularly in the aftermath of the GFC. Thus, policymakers should not view falling debt/GDP ratios complacently. 
The IMF-style standard DSA analysis focuses on key macroeconomic variables, primarily real interest rate, growth rate, exchange rate, and primary surplus in analyzing debt sustainability. As the analysis in this chapter indicates, while these are important for understanding India's debt dynamics and sustainability, a broader perspective is needed, involving constitutional and institutional factors, reform in the generation of government receipts, improved government expenditure management, and other changes.

The chapter notes several institutional initiatives, including the recommendation by the 13th Finance Commission to set up a national DMO and a fiscal council of central and state finance ministers to address India's fiscal management and debt sustainability issues. The Ministry of Finance and the RBI need to agree on the location and functioning of the national DMO.

The chapter also examines fiscal risks arising from other sources such as the cash accounting system and India's increasing reliance on public-private partnerships to finance infrastructure and other amenities in both urban and rural areas. Policymakers envisage a larger role for public sector enterprises in reversing declining investment, so that growth can be sustained. But this approach could lead to higher contingent liabilities, creating fiscal risks.

The government's increasing tendency to support entitlement or rights-based approaches in provision of employment, education, health, and food could portend larger fiscal risks than may be perceived from the standard DSA, while reducing the capacity to make fiscal adjustments when unanticipated adverse macroeconomic shocks occur.

An indicator that it would be a major challenge to correct slippages in fiscal deficit performance in the last three years is contained in the reports that the central government is seriously considering amending the FRBM Act to permit flexibility in fiscal policy (Indian Express 2011). The new targets are a fiscal deficit of 3.5\% and revenue deficit of $2.1 \%$ in FY2014. These represent yet another slippage compared to the originals goals of the FRBM Act. As general elections must be held by May 2014, even the latest revisions in deficit targets are unlikely to be met.

The chapter then suggests measures to enhance fiscal space, such as early passage of the Goods and Services Tax (GST) and Direct Taxes Code, and addressing issues such as tax arrears, tax expenditure, the low rate of cost recovery on social and economic services, and reform of state enterprises. Better public financial management, to substantially improve outcomes from budgetary outlays, will be essential for public debt management and sustainability.

India has a historic opportunity, aided by its favorable demographic profile, to emerge as a major economic power in the next two decades. But, as the GFC has underscored, inadequate policy emphasis on macroeconomic management, particularly ensuring fiscal sustainability and financial stability, could result in a major setback to India's ambitions. The practices India employs in managing its public debt will need to be changed considerably if fiscal and debt management policies are not to constrain the country's future growth and competitiveness internationally and globally. Such changes are also essential if India is to meet 
the aspirations and expectations of the younger generation, which is far better networked and more exposed to national and global developments than were the earlier generations. India's debt sustainability efforts must be pursued in this broader context.

\section{Notes}

1 In this chapter, the fiscal year will be referred to as the year in which it ends; hence, fiscal year 2007/08 will be abbreviated as FY2008.

2 Reasons for differences in public debt and fiscal data (reported by international agencies such as the IMF, and from official Indian sources such as the RBI) include differences arising from the different treatment of "above the line" versus "below the line" items. Thus, the treatment of small savings and other deposits in the Public Account, where the government acts as a trustee for certain organizations, could affect the reported public debt and fiscal data. All public money received by or on behalf of the Government of India, other than money for credit to the Consolidated Fund of India, is credited to the Public Account of India. Public Account liabilities also include "below the line" items in the form of securities issued in lieu of subsidies.

3 Total liabilities of the Government of India are larger than the public debt due to the liabilities arising from the deposits in the Public Account.

4 The Finance Commission is a constitutional body (Article 280 of the Indian Constitution). It is formed every 5 years to recommend criteria for sharing tax receipts collected by the center between the central and state governments, distributing grants-in-aid across the states, and handling any other issues the Parliament wants addressed.

5 See Chapter 3, Figure 3.12 for the graphical representation of annual changes in central government debt ratio: 2011-16.

6 See Chapter 3, Figure 3.8 for the graphical representation of actual and debt-stabilizing primary balance with a positive $1 \%$ deviation on the IRGD.

7 See Chapter 3, Figure 3.14b.

8 For a fuller description of the federal-state fiscal relations, see Srinivasan and Wallack (2011).

9 The Comptroller and Auditor General is India's supreme audit institution, with a mandate concerning accounts of the central and state governments. It performs the auditing function, and the function of consolidating accounts of the government organization. Details are available at http://www.cag.gov.in.

10 India has reportedly entered into 1,017 public-private partnership projects in infrastructure, with an investment of Rs4,866 billion (6.1\% of 2010 GDP). This is likely to grow, given official policy to encourage such partnerships (Singh and Malik 2012).

11 Under Section 17(5) of RBI Act, 1934, the RBI provides "Ways and Means Advances" to the states which bank with it to help them tide over temporary mismatches in the cash flow of their receipts and payments (RBI 2011d).

12 Both a consolidated sinking fund and the Guarantee Redemption Fund fall under the institutional measures adopted by state governments along with fiscal responsibility legislations, value-added tax, and new pension schemes, which have helped them consolidate their finances in the past (RBI 2011c).

13 At the end of December 2011, only Rs 1.1 billion or 3\% of the target had been generated through divestments during the (then) current fiscal year.

14 The exact total is not available due to incomplete asset registry. However, the defense sector controls an estimated 0.7 million hectares of land and Indian railways, 
0.4 million hectares. Estimates of land owned by other public organizations, public sector enterprises, and state and local bodies are not available (Economic Times 2012).

15 As the recovery rates are uneven across states, state-specific measures would be needed to increase overall recovery rates.

16 For an overview of India's corporate debt market and its market infrastructure, see Panda and Dias (2011). They estimate total outstanding corporate bonds at Rs8,895 billion ( $\$ 151$ billion) as of March 2011, only 4\% of the total Indian outstanding bonds. The share of corporate bonds has, however, gone up sharply from $2.0 \%$ in 2008 . More than two-fifths of the corporate bonds are public sector bonds, with ultimate fiscal risk on the state.

\section{References}

Ahya, C. (2012) "Get Cracking on the Deficit," Economic Times, Mumbai, 23 January 2012.

Asher, M. (2009) "Pension Plans, Provident Fund Schemes and Retirement Policies: India's Social Security Reform Imperative," ASCI Journal of Management 39(1): $1-18$.

BCA Research (2011) “Deconstructing India's Public Debt," Montreal, Special Report, August 2.

Comptroller and Auditor General (CAG) (2011) "CAG Report for the Period Ended March 2011, Performance Audit of Recovery Audit of Arrears in Tax Demand," Government of India. Available HTTP: <http://saiindia.gov.in/english/home/Our_Products/Audit_ Report/Government_Wise/union_audit/recent_reports/union_performance/2011_2012/ Direct_Taxes/Report_no_23/Report_no_23.html > (last accessed 23 December 2011).

Chakravarty, M. (2012) "Capital Account: Subsidies are Back to Crisis Levels," LiveMINT, 12 January 2012. Available HTTP: <www.LiveMINT.com/capitalaccount> (accessed 15 January 2012).

Economic Times (2012) “Government Maps out Land Sale Policy," 23 January 2012. Available HTTP: < http://epaper.timesofindia.com> (accessed January 2012).

Finance Commission of India (FCI) (2009) "Report of the Thirteenth Finance Commission 2010-15, December, New Delhi: FCI. Available HTTP: <http://fincomindia.nic.in/ ShowContentOne.aspx id=28\&Section $=1>$ (accessed October 2011-January 2012).

Government of India (GI) (2010) "Government Debt-Status and Road Ahead," New Delhi: Ministry of Finance. Available HTTP: <http://finmin.nic.in/press_room/2010/ govt_debt.pdf $>$ (last accessed on 29 October 2011).

_ (2011a) Public Debt Management Quarterly Report, October-December, 2010. New Delhi: Ministry of Finance. Available HTTP: <http://finmin.nic.in/reports/ PDM3rdQ.pdf $>$ (last accessed 15 January 2012).

(2011b) Union Budget 2011-12, New Delhi: Department of Finance. Available HTTP: < http://indiabudget.nic.in> (last accessed 23 December 2011).

Indian Express (2011) "New FRBM Act to Give Govt Flexibility in Times of Crisis," 7 March 2011. Available HTTP: <http://www.indianexpress.com/news/new-frbm-actto-give-govt-fiscal-flexibility/758869/>

International Monetary Fund (IMF) (2012) Stockholm Principles: Guiding Principles for Managing Sovereign Risk and High Levels of Public Debt. Available HTTP: $<\mathrm{http} / / / \mathrm{www}$.imf.org/external $/ \mathrm{np} / \mathrm{mcm} /$ stockholm/principles.htm $>$ (updated 6 January 2012). 
LiveMINT (2011) “Govt. May Borrow \$9.5 Billion by Asset Pledge, 23 December 2011. Available HTTP: <http://epaper.livemint.com/ArticleImage.aspx?article= 23_12_2011_026_002\&kword=dollar\%20bonds\&mode=1> (accessed 25 December 2011).

(2012a) "Firms Debt Servicing Capacity at 5 Year Low," 4 January 2012. Available HTTP: <http://epaper.livemint.com/ArticleImage.aspx?article= 04_01_2012_010_004\&kword=crisil\&mode=1 > (last accessed 20 January 2012).

(2012b) "West Bengal Faces Fiscal Crisis as Spending Spins Out of Control," 30 January 2012. Available HTTP: <www.epaper.livemint.com/articletext. aspx?article=30_01_2012_004_002\&kword=\&mode=1 > (accessed 2 February 2012). Malik, R. (2011) “India's Pesky Twins," CLSA Asia-Pacific Markets, 5 (35) 5 October.

Ministry of Urban Development (MUD) (2010) Jawaharlal Nehru National Urban Renewal Mission, Government of India. Available HTTP: <www.jnnurm.nic.in> (accessed January 2012).

Mohan, R. (2004) "A Decade of Reforms in Government Securities Market and the Road Ahead," RBI Bulletin, November, Mumbai: RBI. Available HTTP: <http://rbidocs.rbi. org.in/rdocs/Bulletin/PDFs/58617.pdf>

Moody's Investor Services (Moody's) (2011) "Rating Action: Moody's Unifies India's Government bonds at Baa3," Global Credit Research, 20 December 2011. Available HTTP: <www.moodys.com/printresearchdoctopdf.aspx?docid=PR_233954>

Panda, A. and Dias, N. (2011) "India Local Corporate Bond Guide," J.P. Morgan Asia Rates Research, November 3.

Rajaraman, I., Bhide, S., and Pattnaik, R. (2005) "A Study of Debt Sustainability at State Level in India,” Mumbai: RBI. Available HTTP: <http://rbidocs.rbi.org.in/rdocs/ PublicationReport/Pdfs/66511.pdf>

Reserve Bank of India (RBI) (2005) "Report of the Group on Model Fiscal Responsibility Legislation at State Level Reserve Bank of India," Mumbai: RBI. Available HTTP: $<$ http://rbidocs.rbi.org.in/rdocs/PublicationReport/Pdfs/61320.pdf> (2011a) Annual Report, 2010-11. Mumbai: RBI.

(2011b) Handbook of Statistics on Indian Economy 2010-11, Mumbai: RBI. Available HTTP: <http://www.rbi.org.in/scripts/AnnualPublications.aspx?head= Handbook\%20of\%20Statistics\%20on\%20Indian\%20Economy> (accessed December 2011-January 2012).

(2011c). "Policy Initiatives," Chapter III of State Finances: A Study of Budgets of 2010-11, Mumbai: RBI. Available HTTP: <http://www.rbi.org.in/scripts/ PublicationsView.aspx?id=13165 and http://rbidocs.rbi.org.in/rdocs/Publications/ PDFs/3CHSF280311.pdf > (accessed 26 January 2012).

(2011d) Second Quarter Review of Monetary Policy 2011-12, Mumbai: RBI. Available HTTP: <http://rbidocs.rbi.org.in/rdocs/notification/PDFs/SQR251011FL.pdf> (accessed 15 December 2011).

- (2012) Third Quarter Review of Monetary Policy 2011-12, Mumbai: RBI. Available HTTP: <http://rbidocs.rbi.org.in/rdocs/notification/PDFs/TQR250111FL. pdf $>$ (accessed 26 January 2012).

Sankhe, S., Vittal, I., Dobbs, R., Mohan, A., Gulati, A., Ablett, J., Gupta, S., Kim, A., Paul, S., Sanghvi, A., and Sethy, G. (2010) "India's Urban Awakening: Building Inclusive Cities, Sustaining Economic Growth," Washington, DC: McKinsey Global Institute. Available HTTP: <http://www.mckinsey.com/mgi/reports/freepass_ pdfs/india_urbanization/MGI_india_urbanization_fullreport.pdf $>$ (last accessed on 29 December 2011). 
Sheikh, Sh. (2011) "What Are the Significant Determinants of Credit Ratings of Indian Municipal Bodies and How Can the Indian Municipal Bond Market be Further Developed?" Dissertation submitted to the Master in Public Administration Programme, London School of Economics and Political Science.

Singh, S., and Malik, A. (2012) "Modernizing Railways." Available HTTP: <https:// epaper.livemint.com/ArticleText.aspx?article $=0102 \_007>$ (last accessed 20 January 2012).

Singh, N. and Srinivasan, T.N. (2004) "Fiscal Policy in India: Lessons and Priorities," Santa Cruz Center for International Economics, UC Santa Cruz. Available HTTP: <http:// escholarship.org/uc/item/67t3p20w $>$ (last accessed 17 January 2012).

Srikumar, S. (2010) "Municipal Credit Rating: Evolution and Implications for Urban Sector Financing in India," Draft prepared under Indo-US FIRE (D) Project, National Institute of Urban Affairs, July.

Srinivasan, T., and Wallack, J. (2011) "Inelastic Institutions: Political Change and Intergovernmental Transfer Oversight in Post-Independence India," India Policy Forum, 7.

Subbarao, D. (2011) "Central Bank Governance Issues: Some RBI Perspectives," Comments at the meeting of the Central Bank Governance Group in Basel, 9 May 2011. Available HTTP: <http://www.rbi.org.in/scripts/BS_SpeechesView.aspx?Id=563>

Topalova, P., and Nyberg, D. (2010) "What Levels of Public Debt Could India Target?" IMF Working Paper 10/7, Washington, DC: IMF. Available HTTP: $<\mathrm{http} / / /$ www.imf.org/external/pubs/ft/wp/2010/wp1007.pdf>

Vaidya, C., and Vaidya, H. (2008) "Creative Financing of Urban Infrastructure in India through Market-Based Financing and Public-Private Partnership Options," Presented at the 9th Metropolitan Congress, Sydney, 22-26 October 2008.

Ventakachalam, P. (2005) "Innovative Approaches to Municipal Infrastructure Financing: A Case Study on Tamil Nadu, India," Working Paper 68, November. London: Development Studies Institute (DESTIN), London School of Economics.

World Economic Forum (WEF) (2012) "Global Risks 2012 Seventh Edition.” Available HTTP: <http://reports.weforum.org/global-risks-2012/\#> (last accessed 13 January 2012). 


\title{
6 Public debt sustainability and fiscal vulnerability in Viet Nam
}

\author{
Charles Adams*
}

\section{Introduction and overview}

Following the initiation of "Doi Moi" reforms in the late 1980s, ${ }^{1}$ Viet Nam embarked on a farreaching program to liberalize its previous, centrally planned economic system, open up to international trade and capital flows, and create the institutions for a market economy (Riedel and Comer 1998; IMF 2008; World Bank 2010a, b). As a result, Viet Nam has become one of the fastest growing economies in Asia and has moved from low- to middle-income status at the World Bank within the space of two decades. And, even though the last few years have been characterized by severe macroeconomic instability, Viet Nam's economic prospects continue to be viewed very positively, provided it can deepen and broaden its reform program (IMF 2010; ADB 2011b).

For most of the reform period, Viet Nam's fiscal situation remained relatively strong and was not a major source of concern. Notwithstanding significant demands on the budget associated with an ambitious public investment and expenditure program, ${ }^{2}$ bank recapitalizations to address impaired assets carried over from the prereform regime, and declining revenues from a shrinking state sector Viet Nam's fiscal situation remained relatively solid during the first stages of its reform program. From the early 1990s to the mid-2000s, the deficit of the (consolidated) general government-measured according to international conventions $^{3}$ - averaged a modest $3 \%$ of gross domestic product (GDP) while public debt was on a declining trend from over $60 \%$ to around $45 \%$ of GDP. Against the background of the State Budget Law, ${ }^{4}$ the relatively strong fiscal position was facilitated by Viet Nam's access to concessional loans with low interest rates and to grants, buoyant oil revenues, comprehensive tax reform, ${ }^{5}$ and a generally robust economic growth performance with average annual increases in real GDP of $6 \%-7 \%{ }^{6}$

Notwithstanding the apparent strength of Viet Nam's fiscal position, both the International Monetary Fund (IMF) and World Bank expressed concern

\footnotetext{
*The author thanks Benno Ferrarini, Paul Gruenwald, and Hwee Kwan Chow for comments on an earlier draft. However, the author is solely responsible for the views expressed here.
} 
in their reports in the 2000s about the potential size of various government activities that were not included in the budget. In particular, concerns were expressed that significant unrecorded off-budget spending and borrowing might imply a much less benign view of Viet Nam's fiscal situation than is implied by the official data (IMF 2010). And there were worries about the possibility of potentially large contingent liabilities associated with relatively inefficient state-owned commercial banks (SOCBs). Notwithstanding a commercialization of their operations, SOCBs appeared to continue to undertake relatively high levels of directed lending and might have been accumulating significant impaired assets during the reform period. ${ }^{7}$ In addition, the efficiency of some of the investments undertaken in the state-owned enterprise (SOE) sector appeared not to be very high, thus contributing to a relatively high incremental capital output ratio. ${ }^{8}$

The relatively benign fiscal situation recorded in Viet Nam was not sustained during the 2000s. Viet Nam's budget deteriorated sharply in 2008-09 in the context of a period of severe macroeconomic instability caused by both external and domestic factors. As a result, particularly of a large fiscal stimulus program introduced during the 2008/09 global financial crisis to combat severe economic weakness, the deficit of the (consolidated) general government surged to about $9 \%$ of GDP in 2009 and the public debt ratio climbed to about 50\% (Table 6.1; Figures 6.1 and 6.2). Concerns were also expressed that the deficit might increase further as official announcements at the time pointed to the possibility of the deficit widening to well over 10\% of GDP (ADB 2010b; IMF 2010; World Bank 2010a, b).

In response to the weaker fiscal position, the Vietnamese authorities sought to reestablish fiscal discipline in late 2009 and 2010 against the backdrop of a number of significant challenges (IMF 2010). Beyond the need to unwind various fiscal stimulus measures introduced in 2008-09, including a generous interest subsidy scheme (ADB 2011b) the key challenges included ensuring adequate financing for muchneeded new infrastructure programs; further deepening and broadening the tax base to compensate for ongoing declines in revenues from oil, trade, and land taxes; and seeking to better control provincial and local government spending. At the same time, significant new challenges were beginning to emerge as a result of (1) renewed weaknesses in the financial system and in the nonfinancial sector $^{9}$ (which may at some time call for official budgetary support); (2) the possible negative implications of high levels of macroeconomic instability for growth and the exchange rate; and (3) higher interest costs associated with the graduation from low-income official borrower status. In addition, reflecting the relatively opaque nature of Viet Nam's budget and its presentation being not in a Government Finance Statistics (GFS) format, substantive questions have persisted about the extent to which the fiscal situation is adequately covered in the official data (IMF 2010).

Against this background, the objective of this chapter is to assess the sustainability of the fiscal situation in Viet Nam and the major challenges and vulnerabilities that will need to be faced in maintaining sustainability over time. 
Table 6.1 Viet Nam — debt sustainability analysis scenarios (\% of GDP)

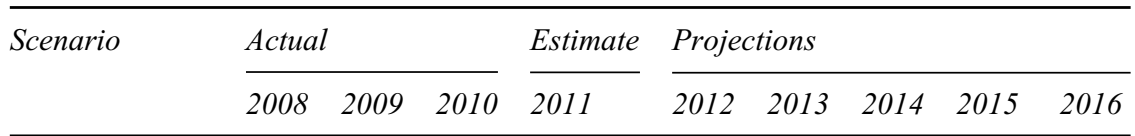

1. No policy adjustment

$\begin{array}{lrrrrrrrrr}\text { Fiscal balance } & -1.2 & -9.0 & -5.7 & -4.0 & -4.0 & -4.0 & -4.0 & -4.0 & -4.0 \\ \text { Primary balance } & -0.1 & -7.6 & -4.4 & -2.5 & -2.5 & -2.5 & -2.5 & -2.5 & -2.5 \\ \text { Public debt } & 42.9 & 51.2 & 52.8 & 54.4 & 52.8 & 51.5 & 47.8 & 44.5 & 41.6\end{array}$

\section{Baseline policy adjustment}

$\begin{array}{llllllllll}\text { Fiscal balance } & -1.2 & -9.0 & -5.7 & -4.0 & -3.8 & -3.5 & -3.3 & -3.0 & -2.9 \\ \text { Primary balance } & -0.1 & -7.6 & -4.4 & -2.5 & -2.2 & -2.0 & -1.8 & -1.6 & -1.6\end{array}$

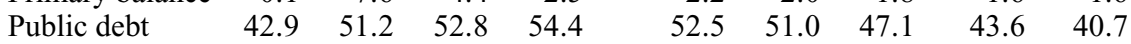

\section{Delayed fiscal adjustment}

$\begin{array}{lrrrrrrrrr}\text { Fiscal balance } & -1.2 & -9.0 & -5.7 & -4.0 & -3.8 & -3.5 & -3.3 & -3.0 & -2.9 \\ \text { Primary balance } & -0.1 & -7.6 & -4.4 & -2.5 & -4.7 & -4.4 & -4.3 & -4.0 & -4.0 \\ \text { Public debt } & 42.9 & 51.2 & 52.8 & 54.4 & 54.9 & 53.4 & 49.6 & 46.0 & 43.2\end{array}$

\section{Growth slowdown}

$\begin{array}{llllllllll}\text { Fiscal balance } & -1.2 & -9.0 & -5.7 & -4.0 & -3.8 & -3.5 & -3.3 & -3.0 & -2.9\end{array}$ $\begin{array}{llllllllll}\text { Primary balance } & -0.1 & -7.6 & -4.4 & -2.5 & -2.2 & -2.0 & -1.8 & -1.6 & -1.6\end{array}$ $\begin{array}{llllllllll}\text { Public debt } & 42.9 & 51.2 & 52.8 & 54.4 & 53.0 & 51.9 & 48.4 & 45.1 & 42.6\end{array}$

\section{Inflation increase}

$\begin{array}{lrrrrrrrrr}\text { Fiscal balance } & -1.2 & -9.0 & -5.7 & -4.0 & -3.8 & -3.5 & -3.3 & -3.0 & -2.9 \\ \text { Primary balance } & -0.1 & -7.6 & -4.4 & -2.5 & -2.2 & -2.0 & -1.8 & -1.6 & -1.6 \\ \text { Public debt } & 42.9 & 51.2 & 52.8 & 54.4 & 50.2 & 46.5 & 41.0 & 36.2 & 32.3\end{array}$

\section{Domestic interest rate increase}

$\begin{array}{llllllllll}\text { Fiscal balance } & -1.2 & -9.0 & -5.7 & -4.0 & -3.8 & -3.5 & -3.3 & -3.0 & -2.9\end{array}$

$\begin{array}{llllllllll}\text { Primary balance } & -0.1 & -7.6 & -4.4 & -2.5 & -2.2 & -2.0 & -1.8 & -1.6 & -1.6\end{array}$

$\begin{array}{llllllllll}\text { Public debt } & 42.9 & 51.2 & 52.8 & 54.4 & 53.6 & 53.1 & 50.2 & 47.5 & 45.5\end{array}$

\section{Real exchange rate depreciation}

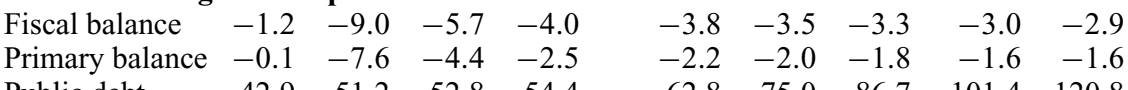

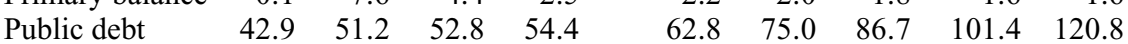

\section{8. "Perfect storm"}

\begin{tabular}{lrrrrrrrrr} 
Fiscal balance & -1.2 & -9.0 & -5.7 & -4.0 & -3.8 & -3.5 & -3.3 & -3.0 & -2.9 \\
Primary balance & -0.1 & -7.6 & -4.4 & -2.5 & -2.2 & -2.0 & -1.8 & -1.6 & -1.6 \\
Public debt & 42.9 & 51.2 & 52.8 & 54.4 & 56.8 & 63.5 & 72.8 & 84.8 & 100.1 \\
\hline $\begin{array}{l}\text { Memo item: } \\
\text { growth interest } \\
\quad \text { rate gap }\end{array}$ & -23.8 & -2.6 & -11.2 & -10.8 & -8.0 & -6.3 & -8.5 & -8.0 & -7.7 \\
\hline
\end{tabular}

$\mathrm{GDP}=$ gross domestic product.

Source: Authors' estimates. 


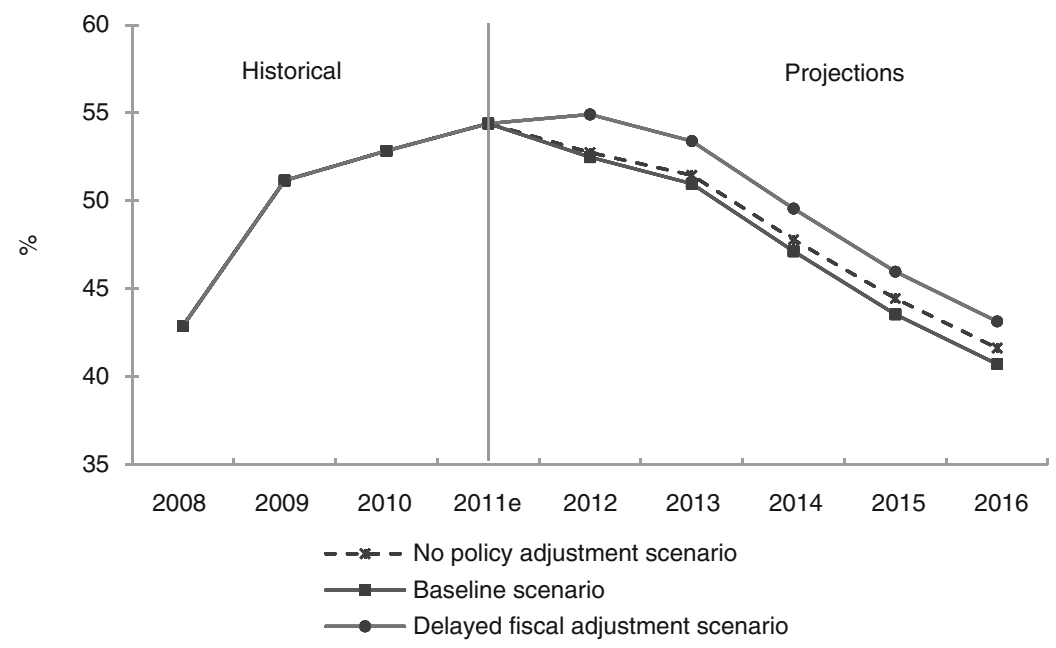

Figure 6.1 Policy scenarios-Viet Nam's public sector debt (\% of GDP). $\mathrm{e}=$ estimate, GDP $=$ gross domestic product.

Source: Author's estimates.

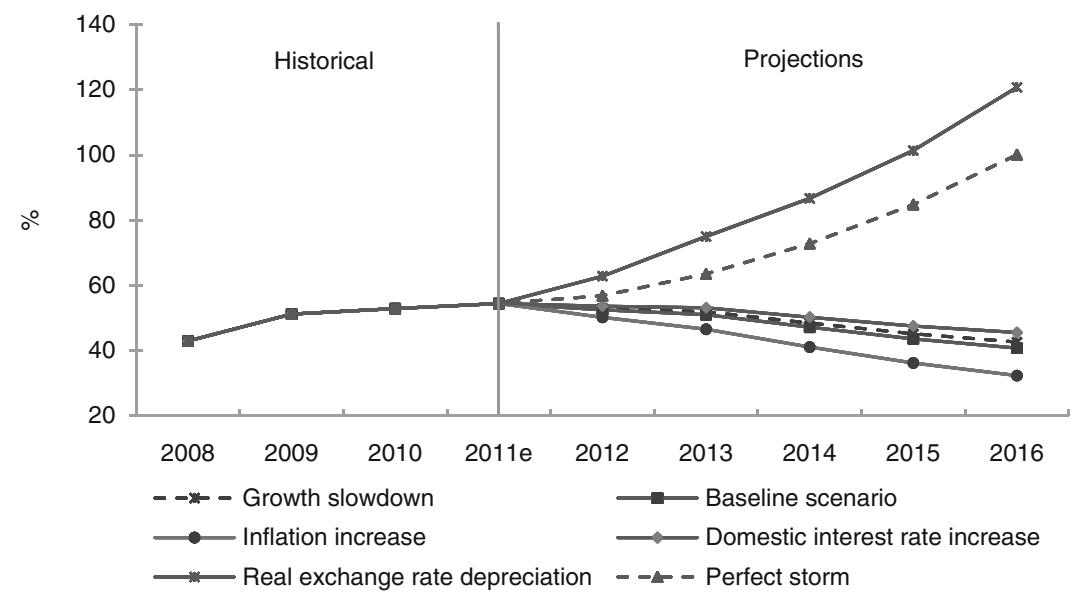

Figure 6.2 Macroeconomic scenarios-Viet Nam's public sector debt (\% of GDP). $\mathrm{e}=$ estimate, GDP $=$ gross domestic product.

Source: Author's estimates. 
To this end, the chapter draws on and extends the analysis of fiscal sustainability presented in Adams, Ferrarini, and Park (2010) based, in particular, on the concept of fiscal vulnerability discussed by Hemming and Petrie (2002). The chapter considers the sustainability of Viet Nam's current fiscal situation-in terms of whether it is consistent with the stabilization of the public debt ratio at a reasonable level over time - and where the main vulnerabilities and challenges to fiscal sustainability may lie and how they might best be addressed.

A number of studies of the fiscal situation in Viet Nam have been done, most notably, the regular debt sustainability analyses (DSAs) undertaken jointly by the IMF and World Bank (IMF 2008, 2010). In addition, several academic studies have addressed aspects of Viet Nam's actual and prospective fiscal situation (Anh 2002; Roy 2003; Giang 2004; Castel 2007, 2009). However, many of them have focused on the early period of the reform process and - subject to a number of caveatshave not generally seen major threats to fiscal sustainability. Some studies have focused on particular components of the budget (e.g., Anh [2002] and Castel [2007] discuss pensions) rather than focusing on the overall fiscal situation. Given the fiscal slippages in Viet Nam during the global financial crisis in 2008/09 (Castel 2009) as well as new challenges associated with Viet Nam's increased reliance on nonconcessional foreign currency borrowing, it is important to revisit the earlier findings and the degree to which the conclusions on debt sustainability remain valid. In particular, it is useful to consider whether Viet Nam's increased reliance on foreign currency market borrowing is making it more vulnerable to the sort of self-fulfilling disequilibria in which even unfounded concerns about fiscal sustainability could become self-validating by raising the local currency value of foreign debt or the interest rate. ${ }^{10}$

The approach to assessing fiscal sustainability taken in this chapter is subject to four important caveats. First, as in the case of any economy under transition from state to private ownership, there are substantive questions in Viet Nam about where the evolving line should be drawn between the state and nonstate sectors in assessing the fiscal situation and the level of public debt. Best practice in assessing fiscal sustainability might be to focus on the broadest concept of the public sector that includes state enterprises in addition to the central and provincial governments (Adams, Ferrarini, and Park 2010). The data for such coverage are not easily available - the SOE sector in Viet Nam has been evolving during the reform period - and such an approach would require continually redefining the public sector to account for ongoing privatization and equitization. In addition, this approach would likely lead to a definition of the fiscal sector that was several times broader and larger than the official measure.

Second, there are substantive questions about the boundaries for the government sector, and continued concerns with regard to the comprehensiveness of officially reported budget spending and revenue data and the sizes of various off-budget accounts, as well as a number of quasi-fiscal activities (IMF 2008, 2010). Fortunately, the authorities are beginning to address these issues and have indicated their intention to bring Viet Nam's fiscal data up to GFS standards. At this point, however, it is necessary to rely on very imprecise estimates of the sizes 
of the various off-budget items and, when the fiscal data are presented according to GFS conventions by the authorities, the measures of the budget may be different from the current measures.

Third, in line with the standard approaches to the assessment of fiscal sustainability, this chapter defines public debt to include the outstanding interestbearing liabilities of the government (excluding the State Bank of Viet Nam) and any nongovernment debt that is explicitly guaranteed by the government. Unfortunately, however, there is some ambiguity about the formal extent of such guarantees, ${ }^{11}$ as evidenced by the lack of clarity about whether the Government of Viet Nam would assume responsibility for the liabilities of the state group Vinashin after its apparent debt default in late $2010 .^{12}$

Finally, an important caveat-related to the lack of a medium-term fiscal framework for Viet Nam's budget — is the absence of complete data on both funded and unfunded medium-term government liabilities associated with items such as social support, pensions, and medical benefits (Castel 2007, 2009). Instead, it is necessary to rely largely on external estimates of the costs of various programs and their possible implications for the budget.

The rest of the chapter is structured as follows. The following section develops and applies relatively standard deterministic and stochastic DSAs to identify the extent to which Viet Nam's current fiscal situation is sustainable and the amount of adjustment required to ensure medium-term sustainability at a reasonable debt level. The approach focuses on the general government and hence covers the central, provincial, and local governments. As in the case of the most recent IMF and World Bank sustainability assessment for Viet Nam (IMF 2010) — based on similar macroeconomic assumptions - the key finding is that Viet Nam's fiscal position is not currently very far from a sustainable level given recent efforts to bring the fiscal deficit down from its peak of close to $9 \%$ of GDP in 2009; in addition, public debt does not appear to be at the sort of levels that flash major warning signals about debt sustainability. And, even though the primary (noninterest) general government surplus will need to increase somewhat to bring the public debt ratio down to a more comfortable rate over the medium term, the adjustment required does not appear too large to achieve if economic conditions remain favorable.

However, based on extensive sensitivity analysis in which a range of less favorable economic assumptions about growth, interest rates, and the exchange rate are adopted - with implications for the gap between the growth rate and interest rate (the interest rate-growth differential, or IRGD) ${ }^{13}$ - the fiscal position potentially appears much less sanguine. Against this background, the chapter's third section discusses some potential vulnerabilities in Viet Nam's fiscal situation and their implications for the outlook. Building on the framework of Hemming and Petrie (2002), a number of vulnerabilities are discussed regarding a possible underestimation of the size of the true fiscal position; the degree of sensitivity of fiscal outcomes to various risks (including refinancing and exchange rate risk); the robustness of the underlying budget situation; and weaknesses in fiscal management practices. The chapter argues that several of these vulnerabilities 
are somewhat elevated in Viet Nam and may make it difficult to maintain fiscal sustainability over time. Finally, section four presents the key conclusions and policy recommendations.

\section{Debt sustainability analyses}

Fiscal sustainability refers to a situation in which the government is able to finance its operations smoothly over time without generating explosive or excessive increases in public debt (Chalk and Hemming 2000; Adams, Ferrarini, and Park 2010). For some purposes, it is useful to explicitly distinguish between the ability of government to smoothly finance fiscal deficits in the short term (a liquidity issue) and medium-term fiscal solvency issues (the ability of the government to meet its debt and other obligations). This section applies relatively standard deterministic and stochastic DSAs to consider issues of medium-term fiscal sustainability or solvency; short-term funding issues are addressed in the next section.

Even though fiscal sustainability is a critical concept, agreement about how it should best be assessed is not universal. As discussed in earlier Chapters 2 and 3, and by Adams, Ferrarini, and Park (2010), there are three broad approaches to assessing medium-term fiscal sustainability. Under time series approaches, fiscal sustainability is assessed through formal tests on the time series properties of variables such as government spending, revenues, and public debt (frequently as shares of GDP) and whether they exhibit stationarity or cointegrating relationships. Essentially, these tests are based on the fact that fiscal sustainability will imply that variables such as debt/GDP ratios do not exhibit explosive behavior and that variables such as government spending and revenues will tend to move together when the government budget constraint is satisfied and fiscal solvency is achieved.

Another set of tests can be referred to as fiscal reaction function (or primary balance) tests, as they measure how the primary (or noninterest) component of the fiscal balance responds to increases in variables such as debt ratios. Intuitively, the basis for these tests is that a tendency for the primary balance to increase as debt ratios rise will tend to support fiscal sustainability. This is because such an increase will imply that fiscal space is created to cover the associated increase in debt-servicing costs. Unfortunately, however, both time series and fiscal reaction function tests require a long time span of consistent fiscal data, which is not available in the case of Viet Nam. ${ }^{14}$

Accordingly, this chapter uses a third approach involving scenarios or stress tests. The scenario approach involves projecting public debt ratios several years into the future on the basis of current and other policy settings in order to assess whether they imply explosive paths for debt. Alternatively, the stress test approach involves considering the implications of less favorable economic conditions, such as weaker growth and/or higher interest rates, for the behavior of public debt ratios. These latter approaches are referred to as stress tests in so far as the sensitivity of the results is typically evaluated under a range of stressed conditions or very large shocks to economic variables (e.g., 2 or 3 standard 
deviation changes in variables such as interest rates and growth rates may be considered to capture stress). In addition, the chapter uses stochastic approaches to assessing debt sustainability. The stochastic approaches to debt sustainability take explicit account of the probabilistic behavior of the variables that influence debt sustainability, as discussed in Chapters 2 and 3.

The key elements of Viet Nam's DSA framework are outlined in Table 6.1, drawing on the latest analyses of fiscal sustainability by the IMF and World Bank (IMF 2008, 2010). In the table, all magnitudes are expressed as shares of GDP unless otherwise indicated; overall fiscal deficits are broken down into their primary (noninterest) ${ }^{15}$ and nonprimary components; and the data apply to the (consolidated) general government. Data through 2011 refer to estimates of fiscal outturns while the data for 2012 and beyond are projections based on alternative assumptions about Viet Nam's fiscal adjustment effort and different macroeconomic forecasts for growth, inflation, and the real exchange rate.

In the first scenario (no policy adjustment) the primary fiscal deficit is assumed to be held constant at its 2011 ratio of $2.5 \%$ of GDP and the public debt ratio is projected on the basis of this assumption. The second scenario (baseline policy adjustment) draws on IMF and World Bank views on the primary fiscal adjustment required by Viet Nam to lower its public debt ratio toward a more comfortable $40 \%$ of GDP over the medium term. ${ }^{16}$ The starting point for both scenarios is an estimated outturn for Viet Nam's (consolidated) general government deficit of about 4\% of GDP in 2011 (down from 9\% of GDP in 2009) and a public debt ratio close to $50 \%$ of GDP in 2011.

Neither of the two scenarios points to significant fiscal sustainability problems in Viet Nam. Even under scenario 1 (no policy adjustment), Viet Nam's public debt ratio would decline over the medium term toward $45 \%-40 \%$ of GDP, albeit at a relatively slow pace. Such a scenario would imply, however that Viet Nam's public debt ratio would remain high for a longer period relative to comparator countries; in addition, it would, in the view of the IMF (2010), remain above prudential norms given Viet Nam's level of development and the strength of its institutions. Accordingly, scenario 2 (baseline policy adjustment) assumes a targeted reduction in the primary fiscal adjustment of $1 \%$ of GDP spread uniformly over several years. In this second scenario, not surprisingly, the public debt ratio declines more rapidly than in the no-policy adjustment scenario and falls to about $40 \%$ of GDP during the next 3-5 years.

Based on these two scenarios, one could conclude that Viet Nam is not very far from a sustainable fiscal position, and the fiscal adjustment that started in 2010 and 2011 (which reduced the overall fiscal deficit by almost 5\% of GDP from its 2009 peak of $9 \%$ ) already represents a significant down-payment on the adjustment required to stabilize the debt ratio at an appropriate medium-term level.

Such a sanguine conclusion on Viet Nam's fiscal situation would be premature for at least four sets of reasons, however:

- First, the conclusion (as noted) is based on the assumption that substantial progress has already been made in reducing Viet Nam's fiscal deficit from 
a peak of $9 \%$ of GDP in 2009 to less than 4\% of GDP in 2011. At this stage, the fiscal outturn for 2011 is a first estimate - slippages from budgeted outcomes are possible and have occurred in the past. In these circumstances, care is needed in assuming that the bulk of the fiscal deterioration in 2009 has already been reversed.

- Second, the conclusion is based on very favorable macroeconomic conditions, including sustained high real GDP growth, the stabilization of inflation at single digit rates, and real exchange rate stability. ${ }^{17}$ In the spirit of DSA, it is important to consider the implications of less favorable economic assumptions and what they might imply for the required adjustment to stabilize the debt ratio. Given recent macroeconomic instability in Viet Nam, it is especially useful to consider the robustness of the conclusions to a "perfect storm" scenario in which there are adverse movements in several economic variables at the same time. To this end, consideration is given below to the implications of an inflation-led growth slowdown accompanied by a period of sustained weakness in the real dong exchange rate.

- Third, the conclusion assumes that the authorities are not only successful in raising the revenue-to-GDP ratio on a sustained basis (even as traditional tax sources need to be replaced by new tax sources and the grant element of aid continues to be reduced) but also that higher revenues are used to improve the primary fiscal balance rather than finance new public spending. As discussed by Adams, Ferrarini, and Park (2010), there has been no guarantee in the past that fiscal savings in Asia will necessarily be used to improve primary fiscal surpluses; in some countries, increases in revenue collection have largely been spent rather than "saved." Thus, it is useful to consider the robustness of the conclusions to alternative assumptions about the fiscal policy reaction function.

- Fourth, the conclusion assumes a continuation of the very favorable positive gap of around 10 percentage points on average between the real growth rate of Viet Nam's economy and the average real interest rate on public debt (Table 6.1). Given this gap-with the real growth rate well above the real interest rate - stabilization of the debt ratio is possible even when Viet Nam is running a relatively large primary fiscal deficit. Either because trend growth in Viet Nam may be reduced by the recent macroeconomic turbulence (IMF 2010, World Bank 2010a), or on account of Viet Nam's graduation to middleincome status and the greater sensitivity of interest rates to market conditions, the favorable IRGDs may narrow. ${ }^{18}$ Alternatively, any sustained weakening of Viet Nam's real exchange rate will tend to narrow the gap by raising the real cost of external debt. It is useful to consider the sensitivity of the conclusions to alternative assumptions about the IRGD, which plays a critical role in the DSA.

Consider each of these qualifications in turn. Essentially, the first qualification centers on the progress already made in reversing the sharp increase in the fiscal deficit in 2009. Based on the assumption that almost 5\% of GDP of the required adjustment has already taken place, only modest further adjustments in the primary 
balance are required to bring the debt/GDP ratio down to $40 \%$ over the medium term. This, however, ignores the possibility of fiscal adjustment delays or slippage in 2011 related to the sharp recent increases in inflation - which had already risen to close $20 \%$ by mid-2011 — and the risk of a slowing of growth in response to the necessary monetary policy tightening (ADB 2011b; World Bank 2011). For purposes of illustration, scenario 3 in Table 6.1 (delayed fiscal adjustment) is based on the assumption that no progress is made in reducing the primary fiscal deficit in 2011 with all the adjustment shifted to later years. Not surprisingly, the debt/GDP ratio remains elevated for a longer period under this scenario, but it then trends down to a shade above $40 \%$ over the medium term. Accordingly, under the assumptions made, a short delay in fiscal consolidation does not fundamentally change the favorable conclusions on fiscal sustainability. ${ }^{19}$

Of greater potential significance for fiscal sustainability would be much less favorable macroeconomic conditions than assumed in the DSA, which narrow the interest rate-growth differential. To this end, Table 6.1 reports the results of sensitivity exercises in which the key macroeconomic variables in the DSA are subjected, one by one, to a number of unfavorable shocks (scaled in standard deviations). More specifically, the alternative scenarios display, in turn, the implications for fiscal sustainability of a 1 standard deviation reduction in real GDP growth (a 1.25 percentage point growth slowdown); a 1 standard deviation increase in the inflation rate (a 5 percentage point increase); a 2 standard deviation increase in the domestic nominal interest rate (about 7.6 percentage points change); and a shock of about a 4 standard deviation depreciation in the level of the real exchange rate (a 14\% real depreciation on the average). Based on the recent high degree of macroeconomic instability in Viet Nam (ADB 2011a, b), each of these represents a plausible shock to which fiscal policy could reasonably be exposed and it is appropriate to consider the potential implications for debt sustainability.

As illustrated in Table 6.1, the key effect of each these macroeconomic shocks is to raise the trajectory for the public debt ratio in the near term and slow the convergence to a public debt ratio of $40 \%$ of GDP. Perhaps most surprising is the very high sensitivity of the debt ratio to weakness in the real exchange rate. With around two-thirds of public debt denominated in foreign currencies, ${ }^{20}$ any sustained weakness in the real exchange rate has a very large adverse impact on the debt ratio and the amount of adjustment in the primary fiscal balance needed to stabilize the ratio. This implies considerable vulnerability for Viet Nam as it has been moving in recent years toward a more flexible exchange rate and there has been severe weakness in the dong exchange rate in the short term.

In all of the scenarios considered so far in Table 6.1, shocks are assumed to occur one by one and the implications for debt sustainability are determined in a relatively mechanical way based on the breakdown of the fiscal accounts into their primary and nonprimary components. In practice, a much more useful exercise involves considering the simultaneous occurrence of several plausible shocks with allowance for behavioral responses. Unfortunately, however, there are no widely used macroeconomic models for Viet Nam that could be deployed for such an exercise. As a result, a considerably less ambitious approach must be taken. ${ }^{21}$ 
The last scenario in Table 6.1 considers the "perfect storm" of an inflationinduced slowdown in growth accompanied by an increase in the domestic interest rate and real exchange rate weakness. As illustrated, the effects are dramatic and imply a large increase in the debt ratio of more than $20 \%$ of GDP over the medium term. While the precise projections should be treated with care, they clearly show that conclusions on fiscal sustainability are dependent on macroeconomic outcomes, especially as regards the real exchange rate. Accordingly, and especially in light of the recent macroeconomic instability in Viet Nam, they suggest the need to be cautious about how easy it will be to attain and maintain fiscal sustainability.

A third key set of assumptions underlying the relatively sanguine view of fiscal sustainability relate to the ability of Viet Nam to mobilize additional revenues and the assumption that additional revenues will go toward reducing the fiscal deficit rather than increasing spending. As Viet Nam does not have binding fiscal rules in place on the size of the deficit, explicit decisions will be needed to save rather than spend higher revenues. As illustrated in Table 6.1, much of the assumed improvement in the primary balance required to stabilize the debt ratio over the medium term (scenario 2, baseline policy adjustment) comes about as a result of an increase in the ratio of revenue and grants to GDP by close to one percentage point. As grants to Viet Nam are on a downward trend and the buoyancy of the tax system ${ }^{22}$ does not appear to be very high, the implication is that tax rates will have to be increased and/or the tax base broadened to reduce the primary deficit. While a 0.5 to 1 percentage point increase in the revenue/GDP ratio does not appear very difficult to achieve, oil taxes have until recently contributed almost 2 percentage points of GDP to revenue and are expected to decline significantly over the medium term (IMF 2010). In these circumstances, about 2-3 points of GDP of (non-oil) revenues will be required to help stabilize the debt ratio even under the optimistic economic assumptions made in the first two scenarios of the DSA analysis. Alternatively put, while the required improvement in the primary balance may (under optimistic assumptions) only amount to $1 \%$ of GDP, the required improvement in the non-oil primary balance may need to be $2 \%-3 \%$ of GDP, given falling revenues from oil sources.

Another key assumption underlining the DSA is that additional revenue mobilized will be used to reduce the deficit rather than finance higher public spending. Or, equivalently, the assumption is that higher revenue mobilization will be used to reduce the primary deficit on a one-to-one basis. Such an outcome is not guaranteed, and may be especially difficult to achieve when there are high demands for public infrastructure investment and the grant component of foreign aid is declining. The highest levels of government in Viet Nam, however, appear to agree that much inefficient public investment can be scaled back to make room for new public investment; in addition, attention is being paid to innovative ways to use public-private partnerships for financing infrastructure (IMF 2008; ADB 2011b). In these circumstances, the priorities of the public investment program will not necessarily preclude devoting higher revenues to reducing the deficit. 
Against this background, one way to assess the likelihood of revenue mobilization being used to reduce the primary deficit is to look at Viet Nam's recent fiscal adjustment experience. Drawing on Adams, Ferrarini, and Park (2010), one approach would be to estimate a primary fiscal policy reaction for Viet Nam that measures the extent to which the primary fiscal balance deficit has historically been reduced as the debt/GDP ratio rises. Such an approach, however, was difficult to implement, as a stable policy reaction function could not be identified for the limited number of time series observations available for Viet Nam. Instead, a policy reaction function was estimated for how innovations in (primary) government spending in Viet Nam respond to innovations in revenues. ${ }^{23}$ Subject to issues of causality, the function can be interpreted as measuring the propensity of the government to spend the proceeds from revenue innovations. The estimated coefficient of the reaction function is relatively high and suggests on average that about $90 \%-95 \%$ of every percentage point increase in revenues leads to higher public spending. In these circumstances, special efforts will be required to ensure that revenue mobilized is used to reduce the deficit.

The final point concerns the large positive excess of Viet Nam's real growth rate over the (average) real interest rate on its public debt. To understand the significance of this IRGD, it is useful to note that the standard approach to debt sustainability analysis in advanced countries is based on the finding that the real growth rate of the economy is normally less than the real interest rate. ${ }^{24}$ In such circumstances, a key result is that stabilization of the debt ratio will call for a primary surplus that is approximately equal to the negative of the IRGD multiplied by the debt/GDP ratio. Accordingly, if the real interest rate exceeds the real growth rate by 2 percentage points and the debt ratio is $100 \%$ of GDP, a primary fiscal surplus of $2 \%$ of GDP will be needed to stabilize the debt ratio. In the case of Viet Nam (and many other rapidly growing emerging markets), the arithmetic is reversed on account of the real growth rate on average being above the real interest rate by a significant margin; in these circumstances, the public debt/GDP ratio can be stabilized even when Viet Nam is running a primary deficit. Even though such a situation would not be expected to continue indefinitely, it can clearly persist for long periods, as discussed by Adams, Ferrarini, and Park (2010).

Table 6.1 reports the real IRGD for Viet Nam during the last decade and clearly shows not only that the gaps have been very large and positive, but also very persistent. Moreover, the large positive gaps have reflected a relatively high growth rate of real GDP, and they have reflected highly negative real interest rates on both domestic and foreign debt over some periods. In the case of foreign debt, the negative real interest rates have reflected the concessional nature of much foreign borrowing and the avoidance of significant real depreciations in earlier periods that would raise the real cost of foreign debt. In the case of domestic debt, the negative real interest rates reflect inflation rates that in many years are well in excess of low nominal rates. While many factors may contribute to the low official borrowing rates in the domestic market, key contributing factors may be the existence of few alternative safe assets that can be held domestically and the effects of financial repression. In the event, the key implication of the large positive IRGD is the 
additional room provided to Viet Nam to stabilize its debt ratio. Conversely, were the real growth rate to fall below the real interest rate, Viet Nam would need to run a primary surplus to bring down its current relative debt ratio to $40 \%$ of GDP over the medium term. Accordingly, the required adjustment in the primary fiscal balance in scenario 2 (baseline policy adjustment) in Table 6.1 would amount to at least $6 \%$ of GDP.

Looking forward, the key consideration is not that the positive real IRGD would be expected to disappear over the next few years; rather, with concessional financing being scaled back and the costs of debt issuance on the domestic market likely to rise as financial liberalization proceeds, there are strong reasons for believing that the gap will narrow due to increases in the domestic interest rate. And, based on the arithmetic, each percentage point narrowing of the gap implies approximately another one-half percentage point increase in the primary surplus needed to stabilize the debt ratio. Furthermore, as discussed in more detail in the next section, the positive gap can be reduced by real exchange rate depreciation and, in the short run, at least, is very vulnerable to confidence crises that lead to sharp depreciations in the dong exchange rate. ${ }^{25}$

Another perspective on debt sustainability can be obtained by explicitly allowing for uncertainty in a stochastic version of the DSA. The stochastic DSA, as in the case of the deterministic DSA, points to the need for caution about fiscal sustainability while at the same time underscoring the degree of uncertainty about fiscal outcomes. Figure 6.3 extends Viet Nam's DSA by accounting for the stochastic properties of the debt dynamics. ${ }^{26}$ In contrast to the deterministic version of DSA, the stochastic approach to DSA randomly generates a large sample of stress tests from which frequency distributions of the debt ratio can be derived for each year of the projection. These are then laid out like a fan around the median projection, permitting a probabilistic assessment of sustainability.

To derive the stochastic DSA for Viet Nam, an unrestricted vector autoregression (VAR) model was estimated on the basis of yearly data spanning 1991-2010 for the real exchange rate against the United States dollar, the real growth rate, the rate of inflation, and the average weighted interest paid on domestic and foreign debt. ${ }^{27}$ The VAR's estimated variance-covariance matrix captures the joint dynamics of the variables, which is then used for Monte Carlo simulations reiterated 100,000 times to produce a probability distribution of shocks that is consistent with those joint dynamics.

The stochastic debt ratio (the dashed line in Figure 6.3) is then projected according to the median realizations of the macroeconomic variables and the fiscal policy assumptions, which are assumed to be the same as those underlying the deterministic baseline (the light gray line in Figure 6.3). The probability distribution around the median projection is shown as a shaded area between the 5th and 95th percentiles of the probability distribution. The stochastic DSA projections assume fiscally responsible behavior by Viet Nam's government, raising the primary surplus by $0.05 \%$ for a unit percentage increase in the debt ratio with a lag of one year. (This coefficient is compatible with the estimates in Chapter 2.) 


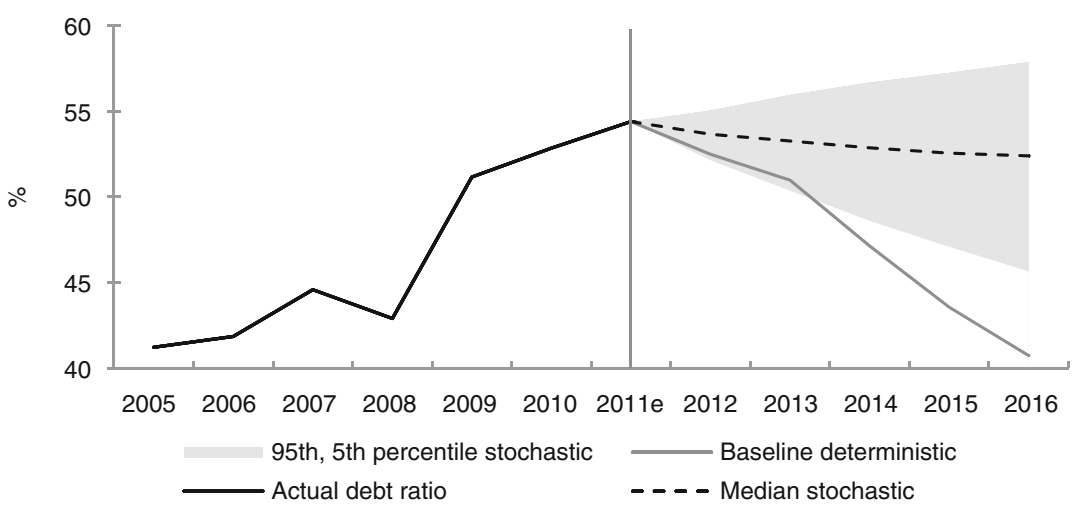

Figure 6.3 Viet Nam's debt sustainability analysis (\% of GDP).

$\mathrm{e}=$ estimate, GDP $=$ gross domestic product.

Source: Author's calculations based on Asian Development Bank and International Monetary Fund macroeconomic and fiscal forecasts.

That the deterministic DSA baseline falls within the 5th to 95th percentile range of the stochastic fan-chart in Figure 6.3 suggests that the baseline assumptions are compatible with a broad range of conceivable shocks to the system of macro variables underlying the debt dynamics. The baseline's allocation in the area above the median of the fan-chart indicates that its underlying assumptions are not overly optimistic compared to the historical trends and correlation structures underlying the projected stochastic distribution.

Based on the conventional DSAs applied in this section, Viet Nam does not appear to be very far from a sustainable fiscal position, notwithstanding the large fiscal deterioration during the 2008/9 global financial crisis. And, even though new challenges for fiscal policy have been appearing, the fiscal adjustment required to meet them does not appear to be of a size that is out of line with past experience. More worrying is the possibility of significantly less favorable economic conditions but, as argued, they would have to be very adverse to eliminate the very large positive IRGD and have a significant impact. Against this relatively sanguine background, the chapter now turns to some vulnerabilities in Viet Nam's fiscal position that are potentially of much greater concern.

\section{Fiscal vulnerabilities in Viet Nam}

This section extends the analysis of fiscal sustainability by considering some of the key vulnerabilities faced by fiscal policy in Viet Nam. To motivate the discussion, this section focuses on vulnerabilities that may limit the ability of Viet Nam's fiscal policy to meet its stated objectives, such as the provision of public goods, equitable redistribution, and macroeconomic stability. Obviously, 
deviations from fiscal sustainability can create vulnerabilities because they may reduce the ability of fiscal policy to finance needed public investment programs. But even in circumstances where fiscal policy appears sustainable, the achievement of fiscal objectives may be compromised by the vulnerabilities that are considered in this section.

Based on the taxonomy introduced by Hemming and Petrie (2002), this chapter considers fiscal vulnerabilities in four key areas and attempts to provide some sense of their potential significance and implications. In all instances, the vulnerabilities refer to factors that may impede to some degree the ability of fiscal policy to perform its intended functions. Accordingly, it will be in the interests of the authorities to try to address these vulnerabilities as part of the effort to increase the likelihood of meeting fiscal objectives.

The four key areas of potential vulnerability are (1) the comprehensiveness of measures of the fiscal balance and the extent to which the budget makes allowance for fiscal contingencies; (2) the robustness of the budget position as reflected in the underlying behavior of public expenditures and revenues; (3) the exposure of the fiscal position to market risk, including refinancing risk and exchange rate risk; and (4) the effectiveness of the fiscal management process.

The information required for assessing the actual and potential significance of all these vulnerabilities is not easy to obtain. Nevertheless, based on the available information, some tentative conclusions may be obtained. Viet Nam's fiscal situation appears vulnerable to potential weaknesses in all four areas and, in particular, potentially significant vulnerabilities related to incomplete coverage of the budget and its failure to allow for various contingencies, and the growing sensitivity of budgetary outcomes to interest rate and exchange rate risk. Each of the four areas of fiscal vulnerability is considered in turn.

Fiscal position vulnerability. Viet Nam's officially reported fiscal position does not, as noted in the preceding section, suggest significant problems of fiscal sustainability. Rather, the key concern is that the official fiscal data may systematically exclude a number of important expenditure and revenue items such the national investment program, including many projects funded by official development assistance (ODA); in addition, the issuance of government bonds ${ }^{28}$ used to finance ODA projects may not always be included in the official public debt data. At the same time, the extent to which official debt guarantees (including in the context of public-private partnerships) are properly accounted for in the fiscal data is unclear, and there is some ambiguity about the extent to which current and capital defense expenditures are included in the budget. If excluded expenditures are significant and larger than excluded revenues, the deficit may be understated and the amount of public debt may be underestimated. In these circumstances, the authorities are potentially vulnerable to "surprises" that could adversely impinge on the credibility of the budgetary process, lead to higher funding costs, and, in the extreme, raise concerns about fiscal sustainability.

Looking forward, there is also a possibility of adverse fiscal "surprises" related to the emergence of significant (unfunded) contingent liabilities for the 
government associated with the still large SOCBs and some of the newer jointstock banks. Currently, the budget does not explicitly account for banking sector contingent liabilities. Discussions with a range of observers - as well as recent World Bank reports $(2010 \mathrm{~b}, 2011)$ - have shown renewed concerns about the health and solvency of several banks in Viet Nam. There are two key types of uncertainties, however, regarding the implications of these weaknesses for the fiscal situation in Viet Nam. One relates to the size of any solvency problems in the banking sector, and the other, to whether and to what extent the authorities would inject official funds to help SOCBs and joint-stock banks return to solvency and/or to restructure in the event of difficulties. Not surprisingly, the authorities are reluctant to make their intentions with regard to any bailouts of financial institutions clear on account of moral hazard concerns. At the same time, recent macroeconomic developments in Viet Nam have again raised concerns about the health of the financial system (IMF 2010).

Given the recent rapid growth of credit in Viet Nam that has brought the credit/GDP ratio close to $130 \%$ and been accompanied by a significant increase in the number of joint-stock banks - and the channeling of significant amounts of credit to the stock market and to fund real estate - a fairly widely held view is that parts of Viet Nam's financial sector are in difficulty and will at some time require restructuring and the injection of additional capital (IMF 2010). The size of the problem in the financial sector is not known, partly because bank statements are not systematically reviewed by external auditors and many banks apply relatively low standards in identifying and provisioning for impaired assets. And, even if there are solvency problems, they need not necessarily be resolved using official money; the problems could, for example, involve healthier large banks taking over small banks and/or allowing for increases in private ownership and capital through stepped up "equitization." In short, a range of options is available for injecting any needed capital into the banking system, other than using official money. In these circumstances, it is not easy to "score" Viet Nam's contingent fiscal liabilities in the financial sector other than to note that Viet Nam does face potential contingencies that it would be prudent not to ignore and for which some contingency planning may be desirable. And any lack of transparency about the size of these potential contingencies may lead some economic agents to fear the worst. ${ }^{29}$

These arguments indicate that Viet Nam appears to be vulnerable to potential adverse fiscal "surprises" related to incomplete coverage of the budget and possible contingent liabilities in the financial sector. Even though the sizes of these "surprises" may not be known, it would be prudent to make reasonable estimates of their potential magnitude and ensure that there is adequate fiscal space to absorb them. And this knowledge could be useful for determining a prudent level of public debt.

Budget position vulnerability. Looking forward, there are potential vulnerabilities on both the revenue and expenditure sides of the budget that policymakers might usefully address with a view to ensuring fiscal sustainability over time. On the revenue side of the budget, the key vulnerabilities are related to the high 
dependence on unsustainable revenue sources such as the oil and gas sectors, SOEs, trade tariffs, and land fees (IMF 2010; Rosengard et al. 2010). In addition, dependence on ODA to finance needed public investment and infrastructure has been relatively high. Given Viet Nam's graduation to middle-income status, ODA is expected to decline. Already, the Vietnamese authorities have made significant progress in reducing its revenue vulnerabilities by broadening and extending the tax base, but the process is not yet complete. Rosengard et al. (2010), in particular, have suggest that direct taxation and the corporate income tax need improvement to help close revenue shortfalls, implying the need for significant further tax reform. ${ }^{30}$ In addition, the current tax system appears not to exhibit a very high level of buoyancy in other areas (IMF 2008, 2010). Unless the revenue system is made more buoyant, at some time in the future the authorities may not be able to meet their expenditure objectives.

On the expenditure side, the key potential vulnerabilities for the Vietnamese authorities relate to their apparent commitment to introduce universal health insurance by 2015 and to significantly expand the coverage of social insurance in order to reduce households' vulnerability to income shocks. ${ }^{31}$ These desirable commitments could add significantly to the budget and increase over time. This is the case, even though Castel (2009) has suggested that current plans to expand health insurance will not incur significant additional budgetary costs and can be largely paid for by a natural decline in pensions provided after the Viet Nam War. Pension obligations do not appear to be a major vulnerability at the moment because Viet Nam's population is relatively young. Nevertheless, schemes introduced should not impose too large a burden on the budget (Anh 2002).

Another potential vulnerability on the expenditure side relates to high provincial infrastructure spending and unnecessary duplication of public investment projects across regions to satisfy local interests. In addition to the adverse implications for efficiency, such spending renders budgetary control difficult. And, as noted earlier, vulnerability is related to defense spending, much of which is not currently included in the budget.

Putting these arguments together, Viet Nam has fiscal vulnerabilities on both the revenue and expenditure sides, but the former are probably more significant. Even though much progress has been made in addressing the revenue vulnerabilities, further tax reform and broadening of the revenue base are likely to be necessary to ensure revenue buoyancy.

Vulnerability to short-term market risk. Short-term market risk refers to the risk of fiscal outcomes deviating from plans as a result of innovations in interest rates, exchange rates, and market liquidity conditions. Domestic and foreign interest rates are becoming increasingly important for fiscal outturns as Viet Nam starts to borrow at market-determined interest rates and given the relatively shortterm maturity of its debt. ${ }^{32}$ Based on these short-term maturities, as well as the relatively large share of foreign currency debt (about two-thirds), Viet Nam is potentially exposed to a relatively high level of short-term fiscal risk from interest 
rates, the exchange rate, and liquidity conditions. Of course, given that perhaps as much of $50 \%-60 \%$ of Viet Nam's outstanding public debt is still bilateral official debt (on concessional terms), the tendency is to reduce the extent of rollover risk $^{33}$ related to market liquidity conditions. This is because official creditors, unlike private creditors, do not typically withdraw credit when market liquidity conditions are tight.

At the same time, foreign participation in Viet Nam's domestic bond market (which is dominated by official debt) is still relatively low as a result of extensive capital controls. ${ }^{34}$ However, market conditions will improve and foreign investors will increase in importance as Viet Nam's financial markets develop and liberalize.

With debt becoming more sensitive to market risk and, in the extreme, subject to rollover risk, prudent practice would be to take into account not only the size of the public debt in considering issues of (short-run) fiscal vulnerability, but also the debt's maturity structure and currency of denomination. Both these factors create vulnerability. It will be important for Viet Nam to avoid (1) significant currency and maturity mismatches in public debt (whereby short-term foreign currency debt is used to finance longer term projects with domestic currency returns); and (2) situations involving a large proportion of foreign currency debt. Foreign currency debt can lead to significant vulnerabilities due to negative feedback loops when there is lack of confidence in the domestic currency.

The risk of negative feedback loops arising in Viet Nam occurred in late 2010 and early 2011 when inflation concerns led Vietnamese to shift out of the dong into the United States dollar, thereby weakening the exchange rate. The weakness in the exchange rate raised the domestic currency value of foreign debt and could have created a negative feedback loop if concerns about increases in the domestic currency value of external debt had further weakened confidence in the dong. Another implication of market conditions becoming more important pertains to the ease of rolling over public debt when it matures. When there is sizable financial repression and "captive" markets for public debt, rollover risk is relatively low. As markets are liberalized, rollover risk becomes potentially more important, as was evident when Viet Nam experienced a number of failed debt auctions in 2008 and 2009 (ADB 2010a).

An important conclusion that follows from the foregoing is that fiscal outcomes are becoming increasingly sensitive to market risk in Viet Nam and that this sensitivity is likely to increase as the authorities further liberalize the economy and dismantle capital controls. This vulnerability should be recognized and ways found to mitigate the risks.

Fiscal management and effectiveness vulnerabilities. The fourth group of vulnerabilities relates to the risk that fiscal management systems (including the public debt management system) may not be up to the task of ensuring fiscal objectives are met. Weaknesses here can be in the structure of fiscal institutions, the approaches taken to budgeting, and the human capital of staff. Not surprisingly, in the case of an economy transitioning from central planning to the market 
economy, new fiscal institutions have had to be constructed and new practices in fiscal management adopted in Viet Nam.

During the early part of the reform period, significant progress was made in strengthening and modernizing fiscal management, but significant challenges remain. This is especially the case for bringing fiscal reporting up to international accounting standards, ensuring complete coverage of fiscal activities in the budget, and forecasting revenues and expenditures (IMF 2010, Rosenberg 2010). In addition, challenges remain in strengthening medium-term budget planning and in moving toward performance-based budgeting approaches. As regards public debt management, there are also still challenges in moving toward allowing more market-determined yields in domestic public debt issuance, setting prudential limits on foreign currency debt issuance, and reversing the recent shortening of debt maturities.

Given these challenges, Viet Nam might reasonably be judged as facing medium to high risk in the area of fiscal management. A new state budget law is, however, proposed to take effect in early 2013, and is intended to address many of the challenges. In addition, under the 2009 Public Debt Law, the authorities are planning to significantly strengthen debt management, including the issuance of domestic public debt (IMF 2010). Together, the fiscal and public debt management reforms, if successfully implemented, could reduce fiscal management risk significantly.

\section{Conclusions and policy implications}

Viet Nam has enjoyed an enviable economic performance since it initiated Doi Moi reforms in the late 1980s. During the global financial crisis, however, Viet Nam's fiscal situation deteriorated sharply as the budget deficit rose abruptly and public debt climbed to about $50 \%$ of GDP. As a result, concerns about fiscal sustainability came to the foreground in Viet Nam and the authorities have been taking steps to bring the deficit down to more sustainable levels in the last few years.

Official data indicate that Viet Nam's fiscal situation is already well on the way to reestablishing sustainability and only relatively modest further fiscal adjustment will be required during the next few years. This finding should not, however, be taken as grounds for complacency. A central argument of this chapter is that Viet Nam's fiscal situation faces a number of potentially significant risks and vulnerabilities that could pose serious challenges to attaining and maintaining fiscal sustainability.

In particular, vulnerabilities relate to the relatively narrow coverage of the budget; contingent liabilities in the banking sector that may be relatively large; weak budget management practices; and the increased sensitivity of the budget to interest rate, exchange rate, and rollover risk. Viet Nam will require a comprehensive approach to address these risks and vulnerabilities and attain and maintain fiscal sustainability on a lasting basis. Looking forward, account will also need to be taken of the likelihood that some of the factors that supported fiscal 
sustainability in the past-including a large positive excess of the economy's growth rate over the interest rates - are unlikely to continue indefinitely. As a result, attaining fiscal sustainability may become more difficult over time, underscoring the desirability of starting to address these vulnerabilities in the fiscal position as soon as possible.

\section{Notes}

1 The Sixth Communist Party Congress took the decision in late 1986 to move from a socialist centrally planned economy to a "socialist economy with a market orientation." In practice, as argued by Riedel and Comer (1998), the transition did not effectively begin until the early 1990s.

2 Major expenditure items included transportation infrastructure and education (Rosengard et al. 2010).

3 Here, and in what follows, Viet Nam's fiscal accounts are measured according to the IMF Government Finance Statistics Manual. Reflecting some significant differences in the classification of expenditures and revenues - as well as regards the treatment of various off-budget accounts - the fiscal data presented in this chapter differ substantially from the official data.

4 The 1997 State Budget Law represented an important milestone in the reform of the budget process. The law addressed issues of fiscal centralization and decentralization and the responsibilities of local government for revenue mobilization for development purposes.

5 Two major sets of tax reform were undertaken during this period. The first took place during the first half of the 1990s and involved introducing a turnover tax, profit tax, trade tax, and consumption tax. The second, in the latter part of the 1990s, involved introducing a value-added tax and a corporate tax to replace the turnover and profit tax (Riedel and Comer 1998).

6 Not surprisingly for a young transition economy, the state-owned enterprise sector contributed a significant share of revenues during this period.

7 Considerable uncertainty has existed, however, regarding the extent of impaired assets on the balance sheets of the SOCBs. The IMF and World Bank have encouraged the Vietnamese authorities to allow the balance sheets of the major banks to be externally audited and bank balance sheets reported according to international standards (IMF 2008).

8 For further discussion, see Hong (2004).

9 Included here are the problems that emerged in the state group Vinashin that led to a default on its external debt in late 2010 as well as reports of difficulties in a number of property-related companies (ADB 2011b).

10 In contrast to the People's Republic of China and India, where most public debt is denominated in local currency, over two-thirds of Viet Nam's public debt is denominated in foreign currency.

11 For further discussion, see Rosengard et al. (2010).

12 Formally, the Government of Viet Nam has indicated that Vinashin's external debts are not covered by a government guarantee. Under Vietnamese law, only the Ministry of Finance and State Bank of Vietnam have the authority to provide official guarantees on debt.

13 For discussion of the significance of the IRGD for fiscal sustainability, see Adams, Ferrarini, and Park (2010).

14 It does not seem appropriate to extend the number of observations by going back before Doi Moi reforms because the fiscal structure was very different under the central planning regime prior to the reforms. 
15 The decomposition of the budget into primary and nonprimary components abstracts from any assets held by the government and hence only takes into account interest payments on government financial liabilities. In practice, the government sector will hold some assets, including ownership of SOEs. See Adams, Ferrarini, and Park (2010).

16 As discussed in subsequent text, the IMF sees a $40 \%$ debt ratio as being as prudent in the case of Viet Nam (IMF 2010).

17 Over the medium term, the scenarios assume that the real exchange rate (measured through relative GDP deflators) is constant. This is more of a technical assumption than a forecast of the most likely outcome.

18 The gap can equivalently be expressed as the difference between the real growth rate of GDP and the (average) real interest rate on Viet Nam's public debt, or as the difference between these magnitudes expressed in nominal terms. Because about two-thirds of Viet Nam's debt is denominated in foreign currencies, the real cost of debt is influenced significantly by changes in the real value of the dong.

19 A delay in fiscal adjustment could have more adverse effects if it damages confidence.

20 In practice, much of the debt is denominated in United States dollars, Japanese yen, and euros.

21 Consideration is given below to a stochastic DSA based on estimated vector autoregressions for the key variables.

22 The buoyancy of the tax system is traditionally measured by the elasticity of tax revenues with respect to GDP. When the elasticity exceeds unity, tax revenues grow more rapidly to GDP. During the latter part of the 1990s, the budget revenue buoyancy was 0.92 . For a discussion of aspects of Viet Nam's tax system, see Roy (2003).

23 Innovations are measured as the residuals from simple first order autoregressive processes for revenues and primary spending.

24 This is one implication of the modified golden rule. For further discussion, see Adams, Ferrarini, and Park (2010).

25 Given pervasive currency substitution in Viet Nam as well as a record of high and variable inflation, the dong exchange rate is very vulnerable to deteriorations in inflation expectations, as occurred in 2008 and 2010.

26 This is done by estimating a vector autoregression (VAR) that captures the correlation pattern of the (nonfiscal) macroeconomic variables underlying the evolution of the debt ratio and then using this information to implement Monte Carlo simulations.

27 Optimally, the estimation of the VAR model would be performed on the basis of quarterly data spanning 10 years or longer, as was done for some countries in Chapter 2 of this volume. Unfortunately, a sufficiently consistent quarterly dataset for estimation is not available for Viet Nam and yearly data had to be used instead. Because the data span only 20 years, the variance-covariance matrix cannot be estimated precisely. Nevertheless, it indicates the basic direction and intensity of the correlations among the variables.

28 Domestically, these would include education bonds, infrastructure bonds, reform bonds (pre-2000 SOCB debt) and municipal bonds. Reportedly, the government has also issued international bonds to help finance SOEs (IMF 2010).

29 International credit rating agencies have expressed concern about the health of the banking system and appear to assume that official bank data seriously overstate the health of the banking system (IMF 2010).

30 Rosengard et al. (2010) argue that the personal income tax has made up only $2 \%$ of Viet Nam's total revenue, compared with about $16 \%$ in other low- and middle-income developing countries.

31 Large parts of the informal sector will enter the system with the introduction of notional individual accounts. 
32 Unfortunately, comprehensive data are not available on the original or remaining term to maturity of public debt. The IMF has suggested, however, that domestic public debt is of relatively short maturity, which is not uncommon in emerging markets such as Viet Nam's. See also the Asia Bond Monitor (ADB 2010a, 2011a).

33 Rollover risk refers to the risk of not being able to refinance maturing debt at any interest rate when it matures. Rollover risk related to the remaining term to maturity of a debt contract may also be due to covenants that may require immediate repayment in the event of some event such as a credit rating downgrade.

34 See issues of the Asia Bond Monitor (ADB 2010a, 2011a).

\section{References}

Adams, C., Ferrarini, B., and Park, D. (2010) "Sustainability in Developing Asia," Asian Development Bank Economics Working Paper Series No. 205 (1 June 2010), Available SSRN: <http://ssrn.com/abstract=1640264>

Anh, V. (2002) "Pension Reform in Vietnam," in Pension Reforms in Asian Countries, Proceedings of the International Symposium, Hitotsubashi University, Japan, pp. 263-84.

Asian Development Bank (ADB) (2010a) Asia Bond Monitor. Mandaluyong City, Philippines: ADB, October. Available HTTP: <http://asianbondsonline.adb.org/ documents/abm_oct_2010.pdf>

(2010b) Asian Development Outlook, Mandaluyong City: ADB. Available HTTP: $<$ http://www.adb.org/Documents/Books/ADO/2010/ado2010.pdf >

_ (2011a) Asia Bond Monitor. Mandaluyong City: ADB, September. Available: HTTP: <http://asianbondsonline.adb.org/documents/abm_sep_2011.pdf>

(2011b) Asian Development Outlook, Mandaluyong City: ADB. Available: HTTP: $<$ http://www.adb.org/documents/books/ado/2011/ado2011.pdf>

Castel P. (2007) Vietnam: Projections of Long-Term Health Insurance Premium, Ministry of Health Workshop, 19 April.

(2009) "Fiscal Space Implications of the Crisis," Background Paper for Conference on the The Impact of the Global Economic Slowdown on Poverty and Sustainable Development in Asia and the Pacific, 28-30 September 2009, Ha Noi.

Chalk, N., and Hemming, R. (2000) "Assessing Fiscal Sustainability in Theory and Practice," in Fiscal Sustainability, Papers Presented at the Banca D'Italia Research Department Workshop, Perugia.

Giang, T.L. (2004) "The Pension Scheme in Vietnam: Current Status and Challenges in an Aging Society," MPRA Paper No. 969,01: 26. Available HTTP: <http://mpra.ub.unimuenchen.de/969/> (posted 7 November 2007).

Hemming, R., and Petrie, M. (2002) "A Framework for Assessing Fiscal Vulnerability," in H.P. Brixi and A. Schick (eds), Government at Risk, Washington, DC: World Bank.

Hong, M.P. (2004) FDI and Development in Vietnam: Policy Implications. Singapore: Institute of Southeast Asian Studies (ISEAS).

International Monetary Fund (IMF) (2008) "Vietnam 2008 Article IV Consultation-Staff Report and Public Information Notice." Washington, DC: IMF.

— (2010) "Vietnam 2010 Article IV Consultation-Staff Report and Public Information Notice." Washington, DC: IMF.

Riedel, J., and Comer, B. (1998) "Transition to Market Economy in Viet Nam," in W.T. Woo, S. Parker and J.D. Sachs, eds, Economies in Transition: Comparing Asia and Europe, Cambridge, MA: MIT Press. 
Rosengard, J. et al. (2010) “The Unintended Consequences of Successful Resource Mobilization: Financing Development in Vietnam," Fulbright Economics Teaching Program. Roy, R. (2003) "Fiscal Policy in Vietnam," in J. Weeks (ed.) The Macroeconomics of Poverty Reduction in Cambodia, New York and Phnom Penh: United Nations Development Programme (UNDP).

World Bank (2010a) East Asia and Pacific Economic Update-Navigating Turbulence, Sustaining Growth. Washington, DC: World Bank.

(2010b) “Taking Stock: An Update on Vietnam's Recent Economic Developments," Consultative Group Meeting, December 2010.

(2011) "Taking Stock: An Update on Vietnam's Recent Economic Developments," Consultative Group Meeting, December 2011. 


\title{
7 Conclusions and other country perspectives
}

\author{
Benno Ferrarini, Raghbendra Jha, and \\ Arief Ramayandi*
}

\section{Introduction}

To combat the recession that accompanied the global financial crisis (GFC), most major countries supplemented automatic fiscal stabilizers with discretionary fiscal stimulus packages. While the global economy has started to recover, these packages, combined with the costs of financial sector and other bailouts and sharp output and revenue losses, have left many countries with large public debt burdens as a long-lasting legacy of the crisis. This is especially true of the United States (US) and several European countries. As noted by Reinhart and Rogoff (2011), the global economy moved from a financial crash to a debt crisis, although Asia was not at the epicenter of the GFC, nor is it at the center of the subsequent debt crisis.

Most developing member countries of the Asian Development Bank (ADB) in the Asia and Pacific region pursued a similar mix of policies, although much less actual support was provided to banks and financial institutions in Asia and there were far fewer bailouts (BIS 2010). As a consequence of the GFC, public debt rose in this region, although not spectacularly as in the US and some European countries. Deficit reduction measures followed this debt accumulation, even as the risk of another global slowdown, if not outright recession, remained high. This is particularly true of Europe but (depending on the slowdown's intensity) the slowdown could spill over to the US and the world economy as a whole (ADB 2011).

This book has inquired into the sustainability of public debt in the Asia and Pacific region and argued that largely because of favorable histories of domestic macroeconomic parameters, major economies in the Asia and Pacific region were able to avoid a prolonged deceleration in economic growth during the GFC. Further, their comfortable fiscal positions enabled them to put into place fiscal stimulus packages without accumulating excessive public debt. Moreover, after the worst impact of the global recession was over, the stimulus packages could be rolled back without causing recession.

\footnotetext{
* The authors are grateful to Charles Adams, Mukul Asher, and Richard Hemming for helpful comments on an earlier draft. Paul Holden contributed the subsection on the Pacific island economies, and Kiseok Hong provided the box on the Republic of Korea. The authors are solely responsible for the views expressed here.
} 
This final chapter provides some tentative conclusions for the issues covered throughout the book plus brief overviews on debt sustainability issues in some economies that are not covered in the country-specific chapters. As much of the previous analyses in the book pertain to the market-access countries, this chapter allocates a specific section to discuss the public debt issues for small and isolated economies in the Pacific region. The Asia and Pacific region's readiness to handle another potential global slowdown, as a consequence of a possible recession in Europe, is discussed.

\section{Public debt and fiscal performance in developing Asia: trends and implications}

Although this book emphasizes what happened after the GFC of 2008/09, Chapter 1 looks at a longer period (since 1994) to facilitate an understanding of the underlying trends. The period since 1994 can be divided into three subperiods: (1) that till 2000 - the end of the Asian Financial Crisis (AFC); (2) from 2000 to the GFC of 2008/09; and (3) the period since then. The AFC represented a watershed for many countries in the region as they experienced considerable fiscal pressures. ${ }^{1}$ Soon after, however, consolidation began and debt/GDP ratios were back to pre-AFC levels by $2007 / 08$. They then slipped again in response to the steps taken during the GFC, and debt ratios peaked in 2009-10. Subsequently, fiscal consolidation resumed.

Public debt ratios across developing Asia have displayed considerable heterogeneity and variation over time. South Asia was the subregion with the highest average debt/GDP ratio in Asia during 1994-2000, and East Asia had the lowest. Since the beginning of the 2000s, however, overall public debt ratios in Asia have been relatively low by developing countries' standards, with the notable exception of South Asia. In most Asian economies, debt/GDP ratios tend to increase following crises as government fiscal balances deteriorate due to the release of fiscal stimulus measures for cushioning the crises' impacts as well as cyclical factors. Such episodes are typically followed by gradual improvements in fiscal positions as governments wind down the stimulus, before debt ratios are eventually lowered. On average, this pattern suggests fiscal prudence in developing Asia in general, where economies tend to react responsibly to increasing debt ratios in the medium to longer term by reining in fiscal positions and lowering debt to more manageable levels when necessary. ${ }^{2}$ This, however, does not necessarily rule out the short-term pro-cyclicality of government spending during high growth periods.

Chapter 2 explores in depth the analytical foundations of debt sustainability analysis. The chapter discusses why the fiscal deficit matters and how it is measured and shows that, although the accounting definition of the fiscal deficit is straightforward, there are a number of issues in measuring it accurately. For example, different taxes and expenditures have different effects on aggregate demand and, hence, on the fiscal deficit itself. The fiscal deficit is sensitive to inflation and to phases of the business cycle. Various modes of financing 
the deficit (e.g., bond financing, money financing, and external financing) will have different effects on the economy and thence on the fiscal deficit itself. Further, the impact of the deficit can vary depending on whether the deficit arises largely from current as opposed to capital expenditure, for example, on infrastructure.

Chapter 2 then articulates the basic notions of public debt dynamics and fiscal sustainability and develops two broad approaches to debt sustainability analysisviz., cointegration between public revenue and public expenditure series, assuming they are each non-stationary, and debt sustainability analysis (DSA) in the tradition of the International Monetary Fund (IMF). Particular attention is given to the fact that although in many developing Asian countries the growth rate of the economy is higher than the interest rate, ultimately this gap will narrow, and may indeed be reversed, because otherwise it would be profitable to borrow indefinitely. The chapter also points out some shortcomings of DSAs: in particular the technical difficulty of applying them; insufficient government control over future revenues; the inadequacy of past data for predicting future outcomes; and the recognition that debt may stabilize at levels that are difficult to service, even though such debt is, strictly speaking, sustainable. The chapter also argues that a solvency crisis (defined as a situation in which creditors are unwilling to lend) may arise even when sustainability conditions are satisfied.

Chapter 2 then alludes to evidence that domestic and external debt may be hard to separate in practice, especially if capital accounts are open, resulting in the need to consider consolidated public debt. The chapter then underscores the importance of issues not considered in the book, including Classification and Regression Tree models of fiscal stress; an evaluation of the risk of meeting debt service obligations, including the use of value-at-risk models; problems with debt dilution; an analysis of fiscal stress and the identification of thresholds ${ }^{3}$; the impact of the composition of debt; and broader interpretations of sovereign debt crises. The chapter then underscores the fact that any assessment of the sustainability of debt can only be as accurate as the quality of the revenue and expenditure data available. In particular, many "hidden" liabilities of the government (including contingent liabilities) and the central bank deficit may be omitted from official debt statistics. But revenue may also be reported erroneously. Practices regarding such matters vary across countries. These and other factors underscore the need for doing country-level DSAs that look closely at specific country practices. Chapter 2 thus sets the stage for detailed examination of the DSA methodology (considered in Chapters 3, 4, 5, and 6).

Chapter 3 formally tests for the existence of a fiscal prudence tendency in Asia and confirms that, generally, economies in the region have exhibited responsible behavior in managing their fiscal positions. This behavior has helped the region lower its average debt ratios or at least keep them from rising uncontrollably as evidenced in the trend of the region's average debt ratios since the beginning of the 2000s. The trend was disrupted during the onset of the 2008/09 GFC as governments introduced fiscal stimulus measures to cushion the impact on their economies. However, as economies started to recover, their debt/GDP ratios 
seemed to fall back to their declining trend, as indicated by the medium-term projection discussed in Chapter 3.

In addition to relatively responsible behavior in fiscal management, developing Asia has also benefitted greatly from favorable macroeconomic outcomes that deliver high economic growth in a low interest rate environment. This combination has helped to lower the interest rate-growth differentials (IRGDs) into negative territory in many economies, thus helping to reduce their debt/GDP burdens. Although favorable for debt dynamics in the medium term, negative IRGDs usually come with their own hazard. First, as previously noted, a negative IRGD implies that it is profitable to borrow continuously, as intake will always rise faster than borrowing. Thus, the IRGDs ultimately need to turn positive because, so long as the IRGD is negative and the debt/GDP is falling, rational agents will have the incentive to borrow at low interest rates, finance higher consumption, and roll over debt. This situation is unsustainable in the long run. Second, as Chapter 2 argues, a negative IRGD may be the result of financial repression, where official interest rates are kept artificially low. This leads to a distortion in the price of capital and, hence, to a misallocation of capital. Thus, the IRGDs may turn positive, forcing governments to take stringent austerity measures and deeply revise their fiscal targets that were previously deemed sustainable. For these reasons, it appears unavoidable that Asian economies will experience a structural narrowing of the IRGD over time and a sign reversal eventually. Whether any given country will experience this reversal before 2016 (the year to which forecasts are made in this book) is an open question. Further, when public debt is denominated in foreign currency, the IRGD is vulnerable to exchange rate changes.

Given such trends, Chapter 3 applies various DSAs to subregional averages and selected individual economies. The aim is to assess the prospect of debt sustainability in developing Asia over a medium-term horizon. The DSA conducted was based on the latest macroeconomic forecasts of probable domestic and global macroeconomic developments as well as fiscal policy assumptions for each economy under consideration. Although the DSAs are unlikely to depict the exact projection of the debt/GDP ratio with a reasonably high probability of being the actual outcome, they are useful for providing the likely scenario to which future public finances might evolve under the assumptions used in the analysis.

On average, the analyses suggest an overall tendency for public debt to be sustainable in the Asia and Pacific region. This comment does not necessarily hold for each economy individually, but certainly all of Asia's subregions are associated with declining or stable debt paths up to 2016, assuming continuing strong growth, low interest rates, moderate inflationary pressures, and the gradual normalization of fiscal policy after region-wide expansion in the aftermath of the 2008/09 GFC. In general, this assessment holds true based on a comparative analysis of applying a standard DSA to eight economies in the region. The findings from the standard DSA are also broadly in line with the results from applying a stochastic DSA, hence validating the realism of the baseline assumptions underlying the former. The stochastic simulations, however, highlight the presence of a large spectrum 
of likely outcomes, not all of which are compatible with the stable or declining debt ratios suggested by the baseline assumptions. The implication for economies with higher risk profiles of public debt is thus to revise their fiscal positions to accommodate future macroeconomic outcomes that may be less favorable than what is reflected in their baseline assumptions.

However, this conclusion is contingent on accepting the reported revenue, expenditure, and debt figures at face value. As indicated in Chapters 2, 4, 5, and 6, because the fiscal positions of several economies lack transparency, the results of the DSA tests are biased toward sustainability.

\section{Issues with assessing debt sustainability in developing Asia}

Assessing public finances for the case of developing Asia is a daunting challenge due to huge difficulties in assembling a comprehensive set of fiscal and public debt data for all the countries. Familiar problems include occasional missing observations over time and across economies. Further, consistent and comprehensive fiscal data, particularly about the exact magnitude of public debt obligations are seriously lacking for some economies. In addition, consistent data on interest payments on debt are also not generally available for the actual interest rates on public debt and the extent to which debt may be serviced at concessional or market interest rates. Consequently, fiscal sustainability analysis is based, for the most part, on published data, which may under-report liabilities and hence create a bias toward sustainability.

How to define the coverage of the public sector when analyzing public finance is another issue. While the coverage should encompass all public sector activities, such comprehensive data are rarely available and the coverage of official figures is typically narrow. This narrowness masks the full extent of public debt that may actually pose a serious threat to a country's fiscal sustainability. Examples are provided in Box 7.1 on the Republic of Korea, and in Chapter 5 on India, which discuss the effects of the "below-the-line" items that are not included in the official fiscal data and their implications for estimating an economy's debt profile.

Getting adequate and appropriate information on hidden (off-balance-sheet) liabilities and their associated contingent liabilities is also a problem. Such liabilities are often the source of "fiscal shocks" occurring during economic downturns and become the key factors in affecting fiscal sustainability over time. The realization of these shocks is, in many cases, closely related with unfavorable economic outturns. For example, much of the deterioration in fiscal positions during the AFC was associated with the realization of contingent liabilities in the form of bailouts of distressed banks and other financial institutions and cyclical factors. The omission of hidden or contingent fiscal liabilities implies that the DSA approach adopted in deriving conclusions about sustainability arguably represents the "best case," because accounting for these liabilities would likely lead to higher rather than lower future debt/GDP ratios, and potentially greater threats to fiscal sustainability. 


\section{Box 7.1 Government finance statistics of the Republic of Korea*}

The Republic of Korea's fiscal situation is known to be relatively sound with its consolidated government primary balance consistently positive at about $2.5 \%$ of gross domestic product (GDP) on average during 2000-10. ${ }^{1}$ Nevertheless, the country's fiscal data need to be taken with caution as the coverage of government finance is complicated, there is inconsistency between the fiscal balance and the national debt statistics, and various quasi-fiscal activities of public enterprises potentially enlarge the country's indebtedness when taken into account.

\section{Coverage of national debt}

The scope of government finance in the Republic of Korea is defined on the basis of accounting and fund units that include only the General Account, Special Accounts, and Funds. In contrast, following the Government Finance Statistics Manual of the International Monetary Fund (IMF), major advanced countries define the government sector on the basis of institutional units, which cover not only accounts and funds of central and local governments but also "all nonmarket nonprofit institutions (NPIs) that are controlled and mainly financed by government units" (IMF 2001: 10).

In addition, the Republic of Korea compiles fiscal statistics on a cash accounting basis rather than the accrual accounting basis used in the major advanced countries. Consequently, the country's stated national debt only includes government bonds and borrowings and is thus less comprehensive than that of countries that include accrual accounting items such as build-transfer-lease projects, payables, advances, and withholdings. For these reasons, the scope of government finance needs redefining in order to facilitate international comparisons.

\section{Inconsistency between the fiscal balance and national debt}

Most of the annual changes in the Republic of Korea's national debt are unexplained by its fiscal balance figures. During 2000-10 the country's national debt/GDP ratio increased from $31.8 \%$ to $36.7 \%$. Not all of the change, however, is explainable by the formula for fiscal debt dynamics that is governed by the consolidated government's primary balance, interest rate-growth differentials and exchange rate depreciation. The residual, which is the difference between the actual and the computed change in debt according to the formula was about $5.2 \%$ on average during the period. This discrepancy arises as the country's fiscal balance and national debt figures cover different items.

As summarized in Table B7.1.1, some items are covered by fiscal balance but not by national debt, and vice versa. In particular, fiscal balance excludes all financial liabilities backed by counterpart assets, ${ }^{2}$ whereas national debt excludes all liabilities of civilian funds run by nonmarket nonprofit institutions in the government sector. Deficit financing liabilities (to be repaid through taxes) in the

* Box provided by Kiseok Hong, Ewha Womans University, Republic of Korea. 
Table B7.1.1 Coverage of national debt and fiscal balance statistics in the Republic of Korea (coverage as of 2010)

\begin{tabular}{|c|c|c|}
\hline & National debt & Fiscal balance \\
\hline $\begin{array}{l}\text { General Account (1) } \\
\text { Special Accounts (18) }\end{array}$ & All are covered & All are covered \\
\hline Funds (64) & $\begin{array}{l}40 \text { government funds are } \\
\text { covered; } 24 \text { civilian } \\
\text { funds are not }\end{array}$ & $\begin{array}{l}52 \text { deficit-financing funds } \\
\text { are covered; } 12 \text { financial } \\
\text { liabilities are not }\end{array}$ \\
\hline
\end{tabular}

Source: Author's compilation.

general account and government funds are covered in both fiscal balance and national debt statistics. This difference in coverage can account for a substantial part of the aforementioned residual in debt dynamics.

To illustrate, the foreign exchange stabilization bonds, which are financial liabilities issued by the foreign exchange stabilization fund, are covered in the national debt but not in the fiscal balance. The social security balance is a main component of the primary balance of the consolidated government, but has no direct effect on the magnitude of the national debt. Except for small items such as payables and financial derivatives, all assets of social security funds are classified as capital rather than debt. Consequently, a surplus in social security will improve the consolidated government balance, but with no significant change in national debt. The conversion of government guaranteed bonds of the Korea Asset Management Corporation and Korea Deposit Insurance Corporation into government bonds, while directly increasing the national debt, is excluded from the fiscal balance statistics for most purposes (including the IMFs 2004 debt sustainability analysis for the Republic of Korea).

When appropriately combined, the three aforementioned factors-foreign exchange stabilization bonds, social security balance, and the conversion of government guaranteed bonds - account for most of the discrepancy between the actual and the computed change in debt (the residual). The residual and the sum of the three factors are plotted in Figure B7.1.1, which shows a high correlation at 0.83 . For $1998-2010$, the average value of the residual is $4.5 \%$ and for the sum of the three factors it is $3.6 \%$.

\section{Quasi-fiscal activities of public enterprises}

Public enterprises' activities in many countries, including the Republic of Korea, often carry de facto fiscal implications. These quasi-fiscal activities may hide the government's true fiscal risk. For example, Korea Land and Housing Corporation and Korea Water Resources Corporation are heavily indebted from governmentinitiated large-scale development projects, and currency stabilization bonds issued by the Bank of Korea are mainly used to support interventions in the foreign exchange market in essentially the same way as the foreign exchange stabilization bonds are used. Yet, these activities are not included in the government debt statistics. 


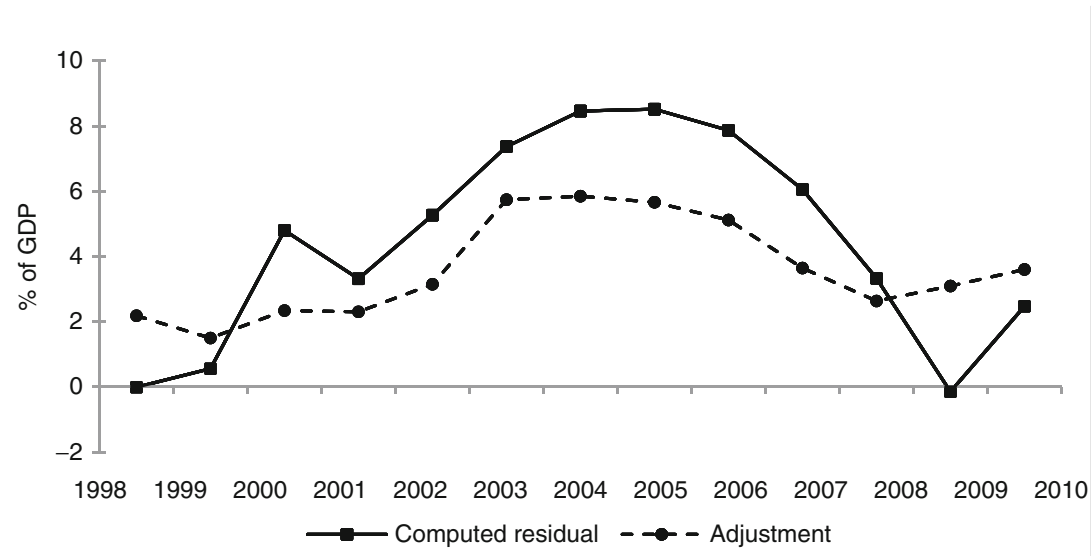

Figure B7.1.1 Debt dynamics residual and adjustment factors.

$\mathrm{GDP}=$ gross domestic product.

Source: Author's calculation.

While such factors may not pose an immediate risk to the country's fiscal sustainability, attention to them is needed regarding the fiscal coverage of various funds and social security balances. In particular, it will be important to keep track of alternate measures of fiscal debt that are defined more comprehensively, in addition to the official figures. The Korea Institute of Public Finance (2008) study claims that the country's fiscal risk, when broadly defined to include the unfunded liability of the social security system and various contingent liabilities, amounted to about $75 \%$ of GDP in 2007 , more than twice the official national debt figure.

Encouragingly, a government-led task force announced in January 2011 a proposal to revise government financial statistics to extend the scope of the general government to cover more funds and public institutions in accordance with the IMF 2001 GFS Manual (KIPF 2011). This is a clear improvement over the previous scope of government finance, although a few issues remain, including the treatment of various quasi-fiscal activities of public enterprises.

\section{Box endnotes}

1 Author's calculations based on the fiscal statistics provided by the Digital Budget and Accounting System of the Ministry of Strategy and Finance.

2 These liabilities are repayable through loan recovery and asset liquidation.

Sources:

International Monetary Fund (IMF) (2001) Government Finance Statistics Manual, Washington, DC: IMF.

Korea Institute of Public Finance (KIPF) (2008), "Government Debt Management in Korea," mimeo, in Korean.

(2011) "Proposals for National Public Finance Data," Monthly Public Finance Forum 176, February, pp. 46-56, in Korean.

Lee, Rhee, and Sung (2006), "Fiscal Policy in Korea: Before and After the Financial Crisis," International Tax and Public Finance, Volume 13, No 4. 


\section{Hidden government liabilities}

Chapter 4 discusses the implications of hidden liabilities on public debt sustainability at length, with particular reference to the case of the People's Republic of China (PRC). The chapter identifies sources for hidden liabilities and discusses the way to go about incorporating them into a standard DSA. The PRC case suggests that the official numbers may understate the magnitude of the economy's actual public debt burden, thus exposing the government to fiscal risks of a potentially increased debt in the future. The figures, however, still appear to be sustainable, as the government's fiscal position provides adequate space for handling reasonable risks and its asset position provides an additional cushion, should more extreme risks materialize.

There are at least two issues in relation to accounting for hidden government liabilities in conducting DSA: their sources and the extent to which they should be counted as debt. The sources of government obligations that have often been referred to as hidden liabilities are as follows:

- Arrears - part of debt that is overdue after one or more required payments is missed-are often considered as part of the government's hidden liability, with some certainty in terms of amount due but less in terms of payment timing. However, arrears could occur on the revenue side as well.

- Contingent liabilities — which arise from explicit guarantees, deposit insurance, and the like, and must be honored if triggered - tend to be uncertain in terms of both amount and timing.

- Contractual obligations - such as government and social security pensions or the purchase of services under public-private partnership arrangementsmay be associated with a government intention of honoring them in full but with some policy discretion to alter such intention.

- Implicit guarantees - or "stand behind obligations"-arise when a government is forced to step in to bail out the financial sector, state-owned enterprises (SOEs), or subnational governments, or to provide disaster relief. Although experience suggests that governments will step in, these obligations will never be made explicit due to moral hazard concerns.

- Constructive obligations - which are at the soft end of government obligations - refer to the services that government is confidently expected to provide, but for which there is no contractual backing.

The extent of government obligations for the liabilities just listed is uncertain, except for arrears. Nevertheless, all these liabilities imply fiscal outcomes that may differ from government plans The deviations from plans may relate to potential sources of future fiscal stress, especially contingent liabilities and off-budget fiscal activities. Uncertainty with regard to both the amount and timing of these potential sources of stress also poses difficulties for determining the extent to which the liabilities should be included in adjusting a standard DSA. 
Determining which hidden liabilities should be included in DSA is essential in order to gauge their impacts on debt ratios during times of fiscal stress. Using the PRC as an example, Chapter 4 discusses a possible way of incorporating hidden liabilities into DSA. To do so, hidden liabilities have to be identified and the nature of the fiscal risks they pose determined. Some of the liabilities may have flow implications, mainly in the form of higher spending (e.g., to honor guarantees), while others may have only stock implications (e.g., if a bailout involves an assumption of debt). One issue is whether flows should in fact be converted to stocks, so that the expected future flow costs of contingent liabilities are discounted to the present and included in an augmented debt figure for DSA purposes.

While turning hidden debt into an equivalent amount of actual debt may be appealing, it would be better to work with a debt measure that meets statistical standards, such as the IMF's Global Financial Statistics, and to treat the consequences of hidden liabilities as exactly what they are, expenditures or stock adjustments. In this way, the liabilities can be incorporated into a modified DSA baseline and used for conducting similar sensitivity tests. This is the sense in which DSA looks at a wider range of fiscal risks, such as errors in macroeconomic and fiscal forecasts and policy uncertainty.

More reliable and accurate information regarding fiscally related government activities will help the process of identifying the appropriate size of the debt augmenting hidden liabilities. For that reason, improving fiscal transparency is highlighted as a priority reform area for better gauging the fiscal risks that hidden liabilities entail. Prior to this, however, budgetary reform (in particular, a shift away from cash accounting) is essential before more accurate fiscal accounts can be prepared.

\section{Macroeconomic environment, fiscal vulnerabilities, and debt management}

Chapter 5 analyzes prospects for sustainability of India's public sector debt in the medium term, that is, until 2016. Despite India's persistently large fiscal deficits, it has thus far managed to maintain its debt/GDP ratio at a stable though relatively high level. India does not have the problem of incompleteness of budgetary accounts on the same scale as the PRC. The chapter underscores the importance of maintaining debt sustainability and a sound debt position in view of India's high current account deficit and the high risk of having large public debt in the aftermath of the GFC. Mainly as a consequence of a negative IRGD (itself a consequence of financial repression), the chapter predicts that public debt/GDP ratio will fall from $64.1 \%$ in 2010 to $61.2 \%$ in 2016 . India developed its domestic government securities market intensively in order to tap cheap funds and to reduce the vulnerability to external sentiments in managing and sustaining its public debt. As a result, the total public debt is mainly internal debt, which is a major factor in containing India's vulnerability to unfavorable external developments. In addition, this strategy helps lengthen debt maturities and allow more market-determined yields in domestic public debt issuance. A large negative IRGD has been another 
major contributory factor in making public debt sustainable. Debt servicing in India is less risky than in many other countries because a predominant share of public sector debt is internal and is held by public sector financial institutions. However, the costs of financial repression are the misallocation of capital and foregone growth opportunities.

The DSA projections in Chapter 5 suggest that this optimistic outlook for India's debt sustainability could be undermined if there were a substantial primary balance shock or an adverse growth shock. Thus, policymakers should not assume that the debt/GDP ratio will continue to fall. The chapter argues that the key to addressing fiscal vulnerabilities would rest on developing effective fiscal institutions that promote government capabilities to take on major fiscal corrections whenever necessary. This includes the ability to create adequate fiscal space (by initiating policies that raise the tax and nontax revenue/GDP ratio), and greater outcome orientation in expenditure policies to cover liabilities that might arise from fiscal surprises. To address fiscal risks and vulnerabilities to maintain debt sustainability, a comprehensive approach would also require fostering fiscal transparency, to bring in more reliable and accurate information regarding the government's fiscal activities and facilitate effective fiscal planning.

Chapter 6 argues that, in the aftermath of the Doi Moi reforms of the late 1980s, Viet Nam enjoyed both good economic performance and good fiscal discipline. However, beginning in the late 2000 s, and partly as a result of its response to the GFC, the country's fiscal situation deteriorated and public debt climbed to about $50 \%$ of GDP. Hence, there is a need to reduce the fiscal deficit at the margin.

Analysis based on official data indicates that the Vietnamese fiscal situation is already responding to this challenge. However, the analysis does not fully incorporate the several risks and uncertainties that characterize Viet Nam's fiscal situation. As in the PRC case, Viet Nam has issues pertaining to the inadequate treatment of several budget items, such as contingent liabilities and, as in India, has a large and artificial negative IRGD that shows up in a formal DSA as sustainable debt. Hence, although Chapter 6 indicates a sustainable public debt for Viet Nam the number of risk factors indicates no room for complacency in the effort to stabilize the debt.

Realization of fiscal contingencies is closely related with macroeconomic and financial instabilities faced by an economy. This is true not only of countries with a high debt burden, but also of those with relatively low and decreasing debt. Emerging markets have defaulted with relatively low debt/GDP ratios owing to risky debt structures as they engaged mainly in borrowing for the short term and in foreign currency, thus exposing them to interest and exchange rate risks. A benign trend in the debt/GDP ratio can suddenly be reversed due to sharp fiscal deterioration caused by severe internal and external macroeconomic instability. Hence, the structure as well as size of the debt matters.

A striking example is the case of Indonesia around the time of the AFC in 1997/98. The country's total public debt ratio was on a declining trend in the first half of the 1990 s before reaching its lowest point at nearly $23 \%$ in 1996 . The debt 
ratio spiked at the onset of the AFC, peaking at $95 \%$ in 2000 , as the nominal exchange rate (the price of foreign currency in terms of home currency) rose dramatically and the IRGD narrowed. In addition, the crisis forced the Indonesian government to bail out its banking sector to prevent its financial system from collapsing; thus, it had to fund a huge amount of its "stand behind obligations." This "fiscal surprise" had a devastating effect on the country's budget and took significant government effort to clean up.

Chapter 6 provides an in-depth analysis of the risks that macroeconomic instability and contingent liabilities pose to debt sustainability, using the case of Viet Nam. The chapter questions the practicality of the baseline DSA assumptions on the grounds of possible fiscal slippages in response to the less favorable macroeconomic conditions that the country is currently facing, a possible sustained weakening of Viet Nam's real exchange rate, and the narrowing gap between the country's interest rate and economic growth. The analysis shows that Viet Nam's debt prospects are vulnerable to negative shocks on the macroeconomic variables, particularly to deterioration of the exchange rate, as Viet Nam has a high proportion of its debt in foreign currency. Such shocks could materialize due to the confidence crisis that the country is facing. Thus, the chapter analyzes some of the key areas of vulnerability that policymakers need to consider, including provision of a comprehensive allowance for fiscal contingencies; the robustness of the underlying behavior of public expenditures and revenues in the budget positions; and the exposure of the fiscal position to market risks, including refinancing and exchange rate risks.

This discussion suggests that the government could face risks of adverse fiscal surprises related to the emergence of significant (unfunded) contingent liabilities. Such risks are particularly associated with the banking sector, especially the large state-owned banks and some of the newer joint-stock banks, as the budget currently does not explicitly account for such contingent liabilities. Vulnerabilities also come from both the revenue and expenditure sides of the budget, as the revenue is highly dependent on unsustainable revenue sources such as the oil and gas sectors, SOEs, trade tariffs, and land fees. On the expenditure side, the commitment to introduce universal health and social insurance could to increased future expenditure quite significantly. High amounts of spending on subnational infrastructure and public investment projects (which is also the case for India) also add to potential budget vulnerability. These fiscal vulnerabilities on both the revenue and expenditure sides call for further tax reform and broadening of the revenue base.

Short-term market risk could derail the fiscal outcomes from plans through unexpected changes in interest rates, exchange rates, and market liquidity conditions. With debt becoming more sensitive to market risk, prudent practice would require taking into account both the size and the maturity structure of the public debt in considering the fiscal vulnerability issues. When the proportion of foreign currency denominated debt is high, significant currency and maturity mismatches in public debt must be avoided. 
If the risks eventuate, Viet Nam could be trapped in persistent fiscal deficits, which is not conducive to keeping public debt in check. To cope with the potential fiscal risks, countries' abilities to manage their debt effectively are important, implying a need to strengthen the structure of fiscal institutions and approaches taken to fulfill the requirements for financing development.

\section{Debt sustainability issues for small, isolated countries: the case of Pacific Island economies*}

The DSA discussions throughout the book have focused mainly on economies that are able to access the market to raise debts for filling their financial gaps. Although most of the DSA implications are applicable to small and isolated countries, some differences need to be taken into account when analyzing their debt sustainability issues. For example, narrow export baskets heavy in natural commodities, external price shocks and natural disasters, and limited access to international credit markets are typical sources of vulnerability for the small island economies of the Pacific, with a significant bearing on public debt sustainability. Some of these vulnerabilities are stylized in this section, with main focus on the smallest among Pacific Islands, ${ }^{4}$ less so on Papua New Guinea and TimorLeste, which are comparably large economies in the subregion, endowed with significant natural resources and with better access to the international capital markets. 5

\section{Economic vulnerability}

The geographic and physical characteristics of the Pacific island economies are a major factor in the evolution and sustainability of sovereign debt in this subregion. Pacific subregion economies are small and isolated; the largest country in terms of population is Papua New Guinea with 7 million people; Nauru and Tuvalu have only about 12,000 inhabitants. Further, many of the countries in the subregion are fragmented and consist of a large number of small islands, sometimes separated by substantial distances, which presents major transport and communication challenges.

These characteristics make them extremely vulnerable to external shocks. Increases in oil and food prices almost immediately result in inflationary pressures to the extent that economies are net importers of these commodities. Earthquakes and typhoons damage farms, roads, ports and towns, requiring large amounts of discreet financing to rehabilitate and large spikes in imports of capital equipment and materials for reconstruction. In some years, damage in the Pacific has been catastrophic, for example, amounting to an equivalent of more than $30 \%$ of GDP in Samoa and Vanuatu. The small market size of countries in the subregion implies

\footnotetext{
* A background note underlying this section was contributed by Paul Holden, The Enterprise Research Institute, Washington, D.C.
} 
that there is limited opportunity for economies of scale and the majority of what is consumed must be imported.

Further vulnerabilities arise from the dependency of many Pacific island economies on remittances, which in some countries amount to as much as $40 \%$ of GDP. The global economic crisis provided a stark illustration of what occurs when remittances decline as a result of the shrinking growth in the economies where migrants are employed. The GDP of several Pacific island countries experienced negative growth as a result, tax revenues fell sharply, and associated budgetary problems arose. Macroeconomic imbalances translated very quickly into budget and balance-of-payments deficits, which must be financed through debt.

Three countries in the subregion have a special association with the US: the northern Pacific economies of the Federated States of Micronesia, Palau and the Republic of the Marshall Islands receive large Compact grants from the US. (Compact grants for the Federated States of Micronesia and the Republic of the Marshall Islands will expire in 2023, and Palau's will expire in 2024.) Grants account for $50 \%-60 \%$ of the overall revenue of these countries under the Compact Agreement and amount to about \$250 million. Without the grants, the three countries' fiscal deficits would amount to $15 \%-30 \%$ of GDP. The overall public sector accounts for more than half the economy in each of the three countries. Significant fiscal adjustment will have to be made before the grants expire. The scale of adjustment is mitigated by the existence of trust funds, which had been put in place with the intent of replacing the grants at the end of the Compact Agreement. However, fiscal adjustment is widely perceived as necessary for the case that trust fund returns were not sufficient to fully replace the grants.

The state ownership of utilities, shipping, airlines, and other services adds to debt problems in Pacific island economies. In some countries, the state operates companies in direct competition with the private sector. While some activities (such as power generation) are natural monopolies, the inefficiencies of many SOEs often result in substantial losses that must be financed through direct budget support or debt guarantees. The extent of the problem in some countries is illustrated by the fact that government expenditure constitutes the majority of spending; for example, in Kiribati it is over $80 \%$ of GDP and in Tuvalu it is close to $100 \%{ }^{6}$ These countries are especially vulnerable to declines in revenue, which concomitantly can easily lead to debt sustainability issues. A factor that is often not considered in assessing the indebtedness of Pacific subregion economies is the contingent liabilities associated with government guarantees of SOE indebtedness. In many cases, the SOEs' accounts are in such poor condition that it may be very difficult to calculate what the liabilities are.

These particular characteristics of Pacific island economies make them especially vulnerable to issues of debt sustainability. IMF Article IV consultation reports routinely raise issues of external debt sustainability for many Pacific countries. In addition, several of the smallest among the Pacific island economies 


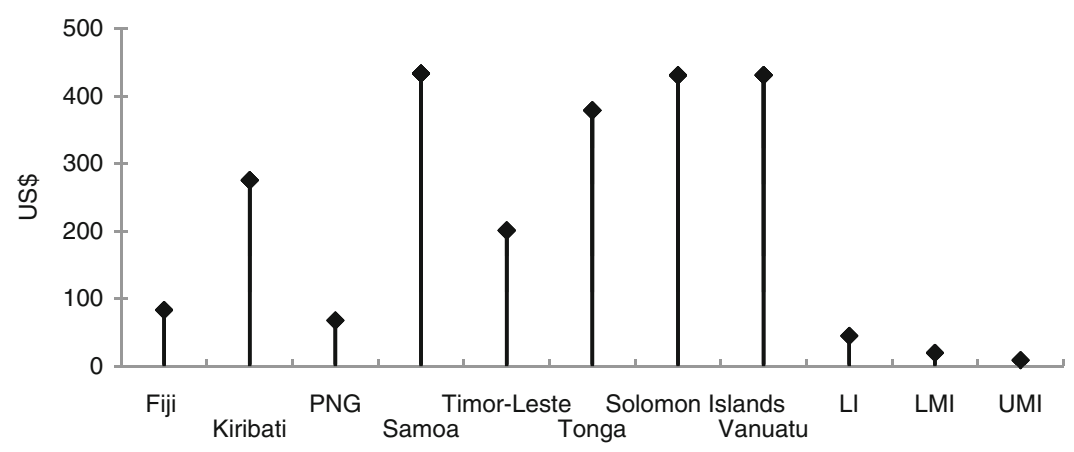

Figure 7.1 Aid per capita: selected Pacific island economies.

$\mathrm{LI}=$ low income, $\mathrm{LMI}=$ low middle income, $\mathrm{PNG}=$ Papua New Guinea, $\mathrm{UMI}=$ upper middle income

Source: World Bank’s World Development Indicators database.

would face unmanageable debt burdens without the foreign aid on which they rely for budget support. In contrast, Papua New Guinea has just received an upgrade on its debt sustainability analysis by the IMF and is not fiscally dependant on foreign aid flows. Although their share of the overall aid envelope is lowest among the world regions, on a per-capita basis, the Pacific islands subregion receives the world's highest amount of development aid (Figure 7.1). ${ }^{7}$

\section{Reducing debt through faster growth}

One of the major factors behind debt sustainability problems in many Pacific countries has been a low rate of GDP growth for an extended period. Productivity growth has been low or negative, often because of the large state presence in these economies. In a number of countries a substantial proportion of the capital stock resides in SOEs, which earn low or even negative rates of return. A recent Asian Development Bank (ADB) study, which compared the performance of SOEs in five Pacific island economies, found that even in Tonga, which had the best performing SOEs, 30\% of the country's capital stock was controlled by SOEs but they contributed only 6\% to economic growth (ADB 2011b). Divesting inefficient SOEs, or at least putting them on a commercial basis, entering into public-private partnerships, or at least requiring them to earn positive rates of return, would substantially improve productivity and growth rates, which in turn would benefit debt sustainability.

Another factor that would contribute to faster growth and stronger debt positions is promoting private sector development in the Pacific island economies. Many of the subregion's faster growing economies that do not have external debt problems have undertaken reform programs oriented to the private sector. 


\section{Sound macroeconomic policies}

Sound macroeconomic management is a major determinant of maintaining debt within manageable limits. A number of Pacific island countries had been making progress in debt management prior to the GFC. Inflation had declined and budget deficits were falling. However, the GFC led to a reversal of the improvement, and the impact was especially strong in countries that rely heavily on remittances.

In some countries, public sector payrolls took an increasing portion of government expenditure, which has led to fiscal imbalances. Such countries also face debt sustainability issues. Restoring fiscally sound budgetary policies is an urgent priority for ensuring debt sustainability.

An important policy for supporting better debt management is the implementation of medium-term budget frameworks. Such frameworks bolster fiscal discipline and stability, promote the strategic allocation of fiscal resources in line with priorities, identify future financing needs, and incorporate debt planning into the formulation of fiscal policy. This has knock-on effects, because the frameworks require improved national accounts statistics and macroeconomic forecasting, which are also an essential element of debt management. External financing organizations should both encourage and assist Pacific island economies to implement medium-term budget frameworks based in effective annual budgets, as currently pursued by many countries in the region.

\section{Better debt management}

With a few exceptions, debt management in many Pacific island economies is not very efficient, usually because of weak public debt management institutions. Although many countries do have a debt management unit within their Ministry of Finance, which is indeed tracking debt closely, their analysis is not integral to decision making on new debt. Some countries track their external debt less carefully or fail to pay much attention to debt schedules that stretch far into the future. Moreover, debt levels appear in annual budgets in the majority of countries, but there is generally little pressure from civil society or political opposition that would raise concerns and promote alternatives to practices they deem ineffective.

An essential component of well-formulated debt management policy is to calculate the net present value of sovereign debt obligations. This is especially important for countries that receive concessional loans. Currently, one failing of debt management in the subregion is the tendency to believe that loans on favorable terms, with low interest rates and principle moratoriums, do not add to the burden of indebtedness, at least for the foreseeable future; therefore, analyzing repayment schedules takes a backseat to problems that are seen as requiring more immediate attention. In many cases, the Pacific island countries have few opportunities to reduce debt accumulation through diversifying revenue sources because customs collections constitute the majority of receipts, and the small size of their economies means that income tax collections have very high transaction costs. 
However, it is difficult to identify with any precision an optimal level of debt. Typically, several indicators of indebtedness are used, but none has perfect predictive capabilities because of variable lags, the exposure to shocks, and the structure of Pacific island economies. Standard indicators that involve exports are of little use in a subregion where remittances, tourism and external assistance are important elements of foreign exchange inflows. Ratios involving GDP are inferior to those using gross national income or gross national product.

The vulnerability of Pacific island economies makes this exercise particularly difficult. The trade-off between investing for the future and ensuring that the level of debt will not balloon out of control in the event of a natural disaster, to which the countries of the subregion are especially vulnerable, is a difficult policy decision, for which there is no single, correct answer. To an extent, aid agencies' grant response to natural disasters softens the debt impact of natural disasters and thereby helps to maintain sufficient fiscal space to allow government a level of comfort in dealing with external shocks. This highlights that the role of funding agencies in the subregion will continue to be essential to compensate for extreme events and to provide assistance to promote faster growth.

\section{Policy lessons and implications}

Whereas this chapter has concentrated on how the Asia and Pacific region fared with respect to fiscal sustainability in the aftermath of the GFC, an important consideration is how the region will cope with the current sluggish economic growth, particularly in the eurozone with possible spillovers to the US. This issue is considered in some detail by ADB (2011), simulating alternative recession scenarios in Europe and the US, and their impact on economies in developing Asia.

Among the findings is that the readiness of those economies to respond to downturns in Europe and the US depends on their individual fiscal positions and abilities to use low interest rates and other monetary policy measures to stimulate their economies. In the short term, governments need to take steps to maintain financial stability and prevent market confidence from deteriorating. If the US and the eurozone both go into recession, a more accommodating monetary policy may be called for. Unfortunately, the scope for this may be limited because of high inflation in the region, which has necessitated policy interest rate hikes by several central banks. In addition, because sluggish growth in Europe and the US may persist for some time, the Asia and Pacific region's economies need to rebalance toward domestic consumption with lower reliance on exports and greater reliance on interregional trade. Countries in the region may again have to resort to putting in place targeted fiscal stimulus packages.

As various chapters in the book indicate, over the medium term, debt in most of the key developing economies in the Asia and Pacific region is sustainable. Thus, there is still some latitude to put in place fiscal stimulus packages. However, in view of the current high levels of debt, there is only limited opportunity to 
exercise this option without running into issues of insolvency and questioning debt sustainability. Regarding sovereign debt sustainability, this book has highlighted the importance of factoring in uncertainties when analyzing the likely debt pathsuncertainties due to macroeconomic vulnerabilities, both externally and internally, and the lack of knowledge about the fiscal risks from the off-budget fiscal activities that cause vulnerabilities during hard times.

To better cushion the impact of external negative shocks, a government can promote a healthy and liquid domestic government bonds market to tap internal sources of funding when necessary. This will help shield the country from external vulnerabilities. A policy to develop a sound domestic government debt market, however, will also have to be balanced with the need to maintain macroeconomic stability and to manage the domestic debt market optimally to avoid crowding out the private sector.

The success of a domestic government bonds market depends critically on a country's ability to maintain the macroeconomic stability that underlies market confidence. Macroeconomic instability will directly undermine a country's fiscal soundness, hence increasing fiscal vulnerabilities that hinder successful debt market development. Thus, maintaining prudent policies that promote economic growth while minimizing the risk for macroeconomic instability is another natural policy implication for promoting debt sustainability in Asia.

An effective domestic government bonds market could crowd out domestic private investment and hamper growth if it constrains the private sector's capacity to expand its activities. Such a market could also tend to pull up the effective interest rate, with both the government and the private sectors competing for funding. This would increase the IRGD, exerting pressure on the overall government debt and worsening the country's medium-term debt prospects. Striking a balance for the role of government debt to support economic development and stability is equally important for debt sustainability. Therefore, improving the debt management institutions is important, and involves promoting government capabilities to execute fiscal corrections when necessary, fostering fiscal transparency to enhance the government's fiscal planning capacity, and anticipating the potential liabilities arising from fiscal surprises.

Developing Asian economies cannot afford to be complacent in their approach to public debt. This book has emphasized several key areas where governments need to take a proactive approach:

- assuring that the revenue and expenditure accounts of government include all relevant items (e.g. noncontingent liabilities) and maintaining complete and well-managed fiscal accounts;

- placing high on the agenda the improvement of expenditure management, reforming of SOEs, and strengthening of debt management institutions and processes; and

- enhancing efforts to augment tax revenue within an overall program of tax and expenditure reform in these countries. 


\section{Notes}

1 One aspect of the problem was that not all countries were able to spend their way out of recession reasonably quickly.

2 Although the assessment holds on average, it may not apply equally to all economies in the region. An in-depth analysis is needed for more detailed pictures of each individual country.

3 A related concept is that of fiscal risk used to describe a situation in which the government runs the risk of not meeting its fiscal policy objectives. Hemming and Petrie (2000) consider four aspects of such vulnerability: incorrect specification of initial fiscal position, vulnerability of short-term outcomes to risk, debt nonsustainability in the long run, and structural and institutional weakness affecting the implementation of fiscal policy.

4 Apart from Papua New Guinea and Timor-Leste, the ADB's Pacific developing members include: Cook Islands; Fiji; Kiribati; Republic of Marshall Islands; Micronesia, Federated States of; Nauru; Palau; Samoa; Solomon Islands; Tonga; Tuvalu; and Vanuatu.

Due to constraints of space, this section does not touch upon a number of relevant DSA issues for small island economies: (i) how to sensibly deal with the significant difference between GDP and gross national income, given substantial offshore revenues from fisheries etc; (ii) how to treat trust funds which are multiples of GDP in DSA; (iii) reliance on domestic debt instead of use of international debt; (iv) risks associated with single or limited institutional holders of government debt, eg., provident funds; (v) exchange rate risk, particularly with increasing level of debt to the PRC.

5 It should be noted, however, that also other countries in the region have been able raise finance on the international markets. Fiji, for example, has been accessing markets since 2006. Other countries with potential access include Cook Islands, Vanuatu, and Samoa. However, these countries tend to raise debt domestically as there is an expectation that this will be a cheaper source of finance and it also typically proves to be scale-appropriate, particularly when amounts of under $\$ 10$ million or so are being sought.

6 However, this ratio is substantially lower in terms of gross national income, which could be argued to more accurately measure the financial ability of government to repay debt.

7 It may be argued, however, that a lack of aid would not be completely filled by debt, in which case investment projects would just be delayed or dropped.

\section{References}

Asian Development Bank (ADB) (2011a) “Asia Economic Monitor," December, Manila: ADB.

(2011b) "Finding Balance 2011: Benchmarking the Performance of StateOwned Enterprises in Fiji, Marshall Islands, Samoa, Solomon Islands, and Tonga," Sydney: ADB.

Bank for International Settlements (BIS) (2010) "The International Financial Crisis and policy challenges in Asia and the Pacific, Proceedings of the Wrap-up Conference of the Asian Research Programme," Monetary and Economic Department, BIS paper \#52, Basle.

Hemming, R., and Petrie, M. (2000) “A Framework for Assessing Fiscal Vulnerability," IMF Working Paper WP/00/52, Washington, DC: International Monetary Fund.

Reinhart, C., and Rogoff, K. (2011) "From Financial Crash to Debt Crisis," American Economic Review, 101(4): 1677-1706. 